\title{
EXILED BODIES
}

\author{
AND
}

FUNERAL HOMES

\section{IN}

\section{AOTEAROA NEW ZEALAND}

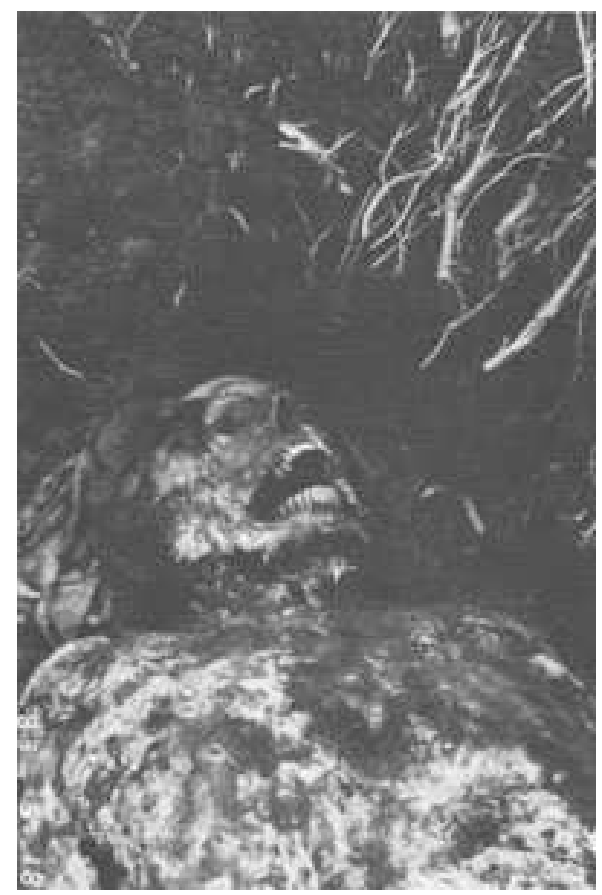

by

Kyro Selket

A thesis

submitted to the Victoria University of Wellington in fulfillment of the requirements for the degree of

Doctor of Philosophy

in Geography

APRIL 2010 


\begin{abstract}
Within the hidden space of the embalmer's room the most abject of objects comes to rest. Embalming rooms, and the funeral homes that house them, are liminal zones, and the dead and decaying bodies that come to occupy them are, for many outside the funeral service industry, objects and spaces of mystification. Situated within contradictory discourses, the dead body is understood as an object/subject to be revered, whilst at the same time bringing to the living a degree of discomfort and fear. The body's decomposition reminds us that nothing can bring the dead back, thus representing the ultimate human fear-one's inevitable annihilation. It is therefore deemed necessary to remove this destabilising object/subject to a safe and contained space. This thesis opens up and explores such a space: the contemporary funeral home, with particular attention given to the principles and practices of embalming rooms, as these rooms represent possibly the most abject space of the funeral home. In doing so it excavates the historical, social and cultural constructs that have come to underpin contemporary funeral service provision and embalming practices, uncovering the various intrinsic dualisms that operate within the spaces of the funeral home - such as the public/private, contaminated/contained, life/death, inside/outside. The central question of the thesis asks: what can an exploration of the abject spaces and bodies of the funeral home in Aotearoa New Zealand offer to understandings about embodied geographies? For even as many geographers increasingly challenge the marginalisation of certain bodies and the spaces they inhabit, little attention is given to the dead body.

Employing primarily the theoretical perspectives of emotional/psycho-geography and feminist geography, the thesis brings a reading of the ways in which death, decaying bodies, and the spaces within which they are separated, marginalised, and othered come to be understood by those within the funeral industry, and thus those who utilise its services. These theoretical approaches also challenge many of the dichotomies that form a major basis for the justification of contemporary funeral practices such as embalming. Through interviews with a variety of key stakeholders in both the traditional and alternative funeral sectors in Aotearoa New Zealand, and close readings of funeral industry texts, it is found that the dead body, embedded within totalising discourses on death, and contained and closeted away in the back rooms of funeral homes, is forced to undergo extensive, invasive practices that sanitise and transform it in order to eradicate any obvious traces that it is now a dead body. In the spaces of the funeral home the material and symbolic manifestations of death are continually regulated, contained, and referred to euphemistically, all the while retaining clear distinctions between what has been constructed as sacred and profane, public and private, clean and unclean.

Ultimately, it is the contention of this thesis that the liminal spaces of the funeral home preserve certain knowledges and practices that ensure that the contemporary Westernbased funeral industry retains a monopoly over the bodies of the dead.
\end{abstract}




\section{ACKNOWLEDGEMENTS}

To all those people who have supported me through my $\mathrm{PhD}$ both professionally and personally - thank you. There are of course, a number of people who need special mention. Firstly, there is my supervisor whose support and enthusiasm for my work was amazing and much appreciated. Sara Kindon, thank you for your unwavering tolerance of a dyke who operates outside the square. I feel like I have learned a lot Sara, especially about becoming a more adequate researcher and academic.

To Robyn Longhurst, thanks heaps for your support and your steadfast belief in me: it has been, and I hope always will be, a pleasure to learn with you.

Thanks to my department: whilst I probably have occupied the space of 'oddity' over the years, I have come to appreciate being in the School of Geography, Environment and Earth Sciences. A special thanks to Phillip Morrison, it has been a pleasure to get to know you over the years and I have valued your support. I want to also thank Shona de Sain, Associate Dean in the Faculty of Sciences; you have made my time here a complete one and I have especially enjoyed our conversations, particularly around your love of netball - all the best for the next season.

I would also like to thank Celia Simpson who helped me get my papers signed and sealed and made sure that enough work came my way to get me through some of the financial hardships I faced.

Special thanks to Ellie Sanderson for her support and for sharing her personal and academic journey with me, it was really valuable.

To all my friends: I wish I could name you all individually and explain how you have all supported me and made my journey that much easier. Unfortunately I can't as I would have to write another thesis, deconstruct my findings and problematise what friendship really means, whilst looking for the common shared meanings of friendship and mate-hood! So in the end all I can say is THANKS guys, you all rock, and over the past few years I have learnt the varied and shared meanings of friendship.

Thanks heaps to my partner Natalie who got me at the end of this journey and I am sure got the most frantic part. Thank you for reading through my drafts (through a haze of alcohol...) and your careful editing skills. Any errors that remain I take full ownership of!

A special and really big thank you goes to the Department of Geography, Tourism and Environmental Planning at Waikato University. You guys rock!!!

A very special thanks to Tee: thank you for your steadfast love and support as well as for always believing that I could do this when I said I couldn't - you were right again!!!!

A special thanks to those funeral directors, educators and embalmers who supported my research and shared your insights and stories. Thanks to the funeral directors who supplied images of their funeral homes not only for my research but also for the chapter 
contribution in Dirt: New Geographies of Cleanliness and Contamination. I want to also thank the funeral directors who took time out to show me around their funeral homes.

My personal thanks to the Student Finance Advisory Service: without your support I might not have finished. One day it would be great to not have the need for such an organisation at universities, however, until the government takes the link between poverty and the knowledge economy seriously, your work and assistance will be very much appreciated by students like me.

A special thanks to all the unnamed people who did such wonderful things for me and in doing so enabled me to get through some of the rough times. You are all very special because you don't realise just how amazing those small acts of kindness were. Thank you.

Most importantly, I want to not only thank but also dedicate my $\mathrm{PhD}$ to two really special dykes, who, whilst not being here in their corporeality, are here in spirit. It is only when we experience the loss of another that we begin to truly appreciate just how hard it is to understand death.

Loretta Mullin, thank you for not only having been in my life but for sharing with me the gift of your death. They say good things come from death. Sadly, without your death I would not have been brought to this place. Thank you for opening up a space to help me face some of my fears. Go raibh mile maith agat.

Rabiah, I still miss you. Your unexpected death still unsettles me. I really miss your passion, your enthusiasm for life and especially I miss hearing your beautiful voice. I still grieve your passing. In your life, as in your death, I have come to understand so much. Losing you reminds me just how important each meeting of another person can be.

\section{Kia kaha}




\section{TABLE OF CONTENTS}

$\begin{array}{lr}\text { ABSTRACT } & \mathrm{i} \\ \text { ACKNOWLEDGMENTS } & \text { ii }\end{array}$

1 BIRTH OF A THESIS 1

THESIS QUESTION, AIMS AND OBJECTIVES

KNOWING DEATH 4

ABSENT PRESENT DEATH

LIMITS: SETTING RESEARCH BOUNDARIES 11

$\begin{array}{ll}\text { THESIS OUTLINE } & 13\end{array}$

2 THEORETICAL CONTEXTS 17

A BODY OF DEATH 20

DEATH MATTERS! 22

GEOGRAPHIES DEAD SUBJECT 26

SOCIOLOGY OF DEATH 28

OLFACTORY GEOGRAPHIES AND OTHER POLLUTING SUBJECTS 29

PSYCHOGEOGRAPHY AND THE POWER OF ABJECTION 31

ABJECTION

EMOTIONAL GEOGRAPHY $\quad 38$

DESTABILISNG BINARIES $\quad 40$

DESTABILISING THE LIFE/DEATH BINARY 44

CLEANING UP AFTER OURSELVES $\quad 49$

3 DEATH COLLECTION

IDENTIFYING AND RECRUITING RESPONDENTS

GAINING CONSENT AND CONDUCTING INTERVIEWS $\quad 60$

GATE-KEEPING

BEING BUTCH AND FAT: A BODY OUT OF CONTROL 66

MAPPING FUNERAL HOMES $\quad 70$

$\begin{array}{ll}\text { TEXTS } & 73\end{array}$

FUNERAL INDUSTRY TEXTS

LOCATING AOTEAROA NEW ZEALAND'S FUNERAL INDUSTRY 77

AUTOETHNOGRAPHY: OPENING UP SPACES WITH A FEW WORDS 78

$\begin{array}{lr}\text { CONCLUSION } & 80\end{array}$

4 COMMODIFICATION OF KNOWLEDGE

HISTORICAL NARRATIVES $\quad 82$

EMBALMING MYTHS $\quad 85$

$\begin{array}{lr}\text { GOOD SCIENCE } & 90\end{array}$

ALL THE WAY FROM AMERICA $\quad 92$

CULTURAL THREAD: CIVILISING MĀORI

REAL CLOSURE $\quad 100$

$\begin{array}{ll}\text { EMBALMING } & 107\end{array}$

$\begin{array}{ll}\text { CONCLUSION } & 109\end{array}$ 
5 SEPARATION - TRANSFORMATION AND THE LIMINAL DEAD

ANXIETY AND RITUAL

WHERE THERE IS SMELL THERE IS DIRT 118

FOUL SMELLING CORPSES 120

COUNTERARGUMENTS 122

SEPARATION: INITIAL CONTACT $\quad 124$

RITES OF ENGAGEMENT $\quad 127$

BACKSTAGE: TRANSFORMATION 128

LIMINAL AND DANGEROUS $\quad 130$

TRANSITION: THE EMBALMING PROCEDURE 138

TRANSITIONING $\quad 140$

WEIGHTLESSNESS

$\begin{array}{ll}\text { CONCLUSION } & 148\end{array}$

6 BRINGING HOME THE DEAD

WELCOME TO THE PARLOUR

BUYING DEATH

MARKETING DEATH 160

FUNERAL HOMES 166

ENTERING THROUGH THE FRONTDOOR 175

DIGNITY AND RESPECT WITHIN THE FUNERAL HOME 183

DIGNIFIED BODIES 189

BRINGING HOME THE DEAD 192

7 LETTING GO OF THE DEAD 195

REVISITING THE THESIS QUESTION 199

FURTHER RESEARCH 201

$\begin{array}{ll}\text { REFERENCES } & 204\end{array}$ 


\section{LIST OF PLATES}

PLATE 2.1: COMMON MIND/BODY DICHOTOMIES 41

PLATE 3.1: KYRO SELKET (PHOTOGRAPH) 67

PLATE 3.2: STAFF OF LYCHFIELD FUNERAL HOME

PLATE 3.3: THREE-DIMENSIONAL CONCEPTION OF DISCOURSE

PLATE 4.1: DR. RICHARD BURR $\quad 81$

PLATE 4.2: UNTITLED 101

PLATE 4.3: THE MORGUE 101

PLATE 5.1: A MODERN EMBALMING ROOM 128

PLATE 5.2: THE LAYOUT OF A GENERIC FUNERAL HOME 133

PLATE 5.3: FEDERICO, GEORGE AND KEITH (SIX FEET UNDER) 143

PLATE 5.4: GEORGE, CLAIRE AND KEITH (SIX FEET UNDER) 147

PLATE 6.1: MEINWALD, MEMENTO MORI 148

PLATE 6.2: LYCHGATE FUNERAL HOME, WELLINGTON 169

PLATE 6.3: THE LAYOUT OF A GENERIC FUNERAL HOME 174

PLATE 6.4: BEAUCHAMP FUNERAL HOME, FEILDING 176

PLATE 6.5: GRAHAMS FUNERAL SERVICES 177

\section{LIST OF FIGURES}

FIGURE 1: THE THIRDSPACE OF LIFE AND DEATH.

FIGURE 2: NEWSPAPER ARTICLE 166

\section{LIST OF TABLES}

TABLE 1: CONTACTS 


\section{BIRTH OF A THESIS}

The funeral industry has held an important if perhaps hidden place within Western societies. ${ }^{1}$ The contemporary funeral industry is viewed as essential in its role of handling the dead. Having situated themselves as more than merely providers of coffins, the industry has become an indispensable service, offering support and solace to those who have recently experienced a death. However, in the last few decades the funeral industry in Aotearoa New Zealand ${ }^{2}$ has come under increasing scrutiny. There are a number of reasons for this. Firstly, growing awareness of environmental issues has seen the 'clean-green' image, once limited to portraying ANZ to the world, take on greater, more critical meaning - one that is beginning to infiltrate all sectors of society including the funeral industry. Secondly, the augmentation of both neo-liberalism and secularism in Western societies has elicited a challenge to the traditional relationships those involved in funeral practices had with the community. Whilst its respected place in wider society has not been utterly eroded, contemporary practices in ANZ and other Western societies are being questioned and there is a growing demand for greater transparency. This has seen certain measures, such as open-days, become commonplace for funeral home operators, in the hope of re-engaging with local communities and cultures and encouraging involvement in understanding funeral industry practices. These measures, however, have been considered by some as merely 'window dressing' as the industry continues to strengthen its borders against radical change.

\footnotetext{
${ }^{1}$ For the purposes of this thesis, when referring to 'Western' societies, I am specifically speaking about the United States of America, England, Australia and ANZ. The reason for this is that the funeral industry in ANZ was largely influenced by funeral practices from England. However, after World War Two, the industry turned to the USA, drawing heavily on their burgeoning industry practices. Today the industry has become a hybrid of predominantly British and American customs and practices. However, as I discuss in Chapter Five, there is now an inclusion of both Māori funeral practices and alternative practices such as environmentally sustainable funerals and pagan based approaches.

${ }^{2}$ Throughout this thesis I will refer to 'New Zealand' as Aotearoa New Zealand. This will be represented without a forward-slash as I do not want to dichotomise the indigenous and colonising names, but instead represent a more holistic inclusion. However, I will abbreviate Aotearoa New Zealand - ANZ.
} 
Modern funeral practices are considered by the industry as unquestionably progressive and are situated firmly within the realm of science and medicine, investing the industry with authority and prestige. Drawing on discourses that help to construct the bodies of the dead as contagious, the funeral industry has come to be the accepted guardians of the dead. The industry, with its belief and reliance on scientism and medical understandings of contamination and disease, has equipped itself with the necessary tools to construct the corpse as polluting, as well as the necessary skills to address this polluting object. Drawing heavily on psychological discourse the industry has combined the need to view the dead with a scientific narrative of disease and contagion, selling embalming practices to the living as an indispensable aspect of the funeral ritual. In doing so the industry has constructed the boundaries by which they define not only themselves but also the bodies of both the dead and the living. For example, the industry argues that without the embalming process, which typifies customary notions of cleanliness and containment, the funeral industry would not exist.

Without embalming, nature begins to take its course very soon after death. In the past, decomposition and its associated problems have given rise to very unpleasant memories and caused emotional scars. Today embalming is basically straightforward and effective. It enables everyone connected with the funeral - family, friends and professionals to take part in rituals with no unpleasantness or embarrassment and without risk to their health, whatever the cause of death (Guardian Funeral Home: 2004 - 2008).

Discussion of embalming though is not salient in the wider discourse offered the living and/or bereaved. Contained within psychological, religious and scientific 'speak', the practices for preparing the dead for burial are now seen as standard, as given, and therefore beyond critique.

Notions of cleanliness and dirt underpin the various practices of the contemporary funeral industry. Through the lens of cleanliness and dirt the dead are initially separated from the living and then transformed and contained within the funeral home and through the embalming process, before being integrated once more into the space of the living. For this transitory period the dead are treated as liminal objects held within the liminal spaces - notably the embalming room - of the funeral home. This space between death and burial is what I have come to identify 
as a post-death stage of the funeral ritual. It is within this stage that some of the most extensive practices around cleanliness and dirt are brought into play by funeral directors and embalmers.

This thesis explores this space by focusing on the symbolic and real sanitisation of the dead for the benefit of mourning. It also examines the links between death, social relations and dirt. This exploration inevitability deconstructs the taken for granted 'common sense' account of dirt and cleanliness surrounding the dead body and questions the classifications that constitute the dead body as the most abject of objects. Definitions of 'dirty' and 'clean', 'profane' and 'sacred' within this context are thus recognised by the researcher as being produced within cultural contexts, rather than being held as unquestionable truths.

In turn these themes are explored through an understanding of how spaces are constructed to address not only death but the manner in which the dead body decays. The use of space then becomes extremely important as it is not only used to isolate, contain and control the bodies of both the living and the dead, but to also manage the livings grief. In so doing, bodies entering or leaving spaces defined as either clean or filthy undergo a type of classification which might involve intense surveillance and discipline. As new information and knowledges are brought into the deathscapes, bodies are then expected to adhere to these new rules of engagement by adjusting to, amending, and eradicating particular performances that may call attention to the polluting abject nature of the spaces and bodies present in the funeral home.

\section{THESIS QUESTION, AIMS AND OBJECTIVES}

Situating my enquiry within the discipline of human geography and accordingly a spatial lens, the principal focus of the research is that of exiled bodies and postdeath decomposition. The research question is: what can an exploration of the abject spaces and bodies of the funeral home in ANZ offer to understandings about embodied geographies? The aims of the research are to explore the historical, social and cultural constructs underpinning contemporary funeral practices, with a particular concentration on notions of the profane and sacred 
which are used around the construction of the post-dead body. A secondary objective is to deconstruct the major narratives underpinning the use of embalming as a method of containment of decomposing corpses. The third but no less essential objective is to explore the movements of the bodies of the living and the dead in and around the funeral home. My intention here is to ascertain how such narratives construct public (clean) and private (unclean) activities and spaces. As part of these narratives it is important to explore various discourses about death, as many of the abstract discussions sustain the funeral industry's knowledges and notions around cleanliness and un-cleanliness within a contemporary context. Therefore, as part of my introduction I want to explore various ways that death comes to be understood in western societies.

\section{KNOWING DEATH}

Death logically cannot have an 'experiential inside' to be enjoyed or to be endured, for 'when death is there we are not' (Rosenberg, 1998: 304).

In 2002, modern day anatomist and manufacturer of plastination ${ }^{3}$ Gunter von Hagens and Channel Four ${ }^{4}$ in the United Kingdom collaborated to bring to air a public autopsy. In doing so, Channel Four aired von Hagens conducting the first public autopsy ${ }^{5}$ in the UK in approximately 170 years. However, their attempts culminated in a public outcry over the treatment of dead bodies. Dr Jeremy Metters (Her Majesty's Inspector of Anatomy) argued that the autopsy was illegal under the English Anatomy Act, due in part to the fact that von Hagens did not have a postmortem examination license. Despite the public outcry and police efforts to stop it, the autopsy went ahead (Moore, 2002).

\footnotetext{
${ }^{3}$ A process known to replace up to seventy per cent of the dead body's water with a resin, hardening the body's blood vessels and tissue. This allows a dead body to be presented in its once natural living state. These art instillations have included bodies riding horses, being seated and reading books or participating in other activities (Walter, 2005).

${ }^{4}$ Launched in 1984, Channel Four (C4) saw itself as an alternative to the BBC. Labelled 'alternative', C4 often televised programmes considered objectionable by other television stations: see debates on South Park and C4's recent documentary on Princess Diana's death.

5 Autopsy is a Greek word meaning to 'see with one's own eyes'. As Tony Walters (2004: 2) suggests, autopsies "...literally opened up the mysteries of the body's interior, in the way that geology came to open up the earth's interior and astronomy the hidden recesses of the universe".
} 
Consequently, in November 2002, whilst the audience covered their noses to fend off the stench wafting from the corpse (Channel Four), Professor von Hagens proclaimed his actions as a stance for the 'democratisation' of anatomy. He argued that he was in fact educating the public about the human body and death. This was not the first time that von Hagens had been critiqued for his use or misuse of dead bodies. His Body Worlds exhibition had also been called into question. Body Worlds, which toured numerous European countries, including the UK, drew approximately twelve million visitors, five thousand of whom signed legal documents donating their bodies for future plastination (Walter, 2004). Opponents of von Hagens' Body Worlds exhibition and the televised autopsy were not only scathing of the 'dubious' educational merits derived from his works, but argued that it trivialised death and flouted the traditional conventions underpinning the dignified handling of the dead. ${ }^{6}$

Andy Miah (2006: 577) suggests, however, that by opening up a space within which an autopsy can be carried out von Hagens was problematising the containing and highly controlled Western discourses underpinning death and medical ethics:

The autopsy challenged the way in which medicine creates boundaries between what is public and private and what counts as a legitimate exercising of personal autonomy.

von Hagens believed that those who attended the 'live' autopsy were confronting their own mortality, thereby gaining a greater insight into the fragility of the human body (Miah, 2006).

This need to comprehend the 'reality' of death by looking at dead bodies can also be read in the following discussion between Robert Fisk, a leading investigative journalist living in Beirut, and John Campbell, presenter for Campbell Live (CanWest TVWorks Limited, 2004). In the interview, Fisk is discussing the war in Iraq when he momentarily diverts to a more in-depth discussion about the 'reality' of death and its possible effects on the public when viewed in its 'fullness'. Fisk

\footnotetext{
${ }^{6}$ In 2006 the director of Te Papa Museum in Wellington decided to ban any visits by Gunther von Hagens' Body Worlds or any subsidiaries of Body Worlds, on the grounds that the show would be culturally insensitive and that it utilised bodies unlawfully obtained.
} 
argues that media moguls sanitise death to make the news more watchable. He insists that the televising of war without the sanitation of death would alert the general public to the horrors of war. Inevitably viewers would cease supporting any war altogether. For Fisk, televising the gruesomeness surrounding death due to war means bringing the reality of war to the viewing public; showing them 'real' death that comes with war.

Both the previous narratives speak of a 'hidden reality' in death, and each commentator believes that this 'reality' must be uncovered and exposed so that the truth of death can be understood in all its fullness. For von Hagens, showing the dead body through either autopsy or plastination is the combination of the workings of the human body and its eventual demise. For Fisk, the reality of death brought about by war must be channelled into each and everyone's home to expose the reality of war with its deadly impact on the innocent. In both discussions death is not considered real unless it is stripped of its sanitising veil.

The funeral industry also attempts to capture and ultimately convey the reality of death to the living, doing so in the belief that there is a "making visible of the invisible'. However, this is not achieved through the stripping away of the veil surrounding death. Instead it is achieved through the containment and sanitisation of the dead body, which allows for an engagement with death that is itself inscribed into the bodies of the dead. Constructing these narratives about death's 'reality', about making visible the invisible, is, however, a difficult task for a number of reasons, primarily due to the language struggle in capturing both the absence and presence of death. This is where the canons of religion and spirituality attempt to give a foundation to the understanding of death, whilst disciplines such as philosophy and linguistics attempt to show the problems with the technicalities of speaking of death from a living-centric positionality. 


\section{ABSENT PRESENT DEATH}

Philosophical debates surrounding death suggest that the word 'death' holds an ambiguous place within the English language, which is in turn reflected in its ambiguous place within society. This is due in part to the fact that the word 'death is a misleading noun. Nouns name 'something', however, where there is death there is said to no longer exist 'someone', for the 'I' that once existed is no longer present, therefore can no longer be named, "... who dies ipso facto ceases to exist" (Rosenberg, 1998: 304).

At this point I want to briefly explore the notion of absent present death particularly the arrival of a corpse after a death. Whilst death is an occurrence that everyone will eventually experience, ${ }^{7}$ it is one that is invariably solitary and can never fully be pre-thought. This impossibility of pre-thinking death is due in part to there being no experiential 'inside' (Haussamen, 1998; Merleau-Ponty, 1962; Rosenberg, 1998). To think or imagine death is always to imagine the living self looking back on the dead self, as an onlooker, an outsider situated safely within the places of the living. Understanding death then can only be achieved via simulacrum (Baudrillard, 1993). No matter how hard the living might try to imagine post-death, death is said to escape closure. As Merleau-Ponty (1962: 12-15) suggests, not even birth allows for an understanding of what death involves:

[For birth and death both]... appear to me as my experiences...I can only grasp myself as 'already born' and 'still living' - grasping my birth and death only as pre-personal horizons.

Therefore, speaking about death, particularly in the presence of the dying, can be extremely difficult and distressing for both the living and the dying (Elias, 1985).

Given that death is the phenomenon of the absence of the self, which in turn is a phenomenon of permanence, death represents an un-becoming. Therefore, speaking about impending death in front of the dying is a reminder that they are about to leave, to no longer be, yet they are about to be dead. Language, on the other hand, is a 'becoming'; it is instrumental, an entering into the symbolic. This, Brock

\footnotetext{
${ }^{7}$ Without being facetious, some contemporary scientists, especially those working in stem-cell research, hope to be able bring a complete halt to illness and disease in the quest of bringing at least longevity to all human beings. See the Immortality Institute's The Scientific Conquest of Death: Essays on Infinite Lifespans. (http://imminst.org). Therefore, the idea of someday being able to choose not to die may well be an option. Until then death is a reality for all.
} 
Haussamen (1998: 309) points out, is in itself problematic. He disagrees with the idea that human beings cannot speak to or of death, arguing that death cannot only be thought but can be and is understood:

It is true that we cannot fully and successfully imagine what it is like to be dead, because being dead presupposes no awareness, and so there is no "what it is like to be" that can be imagined. But we do think about death, and we do so largely with language.

Haussamen (1998) points out that a few centuries ago language did not appear to fail death, due largely to the way people viewed death. Death was a movement from the world of the living into a new realm - that of the dead. However, he suggests that whilst death can be spoken about, language is more oriented to speaking of life. Through scientism and the medicalisation of death there is now a sense of closure, due in part to there being a sense of failure surrounding death. Contemporary medical attitudes surrounding death has seen death as a failure of life, therefore it is an exiting from life, "... a moment of cessation, an end to all purpose and planning" (Bauman, 1992: 130). Thus, death is not only linguistically awkward to capture, it is also viewed as a form of failure, an ambiguity that sees language fall short of speaking of death. This is said to highlight the proximity of human beings to nature, for the vanishing of the subject before the eyes of the living leaves only an empty material vessel that has come to represent the recent departure of someone into nothingness.

Arthur Zucker (1998) argues against Haussamen suggesting that whilst language is ambiguous it is not - in the case of death - unable to describe death. Zucker (1998: 327) argues that Haussamen is mislead by the "... assumption that talking about some thing requires a clear sense of reference" he suggests that 'we' (human beings) make language and wield it as we see fit. Whilst he agrees with Haussamen that human beings are confused about death, he does not believe that this confusion is in fact an inability to speak of death. Death he argues is hard to speak about when one is young but as one ages speaking about death whether in a joking manner or not is more frequent.

Whilst speaking of death may be difficult to pinpoint looking on death one might argue is not. Jay Rosenberg's explores the absent presence of death by posing the 
body of a factious character that he calls 'Ethal'. Rosenberg argues that this new occurrence, the death of Ethal and the arrival of a corpse, does not bring with it a new naming. Whilst death has brought an end to Ethal's life, for where the living Ethal existed there now rests a corpse, there are also the remnants of what her family and friends call Ethal. It is within this new space that the family now find themselves; a mourning space. Importantly, it is this new place which to date the family have not yet experienced, not at least with Ethal. Although Ethal's death may well have been something friends and family had come to expect and most probably prepared for, the demise of any being is in effect new. Ethal's demise is difficult to understand because, as Rosenberg so rightly points out, there is not a language that fully explains this new occurrence, even though there is a corpse to prove the death of Ethal. Death then is present in its materiality yet there is a disparity in the language used to communicate the now deceased Ethal.

This present absent body has been explored by Drew Leder (1990), who views the body as always being in 'dys-appearance and presence'. Whilst the body is in a constant state of lived experience it is never fully closed in its experience, as certain aspects of its being are constantly present, yet largely lived in silence. Take, for example, the inner workings of the body: the organs are not shut down or inactive merely because one does not feel them operating. It is typically in times of illness, an accident, or the onslaught of an anxiety attack that one is reminded of the internal workings of the body (Schumaker, Warren and Groth-Marnat, 1991; Leder, 1990). Death, suggests Leder (1990: 144), is always present, for “...the corpse is always approaching from within...[h]owever, it is also that which never arrives". The presence of the corpse shows an 'ineluctable absence' as well as a presence of the 'other'.

To address the ambiguities of the presence and absence of death, different societies have developed different stories, or in some cases meta-narratives, that situates death within particular disciplines or contains it within specific spaces. In Western societies, religion, science, medicine and philosophy are considered the rightful homes of death. These disciplines help locate death and in turn construct how death can be read and understood. Consequently, death has come to be contained within specific readings and locations. This is particularly true within 
academia, where the disciplines of philosophy, religious studies, medicine and science are considered the rightful homes of death related topics.

Outside academia, religion has played a significant role in easing the fear surrounding death. In constructing a specific understanding of death that sees the soul as central, the dead continue to encapsulate an embodiment - a post-death 'livingness'. This narrative crafts death as active, as souls “...can undergo change (salvation, reincarnation) and can even experience change..." (Haussamen, 1998: 318). Medical science, on the other hand, attempts to pinpoint death; to fix death to a narrow yet seemingly accessible understanding. Death is a moment; a transformation from being alive to being dead. To help mourners to realise death and in turn engage with the dead body the funeral industry has drawn on both religious and medical death narratives. ${ }^{8}$ This helps create the separation of the sacred (religious) encounter, from the profane (scientific medicine). For the industry, then, it is necessary to view death visually and 'up-close'. This is said to help give death the dignity it deserves as well as allowing for a more rational understanding of death: death can be seen as being 'real'. Similar to the function of cadavers within medical rooms, there is a need to find a hidden truth in or upon the corpse, and it is for this reason the corpse must be 'opened up' for viewing. This can only be achieved if the body of the dead is cleansed of all its contaminating demise. This cleansing of the dead body can only be accomplished through the symbolic and material removal of death and decay from the body of the dead, so that death can be 'fully' viewed and in turn fully acknowledged.

There are difficulties associated with fixing death to a particular time and a 'viewable' or observational understanding. Whilst death is understood to be the cessation of life, when this in fact occurs is in and of itself problematic. Religion, medicine and science attempt to not only identify but relieve the anxieties human beings hold about death. Funeral rituals are therefore drawn upon and become part of the matrix of positioning death in an attempt to explain and understand its nature. In so doing, the funeral industry has interwoven science and spiritual approaches. The ritualised separation, transformation and reintegration of the dead

\footnotetext{
${ }^{8}$ This includes drawing on psychology, which underpins viewing and grief therapy. See Elizabeth Kübler-Ross (1973, 2005).
} 
rests on the funeral industry's interpretations of science and religious understandings of death: in turn these are combined with the industry's understandings of cleanliness and dirt.

Before exploring these various discourses it is necessary to begin by setting out some of the limitations for the research. What I am particularly interested in is the use of embalming within the funeral ritual, and how this practice underpins and constructs engagements with the dead body. For this reason, this research concentrates on the private and public spaces, or what Erving Goffman (1959) calls "front stage" and "back stage", of the funeral home, mapping the movements of the bodies of the living and the dead as they are manoeuvred in and around this specific site.

\section{LIMITS: SETTING RESEARCH BOUNDARIES}

Whilst it might seem an exciting prospect to investigate all aspects of one's topic, there are, of course, limits to how much one can include without the research becoming a 'shallow skimming'. This research has therefore been confined to the internal spaces of the funeral home. There were a number of reasons for this. The first reason for exploring these spaces was a personal interest, generated in 1993 from having felt somewhat frustrated at how monitored I had felt when attempting to gain access to view the body of my friend in a funeral home in Dunedin, ANZ. The second reason for concentrating on the spaces of the funeral home came about after researching aspects of the embalming process. I began to question the role embalming played in constructing people's understandings of death and the dead body. This in turn led to an interest in how embalming further constructed notions of private and public, sacred and profane, and clean and unclean space.

While death literature in general is sparse within geography, death has been explored somewhat with the notion of 'deathscapes' (discussed further in Chapter Two). However, death and particular deathscapes have been looked at considerably in other disciplines, such as religious studies, philosophy, and medicine. One might argue then, that the topic of death has in fact been studied to 'death'. Of the literature reviewed, however, few writers have concentrated exclusively on the 
funeral home, particularly as a liminal space. Those who have explored aspects of funeral work in funeral homes (see for example Hallam, Hockey and Howarth,1999; Laderman, 2003; Walter, 1992, 1994, 2004) seem to pay little attention to the use of contemporary embalming practices, often allowing the subject to be subsumed into a space that appears to continue to legitimise its use. The relevance of embalming practices for creating liminal spaces within the home appears to be scarcely considered. In turn, there is not a lot of research that explores the connections of the movement of the bodies of the living and the dead within contemporary funeral homes to understandings of the contemporary uses of embalming. The constraints I came to place around the research then, reflect not only my personal interest in funeral homes and the utilisation of embalming, but also, significantly, the findings from a preliminary literature search.

In ANZ 99.9 percent of all dead bodies are embalmed (Aldridge, 2002: A1). To achieve this, dead bodies must be removed from the spaces of the living. Consequently, those close to the living must also enter the funeral home at some point of the ritualised disposal stage of death. For some of the living, this may be the first time they have ever entered a funeral home. It is here that many families will discuss the arrangements of the funeral and view the dead body prior to it being returned to a family home or sent for burial. Therefore, this site, whilst understood as essential in the process of burying the dead, is an important transitory site: it is where the dead rest momentarily in a post death, pre-burial space - a liminal space. It is also the site where the living moves from one state of being into another: they become mourners. Therefore, this site or deathscape, and the various practices and processes carried out within it, are important in understanding the spatiality of post-death bodies and space. Another reason for exploring the deathscape of the contemporary funeral home is to offer understandings specific to ANZ. Apart from the New Zealand Funeral Directors Association (NZFDA) literature, much of the written material about and for the funeral industry is produced for a predominantly North American audience. This is also true of the majority of work produced within geography around death issues. Accordingly, the site of the contemporary funeral home in ANZ and the various practices undertaken within are important in developing understandings around the spatiality of post-death bodies and space. 
Whilst the following was not a constraint as such, I was faced with the political dilemma of whether I should broach the issue of Māori (indigenous people of Aotearoa New Zealand) tangihanga (funeral) practices and what I had come to identify as the continued colonisation of Māori cultural practices by the contemporary funeral industry in ANZ. As a Pākehā (non-Māori New Zealander) who does not speak the Māori language and has a limited understanding of Māori cultural practices, I was concerned that engaging in such a discussion could become part of further colonisation. Therefore, whilst I believe it is important to include a discussion of tangihanga, as it exposes the industry's contradictions and inconsistencies, this discussion is written from a Pākehā perspective and for this reason must be understood to not fully embody an understanding of Māori tikanga (customs and traditions).

\section{THESIS OUTLINE}

To explore the spaces of the funeral home this thesis unfolds in the following way: Chapter Two concentrates on the theoretical approach underpinning this research. To explore how spaces and bodies come to be considered abject I have drawn predominantly on two theorists: Georges Bataille and Julia Kristeva - both of whom probe notions of exclusion and inclusion through the concept of abjection. In considering the abject body I begin by looking at how death comes to be understood. Seemingly naturalised death is in fact problematic and its ambiguity allows particular knowledges to come into play when defining the borders of death. Part of the process of defining death is influenced by the funeral industry. Under the rubric of science and medicine the industry attempts to explain post-death decompositions and through their particular lens construct many of the rituals which characterise modern funerals. To examine this fixing of death I want to briefly analyse the medical and scientific discourses and their problematising of the absence and presence of death. Such discourses have seen death become 'othered' - a stranger with which few wish to engage. Within Western societies death becomes abject and excluded from everyday life. Death is marginalised, out of place, and its 'cleaning up' is left to a select few ,who, while containing and cleansing, define death and construct its borders. 
Chapter Three outlines the methodological approaches utilised to gather the information that binds my personal and theoretical understandings. In presenting the research within human geography I problematise the space between theory and practice, and also introduce different methods which were used to generate data. With a desire to push the boundaries of writing, engaging with text and interviewing, my approach was instigated by the struggles I initially faced when attempting to interview various respondents. Attempting to engage with such a closed industry is in itself difficult; attempting to do so as a dyke with no hair, a propensity towards environmentalism and a body inscribed with various tattoos proved to be even more challenging. For this reason I turned my attention to Norman Fairclough's work (1989, 1991, 1992, 1995), which does not concentrate merely on the reading of text but also includes reading discursive and social practices.

Chapter Four sets the scene for both Chapters Five and Six by tracing some of the industry's foundation narratives, concentrating on those narratives that have come to underpin the use of embalming as a tool for temporarily halting the advance of decay. In doing so, I explore how the industry has drawn on a particular spiritual discourse that reaches as far back as ancient Egypt. This narrative is then retold as a particular story of service and woven into the principles and practices of contemporary funeral work. Whilst this narrative no longer sits at the heart of the funeral industry's narrative, it continues to construct a particular taken-for-grantedness that has come to consolidate the borders of the industry. As part of the funeral industry's narrative, each country in which contemporary funeral customs are practiced has unique narratives that are also woven into the funeral fabric. For example, in ANZ the use of contemporary embalming has become constructed as essential to Māori. Many of the hygiene practices utilised by the industry drew upon new health and sanitation regulations that undermined traditional Māori tangihanga practices, thus furthering the colonisation process. As the chapter unfolds I also explore how both funeral practices and embalming methods began to change in ANZ as funeral directors gradually shifted their practices from a historical reliance on Great Britain to a more innovative and profitable approach to funeral work, which was introduced by the North Americans. Of particular interest is the way in which the contemporary funeral industry draws on and utilises Māori tangihanga practices as further justification for the use of embalming. 
Chapter Four also explores how the viewing of the dead body has come to be seen as necessary for the acceptance of death in its actuality, and the serendipity of this for the embalming industry. Here we can see that whilst the myths that support embalming are firmly situated within a discourse of disease and contamination, the industry publicly purport that embalming is necessary for viewing and accepting death. The public and private are always fused together within the industry, yet separated for the protection of the living. By positioning what many in the industry call an 'art' within a scientific and contagion discourse, undertakers have not only been able to take control of the dead but have also delineated what constitutes acceptable funeral practices. These practices have in turn determined the geography and strictures of the funeral home, aiding in a monopolisation of the bodies of both the dead and the living - the mourned and the mourning.

Chapters Five and Six investigate how social and spatial relations are understood in the funeral home. A binary separation, in this case between the private and public space, is viewed as necessary for the easy and seamless operations of the funeral home. In the private space transformation is undertaken, which includes both the transformation of the corpse and the initial grieving process of mourners, whilst the public space is where the corpse is reintroduced to the public (family, friends, others). This private/public separation also separates what is viewed as unclean and uncontained from the clean and contained. For example, initial grief over the dead body itself is separated from others insofar as the body is behind closed doors. The corpse, seen as the most polluting of all objects, is at the outset disconnected from the living in the mortuary, and later, even once cleansed, in a coffin. Whilst there appears to be a 'natural' separation of the private from the public, and the contaminated from the contained, this is in fact an illusion. The abject, according to both Kristeva and Bataille (see Chapter Two), can never be fully excluded or controlled. So whilst I have followed the apparently natural separation of these two spaces, within Chapter Five and Chapter Six I show where the demarcation lines mapped onto contemporary funeral homes in ANZ are crossed by death (clean and unclean notions of death), grief and contradictory funeral practices.

For this reason Chapter Five begins by following the transportation of the corpse from its pick- up point and its transferral to the mortuary. This negotiation includes a 
critique of the various discourses that underpin the separation and transformation of the corpse. This chapter also explores how the stigmatisation of the corpse is transferred to the body of the embalmer/funeral director. Ensuring that death no longer weighs on the living, the funeral director/embalmer takes the full weight of the dead. To explore this I draw on an episode of Home Box Office's(HBO) Six Feet Under (2005, Episode 61: All Alone), which highlights how the transportation of the un-embalmed corpse, whilst bringing back the materiality of death, becomes awkward and undignified - something that contemporary funeral directors/embalmers have attempted to erase.

In Chapter Six I traverse the terrain of the public spaces within the funeral home to explore how these spaces are separated, and also how particular unclean behaviours are handled through constructing notions of dignity and respect. With the renaming of the early 19th century 'funeral parlour' to what we have come to know as the 'funeral home', the emphasis on the types of services offered shifted. Funeral homes in the 21 st century became a pivotal site for transforming the 'reality of death'. The funeral director became a master of ceremony and illusionist, exerting his or her (typically his) control over the 'spectacle' that is the contemporary funeral. This controlling element runs the spectrum of funeral services; from ensuring that the location of the funeral home is 'appropriate' to ensuring that the type of music played at the funeral sets the 'right' emotional ambiance. By tracing the movement of both the dead and living bodies in and around the public spaces of the funeral home, particular performances generate insights into how death and mourning and cleanunclean spaces and practices come to be constructed, understood and embodied.

Chapter Seven brings the research to a close, offering some final comments on my analysis and findings of the research. I also discuss what I have learnt personally and how my findings have transformed me in different ways. Because I see this piece of work as a continuing journey, I set out some ideas for further exploration into the field of death and disposal within the discipline of human geography. As part of this ongoing journey I also offer some thoughts on the impact of the research on the geographical sphere, identifying paths that may be ripe for further study. 


\section{2}

\section{THEORETICAL CONTEXTS}

In the previous chapter I introduced the research question, as well as the aims and objectives of the research. I also outlined and discussed some of my concerns about researching the topic of death. In this chapter I outline and discuss the theoretical perspectives that have been drawn on to engage with the research topic. These perspectives taken not only reflect the way in which I view and engage with the world, but they also indicate how I understand myself in relation to death related issues. Therefore, my theoretical approach, like the methods I utilise, is multilayered, interdisciplinary and at times deeply personal.

In utilising a multilayered and interdisciplinary approach one needs to be prepared to not fix oneself: instead the researcher needs to be flexible in what she or he draws upon. This 'dipping in and out' of different perspectives is called bricolage (Derrida, 1981). Bricolage allows the researcher to utilise various disciplinary approaches, while at times allowing the researcher to abandon certain approaches for others. However, when using bricolage one is reminded that the 'tool' that one chooses to use does not instantly fix the user to the tool. For example, Derrida (1981) argues that using a hammer does not make one a builder, or as he calls it, a 'hammerist': the tool is being used because it is available and useful for that particular moment.

To build the foundation of the thesis and shore up some of the more tangible issues I faced whilst conducting the research (see Chapter Three) I have situated my work within the discipline of human geography. The discipline of geography incorporates a diverse grouping of geographical perspectives (Thrift, 2002). With the diversity of research topics the discipline of geography has not only been challenged, but its knowledge base has also been expanded. This expansion, whilst being invigorating for geographers, has according to Matthews and Herbert (2004), meant that the discipline can no longer be easily defined. As part of the push at geographies borders splits have occurred particularly between what has come to be understood as the physical geographers and human geographers. According to Thrift (2004: 438) this 
split is based on the production of '...different knowledge-producing infrastructures". This knowledge-producing has meant that various voices have taken their place within this diverse discipline and challenged what was once a male-centric space (Longhurst, 1995).

These now firmly embedded epistemologies destabilise the 'objective' approaches to research, which has led to a destabilising of accepted knowledge and an exploration of marginalisation and centrality and the concepts of who creates knowledge for whom. Human, feminist and critical geography encourages a crossing of disciplinary borders. In so doing geographers challenge the “...psychotic tendency amongst academics to erect strong subject boundaries" (Sibley, 2003: 397). Such border crossing lies at the heart of this thesis: the mainstay of my work is to open up spaces and transcend boundaries in an attempt to make the central thesis and my work itself more transparent.

Before exploring these unlimited possibilities and transgression of boundaries I want to place myself momentarily into the context of this particular piece of work, and more importantly, within the theoretical approaches I have chosen to utilise. This situating of self is derived from a feminist challenge to Cartesian thinking, a worldview which typically sees the researcher divorced from the landscape that 'he' is researching. This re-embodiment of the researcher through a situation of self has seen a proliferation of more lived and embodied works entering academia. The reembodiment of the researcher has been embraced within many disciplines. However, Gillian Rose (1993) cautions those drawing on this approach to think carefully about what using it means, as it must be remembered that one's identity is not unchanging, but rather fluid and positional to the context in which one places or finds oneself. Whilst in agreement with Rose's warnings there is still embedded within me a resistance or hesitancy around the notion of fluidity. It is a concept I continue to struggle with, as I instead wish to have an unfettered identity that negotiates its way through the world unscathed and generally unchanged.

This struggle can, I believe, allow me to explore various theories more critically as I tend to find myself positioned within the third space, the grey space, of being fixed/unfixed in my continuing search for different understandings of self. This 
complex and conflicting state of 'in-betweenness', wanting to either fix oneself or run free and fragment into several selves, has led me to explore various alternative political and theoretical approaches in an attempt to understand the self, and in turn understand the self in relation to the world. For this reason I believe it is impossible to distance myself from either my theoretical or methodological approaches (further discussion of this is undertaken in Chapter Three).

When employing a post-modern/post-structural theoretical approach I am arguing that there is no fixed researcher to discover truth, nor is there an objective truth to be uncovered. Instead I, like other researchers drawing on post-modern/post-structural approaches, am attempting to explore and understand shared situated meanings seen for example in the works of Frederick Nietzsche (1967, 1967b), Jacques Lacan (1986), Michel Foucault (1977,1978, 1989, 1989a, 2001), Jacques Derrida (1981, 2001) and Judith Butler $(1990,1993) .^{9}$ These diverse approaches have been adapted and incorporated within different disciplines; for example, feminist theorists have utilised post-structural/post-modern theories to challenge the position of the professed objective, disembodied research position by bringing the body 'back' into research and embodying subjectivity. As previously discussed, the inclusion of the researcher's positionality has seen a proliferation of writings opening up not only new approaches but also a degree of candour, helping the reader understand how the writer is situated. This has led to a further opening up of space for different positionalities, marginalised groups and the intermixing of theoretical perspectives.

Although I have already touched on what it means to 'know death', as part of the creation of my argument and examination of contemporary funeral homes, it is important to further expand on understandings of death. The reason being that death - the state of being dead - lies at the heart of any engagement with a decaying corpse, the practice of embalming, and the funeral home. I therefore want to discuss some of the problematic discourses that inform the industry's principles and practices.

\footnotetext{
${ }^{9}$ Whilst these theorists might not position themselves within post-modern/post-structural approaches, they have been so positioned by others because they form a diverse intellectual alliance that through their various works rejects notions of universality and normativity.
} 


\section{A BODY OF DEATH}

In the series Six Feet Under, Season Two, Episode 20: Back to the Garden (HBO, 2002), brothers Nathaniel (Nate) and David Fisher are helping to prepare a Jewish funeral, which is to be held at Fisher and Sons Funeral Home. At the end of the service Nate, who has recently been diagnosed with arteriovenous malformation (AVM), asks Ari (the female rabbi overseeing the funeral) if he can speak with her about death. He wants her to share with him her views, as a Jewish woman and a rabbi, about what death is. Nate begins the conversation by telling Ari that he is going to die:

Nate: Every time I get a headache I'm thinking this could be it.

Ari: You must be really scared?

Nate: Yeah, I'm gonna die.

Ari: Yeah, me too.

Nate: Yeah? What do you have?

Ari: A body....

All human beings have bodies, ${ }^{10}$ and while they come in all shapes, sizes, colours and differing degrees of abilities and (dis)abilities, there is at least one commonality to them - the inevitability of death. Whilst death may occur at different stages in individual lives, in different places in the world, and for differing reasons, death, one could say, is a universal phenomenon that ties each and every one of us together.

The ambiguity and problematising of bodies has been extensively explored by feminist geographers. In conjunction with this increased engagement with feminist theory, questions around the use of quantitative and qualitative research have seen new approaches to researching gendered issues. In addition to these new approaches particular themes have found their way into the geographical canon. These themes include subject matters that are prevalent within feminist debates, such as the personal and the political, private and public, practice and theory (see Bondi, 1999). Most significant has been the embodying, or as Robyn Longhurst and Lynda Johnston (1998) suggest, the 'emplacing' of bodies into the geographical landscape. In emplacing bodies into geography's landscape, questions around identity and selfhood, the 'Who am I?' and 'Where do I come from?', are explored differently. By looking specifically at body-space relations and body-space boundaries new and

\footnotetext{
${ }^{10}$ A more in-depth discussion about death and bodies can be found in Chapter Six, where I explore the containment of death and dead bodies within the funeral industry.
} 
varied forms of bonding among people can be discovered. This investigation of identity and gender has led to a wealth of research into cultural, racialised and sexed identities, as well as exploring subjectivities constructed within particular spatial contexts.

Outside of geography Foucault (1976), in his work The Birth of the Clinic, explores what Chris Philo (2000) calls the 'geography' of medicine and the body especially through new discourses on disease. He identifies how a new impetus of looking into the body as opposed to merely looking at the body became ingrained into new understandings of medical discourse and practice. Important to this advanced notion of the medical gaze was the cadaver, which became a site of truth about wellness and life. Linked to developing understandings of disease the cadaver became important for defining and mapping the spread of disease, thereby creating a context for distinguishing between wellness and illness. This led to disease being read by medical practitioners as something produced from within the depths of the body and therefore by the body, as opposed to disease invading the body from outside. In turn the medical gaze concentrated on making the "invisible visible" (Philo, 2000: 13). Cadavers became important in this search for truth, as they could be cut up, examined, noted, measured and their internal geography further explored: ${ }^{11}$

The objective was to embrace both time and space together, in effect to reconstruct the 'historical geography' of the body, as a means of teasing out the 'spatial and temporal starting point' $(\mathrm{BC}, 140)$ of pathology as a prelude to tracing its dispersion - notably by tracking tissue changes through the spaces of the body over time. Increasingly, the hope was to refine dissection procedures that would enable this progress of disease in time-space to be interpreted from bodily remains and be able to control for bodily changes introduced after death... (Philo, 2000: 15).

Death and disease came to be interlinked and eventually separated from wellness and life. In turn, hospitals became laboratories where doctors were the technicians of death and disease, thereby extending their hold over the dead (Jacyna, 2004). The dead body therefore comes to lie at a crucial junction where multiple readings erupt

\footnotetext{
${ }^{11}$ The mythical narrative of this advance in medicine talks of anatomists so obsessed with this new form of experimentation that they would steal bodies fresh from the grave. Foucault, however, questions this particular narrative of doctors, challenging the "...prejudices of religion and superstition to secure public acceptance for disemboweling the dead so as to benefit the living" (Philo, 2000: 13). What is of importance is the new direction that concentrates on the need to 'gaze' upon; to look directly into the body to locate death.
} 
from its non-being. For this reason the dead body should become important as in its death it becomes merely a body, apparently devoid of character (Hallam et al., 1999). Whilst speaking about death can be problematic, in that spaces where death should or should not rest come to be both understood and (mis)understood, there is a need to rest the bodies of the dead at the centre of any debate.

Death is both an un-becoming and a corporeal experience. However, it is in the margins as the living's 'other' that discussions of death are conducted. It is in these margins that death comes to be understood and engaged with as both an object and a subject, as clean and unclean. ${ }^{12}$ Within the margins to which the post-dead body is confined it is the funeral industry that have been given guardianship of the dead, and as such, those within this industry have come to construct particular discourses for their continued responsibility of disposing of the dead. Death, then, is part of any discussions about the spaces in which the decaying body rests, nor can death be excluded from any discussion of the livings' understanding of cleanliness and 'unclean' post-death bodies. It is for this reason that death must be brought in from the margins and situated within a geographical investigation of dirt and cleanliness.

\section{DEATH MATTERS!}

The statement 'geography matters' is not uttered lightly within geography (Massey and Allen, 1984). The importance of a geographical perspective within discourses exploring the relationship between human beings and their environment has seen the once staid discipline expand and transform through various challenges from feminist, post-colonial, and queer geographers. Once a contained discipline with little interest in exploring the interrelationship between humans and their environment (this, one could argue, had been left for anthropologists and sociologists), geography has reassessed its reductionist discourses. However, feminist, postcolonial and cultural

\footnotetext{
12 In this thesis I use the binary terms 'clean-unclean' when discussing the dead body. Nevertheless, I will alternate this binary with other similar binaries such as sacred and profane; clean and dirty; clean and contaminated. The reason for this alternating of terms is to problematise the use of euphemisms by the industry to discuss the necessary practices for disposing of the dead body. Whilst the industry's literature describes the dead body as a potentially dangerous object due to its decay, this is never vocalised. Instead the dead body is viewed as sacred, but in need of certain cosmetic practices so that it can be viewed by mourners.
} 
geographers argue that geography still grapples with its masculinist framework, and that even today various knowledges, spaces, places, social groups and certainly some topics (see Sibley, 1995) are marginalised, or in some cases completely excluded, from the geographical setting.

The discipline of geography "... at least on the surface is an emotionally barren terrain, a world devoid of passion..." (Bondi, Davidson and Smith, 2005: 1). However, geography has undergone many challenges, particularly around its traditional social science approaches to understanding how the world works (Hubbard, Kitchin and Valentine, 2004). Challenging the once passionless terrain of geography has seen marginalised groups being given a voice. Feminist, cultural, emotional and psychoanalytical geographers have contested traditional geographical approaches, arguing that inhabiting space through human activity sees space become 'relativised' and 'historicised' (Lefebvre, 1999).

Challenging the authority of masculinist voices within geography and the production of knowledge(s) produced from this position, geographers have begun to challenge concepts of inclusion and exclusion, particularly the binaries that exist to support notions of 'giveness'; for example, science's claim to truth (Rose, 1993). However, the disputation of naturalised dichotomies and the inclusion of the 'other' within contemporary geography still appears to fall short according to some geographers, however this is changing and cultural and human geographers are pushing at these boundaries. Particular subject matter that had once been considered by some academics as non-academic pursuits (see Sibley, 1995) are now part of the fabric of geographies. Nevertheless, feminist, human and cultural geographers have and are still playing an important role in exploring and expanding the borders of geography. This is because of the understanding that places make people, people create spaces and places, and that relations are "...constructed and negotiated spatially, and are embedded in the social organisation of places" (Duncan, 1997: 4). The construction of space through social, economic, political and cultural relationships (Bartley, Hubbard, Kitchin and Fuller, 2002) means that spaces are never neutral or value free. Spaces, therefore, are never merely natural environments but are "...constituted through social relationships and material social practices" (Massey, 1994: 254). 
Take, for example, the home. It is a place that is not only constructed as a home by those who live in it but the home in turn constructs those who live there, therefore making it extremely significant to people. Home, according to Gaston Bachelard (1969), is a place where the infant initially comes to understand its world. Home is read as a place where one can feel safe and at peace with the world and oneself. Whilst the home has come to represent a place of intimacy, a space in which people can withdraw to away from the daily demands of the outside world, it is also a place fraught with complex, contradictory relationships. For Alison Blunt and Robyn Dowling (2007) home is significant for geographers as it is a paradoxical space. Like Rose (1993), Blunt and Dowling read home as a place that can be both inviting, bringing feelings of belonging, and alienating.

In naming a space 'home' particular cultural norms are played out that advantage and support cultural dominance. Thus spaces - even apparently naturalised safe spaces such as the home - can be wrought with tension, and as Smith and Katz (1993) suggest, space can never be simple or pure. Space is always interspersed with power relations, with who does and does not belong: "Who is felt to belong and not to belong contributes in an important way to the shaping of social space" (Sibley, 1995:3).

These tensions produce 'safe' and 'unsafe' spaces which become inscribed into the bodies of those who inhabit them. Therefore one can explore how particular bodies and spaces become constructed as 'other', as unclean or clean (Grosz, 1995; Sibley, 2001, 2003). From the personal, such as the example of home, through to public spaces and places, there exists a natural separation of disorder from order (Douglas, 1969; Young, 1990). It is these tensions of inclusion and exclusion that feminist and psycho-geographers are attempting to open up, explore and give space to. However, even within geographies of exclusion there appear to be spaces and places considered outside the geographical imagination. These spaces are said to harbour all that is considered abject, threatening and unsightly and are consequently inappropriate for academic enquiry. Longhurst (2001: 124) tells of an experience when researching the pregnant body: "An editor of a well-known geographical journal once told me that the pregnant body is an 'inappropriate' subject for geographers to consider". 
Longhurst's example speaks about the exclusion of particular material considered not only inappropriate but 'out of order'; taking space away from serious 'scientific' based inquiry. Not only is the spatiality of the pregnant body taking up space, but to study it is to bring disorder to the carefully calculated, measured and ordered spaces of science. Pregnant bodies have a particular space and it is to these spaces they are to be confined. There are other spaces and bodies that are given similar treatment, for example "...toilets/bathrooms tend to be too material, too squeamish, too uncomfortable, too unacceptable (or just plain banal) to discuss ..." (Longhurst, 2001:129) within the geographical context.

The inappropriate must find its own place: the inappropriate must remain at the borders, hovering just beyond the horizon situated as 'other'. Language helps in consigning that which is not desired to the margins. As Bataille ${ }^{13}$ suggests, bodily functions must never be called by their improper name, unless being discussed in inappropriate space. Therefore excrement must never be referred to as 'shit', whilst urination cannot be known as 'pissing' in polite spaces. In turn the human genitals must never be referred to in polite spaces by their inappropriate names, only by their medicalised titles. The anus can only be called an 'arse' and the vagina can only be called a 'cunt' in the confines of particular spaces and conversations.

So what then of the spaces that harbour what Kristeva (1981) identified as the most abject of horrors? What of the autopsy rooms, embalming rooms, cemeteries, crematoriums, and funeral homes? Within geography few of these spaces have been explored. Nevertheless, some geographers have and are making every attempt to bring the dead in from the margins - making 'Dead Bodies Matter!'

\footnotetext{
${ }^{13}$ According to Bataille, words such as 'shit' or 'piss' are important and necessary words. By eliminating them from our speaking through the act of purifying language we close off possibilities for engaging with transgression. He also argues that we deny the underbelly of the philosopher, for without shitting or pissing philosophers would die and there would be no philosophy. Reason, he argues, has to have shit.
} 


\section{GEOGRAPHIES DEAD SUBJECT}

Death related topics as I have suggested remain to some degree on the margins of geography. However, as talked about in the previous section, some geographers have explored deathscapes, particularly concentrating on the profane / sacred spaces of cemeteries. Necrogeography, whilst not a major discipline within geography has made considerable contributions to discussions around place and understandings of the space as sacred and profane, though it has tended to remain on the geographies border.

Within the discipline of necrogeography, writers such as Richard Francaviglia (1971) concentrated on cemeteries as evolving cultural landscape. He argued that cemeteries tended to more about the spaces and attitudes of the living than how the living wishes to display their dead. In a similar tradition Cynthia Fuchs (1995), Elizabeth Teather (1998, 1999, 2000, 2001, 2002) Brenda Yeoh (1999), Lily Kong (1999) challenge the death void within geography by making different aspects of death central to their research. Tan Boon Hui and Yeoh (2002) suggest that the (limited) work in the study of landscapes of death (cemeteries) can be divided into four 'traditions': idiographic empirical work; cemeteries as land utilisation; social and cultural constructs; and cemeteries as 'text'. Scant attention, however, has been given to the stage between death and burial.

For Teather's cemeteries and gravesites are explored as cultural constructs of a nonmaterial world. When looking at Chinese cemeteries, she suggests that they act as a connection, a 'hinge' between the spirit world and the world of the living. This duality of the liminal and the sacred has, according to Teather, been very much overlooked by geographers because geography has operated from a more scientific and technological approach to understanding and engaging with the world. Whilst much of her work is concentrated on Chinese cemeteries her insights are valuable not only in understanding the embodiment of profane and sacred elements, but also in understanding how place is culturally, environmentally and historically constructed. As she points out, place is never neutral, therefore deathspaces ${ }^{14}$ embody notions of

\footnotetext{
${ }^{14}$ This is Teather's term for spaces such as cemeteries where death rests.
} 
time, space, belief, customs, and the tensions of life/death, inside/outside and sacred/profane.

In Patrick McGreevy's chapter, Reading the Text of Niagara Falls: The metaphor of death (1992), McGreevy offers a broader reflection of the changing faces of death concentrating on how Niagara Falls in the $19^{\text {th }}$ Century came to be a deathscape through various daredevil acts and a number of writings that came about after witnessing, surviving or having merely visited Niagara Falls. He suggests that Niagara Falls was a space where people battled death some overcoming death, whilst others succumb in a sense this battle was a challenge to the traditional Christian understanding of death. When standing at the head of Niagara Falls people he said, felt the nearness of death.

Nuala Johnson (2003) whilst not specifically researching deathscapes, such as cemeteries concentrated on investigating relationships between space, identity and representation particularly remembrance of the victims and heroes of Irelands great war. These spaces of remembrance of fallen hero's construct a particularly understanding around death and national identity. In a similar tradition Andrew Charlesworth's (2006) work on post-war Auschwitz - a deathscape and memorial to those who were murdered by the Nazi's in World War II, brings the significance of deathscapes as sites of political and personal remembrance spaces and the contestation of meaning of these deathscapes especially around the issue of space as 'out of place'. Jean-Robert Pitte's (2004), article expands the geographical gaze from a merely scientific countering of cemeteries to discussing cultural similarities and differences around death and funeral rituals. These and other deathspaces, such as funeral monuments and roadside memorials, reveal the tension between the sacred and profane as well as private and public interests.

Whilst the concerns of my research are to some degree different from those I am addressing in my research the discipline of necrogeography provides my work with critical commentary, particularly when exploring the socio-spatial separation of the dead from the living with regards to pollution rites. It is for this reason then that I have extended my field of investigation to geographers writing on and around bodies and spaces of pollution outside the necrogeography. This widening of the frame also 
goes beyond geography and I will draw on sociological and anthropological writings around death and funeral rituals.

\section{SOCIOLOGY OF DEATH}

No research into death related issues can be undertaken without drawing on the discipline of sociology. As I have previously mentioned, death related topics within geography have tended to concentrate on burial sites such as cemeteries or in the case of writer McGreevy's (1992) deconstructing spaces such as Niagara Falls as a death text. Therefore it is necessary to broaden the borders of geography and draw on a wider range of disciplines so as to explore the spaces of funeral homes.

Whilst sociology has been concerned with various aspects of death and how human beings develop rituals to help address death, a spatial understanding of deathscapes is itself limited. Nevertheless sociology has contributed to a broader understanding of death related topics. Other important works include those found in the edited works of David Clark (1993), in which sociologist writers Jenny Hockey (1993) and Shelia Adams (1993) explore notions of embodiment, specifically looking at how ideas about bodies and experiences of death and dying come to be understood within particular historical and cultural contexts. Like geography sociologist have become interested in issues of embodiment.

Other writers such as Elizabeth Hallam, and Glennys Howarth and Tony Walters also investigate how social identity theories have tended to pay little attention to that of the dying and or dead body. In so doing these writers challenge Chris Shilling (1993) notions of embodiment, arguing that identity still has meaning in persons suffering dementia and in many cases in the postdeath body. This exploration of identity in dying and dead bodies also challenges the seemingly seamless notion of a clear cut binary between life and death (see Destabilising the life/death binary, pp: 45 - 50). 


\section{OLFACTORY GEOGRAPHIES AND OTHER POLLUTING SUBJECTS}

As I have suggested the practice of embalming, the mortuary and funeral home have been sadly neglected within geography. As both 'sacred' and 'profane' sites, the funeral home and embalming room operate to help elevate the distress that death is said to have on the living. Whilst being necessary in the ritualised handling of death and the dead, these spaces evoke reverence, curiosity, and fear. These spaces are like the road crashes we wish to see but not look upon. Because of their sacred and profane position the layout of both the funeral home and embalming rooms not only reflects the changing attitudes of society towards the disposal of the dead, but also the need for order when dealing with the dead.

This order is achieved through a number of ritualised acts, one of these being the eradication of any signs of death through the use of embalming. This practice is not only about hiding the corporeal signs of death but also involves the eradication of death smells that emanate from the corpse. Much has been written about the importance of smell, take the works of Frank Schab and Robert G. Crowder (1995); Constance Classen (1992); Robert Burton (1976); and Alain Corbin (1996) who all explore the historical and cultural meanings of smell. In geography the burgeoning discipline of sensuous geography sees the inclusion of olfaction and the importance smell has on the everyday.

According to Paul Rodaway (1994) olfactory geography is an underdeveloped area geographers like many other disciplines tend to be drawn understanding human engagements through knowledge gained from seeing or feelings that are immediate or intimate, like smell. However, without taste, touch and smell it is argued human beings would find it difficult to negotiate our way around our spaces and engage with other humans. Whilst smell plays an important role in helping us understand our environments, it is according to Porteous (1985) limited by language. This inability to pin smell down to a specific label, is understood to mean that smells are not neatly categorised and they escape any attempt at cataloguing (Lebefvre, 1991). What is interesting is the intensity that smell has on people. Smell can be immediate, you can taste and smell an odour, or your immediate environment might very well trigger a memory of a smell. Smell in some sense lingers. 'To smell' something also escapes definition as one might smell something good or it might mean that something smells 
bad - to smell then cannot differentiate from good smell or bad smell, therefore one must attempt to explained it through the use of metaphor.

Smell is extremely important when investigating anything around death. Death is understood through sight, one is encouraged to view, look upon the dead, however, smell plays an important role in understanding death and it is as important to eradicating prior to the bodies re-entry into the spaces of the living. One must see death but not smell it.

For this reason I want to draw on research undertaken in geography around olfaction, so as to explore the various discourses utilised to contain and maintain order within the deathscapes of the funeral home. though this work is limited within geography it is necessary to draw on work outside of geography but, that influence geography such as the works of Julia Kristeva's thesis on abjection and Georges Bataille's work on profane and scared sites and beings (see Abjection pp: 34 - 38

It is the space between death and burial that the most abject of human fear is simultaneously engaged with, cleansed, reconstructed, contained, renamed, and cosseted from not only other dead bodies but also for a brief moment in time from the living. Within this liminal space the separation of life and death are negotiated, regulated and disciplined. This closeting off of the decaying dead body is not merely an act of locking death and decay away behind closed doors; it also involves the concealment of decay beneath the surface of the corpse.

In adding death to this growing geographical mix, especially in regards to notions of constructing sacred and profane sites and social interrelations between the living and the dead, geographers can further explore the complexity of space. It is therefore my considered opinion that unpacking deathspaces and exploring the interplay of abjection towards the dead and their decaying bodies and the need to cleanse death and decay though the use of embalming fluid can lead geography to a further understanding of geographies of exclusion. Longhurst (2001:135) maintains that 'close(t) spaces', spaces that deal with the unspeakable acts involving bodily fluids and orifices, need to come out in geography: 
Writing and talking about body fluids, abjection, orifices, and the surfaces/depths of specific bodies can offer a way of prompting different understandings of power, knowledge and social relationships between people and places.

The closeted spaces of the funeral home, particularly the embalming rooms and the bodies of the decaying corpses need to be explored as they are important sites of human and non-human engagements with abject objects/subjects. These explorations also destabilise the 'taken for granted' binaries that see life and death separated from each other, thereby setting up all engagements with the dead in continuous dichotomies.

\section{PSYCHOANALYSIS, GEOGRAPHY AND THE POWER OF ABJECTION}

Geography writers such as Sibley (1981, 2003), Steve Pile (1993), and Chris Philo and Hester Parr (2003) specifically draw on psychoanalytical theories, arguing that until recently there has been a degree of reluctance within human geography to utilise psychoanalysis. Echoing David Bell's (1991) comments on the lack of enthusiasm of geographers to explore queer geographies, Philo and Parr (2003) argue that this reluctance is comparable to the unwillingness of geographers to engage with other 'squeamish' subject matter. Yet, as I have mentioned, within the discipline there is an 'opening up' of space for geography's 'other', as well as a tentative move to explore untidy and dangerous subject matter.

Psychoanalytical subject matters certainly include undesirable and squeamish themes such as sexuality, repressed sexual desires, child sexuality, real and symbolic notions of 'castration', female orgasm, aggression, birth and death (Sibley, 1981, 2003; Philo and Parr, 2003). It is for these subject matters that psychoanalysis has come under a degree of scrutiny, especially concerning its often grand claims to truth and its repressive utilisation of micro and macro forms of power (Foucault, 1977, 1978, 1989, 1989a, 2001; Irigaray, 1974). 
This critique of psychoanalysis is echoed in many feminists critiques. For many feminists Sigmund Freud's works are viewed as endemic of women's oppression (see for example Betty Friedan, 1963; Kate Millett, 1970). Freud's Oedipus complex was seen to express the father-daughter relationship in such a way that the female child is always in lack. This lack contributes to a particular reading of wanting intimacy with the father, which can be read as a justification of child abuse and rape. Other feminists, such as Juliet Mitchell (1974, 2000); Nancy Chodorow (1978, 1989, 1994); Jane Gallop (1982); and Jane Flax (1990, 1993), have revisited Freud's work arguing that psychoanalysis can be incorporated into the feminist project and can be adapted by women so as to address issues of inequality.

Philo and Parr (2003) caution geographers utilising psychoanalysis that any attempt to look for some unspoken truth that may be said to lay hidden could be taken as a return to grand theorising, something that many geographers have worked to expel from their once masculinist discipline. Both writers argue that whilst geographers need to suspend their suspicions, there is a need to recognise that like any theory one can utilise what is workable, as long as one understands and recognises the limitations of the theory. Whatever one's concerns may be, geography and psychoanalysis appear to share similar interests, ${ }^{15}$ particularly in the exploration of the "...terrae incognitae of people's hearts..." (Pile, 1996: 9). This traversing of the heart's terrain can be extended to the feelings and emotions that underpin not only the concerns of the heart but also the passion and drive behind a researcher's interest in their topic. It is suggested therefore, without taking away from research topics, that researchers perhaps explore their own fears and anxieties about otherness and abjection:

As social scientists, we are not concerned solely or primarily with personal experience but it does constitute one route to an understanding of the fears, anxieties and gratifications of others, and the ways in which they shape socio-spatial relationships. This suggests that understanding the self - and autobiography as a mode of writing - should be taken seriously to what we discuss and write about and what we feel unable to discuss (Sibley, 2003: 395).

\footnotetext{
${ }^{15}$ David Sibley prefers to view any theoretical use of psychoanalysis by geographers as 'geography making use of psychoanalysis', as opposed to some interdisciplinary exchange. However, he outlines his hopes for a more interdisciplinary exchange with those in psychoanalysis and hopes too that psychoanalytical practitioners eventually come to see the importance of geography to their discipline. He points to the works of Biressi and Nunn (2002) and Lucey and Reay (2000) as examples of this interdisciplinary turn.
} 
Sibley (ibid) is particularly interested in how geographers come to utilise particular theories outside the discipline of geography. Not all choices, he argues, are based on some rational or systematic evaluation of theories. Instead he contends that one's choice may be based on the fact that something has 'touched a nerve'. One's theoretical approach may merely be due to some inspirational moment, a serendipitous insight.

This exploration of the precincts between what is considered acceptable or unacceptable lies at the heart of the psychoanalytic project. It is a journey of the exiled, a voyage of those who have learnt to speak in another language (Sibley, 2003). Psychoanalysis, it appears, draws the exiled to its borders (see Freud, 1957; Melanie Klein, 1975; Kelley-Laine, 1997; Kristeva, 1982). The destruction of family life, extreme trauma, exile and unhappiness are the topics of psychoanalysis: it is what gives purpose to both the theoretical and practical elements of this particular discipline.

Psychoanalysis has been employed widely. Geographers who utilise psychoanalytical theories have drawn variously from the theories of Freud (1957), Jacques Lacan (1968), Klein (1975), Kristeva (1982) and Bataille (1984). Of these theorists it is Bataille and Kristeva that most influence my work as they both challenge the borders of language in their explorations of the spaces and margins where language appears to fail the subject. In addition, both theorists, but particularly Bataille, use psychoanalysis to examine subversive ideas. This is especially pertinent when exploring issues around death. For both Bataille and Kristeva the process by which one labels the 'other' as abject, unacceptable and uncivilised is a product of fear - fear of the 'other'. This fear is said to be due to the 'other's' transgressive nature and its polluting ability, which is said to bring about disorder and contamination. 


\section{ABJECTION}

Ecological, disease, and secretion metaphors can all be used to imply displacement. Although their specific implications are different, the result is a common portrayal of geographical disorder in which citizens... are regarded as out-of-place (Cresswell, 1997:342).

The notion of abjection can be traced via the works of Kristeva (1982) and Bataille's (1988) notion of informe. Rosalind Krauss (1997) argues that informe and abjection are not variations on a theme; they should be considered as quite separate. The power of abject spaces, places and peoples is highlighted through the use of metaphor, which helps define and 'other'. In so doing metaphors help define and sanction 'reality', which in turn prohibits or allows particular behaviour and beliefs. The creation of reality through certain behaviours or beliefs becomes 'second nature' or 'common sense'. For Pierre Bourdieu (1990) common sense (doxa) works to produce order, and those who ignore these common sensibilities are said to be out-of-place. They bring with them disorder, and disorder, as Mary Douglas (1969) proposes, is dirt.

For Bataille metaphors surrounding notions of dirt are simulacra for the human fear of a return to nature, a return to a pre-civilised being. Sexual acts, violence, taboos, sacredness and scatology (the science of filth) are, according to Bataille, transgressive by nature, as each act ruptures borders. For Bataille, breaking across the borders of the body unifies human beings (Hussey, 2002). He is not suggesting a return to essentialist thinking, nor to any form of grand theorising or grand narrative; instead his transgression into the space between social constructionist and essentialist theory highlights the contradictions of purely aligning oneself in either camp. It is therefore within this thirdspace that any exploration of the historical, cultural and political notions of being can be explored. To achieve this Bataille argues for people to think and explore everything to the point of fear; to think until one trembles (Surya, 2002). It is for this reason that death and the corpse become central too much of Bataille's works.

According to Bataille, transgression is necessary in containing and controlling acts of disturbance and violence, thereby making acts of transgression a valuable part of society's organisation and overall cohesion. Transgression for 
Bataille is not negative, as eruption through transgression is not perilous to a society. He harks back to a time when pre-industrial societies incorporated taboo and ritual into social festivals, woven together as a unifying force. The disgusting, the sickening and all that revolts were embraced, not marginalised. With the proliferation of Christianity, transgressional practices were brought to a halt and excluded as immoral. This has led to an excess or a 'volatile surplus' which Bataille (1988) termed the 'accused share'. Due to its volatility, through acts of closure the accused share must erupt, and does so eventuating in extreme acts of violence and war. ${ }^{16}$ The deriding of transgressive behaviour also leads to shame, shame from whence human beings have come. Bataille suggests that “... [w]e have fashioned this humanised world in our image by obliterating the very traces of nature" (1988: 62). By tearing children away from

nature by washing them, then dressing them...until they share the same impulse that made us clean them and clothe them, until they share the horror of the life of the flesh, of life naked, undisguised, a horror of the life of the flesh (ibid).

For Bataille the aim is to 'dirty' philosophy, to hit the target by speaking gross and dirty words, for these words are explosive - especially within the academy. In this vein one must embrace one's deviance and play in the 'out-of-placeness'.

Kristeva, on the other hand, does not wish to emphasise the deviance that being out-of-place brings; she instead explores how 'otherness' brings about desire and revolution. What draws us to the unsightly yet instantaneously propels us backwards, clutching our guts fighting to suck back the bile that races from us? For Kristeva exploring the abject must include exploring the relationship humans have to birth and separation. Kristeva sees that the state of abjection occurs prior to the mirror stage. The abject state lies between subject and object; it is a state of being and non-being which the subject is first impelled towards as a possibility of constituting itself. The compelling forward occurs because of an act of revulsion (abjection) against the mother as well as against the need to be contained (as one with the mother).

\footnotetext{
${ }^{16}$ It was World War One and World War Two that Bataille was specifically discussing. Like many philosophers of his time WWI and WWII left a profound effect on Bataille which was to define his philosophical works.
} 
Kristeva critiqued Lacan's theory of 'the mirror stage', asserting that it lacked an explanation for the development and separation of the infant from the maternal mother. The mirror stage does not represent the beginning, nor in fact the end of separation, instead there is a 'secondary repression'. The primary repression occurs within the chora, meaning the receptacle" (McAfee, 2004), by means of an act of abjection. At this stage the child experiences itself as all being, wanting for nothing. At this stage there is no sense of loss as desire as yet does not exist - the infant wishes for nothing. It is from this space that the child undergoes its first 'primal repression'. In repressing the chora through an act of abjection the child begins to establish personal boundaries, which in turn make differentiation possible. Neither the separation of the child from the mother, nor the creation of the binary between subject and object can occur until the child has repressed the chora. Separation comes about when the child expels part of itself from itself: "I expel myself, I spit myself out, I abject myself within the same motion through which 'I' claim to establish myself' (Kristeva, 1982: 88).

This secondary repression allows a human being to become homologous to another so as to become oneself. Important to Kristeva's notion of the primary separation through the abjection of the maternal is the idea that the child cannot and will not ever forget the chora or the abject:

The abject comes back in fleeting encounters, fleeting because we flee, horrified of falling back into the maternal body where no difference - thus not subjectivity - is possible. The abject perpetuates the bounds of oneself with the retreat "of a reality that, if I acknowledge it, annihilates me" (ibid: 118).

It is these fleeting encounters, the possible annihilation of self, the retreat of the self, and the abject that feminists, postcolonial theorists, queer theorists and disability theorists are utilising to explore the creation of the 'other'.

The 'other' is that that not only defines the self, but also allows for a separation of what is not the 'I', therefore the 'other'. The theory of abjection allows for a space to be opened up for the exploration of groups considered outside the norm; groups such as homosexuals, people with disabilities and ethnic minorities. In addition to people there are bodily functions that are considered abject: saliva, blood, semen, excrement, urine and menstrual blood 
(Stacy, 1990). These functions are considered part of the self yet abject as they cross the body's borders (see Longhurst's discussion of toilets in Bodies: Exploring Fluid Boundaries, 2001). Whilst important in defining livingness, substances such as excrement, urine and blood are also reminders of the inevitable annihilation of the self:

The danger of filth represents for the subject the risk to which the very symbolic order is permanently exposed, to the extent that it is a device of discrimination, of differences... [It is] a threat issued from the prohibitions that found the inner and outer borders in which and through which the speaking subject is constituted (Kristeva, 1982: 172).

Ritual and metaphor help separate the abject from that which is considered not abject and the human from that which is considered non-human. Ritual comes to be an avenue through which abject elements are renewed and in turn excluded (Creed, 1993: 8). The corpse, embalming and contemporary funeral rituals highlight this renewal and exclusion. It is for this reason that Kristeva's abjection and Bataille's informe are utilised in my research. Abjection is the glue that binds the absent and the present body. Further, Kristeva's work is applicable to the subject of death, as her understanding of abjection, whilst located within a reading of the child-mother relationship, highlights the extent to which separation underpins abjection. In bringing Kristeva's theories into discussions of death, one can see how death, like birth, brings the living to a place of abjection - the abject similar to the total nothingness that existed at the point that the child separates from the mother. In this moment, fear and need become the same.

Death therefore, read via Kristeva and Bataille, is both fear and attraction. Human beings are drawn to look upon the dead, yet fear underlies the need to run screaming from the thing that attracts us. In this space, funeral work, in the attempt to construct and manage understandings of death, draws on both the fear and loathing and the need to view death. It is the abject that the funeral industry needs and must learn to manage. It is the abject need to simultaneously separate from and move towards death on which the industry bases their ritualised practices. 


\section{EMOTIONAL GEOGRAPHY}

In setting out the research thus far I have touched on aspects of emotional geography. At this point I want to concentrate on the 'emotional' and demonstrate how emotional geography comes to play an important role within this thesis. As Liz Bondi (2005) suggests, the research that one undertakes is loaded with emotional content in that the researcher is expected to have an emotional attachment to their topic, one that she suggests must be played out through the 'passionate' immersion in the topic whilst retaining a "...cool contemplation associated with the capacity to 'stand back' and reflect critically..." (Bondi, 2005: 233). While emotions are argued to interfere with the rationalism of research (see discussion on Descartes, p. 27), and can be considered the rationalist's 'other', emotions are intrinsically interwoven into research.

In 2003 I was asked to present my revised $\mathrm{PhD}$ research topic to colleagues in the School of Geography, Environment and Earth Sciences (SGEES) at Victoria University, Wellington, ANZ. As part of the presentation I decided to share the more intricate details of the practice of embalming, concentrating on how it played an important role in constructing dead bodies as contagious and unclean. As an essential theme in my research I believed it was important to perhaps expose publicly the contradictions and problematic undercurrents of the practice of embalming. However, I later learnt that one of my colleagues was forced to leave the presentation. Four years prior to attending my presentation, she had buried her husband and like most mourners she had indirectly consented to having her husband embalmed so that a viewing could be conducted. Listening to my presentation re-opened some of the pain and unfortunately distressed her as she had not realised just how invasive embalming was. At the time, I had not clearly thought about the emotional consequences of sharing this information with a wider audience. I was intrigued and stimulated by the information and in a sense I was approaching the practice of embalming from a somewhat objective space. I was making a significant point, a rational one at that I thought: on the other hand, I came to understand that I was also re-opening some people's grief, and for some 
people, guilt that they had subjected their loved ones to such an invasive practice.

At the time I was in contact with Liz Bondi and having talked with her about issues of sensitivity and responsibility to not only interviewees but also to those to whom one is imparting information (particularly information as sensitive as embalming and death), I had to not only reassess how to share information but also how to approach such a sensitive issue in a compassionate manner. Personal responsibility, I realised, must be paramount when exploring such an emotional terrain as the disposal of the dead. To echo Bondi, Davidson, and Smith's words “[c]learly emotions matter" (2005: 1), as emotions come to situate and construct interaction, as well as define and map the everyday.

Fundamental to any discussion of death and deathscapes is the emotional turn. As discussed in Chapter One, when exploring some of the ambiguities surrounding people's understandings of death, the emotional distress that death has on the living is seen to be part of not being able to fully comprehend death. Even the materiality of the dead body does not lessen the emotional distress for the living, as the dead body presents the living with their future, their ultimate demise, whilst at the same time holding within its borders the presence and absence of death as subject/object.

The funeral industry makes use of the emotions surrounding death; in particular to justify the use of contemporary embalming practices to the public. Funerals devoid of emotion would be antithetical for the funeral industry. As a result, the funeral industry comes to play an integral role in helping not only with the disposal of the dead through various ritualised practices, but also with mourners' understandings of death, loss and grief their emotional management. Exploring grief through the use of emotional geography is particularly important when understanding how the containment or 'appropriate' display of grief and emotion is interwoven into notions of cleanliness/dirt and the private/public. 
This in turn is embedded within the idea that there are indeed 'appropriate' forms of behaviour that must be 'performed' or adhered to whilst attending funerals or being in the presence of a dead body. Under the general notion of 'dignity', emotional behaviour is constructed and monitored through a similar discourse that underpins the funeral director's need for incident- free funerals. Within this construction notions of the private and public, particularly in regards to how one must act within the 'home', can become blurred. Whilst the funeral home is a business, therefore presumably devoid of emotion, the business of emotions is part of the funeral director's livelihood. Emotions, then, set an interesting juxtaposition, in that the funeral home is a space to express grief, yet this must be expressed publicly in the private spaces of the funeral home. This blurring of the private-public expression of grief is in line with the general themes of containment of the sacred-profane and the cleanunclean concepts and practices that operate within the funeral home. Drawing on emotional geographies therefore allows further understandings of the management of death, dead bodies and the bodies of the living, in and around the funeral home.

This exploration into the funeral home and the various sites of containment and management of the dead I believes exposes the binaries surrounding western notions of life and death. This seemingly safe life - death dichotomy ensures that the funeral industry has a particular hold over the dead. They argue that there is a lack or misunderstanding around post-death bodies. For this reason the industry relies on an uncomplicated, trouble-free reading of death thereby ensuring that corpses are handled in particular spaces and through particular ritualised performances. Before finishing this chapter I want to briefly explore the notion of dichotomies and attempts to destabilise either or binaries.

\section{DESTABILISING BINARIES}

Dichotomies include the splitting of two unrelated terms; however, according to Elizabeth Grosz (1988) this splitting is not merely the splitting of $A$ from $B$; instead it involves the separation of two related terms, $A$ and not $A$. In what she defines as an 
unrelated sequence the positioning of $A$ is given greater status over the opposite, not A. A, therefore, comes to represent what is both socially and intellectually more valued, and in turn, stable. This separation, the Cartesian mind/body split, was not merely an exercise in separating the mind from the body; it was an attempt to completely transcend the body (Leder, 1990).

This absolute transcendence of the body, which Descartes described as a 'cage', would eventually see man (sic) attain the ultimate achievement: 'pure thought'. Combined with his preoccupation with death, Descartes believed that this cleansing of the mind would one day culminate in man's (sic) triumph over death (Leder, 1990). Certainly Descartes' belief in an objective third person could be seen as the initial threads of life being separated from death within academic thought. Speaking from a disembodied objectified space, one could speak 'at' death, as opposed to speaking of one's own death; thus death did not belong to me - it was the other. Descartes' desire to overcome death through the separation of the mind and body can be found in the theoretical writings of Plato, who had also posited the idea that the body obscured the philosopher's thinking. It was Descartes however who took this notion further by mutually excluding the mind and the body from one another (Bordo, 1987).

Needless to say, Descartes' mind-body separation was of course merely abstract thought. To achieve a 'pure' society, Descartes' abstract thinking had to be made tangible; therefore the mind/body split was mapped onto both male and female bodies. This mapping of the masculine/feminine split was in turn mapped on to other polarities (Haste, 1993). The following list shows how the mind/body split has been mapped through into other polarities which in turn have become naturalised and as a result 'fixed'.

$\begin{array}{cc}\text { Mind } & \text { Body } \\ \text { Man } & \text { Woman } \\ \text { Rational } & \text { Irrational } \\ \text { Culture } & \text { Nature } \\ \text { White } & \text { Black } \\ \text { Alive } & \text { Dead }\end{array}$

Plates 2.1: Common Mind/Body Dichotomies. 
This fixed naturalisation of binary opposites relies on one binary being privileged over and above the other (Grosz, 1994). For example 'nature' “...is sharply divided off from the human, is alien and usually hostile and inferior" (Plumwood, 1995: 157). Anything associated with the mind (masculinist) is perceived to have far greater status over anything that comes to be associated with the body (feminine). As suggested, this mind-body separation is not a simple split of two opposites; instead it is an expression of certain values underpinning separation, rather than just simple classification (Lloyd, 1993). Dichotomies therefore are hierarchical, endless, and due to their apparent rigidness appear to be irreversible. Dichotomies are seen to create stability and sustain order, which in turn correlates to an emergence of truth. This truth is represented through masculinist thinking which is credited with rationality, equating to uncontaminated thought and action. This approach became the blueprint for what Descartes believed would one day be a pure and rational society. A pure, objective, and cleansed mind could then be extended beyond merely the abstract into social purification rituals "...in which society establishes some subculture or group as impure and 'taboo', thus defining it as outside the social body" (Douglas, 1969: 54). This outside is often represented through the feminine, so taking on all that is unclean, unstable and polluting: rational man versus hysterical woman.

For Descartes the body was like a rotting piece of fruit in a fruit bowl. This piece of decaying fruit has the potential to contaminate every other piece of fruit, bringing about the eventual collapse of all that it touches. So too can contaminating bodies - such as the bodies of women, black people, the disabled, the mentally ill, homosexuals, and dying and dead bodies - be likened to Descartes' piece of rotting fruit. For this reason one must pluck out or rid society of the potential and inevitable decay that comes from allowing contagious or polluting bodies to freely co-exist. This has been achieved through the ritualised stigmatising and marginalisation of particular bodies, bodily acts, peoples, places and spaces which have been deemed harmful to a rational, harmonious, and contagion free society. However, the notion that rationalism and the binaries that underpin it create stability is a spurious claim, one which has been contested by many philosophical writers. 
Drawing on the works of Friedrich Nietzsche (1967, 1967b), Foucault $(1977,1978$, 1989, 1989a, 2001) problematises Western society's inclination towards essentialism and the desire to fix material and discursive subjects/objects into a 'natural' order of things. In doing so Foucault began unravelling both the material and discursive circumstances underpinning various dichotomies. He argued that nothing exists without its 'other', therefore science cannot stand alone, for if science is to be understood one must have culture. They are interwoven, part of each other, thereby making any and all dualisms false. This is due in part to Foucault's contention that whatever falls into the mind category of the binary is unable to break free from the 'other' - from the body, from the feminine.

It is this dualism that many feminist writers have questioned, concentrating particularly on the dualist nature of gender (Butler, 1990, 1993; Grosz, 1994). Butler coined the term 'performativity' to destabilise the taken for granted notion that gender, and in turn sexuality, or what she calls the 'heterosexual matrix', is natural. For Butler (1990), bodies are “...oppositionally and hierarchically defined through the compulsory practice of heterosexuality" (Butler, 1990: 151). This performativity of sex and gender is founded on the idea that male and female children are labelled at birth as either male or female. For example, the practice of 'girling' the female infant is produced via a form of 'hailing' which is reiterated over time both discursively and socially.

Death, like other performances, is constructed through repetition: the ritualised performance of particular conventions and discursive practices that brings the body into a space where it comes to be understood as dead:

Death is composed not merely of what people say and write about death...but of the entire range of practices, activities and settings which embrace death. Death, therefore is constituted as much in the cemetery as it is in the pathologist's mortuary (Prior, 1989:3).

However, death, like Descartes' rotting piece of fruit lying wasted in its fruit bowl, has the potential to contaminate the living. It is, to some extent, the reason that death and deathscapes have been inscribed as potentially contagious. This fear of transgressive and polluting bodies and places is founded on anxieties and fears involving the contravention of both figurative and physical borders, whether 
it is immigrants 'invading' a nation state's border, or the fears of dirt and filth crossing or penetrating one's skin. Symbolically or materially borders are erected, performed and stabilised through various societal rules and rituals. David Sibley (2003) argues that one can find a heightened fear of dirt and transgression in some of the most developed societies. This fear, according to Bataille (1984), comes from a belief that 'developed' countries have exhumed themselves from the boggy earthliness associated with animalism. No longer have bound by the unpredictability and transgressions of nature, developed civilised nations dragged themselves out of their primordial beginnings, and are developing and advancing enlightened forms of conduct. No longer is the stench of the animal associated with this modern man (sic); however, the fear of degeneration or a return to this unpredictability hovers at the margins.

\section{DESTABILISING THE LIFE/DEATH BINARY}

Drastic changes within medical science have seen a multitude of definitions of death reduced to merely a few classifications of death. However, any attempt to bring death to a single definition - the cessation of all vital functions - is difficult to achieve even within medicine. As Alison Bashford (2000) contends, the increase in discourses of 'death' has seen the dead body become an extremely inscribed body. Many medical practitioners argue that death can never be pinpointed to a specific moment. Instead death should be viewed as a process of changes which sees the body more often than not slip into death.

Norman Fost (1999) suggests that this slipping into death could include six dying steps/definitions. There is 'traditional death' which involves the cessation of cardiac and respiratory functions. The second is 'brain death' which involves the permanent loss of the brain's functions. There is the important loss of self, or 'personal death', whilst 'reproductive death' includes the:

Irreversible loss of the ability to reproduce one's self. This would seem an important point if death is considered a biological issue, since the traditional biological notion of when life begins (or began) depends on the appearance of a self-replicating entity (ibid, 1999:162-163). 
'Genetic death' involves the "...loss of all means of identity, the genetic make-up of the individual" (ibid), whilst 'biological death', refers to the "...loss of all biological activity that can be traced to an identifiable individual (ibid). Lastly, Fost offers up a legal definition of death which conforms to the statutes on death.

Any attempt to define death and pinpoint it to a moment of loss or shift from one state to another is problematic. For example, if death is a process, when does this process begin or in fact finish? Just like traditional definitions of death, alternative understandings of death are problematical and always appear to include a defined separation between being alive and being dead. In Chapter One, in the section 'Knowing Death', I discuss how language helps explain death, yet lacks the capacity to fully express the multiple understandings surrounding death. Language appears to fail the absent-present materiality and non-materiality of death.

Therefore, the materiality of death should expose the truth of death. Death, one would think, can be seen on the body by the lack of being. However, even this seemingly concrete dead body seems to undermine a taken-for-granted notion of death. Take, for example, the following controversy surrounding the definition of death as 'brain dead'. Dr. Keep is an anaesthetist who provoked controversy after writing an article for the Royal College of Anaesthetists. Dr. Keep argued that many doctors and nurses felt uneasy about operating on the bodies of those classified as brain dead.

Nurses get really, really upset. You stick the knife in and the pulse and blood pressure shoot up. If you don't give anything at all, the patient will start moving and wriggling around and it's impossible to do the operation. The surgeon has always asked us to paralyse the patient (BBC News, 2000).

As an anaesthetist, Keep has been asked, more than once, to anesthetise the brain dead patient before operating to remove the organs. His actions have been upheld by other doctors and nurses in a bulletin medical chatroom, which discussed some of the controversy surrounding organ donation.

Medical professionals opposed to his exposé argued that publicising the above incident was inflicting unnecessary pain and anguish onto the families of those 
who had donated the organs of their dead. This negative publicity, they suggested, would have negative effects on the positive representation organ transplants were experiencing. Some surgeons argued that as an anaesthetist, Dr. Keep was not in a position to define or question definitions of death as he was not an 'expert'. Dr. Keep had, according to many neurologists, seen nothing more than the nervous system shutting down - which they argued was nothing exceptional or unusual.

Unfortunately, Dr. Keep's experience is not unique. In 1998 an embalmer at a funeral home in Upper Hutt, Wellington experienced something similar. Whilst in the process of cutting the carotiel artery, cutting the carotiel artery allows the blood of the deceased to be drained prior to pumping embalming fluid into the body, the cadaver he was working on began to bleed profusely. According to medical definitions of death, excessive bleeding from a major artery is an indication that the heart is still functioning, which indicates that the cadaver is in fact alive (Fost, 1999). Immediately stopping what he was doing the embalmer attempted to stop the flow of blood; however, he failed to do so (Alley, 1998: A1).

At the time, Mark Wolffram (Alley, 1998: A1), the then director of the Embalmers Association of New Zealand (EANZ), told reporters that due to the embalmer's inexperience he had misunderstood what was occurring, leading to an assumption that the body was still alive. Whilst there was little explanation for why this particular body had bled out, Wolffram pointed out that 'professional' embalmers are taught to recognise all signs of death. These signs include: lack of circulation or pulse; lack of respiration; alterations to the colour of blood; a cooling of the cornea; and the dehydration of body tissue. Unfortunately, the Upper Hutt embalmer eventually left his job due to the fact that he still believed he had inadvertently killed the particular person/body he had been attempting to embalm.

I am not suggesting that death does not exist, as it is evident in the lifelessness of the corpse that comes to occupy the place that once was filled by a living being. Nor am I suggesting that the corporeality of the dead is not an indicator of death. However, like the various commentators who argue for further discussion about what might constitute death, I also maintain that there is not a straightforward way of understanding death. Death is generally defined via medical and scientific 
discourse, yet in attempting to fix death to a particular diagnosis or a particular time, it becomes problematic - as seen in the narratives of Dr. Keep and the embalmer's experience in Upper Hutt. Therefore, the act of fixing life and death in opposing binaries is merely an attempt to overcome any messiness between the two opposing states of being.

According to Foucault (1989), attempts to define death have more to do with developing an understanding of life rather than a fuller understanding of death. It is the corpse that becomes a map, a landscape for life. This is said to be due in part to the West's obsession with life (Cooter and Pickstone, 2000). Elizabeth Hallam, Jennifer Hockey, and Glennys Howarth (1999) assert that there is a need to challenge the seemingly seamless separation of death from life; however, they also warn that to similarly situate these arguments within an abstract account of death takes away the material reality of death. For Hallam et al. (1999) the life/death binary needs to be prised open, problematised and deconstructed, due to death having 'slipped its moorings'. Death, they argue, is no longer absolute. Thus, they offer the following alternatives to the rigid, fixed notions of life and death. Life and death and in turn the body and the self can be divided into:

socially dead and biologically alive : socially alive and biologically dead socially dead/ biologically alive : alive socially/biologically dead (ibid: 3).

The authors suggest that the first definitions of life and death (see above) are given privilege over the second definition, because it credits livingness over death. In turn this leads to a concentration on the first pairing in any academic research. We research what we know, understand, can see, and most of all, do not fear. This fear and anxiety comes about because of the destabilising nature that any overlapping reading of life and death brings. These more flexible and open definitions allow the life/death binary to intermingle. In crossing the chasm and puncturing the border between life and death one allows the 'monster' or a hybrid of death to enter the safe spaces of the living; thereby allowing both the absence and presence of death to be seen within the living body. 
Hallam et al. (1999) explore this 'othering' or hybridity of death as well as the 'monster' of death and the dead through numerous living/dead-dead/living bodies. Firstly, they explore how people with Alzheimer's occupy both a present and absent body space, neither 'fully' alive nor 'fully' dead. The Alzheimer's patient then is an 'incomplete corpse', a living death (Hallam et al., 1999). This fear of the living dead can also be seen in popular culture where vampires and ghosts simultaneously excite and terrify because of their ability to cross the border between the world of the dead and the living. This crossing of boundaries, whether it be in the form of the Alzheimer's suffer or because of the idea that one might be able to live beyond death, creates a space for absence and presence, as well as an understanding that death and life are similar yet different. Life/death merges into a 'thirdspace'; a hybrid place where life and death come to be understood as interwoven (see the grey space in Figure 1 below).

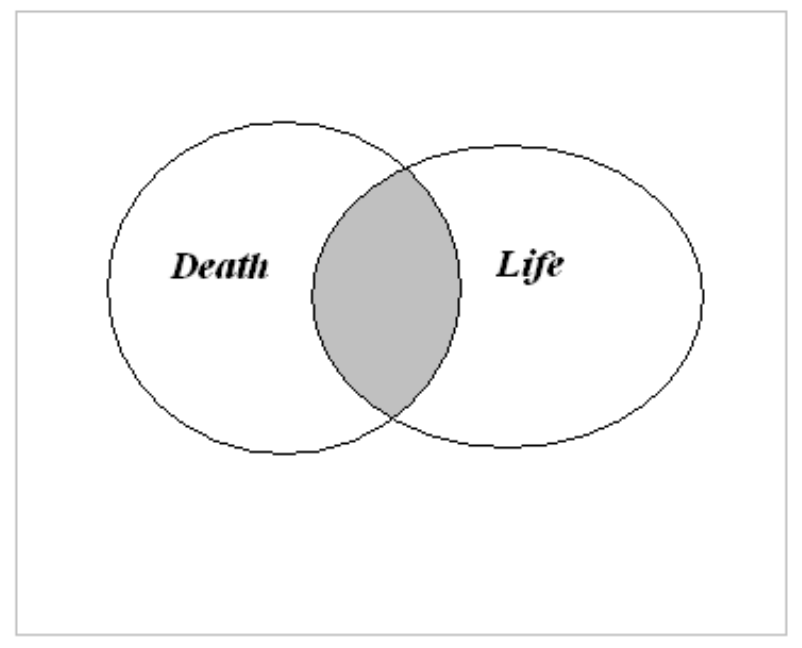

Figure 1: The thirdspace of life and death.

This space - the grey area, which constitutes a third space, is a significant space for theorists such as Edward Soja (1996:5). Henri Lefebvre's ${ }^{17}$ notion of the thirdspace allows one to:

enter a space of extraordinary openness, a place of critical exchange where geographical imagination can be expanded to encompass a multiplicity of perspectives that have heretofore been considered by epistemological referees to be incompatible, uncombinable.

\footnotetext{
${ }^{17}$ Lefebvre's book was not translated into English until 1992, although it had been translated into Italian and Japanese much earlier, in 1975.
} 
To contemplate a 'both/and also' logic, to set aside the demands to make an either/or choice is important, especially when exploring death. Soja suggests that employing the concept of a thirdspace allows for a "...politics that enables new radical alliances to evolve, creating an alternative geography of space, identity, and politics" (Soja, 1996: 406 - 407).

By utilising the notion of the thirdspace, narratives around the separation of death from life, filth and cleanliness and the public and private can be destabilised, and, according to Soja (1996), allows for new understandings of these separations, in turn allowing one's imagination to push beyond its current limitations shaped by opposing binaries. By engaging with the murkiness, the in-between of life and death, the once taken-for-granted, the cleansed binary of life and death can become untidy and uncomfortable, unencumbered to some degree by the rules of cleanliness and containment. For this reason I believe that an engagement with psychogeography is important when discussing death and the decaying corpse. For example, theorists such as Sibley explore what Soja (ibid) calls 'the lure of binarism'. This lure, as mentioned before, involves breaking everything down into an either/or classification and contributes to constructing and shaping social space. All that is considered to 'fit' is situated centrally, therefore deemed acceptable and welcome, whilst everything considered dangerous, polluting, or a threat to order is set outside on the margins, labelled 'uncanny', uncivilised, unclean. Between this inside-outside is a border, a boundary both imaginary and in some cases physical, that separates each from the other. Nevertheless, that which is considered acceptable, clean or civilised can never fully expel its unwanted 'other'. According to Sibley (2003: 243), psychoanalysis can provide a way of:

Thinking about social relationships and relationships with the material world. It brings the unconscious into social theory, connecting the unconscious with the phenomenal and experiential aspects of life.

\section{CLEANING UP AFTER OURSELVES}

In this chapter I have traced the thought processes and theoretical approaches I engage with during this research. I have also explained some of the more personal considerations that have led me to draw on particular theorists. The theme of death as a starting point situates the thesis, showing the need to use 
theories that explore the complexities of ambiguous subjectivities and positionalities. Whilst many theorists and theoretical perspectives explore these themes, very few directly engage with the post-death / pre-burial corpse within the confines of the funeral home. Therefore it is necessary to delve into these themes and spaces; looking upon death and engaging with its ambiguity and paradoxical spaces.

I have set out how my approach is interdisciplinary; an approach situated within what Derrida (1981) has coined bricolage. This allows the researcher to identify and use the necessary tools that will ensure a more holistic and less contained method of engagement with their research topic. This approach, I contend, is fitting for a researcher who is situated within the discipline of geography. Therefore I have drawn on a combination of feminist, emotional and psychoanalytical approaches to research the subject matter. While death and deathscapes are a nascent topic within geography, human, feminist, post-colonial, post-modern and post-structural geographies offer a multiplicity of theoretical approaches and tools from which to draw upon. Therefore I have ventured beyond geography's borders, drawing on the wealth of material written by sociologists about Western notions around death, death rituals and the construction of dead bodies.

Feminist and emotional geographical readings of the home help to prise open and explore the ambivalence of the contemporary funeral home as both a public and private space. Here, the emotional understanding of 'home' is infused with multiple readings of cleanliness and dirtlcontagion. This then led to an exploration of understandings about subjectivity. Through the dichotomous philosophy that shapes the principles and practices surrounding death, the funeral home comes to represent and embody the dualisms of life/death, public/ private and the profane/sacred. Thus I explore where this thesis topic fits within the complex works on and around death.

Within the discourse of space and place I draw directly from the vast wealth of geographies works, especially exploring notions of home and liminal space. It is in the liminal spaces of the funeral home that decaying bodies are brought to rest. 
These spaces that the dead occupy are for many outside the funeral industry uncomfortable, unspeakable, and confusing places; places best left alone until the time is upon them to visit. It is where the material and non-material worlds are socially and historically constructed while simultaneously engaged, regulated and disciplined. Notions of the sacred and profane are negotiated and contained before being reintegrated into the spaces of the living. To excavate these liminal spaces I draw upon the theoretical works of Bataille and Kristeva, as both have attempted to explore the spaces within which language fails to express human understanding. Each theorist is also concerned with passages of time and journeys that are transgressive, thereby opening up spaces to understand 'otherness'. Both writers have also drawn on their own experiences of being 'strangers' or foreigners in their own worlds and academic disciplines. For this reason their perspectives sit well with a holistic approach to understanding notions of sacred and profane spaces and people. Moreover, both Bataille's and Kristeva's readings of the abject have offered various geographers an approach for reading 'matter out of place', something particularly pertinent for an exploration of the deathspaces of the funeral home, for it is in these spaces that matter deemed 'out of place' is taken - in order to transform it and reintroduce it into the spaces of the living. The combined theoretical approaches of Derrida's bricolage and Bataille's and Kristeva's respective notions of informe and abjection enable me to analyse the specific discourses constructed, spoken and performed by the contemporary funeral industry in ANZ. 


\section{Death Collection}

In the previous chapter I outlined the theoretical approaches I used to explore the subject matter of my thesis. In this chapter I outline the multi method approach I employed for gathering information from various stake-holders within the funeral industry. I concentrate on how the interviewees were selected and how the interviews were conducted, which texts were identified from within the funeral industry and the technique used to deconstruct these texts. As part of the journey I also explore some of the more challenging engagements that plagued attempts to organise and conduct interviews. By drawing on Kim England's (1994) work on 'failed research' I explore how some of the difficulties I faced when attempting to access people and information highlighted the various binaries - such as public and private, insider and outsider, proper and improper behaviour - which underpin and construct the borders between the general public and the funeral industry's daily practices. These restrictions on who can or cannot access this knowledge places the funeral industry as indispensable. Highlighting these issues helps to weave personal experience into the more abstract areas of the work. For this reason I also outline why I employed a more autoethnographic approach for presenting the information gathered via interviews, text and my own experiences.

\section{IDENTIFYING AND RECRUITING RESPONDENTS}

Gill Valentine (2005: 113) suggests that when a researcher begins thinking about whom they want to interview it is important to think about "....who you are and how your own identity will shape the interactions that you have with others". This notion of identifying oneself as part of the research process is known as positionality, and involves the practice of engaging in self-reflexivity. By identifying and utilising various positionalities and incorporating them into the methods we use it is hoped that we are able, as researchers, to recognise power relationships that ebb and flow between respondent and researcher. By employing 
self-reflexivity the researcher hopes to avoid any form of false universality or neutrality (Rose, 1997). Reflexivity works at a multiplicity of levels. The researcher attempts to question the relationship between themselves and the respondent by recognising similarities and differences. In doing so one also positions oneself and acknowledges the 'I' is biased.

Rose (1993, 1997), Sarah McLafferty (1995) and Melissa Gilbert (1994) argue, albeit to differing degrees, that the researcher can hold a privileged position, especially in the early stage of the interviewing process. It is the researcher who decides what the topic of investigation will be, who will be researched, and how potential respondents will be approached. The researcher also decides what questions will be asked and how these questions will be asked. Some of the interview criteria are imposed upon the researcher through funding criteria guidelines and departmental requirements. Thus, power can be seen to be constantly moving between the interviewee and the interviewer, depending on the circumstances.

Linda McDowell (1992: 413) cautions researchers about the “...real dangers that are inherent in our position within the powerful institutions of knowledge production". These dangers, she asserts, do not begin when the researcher approaches potential respondents, but starts at the very moment a researcher identifies the field of investigation. She advises researchers to actively clarify, to think about the ways in which their identity can influence their interactions with respondents. Take, for example, the postgraduate researcher who straddles the space between apprentice and accomplished researcher. These people are in a tenuous position as they are armed with the latest research literature, venturing out into the field to potentially coerce and cajole respondents to participate in their research (see Kobayashi, 2001; Valentine, 2005).

There are various ways to identify potential interviewees. For this research I employed the techniques of purposive sampling and snowballing. Purposive sampling involves the researcher identifying people or organisations s/he believes will provide relevant information and insights to the research. Snowballing, on the other hand, involves respondents recommending further possible respondents to 
the researcher (Sarantakos, 1993). Because snowballing relies on a degree of serendipity (Bradshaw and Stratford, 2000), one can end up, particularly in the field I was working in, with an assortment of very interesting people - yet they may not be relevant to the subject matter.

Due to the growth of both the traditional and the alternative funeral industries, I initially decided that the interviews needed to encompass the multiplicity of these businesses. These two sectors have come to represent the breadth of contemporary funeral practices in ANZ, yet the traditional and alternative key informants view themselves as separate from each other. Within the more traditional funeral industry sector, practitioners understand their approach to handling and disposing of the dead as a 'natural' process based on centuries of religious and scientific knowledge and practice. The alternative sector draws from narratives that highlight the growing concerns for the environment, and weaves these concerns into a more historical understanding of the spiritual interconnectedness between human beings and planet earth. For example, Chris Foote, a funeral director with the Natural Funeral Company in Auckland, views alternative funerals as 'organic'. He argues that in its natural state, death is an organic process rather than an incident, which, when seen as such, allows people to accept the reality of death; one not merely based on environmentally sustainable funerals, but also on a relationship with the dying prior to their death. This allows for a natural relationship to develop between the family, the dying, and the funeral director, which Foote maintains can only be good for the earth (Documentary New Zealand, 2005).

These differing narratives have seen a growing tension around issues of sustainable and unsustainable practices when disposing of the dead. Whilst some in the traditional funeral industry argue that there is room for new approaches, others argue that tradition will always hold a preferred place in people's psyches. This is because traditional practices are viewed as the appropriate and timehonoured way in which to conduct funerals and dispose of the dead. This, they argue, is due in part to people's need for conservatism when death has occurred. This conservatism is equated with comfort, consistency and stability (TV One, 2005). This separation of the alternative from the traditional reflects the numerous dualisms operating within the traditional funeral and alternative funeral sectors in 
ANZ. Traditional, in this case, is equated with a historical past which is believed to be a connection to something greater than its whole, something timeless.

Conversely, the burgeoning alternative sector is equated with openness and innovation - the types of practices that many in this sector argue cannot be found operating in the mainstream contemporary funeral industry. Therefore, I decided that it was necessary to approach organisations and individuals from both sectors in order to explore the dualisms referred to in my research aims. To do so I needed to begin by identifying key informants within both sectors.

Whilst there was little difficulty in identifying potential interviewees from within the traditional funeral sector, engaging in interviews did become increasingly difficult for a number of reasons. One reason, which I discuss in depth in Chapter Five, involved a number of tensions relating to my right to speak about this particular topic, which has been constructed as sacred and sensitive by both the general public and the funeral industry. For this reason I was regarded not merely as an outsider, but as a 'dangerous' outsider.

Once I identified which sectors of the industry I wanted to approach - the traditional funeral sector comprises not only funeral homes, but also self-employed embalmers, coffin makers, cemetery workers, florists, make-up artists, embalming product manufacturers and distributors, celebrants, embalming and funeral service educators, pre-funeral insurance agents and governmental departments that inform and oversee the industry around health and safety issues - I made contact via email with funeral directors, embalmers, a manufacturer and distributor of funeral products (specifically embalming products), an embalmer and funeral service educator, and someone from the Ministry of Health (see Table 1. below). 


\begin{tabular}{|c|c|c|c|}
\hline Respondent & Where & When interviewed & How contacted \\
\hline $\begin{array}{l}\text { John Duncan } \\
\text { Owner/operator }\end{array}$ & $\begin{array}{l}\text { Ninness Funeral } \\
\text { Homes }\end{array}$ & 2003 & email/telephone \\
\hline FDANZ & $\begin{array}{l}\text { Wellington } \\
\text { Head Office } \\
\text { prior to } \\
\text { interview }\end{array}$ & 2006 & email/telephone \\
\hline Wolffram & $\begin{array}{l}\text { Inner city } \\
\text { Café in } \\
\text { Wellington }\end{array}$ & 2006 & $\begin{array}{l}\text { Telephone and } \\
\text { meet at Weltec }\end{array}$ \\
\hline $\begin{array}{l}\text { Funeral Director } \\
\text { 'A' }\end{array}$ & $\begin{array}{l}\text { Funeral Home } \\
\text { Wellington }\end{array}$ & 2002 & $\begin{array}{l}\text { email/letter } \\
\text { telephone }\end{array}$ \\
\hline $\begin{array}{l}\text { Funeral Director } \\
\text { 'B' }\end{array}$ & $\begin{array}{l}\text { Funeral Home } \\
\text { Wellington }\end{array}$ & $\begin{array}{l}\text { reconnected } \\
2006\end{array}$ & $\begin{array}{l}\text { email/letter } \\
\text { telephone }\end{array}$ \\
\hline Embalmer A & $\begin{array}{l}\text { Embalming } \\
\text { Room in } \\
\text { Wellington }\end{array}$ & $\begin{array}{c}2006 \\
\text { owner operator }\end{array}$ & Introduced by \\
\hline $\begin{array}{l}\text { Embalming } \\
\text { Manufacturer }\end{array}$ & $\begin{array}{l}\text { Factory } \\
\text { Wellington }\end{array}$ & 2005 & $\begin{array}{l}\text { email/letter } \\
\text { telephone } \\
\text { Unsuccessful }\end{array}$ \\
\hline Lynda Hannah & $\begin{array}{l}\text { Supervisors } \\
\text { home }\end{array}$ & 2003 & Via supervisor \\
\hline Dodge Company & $\begin{array}{l}\text { NA } \\
\text { Unsuccessful }\end{array}$ & 2006 & email \\
\hline Ministry of Health & $\begin{array}{l}\text { N/A } \\
\text { Passed on to fun }\end{array}$ & $\begin{array}{c}2006 \\
\text { eral people }\end{array}$ & email/telephone \\
\hline
\end{tabular}

Table 1: Contacts

The first organisation I approached was the Funeral Directors Association of New Zealand (Inc) (FDANZ) in Te Upoko o te Ika a Maui Wellington. The FDANZ is the national body that oversees and supports 111 funeral homes in ANZ. They also produce the FDANZ magazine, which is distributed nationwide. Making contact with this organisation was an important entry point into a significantly closed environment; therefore, in making contact I hoped that they would help me make further inroads into the industry. The then secretary played a pivotal role in helping 
me access information as well as understanding some of the more intricate interrelationships between different governing bodies.

Another group that I identified early on in my research was the alternative sector. This sector was to prove more difficult to make contact with, as there were no well established channels or a governing body that I could contact. Entry therefore came via a serendipitous moment with a colleague in the SGEES who had read an article in North and South magazine. North and South is a monthly current affairs magazine which specifically targets the middle-class in ANZ.

Once I made contact with the person identified in the article the snowballing technique became invaluable. In addition, many of those I contacted worked independently; therefore contacting people meant having to tap into a more informal network that operated between some of the alternative organisations and people involved in them in some form.

As I began to understand the important differences between the two sectors, the differences initially appeared to be nothing more than an aversion to or a preference for embalming practices, I decided that it was essential to approach someone within the alternative sector as it would bring to the work what could be seen as an outsider's voice regarding contemporary funerals. Therefore, as part of building up a picture of the modern funeral service, I became aware of just how important proponents of alternative and sustainable funerals were. Their role was not only to promote environmentally sustainable burials but also to inform the public about the contained environment in which the traditional funeral services operated. By challenging the traditional industry those identifying themselves as 'alternative' are not only attempting to open up spaces to allow for different funeral approaches, but they are also attempting to bring greater transparency to the existing industry. Some of the people within this diverse arena have worked for a time in the traditional sector. For this reason alone I believed that conducting interviews with some of these people would provide valuable comparative insights into the various practices of the handling and disposing of the dead. 
At the time I was interested primarily in how the industry understands itself and how these understandings helped to construct a narrative that is then imparted to the general public. Thus, I decided to limit my research to the traditional and alternative sectors, and not interview those who utilise these industries - i.e. the bereaved. Nevertheless, it is important to note that when talking with respondents or gathering information from other sources, personal communications (this included a friend from the UK who is an embalmer) came to play a significant role.

As was discussed earlier, the diversity of trades and businesses within the funeral sector meant it was necessary to limit who would be approached for interviews. For this reason I returned to my research question and decided to only approach those working in funeral homes; specifically traditional funeral directors and embalmers. As my readings began to highlight the different aspects and array of practices that weave together to create the traditional funeral industry, I started to see how particular areas of the industry operated to ensure an 'ideal' type of funeral. With this I became aware of just how central the funeral and embalming manufacturers are in constructing public understandings around death, disposal and burial. Not only do manufacturers promote their products as essential for the safety of the living, but also as an indisputable necessity when disposing of the dead. Not only then do they supply funeral homes with funeral and embalming products, but they also underpin this by producing and distributing literature that complements the practice of embalming. This is something which, as shall be shown, forms the foundation for the entire traditional funeral process. In addition, the manufacturing industry's literature has become an essential part of the funeral industry's educative curriculum. Therefore, both the manufacturing and education sectors of the funeral industry became important subjects to include in my research, as they were both integral to the contemporary deathscape of ANZ. As previously mentioned making contact with those working in the traditional funeral sector began via the FDANZ; of those I was put in contact with only one person from this particular sector was interviewed. The first respondent who agreed to be interviewed was a significant key informant as he had worked in the industry for many years as a funeral director/embalmer. Now an owner-operator of a funeral home in the Wellington region, this person had also held office in both 
the FDANZ and the New Zealand Embalmers Association (NZEA). The respondent had also been a spokesperson for the industry and was still called upon by the media.

The second respondent, also an owner-operator of a funeral home in the Wellington region, had participated in research I conducted in 2001. After discussing some of the difficulties and frequent closing of doors that I had encountered in the past year, this funeral director not only offered to support my research by participating in an interview, but also introduced me to their resident embalmer who was more than willing to be interviewed. The third respondent then was the only embalmer that I was able to interview.

Respondent number four had also been involved in the traditional funeral sector for a number of years, having served on both the FDANZ and the NZEA. Now a funeral sector educator, this person showed an interest in my work and assured me that many of the negative responses I had encountered were to be expected. It was pointed out that whilst this industry has to be open and approachable, when it came to anyone critiquing the industry, doors could be gently but firmly closed. Consequently, this respondent turned out to be not only valuable for the wealth of information that was shared, but also for insights about my experiences with the industry thus far. In addition to the support I received, this respondent pointed out that there were no problems them being identified in my thesis.

As previously suggested, organising interviews and gaining access to information from the alternative sector did not prove easy. However, once I made contact people were happy to share their information and insights. Of the three people that were approached though, only one interview was able to be secured due to unfortunate timing. Due to the nature of funeral work, whether it is in the traditional or alternative sector, the reality is that people do not die within a prescribed timetable. Therefore, a number of interviews were cancelled due to funeral directors being called to a job at short notice, or interviews had to be rescheduled more than once - often months after the first attempt. 
The fifth interview I was able to secure was invaluable as it was with the director of an alternative organisation, not a freelance operator. This respondent not only argued for environmentally friendly funerals, but at the time was in discussion with the local city council about the possibility of opening the first environmentally sustainable burial site in ANZ. The organisation which he headed openly challenged taken-for-granted notions underpinning contemporary funeral rituals and burial practices. This respondent was also well known for publicly discussing his concerns about the hazards to the environment from the practice of embalming. For this reason this respondent was more than happy to be interviewed and did not have a problem with having himself identified in the thesis.

\section{GAINING CONSENT AND CONDUCTING INTERVIEWS}

Each respondent was given an outline of my thesis topic, information and invited to participate in a one-on-one interview that would run for approximately one hour. Consent forms were sent out prior to each interview, giving respondents the option to be identified or to remain anonymous within the research. I also informed respondents that interviews, with their consent, would be taped using a dictaphone. Each respondent was informed that they could decide where they wanted to have the interview conducted. This was important as four of the five people interviewed were responsible for participating in some aspect of the funeral process, whether it be embalming or overseeing a funeral. The fifth interviewee, whilst working in the alternative industry sector, also ran another business. For this reason his time was limited and the interview was conducted in my office at university.

Operating from what I now understood about the traditional funeral industry, principally that there appeared to be standardised answers to many of my questions, particularly when discussing embalming practices, I decided to employ semi-structured, in-depth interviewing techniques. I did this in the hope that a more relaxed approach might allow for a more comfortable, thereby less confrontational situation. This was also an appropriate technique due to the history of encounters I had had to date. As a result I chose not have a rigid set of questions, but I did have a number of themes which I wanted to cover. These 
themes included: history of funeral homes and embalming, embalming room protocol, embalming principles and practices, attitudes to alternative techniques, funeral directors bodies, removal of the dead, and funeral space.

As several researchers have suggested, in-depth interviews are known for providing a richness of information, as the researcher is able to discuss issues in a more relaxed manner, thereby probing interviewees for clarification on certain issues without being too inflexible (Denzin and Lincoln, 1998; Dunn, 2000; Fontana and Frey, 1998; Sarantakos, 1993). This was, as suggested above, necessary, as I wanted to get beyond, as best as I could, the seemingly standardised answers I had been previously given.

However, this approach had to be weighed up carefully, as semi-structured, indepth interviews can at times have the reverse effect. For example, one of interviews conducted early on in the research collapsed, due in part to the interviewee having a sense that the interview was redundant. The interviewee felt that the interview lacked progression, and at one point I was asked what exactly I was after, and why I did not just read the literature that had been produced by the industry, as all the answers to my questions, could be found there. While semistructured, in-depth interviews worked with the other interviewees - mostly those who were already publicly vocal about their beliefs or happy to self-reflect about their position in the funeral industry - the interviewee referred to above decided that they did not want their interview included in my research. To some extent this situation reflects the closed and controlled nature of much of the traditional funeral sector. Issues surrounding knowledge, rights and scientific bias were given for not wishing to make information available.

As England (1994) points out, the idea of discussing the 'making' of research has tended to be abandoned for the more important data collection and dissemination of research to the appropriate persons. Any discussion of issues surrounding research 'failure' are written out of most people's research. Although it is not often part of the research landscape to discuss what could be considered failed research, I believe that it is necessary to briefly explore two particular situations that helped shape this thesis. Like England, I believe that there is no failed research; instead 
each hurdle or closed door that a researcher encounters helps the researcher learn new ways of understanding how they influence and construct research methods. The issues I found myself having to deal with, from terminated interviews to being excluded from possible areas of information collection, I found to be part of the heightened self-surveillance operating within the funeral industry.

Before looking at the other forms of data collection utilised in the research, I want to briefly turn to the notion of gate-keeping and how various incidents of gatekeeping helped shape and inform the research.

\section{GATE-KEEPING}

Interviews, it is suggested, can at times be confrontational and from time to time they also have a disruptive element to them on the lives of those interviewed (Crapanzano 1977; England, 1994; Hastrup 1992; Rainbow 1977). It is assumed that the interviewer, more often than not, holds most of the power when conducting interviews (Schoenberger, 1992). However, this is said to change when interviewing people who are accustomed to being 'in control'. Those identified as having the greatest control have been identified as 'elites' - in this context elites being people who are insulated from probable intrusions, or who are protective and defensive, especially if they feel that the issues being addressed are sensitive (England, 1994). Erica Schoenberger (1992) suggests that when researchers make contact with the business world they can be faced with numerous issues about control. She argues that businessmen and women are accustomed to being in control and, depending on where exactly they are positioned in the corporate hierarchy, have the power to exert authority over others, both inside and outside the corporate world. Corporate people are often seen as 'suave go-getters', in charge of both themselves and their environment, therefore capable of taking on new challenges as well as pushing boundaries. Schoenberger (ibid) contends that interviews with this particular elite group can be undone by issues of control and power, whereby there is a risk that the respondent will impose his or her own agenda on the interview situation. 
Whilst funeral homes and the funeral directors in ANZ are not immediately comparable to the highflying corporate world, some in the funeral industry are considered entrepreneurs; suave go-getters who not only bring a new ethos to a once conformist trade, but who also change the aesthetic funeral directing. Whilst, this might well stand in opposition to the seemingly traditional image that the industry wish to portray there is at times multiple narratives underpinning how the industry wish to be seen and how they in fact operate (Wolffram, 2006).

Whilst directors and funeral homes must be accessible to the general public, owner operators do employ various forms of gate-keeping around information sharing. Different forms of gate-keeping can be found operating in various sectors of the funeral industry. They can include many of the gate-keeping techniques described by England (1994), which include actual gates, security guards, closed-circuit television and the receptionist, whom, England points out, can thwart any attempts by the researcher to make contact with the company's director.

In ANZ the regulatory bodies FDANZ and NZEA form a net around those affiliated to the industry. However, embalming manufacturers also help shore up this network of protection. Although these two organisations do not have the same power as their counterparts in North America, they are still the leading authorities on funeral issues. Each organisation produces, disseminates and protects the flow of information within and between the funeral industry and the general public. At times they will be called on to impart, explain and clarify information. Take, for example, a situation that occurred in 1998 (referred to in Chapter One). The Director of the then NZEA was called upon to clarify and correct what they considered inaccurate information. An embalmer had publicly confessed that he believed he had killed a woman who had been pronounced dead. The director of the NZEA believed it vital that this situation was addressed and that the narrative voiced by the embalmer was immediately counteracted so as to limit any misunderstanding or harmful impact on the general public. This action can be regarded within this context as gate-keeping, for it involved managing and maintaining the taken-for-granted understanding of death by constructing the embalmer as misunderstanding what had occurred, but also explaining the situation the embalmer found himself in as due to his inexperience. This 
positioning of people as inexperienced helps create a dualism around knowledge. There are those who hold the knowledge (insiders) and those who do not have adequate knowledge (outsiders) about funeral and embalming practices.

In some of the early research encounters this positioning of me as an outsider meant that I was, at times, completely shut out of particular parts of the industry. A further example of this took place when I made contact with the North American funeral and embalming manufacturer and distributor, the Dodge Company. The Dodge Company is one of the world's largest manufacturers of embalming fluid and suppliers of funeral home products. Based in North America, they have satellite businesses in several countries, such as Australia, Canada, Germany, Japan, Mexico, the U K, Puerto Rico and ANZ. Established in Boston in 1893 by A. Johnson Dodge, the company began manufacturing embalming chemicals in the basement of Dodge's home. In 1907 The Dodge Company established their first school called the New England Institute of Anatomy, Sanitary Science, and Embalming. Fourteen years later the first educational magazine, Climbing the Ladder, was published, now known as The Dodge Magazine. This organisation is well established in ANZ through one of the leading manufacturing companies who distribute not only Dodge's embalming fluid but also their magazine and other related products. The Dodge Magazine is utilised by the majority of funeral directors and embalmers in ANZ and as a leader in its field it produces information not only about embalming but also about the significance of viewing the dead by the bereaved. I identified this organisation as an essential component of my research. The prospect of being able to access such a wealth of information from a leading distributor was exciting, especially as the company's magazine plays such a crucial role in constructing various funeral practices in ANZ.

For this reason I approached The Dodge Company, outlining my work and asking permission to access their website. Unfortunately, my request was turned down. There were a number of reasons given, the first being that I was not employed in any identifiable capacity in the funeral industry. The secretary pointed out that only applications made by known and reputable organisations within the funeral industry could be accepted. I emailed The Dodge Company again and pointed out that in making this application, I was hoping to be able to draw on their 
information as I knew that their organisation was reputable and that the information would be trustworthy, therefore ensuring that any data I would impart through my research and other affiliated sources would be sound. I also pointed out that as I was bringing together information from various sources this would help balance any discussion around the use of embalming fluids. The secretary of The Dodge Company then emailed me with a second reason for not allowing my application to proceed: not only was I not affiliated but the information that I was requesting was of a highly sensitive nature and for this reason I would not be given access. Within this rebuff were a number of other reasons cited, mainly concerning issues of confidentiality. The secretary pointed out that by having access to their website I would also have access to information about the production and manufacture of Dodge's embalming fluids. It was pointed out that only customers of Dodge's embalming products are permitted access to this information.

I attempted to negotiate a compromise around this issue and suggested that some form of access code, such as a password, be utilised, thus allowing me access to only particular information. However, the secretary again pointed out that this would not be feasible and reiterated what had already been discussed. However, this time I was told that as an outsider, in this case a lay-person, I could misinterpret their information. This in turn could lead to further 'misinformation' and possible misunderstandings by anyone reading my final report. Even after assuring the company that I would ensure a representative from their affiliated company in ANZ could read my work prior to publication, I was still refused access.

While this challenge from The Dodge Company was not antagonistic, there was a degree of questioning my 'right' to have access to sensitive material as a nonindustry professional. Whilst The Dodge Company offered a compromise, putting me in contact with the manager of one of ANZ's leading funeral director suppliers who distributed their embalming and funeral products, it was made very clear that they believed that any information I gathered had the potential to be 'dangerous' in my hands. This gate-keeping set up what clearly underpins the contemporary funeral industry; a dualistic 'them and us' - in this case The Dodge Company viewed me as an interloper, an outsider, a dangerous 'other'. This positioning of 
myself and my work as being 'outside' continued when I made contact with their distributor. In this case, I was informed that my lack of scientific background hindered any possible understanding of their field of work. It was pointed out to me that any information I would impart through my research would be biased, as I was unable to fully grasp the complexities surrounding the use of embalming fluid within the funeral process.

This however, was not the only form of gate-keeping I experienced when making contact with organisations and people within the traditional funeral industry. Once more I want to stress that the industry is highly self-monitoring and the culture of this particular industry rests on understandings around dignity and professionalism. These concepts are played out in various ways; the most obvious being through the bodies of those working in funeral homes (I explore issues of dignity and containment in Chapter Six). Funeral directors come to embody notions of dignity and professionalism, in turn presenting these embodied concepts through a hyper-performance that sees their bodies become extremely selfcontained, displaying mannerisms and motilities they consider appropriate for engaging with the dead. This is achieved through extremely detailed self-grooming and self-surveillance.

\section{BEING FAT AND BUTCH: A BODY OUT OF CONTROL}

Professionalism is certainly encouraged within the academic community. A standard of dress is expected of lecturers, whilst sessional assistants can perhaps get away with a more casual appearance ( see plate 3.1 below). Nevertheless, compared to other professionals most lecturers and researchers will be found to be attired in more informal clothes. When engaging in interviews it has been suggested that the following should be considered prior to meeting with interviewees:

- Wear comfortable clothing

- Dress in a culturally sensitive manner

- Dress specific to research context

- Wear slip-on shoes

- Don't wear strong scents

- Don't smoke unless invited to 
- Don't chew gum

- Wear a watch

- Turn off pager or telephone, if applicable

- Check teeth for spinach, poppy seeds, etc.! (cited in Valentine, 2002:126)

Taking my thesis and potential interviews seriously, I attempted to adhere to some of the above suggestions. I cleaned my teeth and due to not being able to wear strong scents I didn't wear any. Silliness aside, the point is that even dressed well, my out-of-control body fights against tidy containment; therefore constantly in conflict with the flawless, clean and controlled manner found operating though the bodies of those working in the funeral industry. Furthermore whilst I believe that I am not the worst dressed person in the world, my standard of dress crosses various boundaries and as a self-identified butch dyke, I tend towards a more 'masculine' form of dressing (see Plate 3.1 below). This, more often than not, set me apart from the more conservative people I met in the industry.

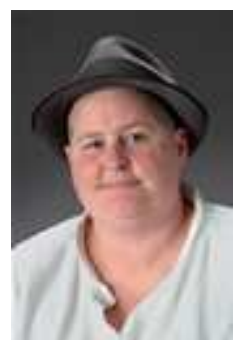

Plate 3.1: Kyro Selket (SGEES, 2008).

As I have suggested, containing the bodies of the dead can only be achieved through highly regulated and controlled performances. To achieve this, various discourses, knowledges and performances come into play. These performances have come to be embedded within a history of service which is said to date back to a bygone era (Strub and Frederick, 1981). This history of service is based around notions of sacred commitment and professional progression (see Chapter Five for further discussion). Even with new understandings and alternative approaches to burying the dead, funeral workers continue to hold to a more conservative approach when engaging with both the dead and the living. This conservatism is portrayed not only through their opinions about appropriate and inappropriate behaviours, but also by the way in which many in the industry portray themselves publicly. For this reason funeral directors are never 'sloppily' dressed, nor do they 
allow themselves to slip into what may be seen as slovenly behaviour (see plate 3.2 below).

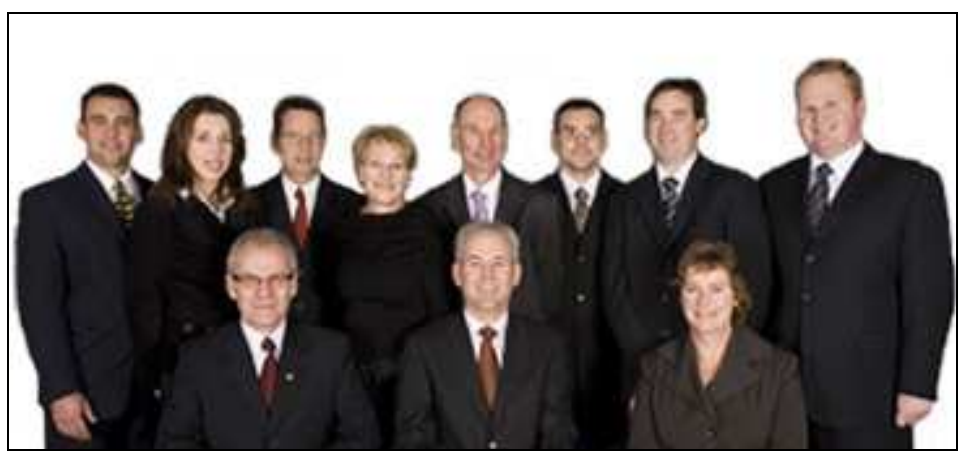

Plate 3.2: Staff of Lychgate Funeral Home (Lychgate Funeral Home, 2006).

As one can see in the above plate, the staff at Lychgate Funeral Home are dressed 'appropriately', and professionally. There are no undone shirts, the men wear ties, and the women emulate the men by dressing both professionally and in sombre colours. Contrast this to my official $\mathrm{PhD}$ photograph above, which is displayed publicly in the SGEES and on their PhD Students website. Whilst I am not 'untidy', I am less formally dressed and, one might argue, less traditional in appearance.

For these reasons arriving to talk with potential interviewees often made me feel quite dishevelled in comparison to the funeral directors and funeral product manufacturers, who at times I am sure spit-polished their shoes and maybe even their buttons. This again had the effect of positioning me as an outsider, as I appeared to embody none of the qualities held by the funeral directors and funeral product manufacturers with whom I spoke. Even when I attempted to contain and confine my body into neat and tidy clothes, my body continued to scream an out-of-control-ness that again made me appear unkempt, therefore undignified and unprofessional. My body also screamed its uncontrollability due in part to society's reading of fat people (see Longhurst, 2003, 2005). When the above factors were combined with my highly visible tattooed and modified body, it took many funeral directors, receptionists and embalmers by surprise, to say the least. Whilst no one ever commented directly about the 'me' that was 
presented to them, I did hear later that initial contact with me did deter some funeral directors from being interviewed.

Furthermore, my body could not hide its obvious sexual identity. This, unfortunately, created a barrier between me and many of the predominantly conservative heterosexual men I encountered. I would often be welcomed with strange looks and at times there was confusion as to what gender I might in fact be. This confusion was exemplified in secretarial staff telling potential interviewees that there was 'some-body' to see them.

Always aware that first impressions set the standard for engagements between the public and their work, funerals directors are always careful about their public face therefore, their public image must always be professional. This professionalism is laid down in texts such as The Principles and Practices of Embalming (Strub and Frederick, 1989) as well as texts utilised at Wellington Institute of Technology (WelTec) ${ }^{18}$ and other training organisations. Funeral directors who do not comply with these professional standards can and will be censured via the rigid network surrounding them, as well as through the Code of Ethics, which each affiliated funeral home director is expected to sign up to. The Code of Ethics is managed by the FDANZ. Dissatisfaction of service or conduct can be addressed by those outside the industry via the Code of Ethics; however the quickest form of censure comes through withdrawing financial support from a funeral home.

Consequently, my initial engagements had repercussions within the industry, particularly in the Wellington region. As mentioned previously, the industry includes approximately 111 funeral homes and 76 non-affiliated funeral homes. It did not take long for the word to get around that I was investigating the funeral industry. Both my body and my seemingly biased approach become an obstacle for some funeral proprietors when I attempted to organise interviews. As I have pointed out, initial contact with some of the more conservative people in the industry, which saw me positioned as a 'dangerous' outsider, meant that I

${ }^{18}$ Weltec is an applied tertiary provider that offers students trades and technical training. It offers a National Certificate in Funeral Directing and a National Certificate in Embalming. 
ceased approaching further prospective interviewees. Whilst this could have limited the potential for gathering information, I found that those that I did talk with were extremely supportive and forthcoming and a number of them made themselves available beyond the hour-long interview.

An important aspect of understanding the processes and practices surrounding funerals involved understanding how the private and public spaces of the funeral home came to be constructed. For this reason I decided to ask the funeral directors I knew to show me around their homes. Over the past decade funeral homes in ANZ have started to open their doors to the public. Whilst this is limited in that it still holds fast to a careful and controlled imparting of information, there are more opportunities for the general public to explore the physical spaces of the funeral home. Thus, I approached two funeral homes and asked if I could be taken on an in-depth tour of their homes. This was important as up until now some interviews had been conducted away from the funeral home, or were confined to one area, such as the interview room in the home. This had been suggested as necessary so as to avoid interfering with or accidentally intruding on mourners' space, as well as the funeral director's desire to not be disturbed or called upon whilst undertaking the interview. The only interview that I conducted behind the closed doors of the home was with the embalmer, who decided to talk with me in the embalming room. This was conducted after hours, and the embalmer said that they felt it was easier to talk about their work by being in their place of work. Therefore, gaining permission to walk around the home and view the daily activities of the funeral workers was important. By walking around and seeing the whole of the funeral home meant I was able to put together a generic map, which has been utilised in my research to show how the bodies of the dead and living move in and around a typical home (see Chapter Five).

\section{MAPPING FUNERAL HOMES}

Mapping is understood as a way of viewing and coming to know the world:

This notion of map-able space involves a specific epistemic topography: a landscape, a form of knowing or seeing which denies its structuring by the gaze of white male bourgeois knowers or Other knowns. It limits the possibility of critique by refusing to acknowledge other kinds of space (Pile and Rose, 1992: 131). 
Feminist and cultural geographers view mapping as inescapably biased, and inherently political. They question who maps are made for and who they are by. In challenging traditional notions of mapping, feminist and cultural geographers ask researchers to think about, as with any theoretical approach, who or what is being included or excluded.

Social cartography explores the locations, relations, and movement of ideas, persons, or social groups in social space. It is utilised in an attempt to continue the destabilisation of traditional mapping. In doing so social cartographers are reclaiming mapping by shifting the focus away from hegemonic map-making practices to include sociospatial relations and how people come to understand and represent them (Kitchin and Dodge, 2007; Paulston, 1996; Perkins, 2003). Brown and Laurier (2005) argue that mapping is part of a process of finding a solution to a particular issue, therefore people who make maps are never simply 'mappers'.

In deciding to map the movements of the living and the dead in and around the funeral home, I aimed to obtain a different understanding of how the bodies of the living and the dead are managed and manoeuvred though the contained and defined spaces of the funeral home.

Up until now I had only achieved an abstract understanding of what might lay behind the closed doors of the funeral home. By physically moving through theses spaces I aimed to move away from the prescribed discourse often discussed in interviews and through the funeral industry's texts, in a hope that through the physical action of moving around the home, those showing me around might become more animated. Whilst my intention was not to produce a map in the sense that Paulston (1996) and others write about, the map does reflect the highly controlled movements of both the living and the dead body in and around the homes.

Three funeral homes offered to open their doors so that I could look around. The invitation, however, did not include being involved in an actual pick-up, embalming or funeral. It was stressed that in no way would I be allowed into a room with a dead body. As far as the industry was concerned, even if my university had given permission via ethical approval, I would not have been invited to participate in or 
observe any of the more private functions of the funeral home. However, both funeral directors did offer to walk me through the process of handling the dead body - from its arrival to its final departure. In doing so I was able to make a reasonably detailed map (see p. 118), which shows the movements of both dead and living bodies as they negotiate and are manoeuvred around the home and each other. I need to add here that not having a background in mapping meant I needed to rely on someone with these skills. I was put in contact with Tim Wray, who produced the map that shows the layout of a generic funeral home and the movements of the living and the dead within it.

Whilst these maps may seem sparse when undertaking such a detailed engagement, John Duncan of Ninness Funeral Homes (pers. Com, 2003) in Porirua informed me that all funeral homes would in affect follow similar floor plans. This he argued was due to the nature of their work with embalming and the need to separate the embalming room and holding rooms from the front of the funeral home. Whilst the funeral home he managed was a two stored building, which he argued made it easy to separate the embalming room from the front entrance, chapel and viewing rooms, all homes had to place the embalming room at the back of the funeral home, therefore he suggested I merely visit a few homes and look at the designs which he argued would all be laid out similarly. This I found to be true, whilst each home was unique the floor plans regarding the separation of the front entrance, chapel and viewing rooms from the car bay, embalming room and holding rooms. Whilst I have only engaged with the funeral directors with regards to mapping the funeral home my personal observations and experiences of walking around these spaces have been woven into the research.

As I have pointed out, there were times in my research when engaging with the industry proved to be difficult, therefore it was necessary for me to draw heavily on texts that were produced by the industry. Texts are a necessary and essential part of any research, but in this case the industry's texts became indispensable. With a wealth of information gathered from my interviews it became clear that in a number of cases, which I had experienced even in short engagements with some key informants in the funeral sector, interviewees tended to repeat what they had been taught through their training and literature. 


\section{TEXTS}

Dean Forbes (2000) proposes that there is no set method for reading text. Many human geographers take an eclectic approach when engaging with texts, and textual analysis is just one of the various methods that can be utilised when conducting research. While there are distinctly different approaches to engaging with discourse analysis, Louise Phillips and Marianne W. Jorgensen (2002) point out that these different analytical approaches can be traced back through the work of people such as Fairclough (1989, 1991, 1992, 1995), who draws heavily on the works of Ernesto Laclau and Chantal Mouffe $(1985,1987)$ and Foucault (1972).

For Fairclough, discourse analysis is not an attempt by the researcher to find the 'real' or to find truth. Instead it is an attempt to find the shared meanings of text. Therefore there are no 'right' or 'wrong' readings, only a process of showing the 'taken for granted' and naturalised statements written into text. Fairclough's approach is based on the idea that text can never be understood in isolation (see Plate 3.3 below), but can only be understood in its interconnectedness with other texts and in turn to the social context of the text. Text refers to not merely books or manuscripts, but also to other written material and spoken conversations, which once transcribed can be deconstructed. Fairclough describes discourse "... as being simultaneously a piece of text, and an instance of discursive practice, and an instance of social practice" (1991: 41). 


\section{SOCIAL PRACTICE}

(Social and Historical power relations)

\section{DISCURSIVE PRACTICE}

(Production, distribution, consumption)

TEXT

Plate 3.3: Three-dimensional conception of discourse (Fairclough, 1992: 73).

By utilising deconstruction as a tool we can reveal ideologies and multiple meanings and interpretations of the texts, which in turn means that there are "...internal contradictions which expose them to multiple interpretations" (Forbes, 2000: 123). This is of particular use when discussing and interpreting the intersection between human beings and their environment - both the material and the discursive. For Fairclough, the material (building, transport etc.) is also text: it tells us much about how our world operates. For many discourse theorists, language is not seen as an exact tool nor does it embody some unique meaning. Fairclough (1991:1) proposes that:

Individuals working in a variety of disciplines are coming to recognize the ways in which changes in language used are linked to wider social and cultural processes, and hence are coming to appreciate the importance of using language analysis as a method for studying social change.

For Fairclough (1991), social practice involves discourses operating within a hegemonic power struggle. Therefore, discourse analysis in the context of this research includes an analysis of written material from across the different sectors of the funeral industry. In addition to the texts generated by the funeral industry I also draw on texts produced through the interviews. It will include an analysis of the production, distribution and consumption of information as well as the construction of deathscapes; in particular the public and private spaces within traditional funeral practices and funeral homes. 


\section{FUNERAL INDUSTRY TEXTS}

Four specific texts were identified as being crucial in understanding the process and operation of funeral and embalming practices in the contemporary funeral industry. These were Strub and Frederick's (1989) text The Principles and Practices of Embalming; Robert Mayer's (1996) Embalming: History, Theory and Practice; the FDANZ magazine; and a report written by the NZEA (2002). The Principles and Practices of Embalming; (Strub and Frederick, 1989) Embalming: History, Theory and Practice (Mayer's 1996) are key text for the traditional embalming and funeral sector in ANZ. The reason that the industry relies on books written in North America is twofold. Firstly the industry here relies on North American techniques and products for the practice of embalming. Secondly, embalmers and funeral directors in ANZ have as yet published texts that are specific to our particular situation and or location. Until this happens embalmers and funeral home operators will continue to rely on texts imported from North America.

In conjunction with these texts I sourced a large selection of secondary texts, most of which were published by the FDANZ and NZEA. These texts mainly dealt with issues specific to the industry in ANZ as well as the development of embalming techniques and social and political changes the industry has and is facing. As well as these texts I was given a few copies of The Dodge Magazine, which were passed on to me by an ex-embalmer.

These primary and secondary texts helped build a picture of the resources that the traditional industry in ANZ rely upon to construct their understandings of death particularly of body disposal and the handling of the dead. What became clear when reading these texts was just how reliant the industry was on these particular works. Of the four main texts only two were produced in ANZ. The rest were produced by North Americans for an American audience. Therefore, it was necessary to draw on secondary text, itself drawing on North American literature, but produced with an audience base in ANZ. These materials were produced by the FDANZ and the NZEA 
under the umbrella of Griefcare, ${ }^{19}$ which include a number of brochures that help form the basis for supporting mourners through the various stages of grief, as well as helping them understand funeral home practices. Other brochures available to the public covered everything from pre-paid funerals, the importance of viewing the dead, helping children grieve, coping with the death of infants, and organising alternative ceremonies, to the importance of embalming. Of particular interest in this abundance of pamphlets is My Life, My Funeral, which is a planning kit to help people plan their own funerals. These brochures are in all funeral homes and are made freely available to mourners. A less utilised book was Doug Manning's Special Care Series,${ }^{20}$ which, whilst being made available to some mourners, was limited to certain funeral homes. From the little I could fathom, Manning's books were supplied to funeral homes that purchased a particular brand of embalming fluid; however, this was never really confirmed. I was also given a copy of Margot Schwass' (2006) Last Words: Approaches to Death in New Zealand's Cultures and Faiths; a book that traces the diverse cultural history of changing funeral practices. It looks at how funerals have moved from a typically Western-centric tradition to funerals that must be aware of, and attempt to encompass, all the cultures now living in ANZ.

\footnotetext{
${ }^{19}$ Griefcare is the "...quality mark for New Zealand funeral practices - your assurance of ethical, professional and caring service" http://www.griefcare.org.nz/. Griefcare pamphlets are distributed at FDANZ approved funeral homes and they also run an internet site, as well as a Tributes webpage at http://www.tributes.co.nz/ViewMyTribute.aspx?id=2151.

${ }^{20}$ Doug Manning has published a four book set entitled The Special Care Series (2003). These are utilised within the industry and can be brought via booksellers such as Amazon.
} 


\section{LOCATING AOTEAROA NEW ZEALAND'S FUNERAL INDUSTRY}

To situate the research within a cultural context it became necessary to draw on texts from outside the funeral industry. Little has been written about funeral practices and processes in ANZ. Whilst I was able to have access to the FDANZ in-house magazine I also drew on a number of television documentaries specifically addressing funeral issues in ANZ, as well as drawing on local newspapers and magazines such as North and South (2003) for funeral industry related material. At the outset of this research the funeral industry had suddenly come into the spot-light for a number of reasons. The first reason was ANZ's aging population and the eventual demise of the 'babyboomers'; reflecting baby boomer statistics in a number of OECD (Organisation for Economic Co-operation and Development) countries:

And no wonder - projections for the business are good. "Deathcare professionals" posting on message boards on the Six Feet Under website note that US death rates are set to rise 30 to 40 per cent as babyboomers drop off in the next 20 years (McKessar, 2002: A14).

This had seen a number of North American funeral groups attempt to buy funeral homes in ANZ, bringing a negative reaction which was aired by the media. Secondly, there was a growing interest in the HBO series Six Feet Under, which had made an impact on both the general public and the funeral industry in ANZ alike. Death, it appeared, was a hot topic.

Ultimately, academic literature was drawn on to construct the foundations of much of my research. This included an eclectic combination of geographical, sociological, anthropological, philosophical and thanatological ${ }^{21}$ narratives. However, I also used the World Wide Web (WWW), as the industry increasingly inhabits this space (see reference to the Griefcare site). The virtual space of the internet is also being used to destabilise the secretive spaces of the funeral home and of funeral practices. For example, there are sites that show the once hidden world of the embalmer. ${ }^{22}$ Whilst the internet cannot be totally relied upon for offering academically peer-reviewed information, it is certainly becoming a space within which the unwrapping of the

\footnotetext{
${ }^{21}$ Thanatology is the study of death.

${ }^{22}$ The embalming process can be viewed at the following websites: http://www.embalmingpictures.com/category/embalmingpictures and http://video.google.com/videoplay?docid=-3069100159888160852
} 
industry is having a major effect. It was important to explore this space as issues of sensitivity had arisen in a few informal conversations. One particular conversation was in reference to an article in the North and South, which showed the author, Sperber (2003), lying in an open coffin. Sperber's actions were read by some in the industry as grotesque and an extremely undignified act. As well as the article exploring alternative approaches to the traditional industry this article was important in exploring the diversity and burgeoning challenges that the traditional industry is experiencing.

Another important text was the newly screened American soap/drama Six Feet Under (HBO, 2000 - 2005). Initially questioned by some in the industry as dubious this series was eventually embraced by many in the funeral industry. Six Feet Under subsequently became an important resource for researching issues around embalming and also the interconnectedness of the North American and New Zealand industry. What were also appealing about the series were the creators' attempts to destabilise some of the tensions and inconsistencies that exist within the North American funeral industry. Whilst Six Feet Under (HBO, 2000 - 2005) highlights numerous issues and opens up death spaces within the funeral home, it must be remembered that there are cultural (dis)similarities between the ANZ context and the American based television series.

\section{AUTOETHNOGRAPHY: OPENING UP SPACES WITH A FEW WORDS}

An autoethnograpic voice concentrates on telling a personal, evocative story to provoke other's stories and adds blood and tissue to the abstract bones of the theoretical discourse (Ellis, 1997:117).

When I initially presented my thesis to colleagues at the SGEES, I was surprised by the questions and discussions that were generated. I was not grilled about my epistemological or ontological approach. Instead, I was told stories about mothers, fathers, infants and pets who had died and the impact their death had on those telling the stories. I was asked why the industry did not understand how the pain of losing a loved one was sometimes sidelined by the need to embalm the body and sell expensive coffins. It was the personal stories that reinforced the need to begin researching the funeral home and the practices and procedures that are undertaken 
within. It was for that reason I began to think about how I would share my findings with academics and laypersons alike, as these two groups, like any others, share the commonality of death.

As I pointed out in Chapter Two, at times I have woven narratives about myself and how I view and am affected by the research topic. An autoethnographical approach developed through a feminist infusion of writing not only the voices of those that were interviewed but also writing themselves back into the geographical landscape (Besio and Butz, 2004). This 'writing back' challenged the euro-centric, objectified, masculinist approach to undertaking research. It is based on the belief that one is never separated from the subject one chooses to research. As Carolyn Ellis (1997) points out, introspective data is frequently written out of or hidden within the research. In doing so there is something missing; something that cannot quite be touched or perhaps felt when reading some texts. Writing out the experiences of others, and the personal experiences of the researcher, I believe, is similar to the way in which death has been constructed as the 'other' to life (see Ariés, 1981; Noy, 2005). Death is like the elephant that sits in the corner of the room; seen but not spoken about. Yet death has an "I", an "I" that cannot speak; consequently, it is necessary for the living to speak to death in the best possible way that they, I, we, possibly can.

It is also the role of the researcher to explore through their work ways in which discussions about death and the post-death process are part of the whole. For this reason I have utilised a semi-autoethnographical approach, in an attempt to cross the boundaries that are constructed not only around academic writing, but also to traverse the border that has been constructed around death. Although I have not taken such a radical approach as Ellis (1997), Bataille (1988), Kristeva (1982), Richardson (1990, 1997) and others, I have woven my own stories into the thesis, thereby giving the thesis what those utilising autoethnography would argue is a 'freeing up' of and a destabilising of academic constraints on writing. In doing so one can move forward, backward, and dip in and out of the research, and in writing in such a way, mostly through the use of a journal, one is attempting to reframe and connect research with story telling, academic and lay-persons, and in this case life and death. 


\section{CONCLUSION}

This chapter outlined the multi-method approach employed for gathering information from various key informants within the funeral industry. In utilising these approaches however, the researcher is cautioned to think about the possible ramifications of engaging with interviewees. The researcher is advised to think about effects and limitations, particularly looking at ones insider - outsider position and how this can affect the dynamics of an interview. I recognising these and other suggestions the researcher is able to include their voice into the research without taking over the research. The utilisation of an autoethnographic voice helps weave the personal into the theoretical understandings.

Each approach, each method then helped build up a picture of the workings of the contemporary funeral industry operating in ANZ. In limiting my research to the operational understandings of funeral work, I explored how the traditional and alternative funeral sectors approach and understand the practices of disposing of the dead in the $21^{\text {st }}$ century. In doing so, I have opened up these spaces, thereby adding to the laying open of an industry that until recently has been closed to the general public. Whilst at times I found myself shut out of the traditional sector and having to rely on texts to understand how parts of the industry constructed and limited its borders, I was also heartened by the generosity of those who did step forward to support my research. This exclusion was an essential part of learning, not only about how to undertake and engage in research in the future, but also in helping me understand first-hand the restrictive and overprotective nature of parts of this highly-monitored and controlled industry. 


\section{4 \\ COMMODIFICATION OF KNOWLEDGE}

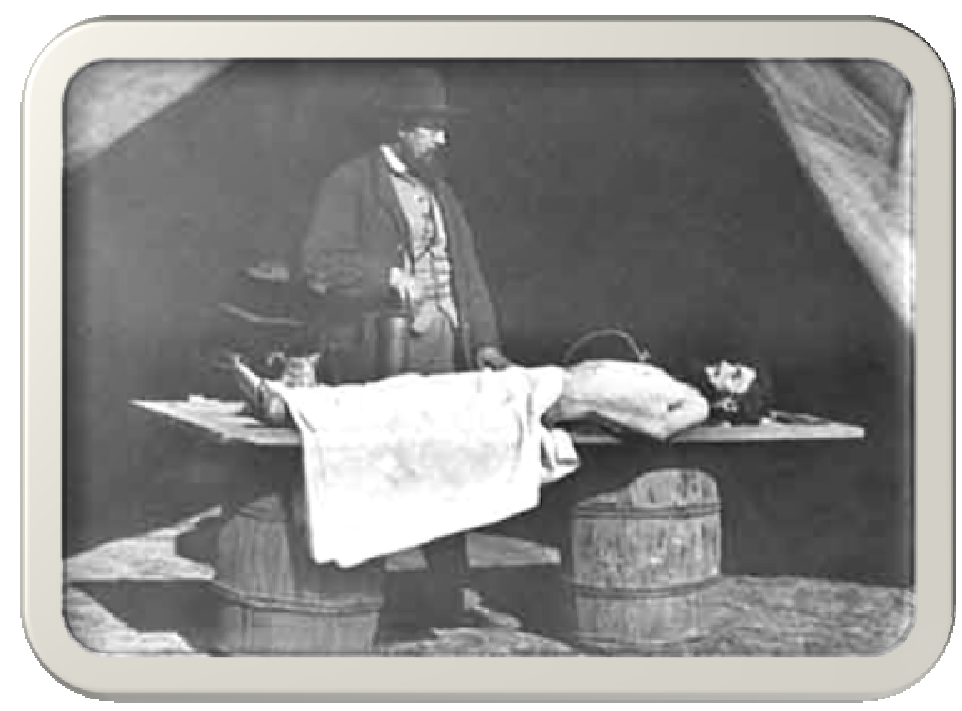

Plate 4.1: Dr. Richard Burr, Embalming Surgeon, Army of the James: Embalming a Dead Soldier (Prosser, 2005).

Western societies often speak of history as a naturalised progression; a timeless march beginning with a source; a starting point from whence Western human beings' knowledge came into being. This progressive march expands out towards an unseen horizon, which holds within its borders a totalising, civilising and technologically progressive society; an unfolding history that on first glance seems natural. Written into this history is a developmental narrative that becomes embedded within society's other narratives. In turn, these narratives come to be inscribed into everyday language and at some point onto the bodies of those citizens living in these societies. This helps create a particular 'taken for grantedness', which is played out through certain social behaviours as well as becoming a fixed narrative that underpins and strengthens society's bonds. According to Mircea Eliade (1961) this taken for grantedness becomes 'magical' in its naturalness.

In critiquing this supposed linear historical march, Foucault (2001) points out that numerous narratives come to compete, with some narratives 'winning out' over 
others, thereby creating a particular truth. For example, within the embalming manufacturing discourse, itself based on a scientific reading of natural progression, contemporary embalming methods are seen to be part of the natural development of burial practices within Western societies. This truth is based on 'grand narratives', which in themselves have become embedded through their apparent sensibility, thereby insulating the narrative from any constructive challenge. Grand narratives operate in such a way as to construct legitimate customs and laws which appear as fitting, as 'commonsense'. Naturalisations of normalising behaviours or proper ways of being make anything unnatural or out of the ordinary feel 'wrong'. Within the funeral industry the narratives/myths spoken and performed by the industry are drawn from a number of discourses; however, the central discourse that the modern industry has come to rely upon is situated within a scientific paradigm. This pivotal narrative has seen competing narratives closed down and marginalised. In this chapter I explore the historical narratives drawn on by the modern funeral industry in ANZ. In mapping the movement of these narratives and deconstructing the various texts that come to underpin the apparent natural progression of funeral practices, I argue that modern funeral practices rely on a particular discourse that constructs this industry as essential and indispensible.

\section{HISTORICAL NARRATIVES}

Historical narratives are utilised to stabilise and help bring about order to a society. This order of things is achieved via a hegemonic narrative that depicts the progressive march of civilisation. Each narrative, whether it is Science or Christianity, begins with an origin, a starting point. In the case of Judaeo-Christianity, the bible speaks of an origin that was the 'word'. From these origins time is said to stride forward in a linear fashion, bringing with it technological progress which is said to lead to an improvement in society. This advancement is in turn believed to bring about civilising effects on its citizens. These effects turn back on themselves to create a naturalised and normalised historical narrative until it becomes pure and unchallengeable; until the narrative spoken, written and enacted becomes an absolute truth. The Enlightenment influences on the structures of knowledge have seen the rise of rationalism, which has created a dualistic worldview. This has set up competing paradigms that are inherent to the rational approach. The aim is to create 'pure 
knowledge' - free of interference, completely objective, understandably rational, value-free and untainted by the researcher/theorist. Any theories or discoveries that might challenge this or do not fit the modern paradigm (reality) are, as I have suggested, either marginalised or negated, categorised inadequate or critiqued as illinformed. However, competing narratives may come into being if they shift important aspects of the dominant paradigm (Shiva, 1989).

Those using genealogy, feminism, and post-modern and post-colonial theories to critique Western historical narratives are opening up what was once closed and takenfor-granted. Foucault's genealogy unpacks the narrative of truth, and as Foucault (1977) suggests shows that an absolute truth is discovered by chance, which more often than not is supported by those in power who have an interest in maintaining a particular version of the truth. For example, embalming is viewed as being beyond reproach as its history not only shows its positive progressive impact on the modern funeral ritual, but also certain powerful institutions that hold the knowledge and therefore the power to construct its history as truth. It is for this reason that Foucault (1977) argued that all truths are questionable. Once the practice is institutionalised in this case embalming - it can be named and given the power and status it so rightly deserves. To study the underlying contestations, knowledge and power, one attempts to explore what is not evident.

In retelling the narrative that underpins the performance of this absolute truth, the act or theory becomes naturalised. At this point it appears unthinkable that the narrative, act or theory would not have come into being. This truth, however, is said to be 'unsullied' by power and that a retelling operates from the idea that words retain their meanings and that "...desires still point in a single direction, that ideas retain their logic" (Foucault, 1977: 139). Again, if we look at the contemporary funeral industry, it is said not to be founded on base materialism for this degrades the sacredness of the profession. Therefore striving for professionalism is not tied to monetary rewards; instead it is based around the historical professional development, embedded within 'service' to the community.

As I have suggested, countering hegemonic narratives, especially ones that have embedded within their discourse psychoanalytical notions of well-being and 
appropriateness, can bring with them feelings of discomfort and 'uncanniness' and are argued to be disruptive to society's need for order. Narratives that challenge metanarratives are cast as destabilising elements, positioned as dangerous outsiders, pushed to the margins - 'othered'. It is these border transgressions that those drawing on Foucault ${ }^{23}$ attempt to explore and simultaneously destabilise. It is the 'what', the 'who' and the 'why' of exclusion that is being explored.

The construction of 'myths' ${ }^{24}$ is said to function as a synonym of 'ideology', and like Foucault, Roland Barthes (1972) argued that myths are purported to be natural. In calling them myths Barthes attempts to unravel the values and interests said to be embedded within these myths, especially by the middle classes. For Barthes progress is class based and it is those from the upper classes that benefit from legitimating and universalising their beliefs and values, becoming self-evident in their performance. Once more any critique or challenge is a slight on a particular group or theory, and therefore dismissed as repugnant.

Such 'mystification', as it is commonly known, frequently takes the form of masking or suppressing social conflicts, from which arises the conception of ideology as an imaginary resolution of real contradictions (Eagleton, 1991:5-6).

This imaginary resolution, said to have come about due to the battle and final triumph of commonsense over irrationalism, can be found operating in contemporary funeral homes in ANZ. This is evident in the challenges I received when starting out the research, whereby I was charged with being biased (see Chapter Three) - particularly from those manufacturing embalming products. As discussed, this challenge was based on a number of beliefs; primarily that I was unqualified to speak about embalming as I was not a trained expert and that this would lead to misunderstandings and misinformation. This power and knowledge has been constructed through various discourses that has seen not only funeral directors and embalmers given authority over the dead, but also the embalming manufacturers, who align themselves with the narratives that ensure the sustainability and use of their products.

\footnotetext{
${ }^{23}$ Foucault also drew on the works of Georges Bataille when exploring notions of order and transgression.

${ }^{24}$ Roland Barthes (1970) uses the word myth as opposed to narrative.
} 


\section{EMBALMING MYTHS}

[A] myth is an account of events which take place in principio, that is, "in the beginning', in a primordial and non-temporal instant, a moment of sacred time (Eliade, 1961: 57).

Myth is a type of speech (Barthes, 1957: 109).

... 'modernity'...thinks of itself as the heir to a long tradition of ideas, values, principles and practices going back thousands of years (Danaher, Schirato and Webb, 2000: 28).

Contemporary embalming practices are said to have originated from the preservation rituals of ancient Egypt. In this highly religious society, death was central to religious beliefs. Embalmers or 'wahets' were selected from groups of men who had been tutored in the spiritual arts of medicine, which in itself was viewed as prestigious position (El Mahdy, 1991). Selecting wahets could well have occurred by way of lengthy and intensely sacred shamanic rituals. To gain entry into the shamanic world selection may have involved one of three processes. The first process may have seen the inductee gain entry through inheritance. Alternatively an inductee might well have entered his profession because he felt 'called' to the position. Another possible entry into a sacred position was by embarking on a personal quest (Eliade, 1961).

Admission into this sacred sect was extremely privileged and wahets were honoured and protected.

Whilst modern embalmers no longer undergo complex shamanic initiation rituals, entry into this 'honourable' profession could be said to hold some similarities to the once sacred selection process undertaken by the ancient wahets. Many funeral directors/embalmers, ${ }^{25}$ for example, suggest that they have been 'called to service'. Joan Krammer, a funeral director/embalmer at a Nelson funeral home, emphasises the fact that she sees her role as a 'servant' to and for the public (The Nelson Mail, 2002). When asked by Peter Lawrence (The Press, 2001: A2) about his work, another funeral director said that he:

wouldn't change my job - I've found funeral directing very satisfying and rewarding, even though the hours are long. It gets into your blood, and you build your life around being on call.

\footnotetext{
${ }^{25}$ These two professions are often combined. Therefore many funeral directors also embalm dead bodies.
} 
Other funeral directors/embalmers are drawn to funeral work due to unsatisfactory experiences in their childhood around death and funeral rituals. Andrew, a funeral director/embalmer based at an Auckland funeral home, tells of his 'coming into service' due to the personal experience at the age of four of his mother's death. Andrew points out that in 'those days', children were not encouraged to attend funerals, which meant that Andrew was not given the space to say goodbye to his mother. When visiting his mother's grave at the age of eight, Andrew saw a group of men dressed in black suits. He asked his older sister who they were and what they were doing and on finding out what they were, he informed his sister that he too would be a funeral director when he grew up (Documentary New Zealand, 2005).

Ese, a young Samoan man, decided to become a funeral director after the death of his father. Becoming an embalmer has meant that he has been able to explore some of the many questions he holds about death (Documentary New Zealand, 2005). Funeral director Simon McKenzie entered funeral work because he viewed it "... as a very important industry to be involved in..."' (The Press, 2001:14). Becoming a funeral director gave McKenzie a sense of personal satisfaction, due in part to his belief that his work assists in alleviating some of the burdens of the bereaved. Whether funeral directors or embalmers are drawn to their profession because of altruistic sentiment or because of previously painful childhood experiences of death, the sense of being 'called to service' appears to be a significant aspect of the entry of many contemporary funeral directors and embalmers into their profession.

Embalmer ' $A$ ' talked about how embalming gave them a sense of service. Helping mourners revisit their loved ones prior to burial gave a sense of accomplishment - of purpose:

I feel like I am helping - not like a social worker, but as someone who can give them a last farewell. They're not going to be around ever again. So we have to give them one last goodbye (pers. comm. 2006).

It is for these reasons that contemporary embalmers are reminded that their 'calling' to service is based on one of the:

most ancient and honourable professions that existed since the dawn of written history. As long as 7,000 years ago the embalmer-priest of ancient Egypt occupied the most responsible and respected position in the religious hierarchy of that era. It was only to the care of these 
embalmer-priests that the sacred bodies of the god-emperors could be trusted (Strub and Frederick, 1989: 2).

This sense of calling helps to create a backdrop endowed with a certain degree of entitlement. In turn, this sense of entitlement bestows on those in the industry an innate right to continue certain practices. For example, embalming is an ancient art that has progressed with the natural evolution of the civilised world, a world that has come to see the fighting of disease as a necessity. It is the funeral director and embalmer who shoulder this burden because of their commitment to ensuring that the funeral will hold the sacredness of the past, and also their personal commitment to ensuring that funerals are as pain-free and incident-free as possible for the mourners.

This is reiterated through the retelling of the funeral industry's 'history' - especially around embalming - which reemphasises the work those in the industry do as a time honoured practice. However, funeral work, according to Strub and Frederick (1989: 4 ) is not simply a time honoured tradition, it also encapsulates an innate and “...genuine reverence for the dead which stems from deep personal convictions rather from crass materialism". The position of a funeral worker is therefore viewed as a sacred one, which asks those within it to sacrifice much for the good of both the living and the dead. In this sense some in the industry draw parallels with the sacred calling of the ancient wahets. This view of funeral service is supported by death writers such as Allan Kellehear, who contends that "Our experiences of dying have been shaped by ancient ideas about death and social responsibility at the end of life" (2007: i).

Disposing of the dead is endowed with a narrative of inviolability: it is a profession with a hallowed past. However, this narrative also implies that funeral work embodies something special that might only be found in countries that have 'progressed' and hold notions of equity and fairness. Locality, then, is viewed by some in the industry as underpinning this vocation. For example, in the USA the deeply personal conviction and the sense of service that accompanies funeral work goes beyond any commitment expected of other embalmers from other Western countries. Embalmers in the USA are drawn to their profession because of their deep-rooted conviction for 'fair play'. In 1967 Strub and Frederick (p. 5) pointed out that, "We do not believe in 
taking unfair advantage of the weak; we do not believe in abusing the defenceless. And what is more defenceless than the dead?" For this reason potential funeral directors/embalmers were asked to evaluate their character and meet certain criteria before undertaking their vocation:

1. Does he limit his acquaintances to a select few?

2. Are his feelings easily hurt?

3. Does he stay in the background on social events?

4. Does he prefer to work alone rather than with other people?

5. Is he easily embarrassed?

6. Does he avoid anything like public speaking?

7. Does he worry over what may happen?

8. Is he introspective?

9. Does he daydream?

10. Is he absent minded? (Strub and Frederick, 1967: 9)

These criteria, used in 1967 to determine the suitability of a candidate for embalming/funeral work, demonstrate the expectation that a funeral worker will have the capacity to prioritise his (and they were male at that time) profession over and above all else and keep his emotions in check. While these particular criteria may no longer apply today, the general sentiment remains.

Whilst the character of the funeral director/embalmer is essential for the appropriate attitude for working in the industry, Stub and Frederick (1989) no longer rely on an innate sense of fair play; instead they now draw on a more publicly orientated commitment, which sees funeral directors and embalmers being committed instead to the ultimate protection of the living from potential diseases that could be spread by the dead. As Strub and Frederick point out, the life of a funeral director/embalmer is not easy. It is often a dangerous, unpleasant, and gruelling profession. Whilst a career in the funeral industry may be difficult, they argue that the pride that an embalmer gains from his or her work, especially when helping the living deal with death, far outweighs the hardships. True professionalism and commitment, they argue, can only be found 'in the heart' (ibid). Funeral directors and embalmers are now the regulators of safety: they are police men and women of the dead. Whilst the shift is part of the overall movement from a sacred profession to one of a more scientific nature, the gravity, the weightiness and the significance of the funeral director's and embalmer's role still retains elements of prestige and 'holiness' that the position of the wahet held in ancient Egypt. 
Commitment alone is not sufficient when working in contemporary funeral homes, and with the changing face of the industry, particularly with few funeral workers entering the field through family connections and the increased pressure to adhere to 'professional' standards, education has become extremely important in shoring up the necessary attributes a candidate needs for this particular type of work.

In ANZ, persons wanting to take up funeral work as a career are required to attend the Weltec. The programme requires that students be at least twenty years of age and already be working in a funeral home (Weltec, 2005). The introduction of such study is viewed as part and parcel of the progressive and shifting nature of the funeral industry. Formerly a career in the funeral business was handed down to the son of a funeral director: modern funeral directors and embalmers, however, choose to enter the industry. At Weltec, students wanting to specialise in funeral directing or embalming must attend specific courses which offer the following qualifications:

- National Diploma in Funeral Services (Level 5)

- National Certificate in Funeral Directing (Level 5)

- National Certificate in Embalming (Level 5)

Trainees are expected to learn:

How to carry out all the procedures necessary for the successful arrangement and direction of a funeral, as well as the administrative tasks related to a funeral. In Behavioural Science, students learn about psychological, social and cultural behaviour related to death and dying and develop the interpersonal skills needed for dealing with the bereaved (Weltec, 2008).

This modern approach to entering the funeral industry is viewed as a progressive move that cuts ties with the romantic attachments that once underpinned funeral work. No longer is the profession of embalming based solely on an historical narrative which saw the origins of modern funeral work in ancient Egypt:

Any similarities between modern scientific arterial embalming and that adopted by the ancient Egyptians is in name alone, thankfully they have little else in common (The British Institute of Embalmers, 2001).

The historical narrative spoken within the funeral industry speaks of progression, a progression that shows both funeral practices and embalming practices have advanced akin to the civilised societies in which they are based. Funeral rituals are said to have 
evolved and developed due to the progressive nature of both science and medicine (Strub and Frederick, 1989). This can be seen in the texts of Strub and Frederick (1989) and Robert Mayer (1996). These writers draw on the historical journey of embalming and funeral practices, beginning with the civilising origins of the ancient Egyptians, whilst pointing out that science and medicine, both equated with civility and progress, have taken over the initial stages of embalming and funeral practices. This movement away from a narrative based on a 'calling' has seen the introduction of such subjects as behavioural sciences into the National Certificate in Embalming. Students are now expected to understand behavioural sciences, engage in psychological and cultural behaviour, and incorporate interpersonal skills that will allow them to be 'sensitive' to the needs of their clients. No longer is a funeral director or embalmer called to their profession solely for spiritual reasons.

Like most myths or totalising narratives, the funeral/embalming narrative is a form of speech, a system of communication, which is understood not in what is being said but in the way it is being said (Barthes, 1957). Therefore, whilst contemporary embalmers no longer prioritise a spiritual foundation, the spiritual narrative has not been totally erased from their discourse. Instead it now acts as a backdrop to their commitment to service. More importantly, it is the way in which the spiritual narratives have come to underpin their 'professionalism' that sees some embalmers in particular equate their work to that of the progressive nature of 'doctoring' - as traced from ancient times to the modern Western ascendancy of science and medicine.

\section{GOOD SCIENCE}

Between 1650 and 1861 European scientists began preserving dead bodies for anatomical research. Parisian liberal laws permitted scientists and doctors easy access to dead bodies so that they could experiment with preserving fluids (Mayer, 1996). Embalming of cadavers became viewed as a valuable technique that allowed anatomists insights beyond the border of the body, thereby transferring the medical gaze from the external to the inner workings of the body.

In opening up corpses and delving into the body's interior, scientists and doctors argued that they had found the 'origin' of not only death, but also of disease. 
Consequently, this has seen death narrowed down to a few possibilities (Foucault, 1977; Shildrick, 2004). With these new insights, scientific medicine was able to cleanse away opposing theories on disease, creating a new metanarrative which came to be known as 'germ theory'. Germ theory was utilised to construct an "... aura of a timeless and universal truth" (Tomes, 1998: 2). This universal truth - based on a debatable hypothesis - has come to be accepted as a scientific fact. Drawing on this new body of work, embalmers have been able to further construct narratives about the potential dangers corpses pose to the living.

In doing so, embalmers, or more specifically the manufacturers and distributors of embalming products, create a barrier which denotes a non-scientific approach to handling the body as less superior to the rational project in which they see themselves positioned. In positioning embalming within a scientific discourse, other approaches remain outside, peripheral, unacknowledged. However, drawing on scientific discourse is not enough to allow scientific based practices to stand alone: the introduction of laws or the 'surrogate scientization of life' (Santos, 1995) shores up scientific based claims to truth. By weaving science with societal laws there is a separation of 'belief' from 'fact', with both law and science playing a central role in issues of power/knowledge, thus cementing the hegemony of modernist ideals.

In intertwining these narratives with the closeting of the dead body from the living, the embalming manufacturers have been able to draw on even more specific narratives that suggest that "[e]ven when the cause of death is known to be noninfectious there may well be a hidden or undiagnosed disease(s) present" (Sawyer, 1994: 28). Therefore embalming is crucial for the safety of the bereaved. For this reason embalmers have come to see themselves as the 'guardians' of the public's health, and whilst 'restoration' ${ }^{26}$ of the dead is viewed as a valuable component in the grieving process, the "...really important service, however, is the invisible service... that which functions to protect the health of the community and the nation" (Strub and Frederick, 1989: 3). With further advances in scientific and medical knowledges embalming manufacturers and embalmers argue that the general public have an even

\footnotetext{
${ }^{26}$ Restoration is an American term for embalming. This term is rarely if ever used in the funeral industry in ANZ. The term most commonly used is that of 'presentation', which is similar to restoration. One funeral director I spoke to suggested that the term restoration has been rejected because of its reference to a more 'artificial' association (pers. comm. 2004).
} 
greater chance of coming into contact with extremely infectious diseases, especially via contaminated blood - due in part to AIDS. Even worse is the possible contamination from diseases such as Staphylococcus aureus, ${ }^{27}$ which is why it is seen as in the interest of public health to embalm all dead bodies (Bremer, Fletcher and Osborne, 2004; Wyoming Funeral Association, 2000). ${ }^{28}$

Embalming is therefore considered by many outside the industry as an essential part of modern funeral and burial rituals, due in part to the perceived 'natural' evolution of burial rituals. Alternative funeral practitioner Lynda Hannah $(2002)^{29}$ suggests that few people outside the funeral industry ever question the various processes and procedures sold to them by funeral directors. This taken-for-granted process has been reinforced through various health and sanitation reforms and legislative decree. In the USA, all bodies, excluding a very few, are required to be embalmed prior to burial. Whilst funeral homes in ANZ are not forced to embalm all bodies by law, they continue to follow their North American counterparts.

\section{ALL THE WAY FROM AMERICA}

Prior to World War II, embalming techniques were infrequently practiced in urban areas. Up until the entry of American troops into the Second World War, funeral directors and funeral homes in ANZ tended to emulate their British counterparts. Marion Barnes (1991) suggests that the traditional British funeral was dowdy and disengaged. Priest and other clergy spoke of God and not of the dead. The ceremony barely reflected or commented on the life of the deceased. At the time embalming practices followed the low level use of the funeral industry in Britain and bodies underwent temporary embalming. This meant that the arterial embalming (full embalming) undertaken today was not practiced in ANZ.

\footnotetext{
${ }^{27}$ Staphylococcus aureus is a bacterium that lives on the skin or nose of living people. It can cause a range of problems such as pimples and boils. It is also responsible for more life-threatening diseases such as pneumonia, meningitis, or endocarditis (Bremer, Fletcher and Osborne, 2004).

${ }^{28}$ See K. S. Creely's Research Report - Institute of Occupational Medicine (2001), Infection Risks and Embalming, on behalf of the British Institute of Embalmers (BIE).

${ }^{29}$ Lynda Hannah began operating her business in 2001 in Nelson, ANZ, and is now part of a burgeoning alternative environmentally responsible funeral service.
} 
However, with America's entry into WWII and with ANZ becoming a stop-over base for American soldiers on leave, this was to change. American law required that any soldier killed outside America had to be embalmed prior to being returned home. Although army based embalmers travelled with the American units, undertakers in ANZ were employed to assist, if not conduct embalming. For this reason some funeral directors needed to become proficient in preservation techniques.

This need to impart information wider than merely the city funeral homes is reflected in some of the advertisements and educational articles run in the Funeral Directors Association's ${ }^{30}$ newsletters between 1940 and 1945. Several articles began instructing funeral directors on the procedures necessary for the use of embalming fluids. By the late 1950s funeral directing and embalming began to reflect the practices and principles adhered to by the funeral industry of North America. However, some rural funeral directors felt put upon by the introduction of embalming practices, pointing out that in more rural areas access to chemicals was near impossible. Therefore, some directors viewed this new technique as a city phenomenon. As a consequence, some rural funeral homes tended to adhere to the more traditional practices acquired from Great Britain.

Nevertheless, embalming procedures were becoming recognised in ANZ as the only safe sanitary practice that also offered mourners a body to view and grieve over for an indefinite period of time - at the same time knowing that it would remain 'life-like'. With the advent of World War II many funeral homes faced supply shortages, from petrol rations to a lack of metal handles and ornaments. Discussions on the changing face of funerals dominated the then FDA newsletters. This might have been due in part to the arrival of the American soldiers, while post-war saw the introduction of American goods, traditions, and in the case of funerals a modernising of the once staid funeral home.

Concern was voiced by many funeral directors, especially as there was a sense of 'tradition' being eroded by these new ways. However in the mid 1960s a small but committed group of funeral directors travelled to the USA to be trained by their

${ }^{30}$ Now known as the Funeral Directors Association of New Zealand (FDANZ). 
American counterparts. Once these contemporary techniques were attained, many funeral homes around ANZ rallied together and began teaching their new trainees the principles and practices of modern embalming procedures. As previously suggested, scientific and medical understandings about the spread of diseases came to be embedded within contemporary practices. However, locality appears to also play a role in the construction of embalming narratives, particularly around the purpose of embalming (Wolffram, 2006).

The idea of locality playing a role in the funeral director's/embalmer's development was said to bring to their work a 'deep personal' conviction which went beyond other Western funeral directors/embalmers. In ANZ locality and image are coming to play a distinct role in defining and constructing certain funeral practices. As a country known for its ‘clean-green' image and environmental attitudes, traditional burial practices are being challenged by a growing environmental awareness.

Traditional Māori tangihanga is said to now have some influence on Pākehāa ${ }^{31}$ approaches to funeral and burial practices. However, with a more multicultural society some funeral directors argue that they are seeing a more Pasifika ${ }^{32}$ flavour in Pākehā funeral (Schwass, 2005). Schwass goes on to argue that: (2005: 7)

Death is part of all our lives... There was a time in New Zealand when only two traditions of death and dying - Māori and Pakeha - were widely observed...In recent years, things have become a lot more complex. Not only are New Zealanders now much more ethnically, culturally and religiously diverse...Today there is a greater awareness of cultural diversity, and more choice about the way we die.

\footnotetext{
${ }^{31}$ The origins of the term 'Pākehā' are as unclear as its meaning. From early records it appears to be a term used to mean 'white person'. A Pākehā was therefore a person who came from England. With time, Pākehā referred to the fair-skinned person who was born in New Zealand. Later the term was applied to all fair-skinned people in New Zealand, no matter what their ancestry or place of birth (Department of Labour, 1985). By 1960, the term had come to mean "a person in New Zealand of predominantly European Ancestry" (Ausubel, 1960). The English-Maori: Maori-English Dictionary (Biggs, 1990) defines Pākehā as "white (person)". Mary-Ellen O’Connor (1990) defines Pākehā as "the dominant white race in New Zealand. This would cover anybody of Anglo-Celtic origin (England, Scotland, Ireland, and Wales) and, as they integrated, Northern Europeans (Scandinavians, Germans, and Dutch), white Americans, Canadians and South Africans".

${ }^{32}$ An all-inclusive term for Pacific Island people living in New Zealand.
} 
Whilst Schwass is accurate in pointing out the growing cultural diversity in contemporary ANZ, this overlooks the important partnership between tangata whenua and Pākehā as outlined and contested through Te Tiriti o Waitangi. ${ }^{33}$ The idea that cultural diversity is alive and thriving overlooks the tensions that exist between Māori and Pākehā ways of being. It is this paradoxical tension that is disregarded by many Pākehā operating funeral homes.

\section{CULTURAL THREAD: CIVILISING MĀORI}

In 2001 I had an interesting conversation concerning the possible body preservation practices of Māori prior to colonisation. Some in the funeral industry argued that the industry had played an important role in the implementation of tangihanga in contemporary ANZ. While talking with a colleague about this it was suggested that Māori did not have preservation practices due in part to their ability to 'tolerate' the stench of the dead body. This suggested that Māori were aligned with 'nature', thus enabling a greater ability to withstand the smell of decomposition. Conversely Pākehā, who utilised practices that could arrest the decomposing process, might well be viewed as having an aversion to decomposition that equated with being civilised and therefore aligned with 'culture'.

Later, when discussing the issue of embalming and preservation practices with an embalming products manufacturer, I was informed that Māori were more than likely to have engaged in some form of 'primitive' preservation practice that may well have had negative and dangerous repercussions for mourners. However, so this narrative went, with the arrival of Pākehā to ANZ and the eventual incorporation of contemporary embalming methods Māori were able to practice tangihanga in a more sanitised manner, which in turn gave Māori more time to spend with their dead. Contemporary chemical embalming methods are therefore said to not only enable Māori to preserve traditional tangihanga, but with the incorporation of culturally

\footnotetext{
${ }^{33}$ Te Tiriti of Waitangi was signed in 1840 between the British Crown and approximately 540 Māori rangatira (chiefs). In essence, the English version of the Treaty sought to legitimise Britain's presence in New Zealand. Conversely, the Māori text simply acknowledged the need for British governance of the people in ANZ, recognising and guaranteeing tino rangatiratanga (self determination or sovereignty) for the Māori people. The clear inconsistencies between the two texts and the subsequent dishonouring of the Treaty have resulted in an unsettled history.
} 
based policies and practices the funeral industry now plays a pivotal role in the continuance of tangihanga in contemporary times:

Don't know why we adopted the custom of embalming in this country, but I rather suspect that it fitted together with the demands of Maori culture to spend time with the body in the days before the funeral (Logan, 1999). ${ }^{34}$

The colonisation of ANZ brought new cultural ways of being for Māori. In 'partnership' with tangata whenua, through the signing of Te Tiriti of Waitangi, the British colonisers began eroding traditional Māori practices. Māori ways of life, spirituality and death traditions were viewed as 'primitive' and nothing more than the uneducated practice of 'witchcraft' (Williams, 2001: 186). In 1884 J. H. Pope published the first health manual that would have major implications for Māori: he argued that "...Maori funeral rites were dangerous and bad, especially if a person died from an infectious disease" (cited in Williams, 2001: 228), therefore it was deemed necessary to improve the sanitation of Māori communities. Through the implementation of statutes and the development of legal, health and welfare policies deliberately targeting Māori culture, it was hoped that these superstitions and 'savage' customs would be cast off and Māori would assimilate, eventually embracing a more civilised way of living, namely a British way of life.

Prior to the arrival of British colonisers, Māori engaged in a funeral practice known as hahunga (double burial). Hahunga involved placing the dead body either in a shallow grave or submerging it in the sea until the flesh had fallen away from the bones. Once this was achieved the bones were exhumed, scraped and cleaned before being buried (many cultures such as the Chinese and Mexican peoples have practiced some form of double burial). Hahunga continued to be practiced up until Pākehā outlawed the custom through health and sanitation laws. In more rural areas some iwi (tribes), particularly those that shunned Pākehā ways, possibly continued hahunga, some until the late 1940s. It is also possible that the modern custom of unveiling the headstone a year after burial may well have been implemented as a proxy for hahunga, however this remains speculation (pers. comm. 2005). With the banning of hahunga, Māori

\footnotetext{
${ }^{34}$ I interviewed Logan, a celebrant based in Wellington, in 2001 and have utilised some of the interview data in this research.
} 
have made every attempt to hold onto tangihanga, arguing that it is one of the few traditions that retain ancient customary practices.

While in no way wishing to undermine Māori by suggesting that tangihanga has slipped from their grasp, I do want to briefly explore how political and policy changes around notions of hygiene and sanitation have seen tangihanga practices - especially those based on traditional notions of tapu and noa (sacred and profane, respectively) marginalised or eradicated by Western notions of hygiene and sanitation. Before proceeding I want to draw attention to the care needed when investigating the cultural spaces between Māori and Pākehā cultural approaches to burying the dead. In so doing it one must be aware to not take for granted the developing relationship between Māori and Pākehā owned and operated funeral homes. However, there does appear to be a tension that could well be read as part of an ongoing colonisation of Māori customary practices by Pākehā in the funeral industry. Therefore, whilst not being able to fully explore this tension I do believe that it highlights the tenuous relationship between Māori customary practices and Pākehā funeral practices, which in turn shows the contradictory nature of embalming practices.

In the early years of the colonisation of ANZ Māori continued unhindered, at least by the burgeoning funeral industry practices, in their practice of traditional tangihanga. However, later, as the industry gained a greater hold over the bodies of the dead, and possibly saw a chance to expand this hold, Māori came under some criticism by the then New Zealand Federation of Funeral Directors (NZFFD). For example, in an article written by Mr Gerald Dunn (1943), a funeral director from Dargaville, the cultural and spiritual practices of Māori tangihanga are scorned, with Mr Dunn arguing that their primitive practices where not merely laughable but possibly dangerous to Māori themselves (NZFFD, 1935).

Since the arrival of Pākehā, tangihanga has been targeted for various reasons by health and sanitation laws. Tangihanga was viewed as a "...lavish and reckless expenditure..." (Williams, 2001: 228), which saw semi-starvation and physical depreciation of Māori due to post-burial practices. Efforts were made by both Pākehā and Māori health officials, working for the then government, to address some of the more hazardous tangihanga practices. In 1918 tangihanga gatherings were prohibited 
due in part to the influenza epidemic. In the 1930s efforts were made to regulate the practice of lying in state. It was suggested that:

Lying in state was permissible in a meeting house if the lid of the coffin was screwed down; If it wasn't screwed down then a corpse could lie in state in an annex to the meeting house or a temporary shelter at least 20 feet away from the meeting house; There was a definite prohibition if death was caused by a communicable disease; Medical Officers of Health had power to stop a ceremony if an outbreak or epidemic occurred or those gathered were at risk of contracting a disease; Permission had to be given by the Chairman of the Maori Council; A fine not exceeding $£ 10$ could be imposed for breaching any of the bylaws (cited in Williams, 2001: 233).

Whatever form of oppressive policies the government took against Māori and tangihanga practices, tangihanga has been to some degree forced to evolve and adapt to accommodate health and hygiene concerns. As Williams suggests:

The resilience of the tangihanga customs and protocols to survive and flourish in modern society is noteworthy. Yet the resilience appears to owe little to Crown policies, as for many years the abolition of tangi was the assimilationist hope, and was indeed the express policy of some Crown officials (ibid: 235).

Only recently have traditional funeral homes made greater efforts to implement culturally appropriate practices for Māori. However, these implementations appear to be based around a narrative that situates Pākehā funeral directors at the centre of this resurgence. This appears to take onboard the wishes of Māori to perform their customary rituals, yet confines them to a Pākehā reading of hygiene and sanitation (see Chapter Five, subsection 'Rites of Engagement')

With the advent of 'Griefcare' (see Chapter Three, subsection 'The Texts'), an initiative of the FDANZ, tangihanga is seen to be 'reintroduced'. Yet this reintroduction comes with a number of stipulations, one of which is that Māori are still unable to stay with their dead whilst an embalming is being carried out. In particular parts of the country Māori people are opening up their own funeral homes so as to accommodate traditional cultural practices that have to date been sidelined by Pākehā notions of hygiene and sanitation. Take, for example, Murray's mobile mortuary service, which he operated in the Kaitaia ${ }^{35}$ region. Murray had set up this

\footnotetext{
${ }^{35}$ Located $116 \mathrm{~km}$ from the tip of the North Island, Kaitaia is the northernmost town in the North Island of Aotearoa New Zealand.
} 
service after twenty years in the funeral business so as to offer a service that would assist Māori with the transportation of their deceased to hospitals and Marae (meeting places where, among other things, tangihanga are held). This service was intended to address issues of concern for Māori around Māori rituals and customs (Dominion, 1999). As Mike Pehi of AAA Colenso-Pehi Ltd Funeral and Monumental Services in Feilding points out, Pākehā operated funeral homes are often very cold and alienating spaces for Māori. For this reason Pehi offers Māori a variety of services such as acting as poutiriao (intermediary), and he states that whatever he does, he does Mahia-i-roto-i-te-wairua-Māori (working in the Māori spirit). As he points out, Māori have a different perception of death from that of the Pākehā.

Nevertheless, the industry, particularly through the FDANZ, is now promoting a new narrative which emphasises the importance of embalming for Māori. Some in the industry argue that without embalming tangihanga could disappear, as embalming now allows Māori to practice their customary funeral rites with an adherence to legal dictates and without fear of contamination from their dead. This is based on an assumption that Māori had either 'primitive' or no preservation practices. However this assumption is false, as:

Mäori have always had their own skilled people and methods for preparing the tupāpaku, the body of the dead, for the tangihanga, or funeral. There were differences between iwi. Some, for example, used salt water to wash the body daily; others used shark oil (Pehi, 2003).

It is important not to cast doubt on the resilience of Māori to colonisation, especially their concerted efforts to ensure that tangihanga survived appropriation and assimilation. I believe, that the funeral industry in ANZ, whilst appearing to give Māori what they require, continues to some degree to misappropriate aspects of tangi practices for monetary benefits.

In ANZ contemporary funeral industry stakeholders draw on various narratives to validate the use of chemical embalming. Drawing on an historical narrative we are told that embalming is a sacred profession 'as old as man himself' - a profession that has expanded its borders to incorporate various scientific approaches that have helped shore up and protect the general public. The funeral director has also developed, grown, and depending on locality, embodied the necessary criteria for working with 
difference, whether it is cultural or religious. In ANZ funeral directors have taken on the cultural needs of Māori, seemingly playing a role in the continuation of tangihanga. This positioning of Māori cultural practices is problematic as it was the burgeoning funeral industry that helped play a role in the erosion of tangihanga. They now, ironically, take partial credit for its resurgence. This has come to be embedded in the narrative of the funeral industry in ANZ, thereby giving the value of embalming a strategic place within the ever-changing face of contemporary funeral practices. Whilst it is difficult to discern where this narrative begins and ends, unpacking it is necessary to continue to bring transparency to an extremely contained and closed industry.

What can be deduced from this discussion is the need for the industry to have a history that situates it within the overarching space of the disposal of the dead. The industry places itself at the heart of all practices surrounding the disposal of the dead: without it mourners would be at a loss to handle disposing of their dead in a hygienic and safe manner. However, the reliance on this particular narrative is placing embalming and funeral practices within an efficient, rationalist approach to burying the dead. Therefore, the funeral industry deem it necessary that this narrative be fronted by a more decorous and humanistic understanding of burial practices. Here, the bereaved are not confronted by the overriding need to have their loved one cleansed and embalmed; instead they are given a far more palatable narrative which tells of the need to view the dead as part of a process of engaging with the reality of death, thereby allowing for healthy grief closure.

\section{REAL CLOSURE}

Embalming, the funeral industry argues, is merely giving the public 'what they want'. According to one embalmer, embalming removes the physical effects of terminal illness from the body whilst keeping it contained so that it does not carry contagions harmful to the living. What the bereaved want is a 'familiar' body (see Photograph 4.2 below). What the bereaved want is a simulacrum, a body erased of its signification of death, and a body whose empty, piercing, sightless eyes do not reflect back our inevitable mortality. What the living want is an image that they can recall that will not bring with it the ravages of its death: the helpless, alienating body that 
shows the living a once contained and familiar corporeal body, unlike the body in Photograph 4.3 (below). Viewing must be safe and death must be present, but it must be a peaceful, sleeping death.

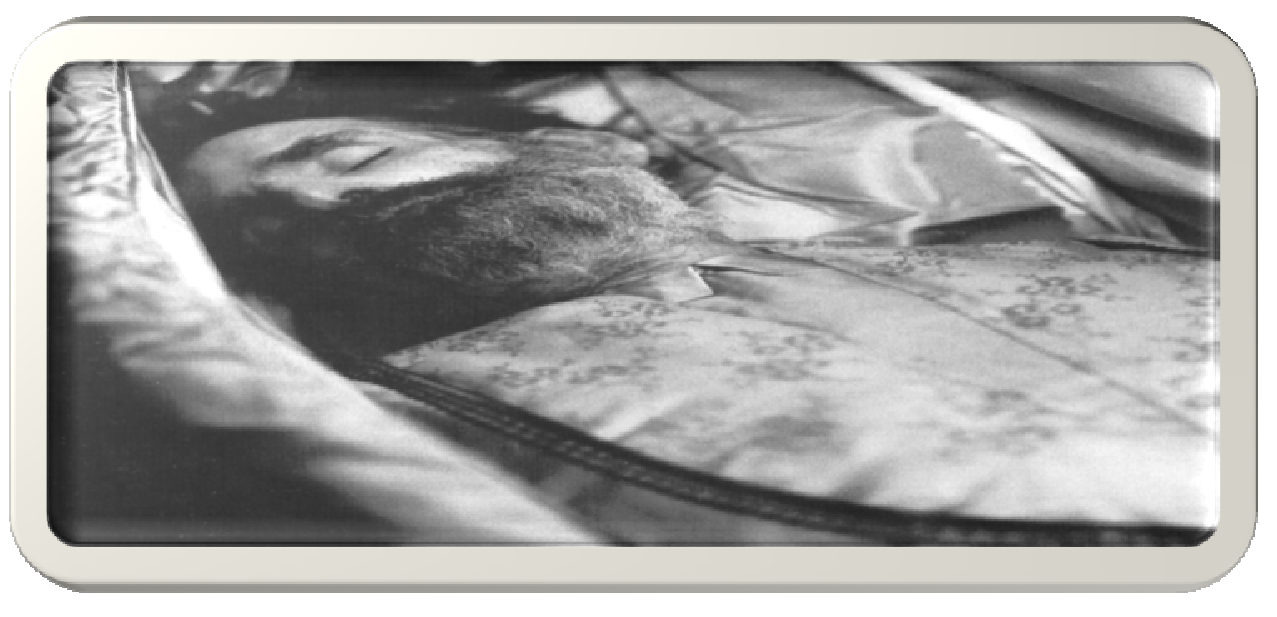

Plate 4.2: Untitled (Kilpatrick-Ayre in Townsend, 1995: 114).

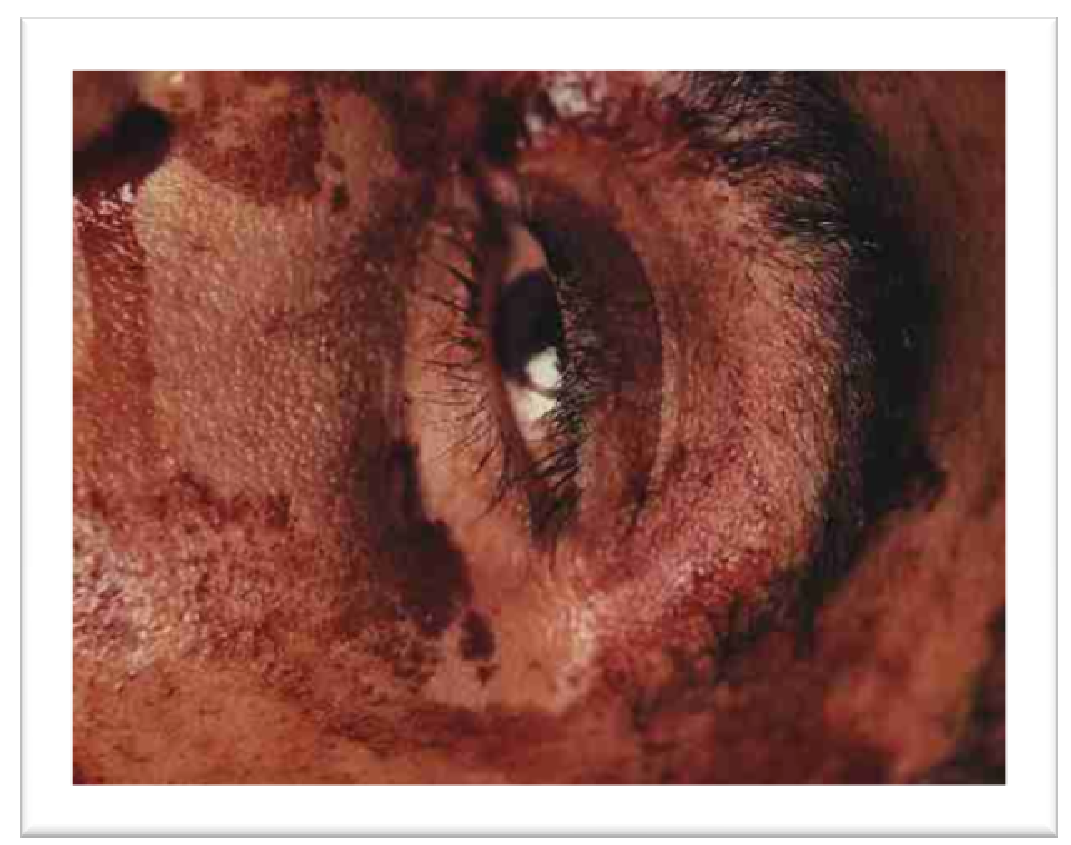

Plate 4.3: The Morgue (Serrano, 1992).

According to the industry, viewing is essential in the grieving process in order to accept and understand death. Any cultural rejection of viewing is regarded by many in the funeral industry as endemic of society's growing 'death-denying' attitude. The Dodge Company points out that:

- Viewing the body of the deceased is helpful to family and friends because: 
- Viewing helps the bereaved to test the reality that this death has indeed occurred;

- Viewing provides comfort;

- Viewing provides a means of social support (Sawyer, 1993: 8).

Viewing the dead body therefore is considered an important element for engaging with death. Seeing is said to be believing. Viewing helps mourners construct a postmortem identity for not only themselves but also for the dead body in relation to the living (Hockey and Draper 2005). At the point of viewing the reality of death is said to bring truth:

It is as if the formal knowledge acquired through verbal or visual evidence makes the event real and therefore undeniable. Privately we may suspect the 'truth', but only when it is confirmed socially are we no longer able to deny it. This is reflected in the concealment of the sight of death. Despite all the aural information, those who had not actually seen the corpse had not faced death - and everyone involved could act as if the death had not happened (cited in Hockey and Draper, 2005: 53).

The body thus plays a major role in defining what must be death and what must be looked on as death. To view or not to view is seen then as an important question in continuing connections post-death as well as understanding one's place after death.

The issue of whether to view or not to view is explored in Six Feet Under, Season Two - Episode 19: 'In Place of Anger' (2005). Matthew Collins has died after falling to his death from a luxury yacht. His body is severely mangled by the yacht's propeller. The extent of the damage means that Collins' body is beyond restoration and for this reason Collins' widow is discouraged from viewing it. David and Nate Fisher point out that viewing may well be detrimental for the grieving and recovery process. Nevertheless, Mrs Collins insists that she wants to view her husband's body so that she can 'understand'. She implores them to help her achieve this. In reply to her plea Nate quotes from C. S. Lewis', A Grief Observed (1961): 'No one ever told me grief felt so like fear'. In spite of Nate's attempts to temper Collins' need, she arrives at the funeral home early on the day of the funeral. Yet again she pleads with Nate to allow her to view her husband's body. Finally Nate yields to her requests and allows her a viewing. As she gazes upon his mangled remains she begins to laugh, and leaning closer to the coffin she spits out the following: "Look at you, you fucking pig. I'm glad you're dead. I'm fucking glad and I hope it hurt like hell'". She turns to 
Nate and asks: “...he can't hit me anymore [pause] can he?” Nate replies with a quiet "No". Mrs Collins turns to Nate, thanks him and leaves - not to return for the funeral. Her yearning to view the battered and disfigured body of her husband falls slightly outside the funeral industry's discourse around the benefits of viewing and grieving. Collins' widow needed to 'gaze' upon the body so as to ensure that death had in fact occurred. She was not there to come to terms with 'death' per se, but to know that he (her abuser) was dead, which in turn confirmed that he was no longer capable of doing her harm.

Viewing is understood by the funeral industry to help the living understand the physical reality of a death. By looking upon the corpse the living are said to understand that the person lying before them is 'dead'. Whilst this death is the death of another it brings home that that this death will eventually be their own demise. It is for this reason that coming to terms with death via a viewing is encouraged. However, the severity by which the corpse died is tempered for the viewing. In the case of Mrs Collins in Six Feet Under (see above), the request to see the body of her dead husband raised the issue of 'mental anguish' due to the condition of the body post-embalming. There was a possibility that the widow could undertake litigation if she felt traumatised by viewing. Therefore, while viewing is understood to be imperative to the grief process, this, especially in the USA is weight against possible litigation if the viewing is understood to have a potentially negative outcome for the living (Renteln, 2001).in fact this is later explored in the next episode of Six Feet Under, when Mrs Collins attempts to take a litigation against Fishers Funeral Home. Issues around who has control of the deceased body and the funeral arrangements are protected under both North American federal and state legislation. The fear of creating mental anguish fro grievers exists for each and every funeral director in ANZ but not for the same reasons, the living in ANZ cannot sue the industry if they feel that a viewing has caused mental anguish.

The situation that the characters find themselves in, in Six Feet Under, is a reminder that the industry is to some degree attempting to address the multiple reasons for the living to view their dead. The following narrative exemplifies the industries narratives for viewing the dead. It shows how the living need to understand that their loved one is dead: 
Mrs. A left her husband at home when she went to work on Tuesday morning. In the early afternoon, Mr. A suffered a heart attack and died immediately. Mrs. A made all the necessary preparations at the funeral home for a complete funeral and visitation. During the evening of the first day and throughout the next day, Mrs. A said that she could not believe that he was dead, and was concerned that even in the casket her husband might be alive. She also concerned herself that Mr. A would be alive while in the grave, allowing her conflicts to center on the fear of leaving him alive in the cemetery. At the visitation Mrs. A saw that her husband was dead and went so far as to touch his lifeless body.

After the visitation, at home again, she said that she was relieved to see him and to touch him... "I now will not worry about him being alive in the grave because I know that the body I saw and touched is very different from the live and warm body I knew" (Steele, 1993: 27).

Whilst this scenario may not be exactly the scenario set out by the industry, the need to connect, see that the dead are dead is diverse and very personal for some mourners.

The public, according to those in the industry, want to look upon their dead to remember one last time a loved family member and friend. It is the 'reality test' which means the living have both a visual and tactile engagement with the dead, which in turn allows mourners to connect with what death means:

We know that being dead is different than being alive, and we know that the person whom we loved is truly dead, not simply gone away (Steele, 1993: 27).

In an informal conversation with a close friend we discussed the importance of viewing the dead body prior to burial. I pointed out many of the discussions that I had with funeral directors and manufacturers emphasised how important viewing the dead was. At some point I remember that my friend went very quiet. I sat and waited as my friend began recounting the emotional experience of looking on the body of a brother who had died, aged in his thirties, from cancer. The effect, my friend said, was devastating, and my friend left the funeral convinced that they had buried the brother alive. For months my friend experienced nightmares about the funeral. I asked what in particular was disturbing:

The fact that he looked so 'perfect' - asleep, not dead. I needed there to be something, anything, to show that he was not merely asleep but dead. Not even touching him helped make me really feel this (Anon, pers. comm. 2005). 
According to Steele (1993), it is difficult to place a value on comfort. However, viewing is valuable for providing comfort, reality, and bringing to the living social support. Whilst the above narratives embody aspects of this comfort, there is a sense that each falls short of the overarching sense of comfort argued to be good for mourners. Whilst the funeral directors cannot ensure a positive effect from viewing the dead body, they continue to state that viewing is important. To support themselves they draw on psychological discourse. This discourse emphasises that viewing the dead body ensures that mourners understand the reality and finality of death:

There is a strong advantage to having the family members see the body of the deceased loved one, whether it be at the funeral home or at the hospital (Worden 1991: 61).

The idea that the continued attachment of the living to the dead is harmful has been questioned - according to Robert Epstein, Christine Kalus, and Mike Berger (2006). Howard Raether and Robert Slater (1974) argue that there is a degree of tension surrounding the viewing of the body of a loved one, and whilst viewing might well be therapeutic it will most probably also be distressing. Viewing can therefore either hinder or help in acknowledging that a person has died and will not return. However, from some of the literature produced by the funeral industry (see NZFDA, NZEA, The Dodge Magazine) on the importance of viewing the dead, 'time' appears to be most important in learning to live with a death. Viewing may well start this process, but for some it may hinder it.

Again, some in the funeral industry would argue that they are only giving the public 'what they want'. Jessica Mitford (1963: 200), however, argues that few mourners clearly know what it is that they want when a death occurs, even if that death was not sudden. Mourners may well know what music should be played at the funeral, or what clothing the deceased should be dressed in, or where the reception could be held. Few mourners, Mitford suggests, ask themselves 'do I want this person, this corpse, this loved one of mine embalmed'? Fewer still ask 'at what cost to the dead body is seeing the dead body'?

As part of Darcy Heath's (2002) thesis he spent nine weeks participating and observing embalmers as they went about their daily work in an Auckland funeral home. Whilst there he noticed the differing attitudes of individual workers toward the 
dead: for example one embalmer he spoke to saw the bodies of the dead as merely decomposing objects that needed nothing more that an industrial process 'stamped' on them. Other embalmers attempted to preserve what they believed to be the internal and external characteristics of the once living person. This was achieved by 'reading' the body of the corpse, of which they believed still held an identity of the once living person. This embeddedness could be found through hairstyle, jewellery, clothing and the fixed facial expression that would be softened post-embalming.

Some embalmers argue that the time spent in the presence of the dead has bestowed upon them a 'natural eye' for what someone looks like without the help of a picture. By simply looking on the body and speaking with relatives or friends an embalmer can gather enough information to present the living with a dead carbon copy of their once-living loved one - a narcoleptic sleeping beauty.

Embalmer ' $A$ ' talked about how some embalmers try to assume identity, looking for signs on the cadaver about how the cadaver once looked and acted. Whilst embalmer 'A' believed that embalmers could never get it 'right', they were still able to read the deceased's body to a significant degree. Yet embalmer 'A' also thought that a lot of what one tried to bring back was based on what one knew or believed that they knew about, for example, how a woman of a particular age should or would probably look:

Making assumptions about people because of the way I've been exposed to people socially in my 'life' ... I reckon this gives you that judgment, like we know what old nanas look like. So when we embalm an older woman who has grandchildren we know what they are like. I don't know, you don't always get it right (pers. comm. 2006).

For this reason it is necessary to present the body in the most natural way possible. For example, The Dodge Company (1998) advises embalmers to be sparing with make-up. It is essential not to over-do making up the face of the corpse, as this may well have a devastating effect whilst viewing. Too much lip colouring, especially on men's lips, can bring a degree of 'garishness' to the corpse, thereby detracting from the entire presentation. As embalmer ' $A$ ' pointed out, every aspect of the funeral process, especially the presentation of the body, is under constant scrutiny by the living (pers. comm. 2006). 
Whether this brings comfort and closure is relative. However, viewing the dead body has become paramount within the funeral industry discourse for embalming the dead. Without viewing, the need for embalming would be redundant; therefore viewing is part and parcel of the narratives underpinning the funeral process. As long as mourners believe that viewing is the only way in which to come to terms with death, and as long as funeral industry workers stress this narrative, viewing will continue to be a taken-for-granted practice within the funeral ritual.

\section{EMBALMING}

Embalming is, according to the industry, essential for the "... honest confrontation of the realities of death...' (Mayer 1996: 7). Before I conclude this chapter I want to briefly chart the embalming procedure. As science and medicine become part of the industries disposal narrative, technology allowed the industry to move from its early and 'explorative' practices to what is understood as a scientific art form.

Once the dead body is taken into the embalming room it is placed on stainless steel or porcelain operating table. The table is often slightly titled and a plughole so that any fluid leakage can be drained from the table. The body is washed with a germicide-insecticide-olfactant. The insides of the nose and the mouth are swabbed with the solution.

If there is rigor mortis the embalmer will may massage the body so as to make the body suppler. Massage cream is worked into the face and hands so as to keep the skin soft and pliable. Facial features are set by putting cotton in the nose whilst eye caps are placed below the eyelids. Cotton or gauze will be placed in the throat to absorb fluids. The mouth is then shut either with wire or sutures; sometimes glue may be used to keep the eyelids and lips closed. If necessary facial hair is either shaved or removed.

The body is now ready for the first stage of embalming known as 'arterial' embalming. An incision is made on the right side of the body near the collarbone. This is where the right common carotid artery and the right internal jugular vein sit next to each other. A small incision is made and an aneurysm hook (the hook looks 
similar to a crochet needle) is used to separate the tissue above the vein and artery. The embalming fluid is then slowly pumped into the artery while blood is drained from the jugular. Approximately $7-8$ liters of a formaldehyde mix are pumped into the body. This mix known as arterial fluid is made up of preservatives, germicides, anticoagulants, dyes, and perfume. With this done the embalmer prepares to begin the second part of the embalming process known as 'cavity' embalming.

Because arterial fluids mainly treat the skin, muscles, and organs themselves it is now necessary to address the cavities within the body. A trocar, which is a long, pointed, metal tube attached to a suction hose is inserted close to the navel. It is used to puncture the stomach, bladder, large intestines, and lungs. Gas and fluids are then suctioned from the internal organs in the abdomen and thoracic cavity. Once this is achieved cavity fluid, which is a much stronger mix of formaldehyde, is injected into the torso. Once this is finished the trocar is removed and a trocar button is screwed into place. It is important to point out that his procedure only happens if the body has not undergone an autopsy.

During an autopsy all the internal organs are removed and inspected once this has taken place the examiner places them back inside the body. Once the body arrives at the funeral home the embalmer removes the internal organs and places them in a plastic bag called a "viscera bag". This is then left to soak in cavity chemical. The inside of the body cavity is suctioned with a special instrument then coated with an embalming gel and/or an embalming powder. The treated organs are then placed back inside the body.

Important is the filling of the anus and vagina with cotton or gauze so as to prevent any seepage. All incisions made in the body are sewn closed or filled with trocar "buttons." The body is washed again and dried. The body is now ready to undergoing a post-embalming make-over. The deceased's nails are manicured, if necessary facial features are molded from wax, hair washed combed and styled, and makeup is used on the face and hands. Finally the body is dressed (relatives may cloth the deceased) and placed in the casket. To achieve the final pose fingers may be are glued together. While each body is different on average an embalming takes between 4 - 6 hours to complete. 


\section{CONCLUSION}

For the funeral industry to maintain their hold over the bodies of the dead, specific narratives have come to be embedded within the ritualised performances for death management and disposal. While I have not been able to address each and every narrative promulgated by the funeral industry, I have attempted to open up those narratives that have come to be entrenched within the contamination discourse. These themes are further explored in the following chapters. Nevertheless, this chapter situates the contemporary funeral industry through its narratives in ANZ. Whilst these narratives appear as 'given' to many inside and outside the industry (it must be remembered that mourners are complicit in reiterating these narratives), there is growing opposition to the stranglehold the industry has over the dead. Organisations such as Natural Burials ${ }^{36}$ in Wellington are challenging the extensive use of embalming by the funeral industry, arguing that: Dead bodies pose no special or particular health risk in the first five days after death provided they are adequately refrigerated and there is no evidence of any significant ante-mortem infection (Natural Burials, 2006).

They also point out that viewing can occur even without fully embalming the body (Blackham, pers. comm. 2003). Alongside people like Mark Blackham, individuals such as alternative service provider Lynda Hannah - owner operator of Living Legacy in Nelson - and embalmer Lloyd Shaw ${ }^{37}$ are also contesting these taken-for-granted narratives by opening up space(s) for alternative narratives to be heard. Such voices are beginning to take a more central place within this field.

In ANZ Māori are also in the process of destabilising the once taken-for-given historical narratives that place a Eurocentric telling of preservation practices. This destabilising of Pākehā dominated funeral practices can be witnessed in tangihanga,

\footnotetext{
${ }^{36}$ Natural Burials (2003-2006) is a not for profit organisation formed in 1999 by a group of New Zealanders wanting to create and operate a natural cemetery. Their fundamental premise is that in death people can make the ultimate gesture to the environment by ensuring their death nourishes the earth through the restoration of land to a more natural state. The principle is part of the wider movement that aims to bring a psychologically healthier social attitude to death. The first Natural Burial cemetery was set up in 2005.

${ }^{37}$ Lloyd Shaw once worked as a traditional embalmer in the funeral industry in Auckland. After years of working with embalming fluid Lloyd left to experiment with alternative methods of preservation. His hope is to manufacture an alternative biodegradable embalming fluid that is not only less hazardous to the living but also to the environment. I made contact with Shaw after reading an article in which he was interviewed by the editor of North and South (2003).
} 
such as the one held at Parihaka for kaumātua (respected elder) Te Ru Koririhoka in 2007. Committed to Tikanga Māori (Māori customs), Te Ru Koririhoka’s whakaaro (wish) was not to be embalmed or placed in a Pākehā coffin. Instead he was covered with kawakawa, ${ }^{38}$ a whāriki (a blanket used to cover the dead body (Williams, 1992)) was wrapped around him and a korowai (cloak) was placed over him as he lay on a waka (canoe - in this case it was a stretcher but because it was carrying someone it was referred to as a waka (Williams, 1992)). Te Ru Koririhoka's tangihanga broke free of what Merewi Broughton (Te Atiawa/Ngati Mutunga) called 'Pākehā norms of tangihanga' and instead called on Māori to take back their tradition - their destiny (Marae, 2007).

The actions of those situated within the 'alternative' funeral industry and those Māori demanding a return to traditional tangihanga are beginning to challenge contemporary funeral practices by highlighting the inconsistencies underpinning the industry's narratives. By limiting all discussions and any challenges to the funeral industry's narratives around the potential hazard that the cadaver is, according to the industry (Strub and Frederick, 1981, Mayer, 1996) said to pose to the living, the funeral industry continues to fortify its borders, simultaneously excluding alternative narratives, thereby constructing traditional practices as natural, given, sacrosanct and sanctioned by the living.

Historical narratives come to be embedded within the fabric of societies. Within many Western societies funeral practices based on the narratives discussed above have come to be understood as natural. For many within the industry stepping away from this proven approach to disposing of the dead would feel like an antithesis to what has come to be understood as progressive and civilised and hence superior. Therefore these 'myths', these narratives, need to be unpacked and made transparent, if only to expose the contradictions and presumptuousness of their double-speak. In the following chapter I continue to explore some of the themes looked at in this chapter. By following the movement of the living and the dead I want to destabilise

\footnotetext{
${ }^{38}$ The kawakawa is a shrub or small tree that grows up to $6 \mathrm{~m}$. It has large, flat dark green to almost yellow-green heart shaped aromatic leaves $5-10 \mathrm{cms}$ in diameter. The brown, jointed branches resemble slender bamboo stalks. Kawakawa is placed between the dead body and the clothes so as to keep the body from decaying for a period of time (Treknature, 2008).
} 
these narratives and show the paradox embedded within the narratives and performances of contemporary funeral practices in ANZ. 


\section{5}

\section{THE}

\section{LIMINAL DEAD:}

\section{SEPARATION \&}

\section{TRANSFORMATION}

It is said that human fear and anxiety of our imminent death underpins many of our death rituals. These rituals were and are still intended to help explain, relieve and assist not only an understanding about death but these rituals also help us manage the bodies of our dead. Whilst knowledge about the causes of death has meant many cultures no longer believe death to be an evil act, there still exists an element of abhorrence towards dead bodies. Integral then to these death rituals are specific prohibitions and taboos. Prohibitions and taboos can be understood by look at the daily undertakings carried out in contemporary funeral homes. This chapter explores the liminal spaces of funeral homes concentrating on the embalming room and the activities conducted in this space. Whilst the funeral home as a whole is understood to be a liminal space because of the activities undertaken within it, there is still a separation of intense liminal space, the embalming room which is situated in the backstage of the funeral home and the less liminal space situated in the front of the funeral home. Each space interconnects with the other to create an intact narrative of death and disposal of the dead. However, for the purposes of this thesis I have separated the front and backstage of the funeral home so as to concentrate on the different ritualised performances that are conducted on the dead body with in them. In so doing it could be argued that I have set up a dichotomy, however, it is a dichotomy that the industry relies on to undertake their specific work.

Ritual, is understood as the movement from one space or being to another and this movement can be considered as a 'rite of way': a recognition of transition from one space to another or from one stage of being to another, which in regards to the funeral 
process can and does affect both the living and the dead (Lewis 1985; van Gennep 1960). For Arnold van Gennep, investigating engagements of transition meant exploring moments of crisis, at theses times the rituals that came into practice often held elements of danger such as in death with the decaying body therefore death rituals would be shrouded in prohibition and taboo. van Gennep argued that there are three-stages that make up ritual, they include separation, transition, and reintroduction:

Through this sequence of activities, rituals effect the person's removal from one social grouping, dramatize the change by holding the person in a suspended "betwixt and between" state for a period of time, and then reincorporate him or her into a new identity and status within another social grouping (Bell 1997: 36).

For van Gennup the funeral ritual demonstrates his three stages. These rituals especially concern the perceived polluting element of death and involve ritualised performances that see the dead body being separated and transformed before being reintroduced into the spaces of the living. It is for this reason that I utilise van Gennep's first two phases of the ritual process to explore the separation and transformation of the dead. To fully understand how these two phases help create the need for a transformation of the post dead body to the pre-burial body I also want to draw on Goffmans notions of 'backstage' and 'frontstage' performances. This weaving together of van Gennep's phases of separation and transition with Goffmans work on back and front staging will help build a picture of the workings of the ritualised process of disposing of the dead.

I begin by briefly considering some of the discussions about human fears and anxieties said to underpin the necessity for modern embalming techniques. From here I trace the movements of the dead body from its initial removal from its place of death through to its transformation prior to its reintroduction into the spaces of the living, in this case the frontstage of a funeral home. By drawing on the industry's texts and interviews and interweaving these with van Gennep's (1960) theories of separation and transformation and Goffman's (1959) theory of back/frontstage performance, I argue that whilst much of the industry's handling of the corpse appears to be part of a narrative about dignity for the dead, these performances are in fact about de-stigmatising the corpse of death, especially the smell of death, which is 
understood as polluting and therefore disrupting of the order of things. Whilst I cannot discuss every possible scenario surrounding the removal of dead bodies I will concentrate on the movement of the dead from the place of death which I have identified earlier as the home.

\section{ANXIETY AND RITUAL}

Everybody is worried about dying...But to die is extremely simple. You breathe out, and you don't breathe in (Rinpoche, 1993, no pagination).

Regrettably, the art of dying for many people, predominantly those living in Western societies, is not the uncomplicated act of merely ceasing to inhale. For the majority of people thinking about the inevitability of their demise often culminates in momentary waves of anxiety and fear. For some these waves may be nothing more than a featherlike touch, stealing its way down through the spine and dispersing once it hits one's bowels. For others it might well take the form of severe spasms that lock up the bowels and briefly stop the heart.

The irony of man's [sic] condition is that the deepest need is to be free of the anxiety of death and annihilation; but it is life itself which awakens it, and so we must shrink from being fully alive (Becker, 1973: 181-182).

These moments of fear or extreme anxiety are known as 'necrophobia' - the fear of either dead things or death itself. Necrophobia is the product, some argue, of a wider crisis of 'being', which is said to be deeply embedded within Western societies (see Chapter Three). This crisis of being, including the fear around death and dying has been equated with the ever increasing secularisation of Western societies (Noy, 2005). However, there has always been some degree of fear and anxiety around the inevitability of one's demise. Take, for example, the ancient Roman poet and philosopher Titus Lucretius' (ca. 99 BC-ca. 55 BC) explorations of human anxieties and fears of death. He argued that the occurrence of one's fear can be pinpointed to a dread of the invasion and collapse of one's corporeality. It is the dead body's decomposing corporeality that human beings are said to fear. It is also the stench that drifts from the putrid corpse to assault the nostrils that reminds the living that this body is not merely sleeping but rotting before our very eyes. According to Epicurus and Hellenistic philosophers, it was what lived beneath the skin that human beings 
feared, for this hidden foe within was what transformed one's once warm flesh into that of a putrid corpse. It is the helplessness, the self-alienation of the changing of the corporeal form as it comes to an end - no longer one's 'self' (Segal, 1990).

German philosopher Martin Heidegger contended that to overcome the trepidation around death one had to understand that "...[a]s man [sic] comes to life, he is at once old enough to die" (1962: 289). This 'being toward death' is said to assist human beings in engaging with life more authentically. Thus an awareness and acceptance of death is a requirement for authentic existence. Whilst Heidegger demands that human beings face their eventual demise with courage, he accepted that this courage retained traces of fear, and suggested that human beings could embrace death through a “...impassioned freedom towards death...a courageous anxiety” (ibid: 310-311).

For French medievalist and historian Philippe Ariés (1981), death has become taboo. This taboo he too attributes to the secularisation of Western culture. Prior to death becoming a taboo, Ariés purports that it was fully embraced, in what he termed a 'tamed death'. Once the dying understood that they were about to die they prepared themselves for death. One would begin by expressing grief over one's approaching death. One would then forgive those attending the dying, in turn receiving absolution, and then one would wait for death to arrive. Death, therefore, was seen as salvation and in turn was a public affair.

As suggested, the 'forbidden death' is said to have eventuated along with the secularisation of Western societies. This, Ariés argues, was due to a more secreted approach to death. Death was removed from the home to the institutional care of the hospital. Death was no longer a ritual, no longer a public performance: death was not only hidden but something of which to be ashamed. This shame was a burden for the dying as it is them who are bringing death into the spaces of the living. However, as medicine began to be understood to prevent death, through their medical dexterity doctors also took on some of this shame.

For Swiss/American scientist, doctor, and educator Elisabeth Kübler Ross (1969), understanding and coming to terms with death involves recognising its many faces. According to Kübler Ross any approach for comprehending and acknowledging one's 
own death or that of another can only be achieved by bringing death into all public spaces. Kübler Ross contends there are 'Five Stages of Grief', which not only assist the dying to speak openly of death, but also allow the living to come to terms with their own eventual demise. These five stages are: Denial - the initial stage that is expressed through statements such as 'This cannot be happening'; Anger - this is the stage when a person asks 'Why me?' or screams 'It's not fair'; Bargaining statements such as 'Just let me stay alive until I see my children graduate' could be uttered in this stage; Depression - this stage might see the dying reject help and make statements such as "I'm so sad, why bother with anything?"; and Acceptance - at this point the dying come to accept the inevitability of death.

The crisis of being that underpins attitudes towards death is played out through various spaces, however the corpse and the handling of the dead epitomises death as it exposes the fragility of the border between self and other (Kristeva, 1982). That which comes to be viewed as 'other' - anything that is defined as nothingness (Segal, 1990) - must not only be removed but its removal must be handled by others. To ensure that there is no return of that which disturbs, in this case death, the handlers must be imbued with particular powers which are embedded within stringently structured rituals. These rituals must appear meaningful so as to facilitate some semblance of understanding and ability to explain the death.

German philosopher and anthropologist Ludwig Feuerbach (1804-1872) took the works of Hegel (1770-1831) to argue that death comes to represent a final surrendering of the self to communality. His work critiqued the creation of Christian doctrine. Feuerbach argued that the driving force behind the construction of heaven was based on the human condition, which was such that it had a need to explain death and alleviate the anxiety with which it is surrounded. For many Christians, death is an enemy:

According to Scripture, death is not really normal or natural even though it is a persistent fact of human history. Why? Because man was created by God to be a unity of body, soul, and spirit and in that state to live forever with God in fellowship with Him. This is the natural, normal state that God planned for man. This is why we have the hope and promise of the resurrection (cf. 2 Cor. 5:1-9). Further, according to Scripture, death is an enemy, the last enemy to be conquered by God, and as such, it is the result of a cause, the result of sin and the fall of the human race. "For he must reign until He has put all His enemies 
under His feet. The last enemy that will be abolished is death" (1 Cor. 15:2526) (Bible.org, 2008).

Hence heaven, to those who believe, not only offers an eternal home, it also softens the brutality of death by giving death a higher purpose.

Similarly, Buddhists offer up an understanding of death that gives purpose to both life and death. Dying is viewed as part of a natural cycle - it just 'is':

All that is born in the world will return to death. While their life spans may be measureless it is necessary that they have an end. The sage, too, must have his waning. What comes together and assembles must break apart and so the healthy years eventually come to an end. The prosperous form is transgressed by disease and life is swallowed up by death. There is nothing (no dharma) that lasts forever (cited in The Wordsworth, 1999, no pagination).

Whilst fear and anxiety are acknowledged to exist in all human beings, Buddhists believe that one can overcome these fears through meditation:

Death is not the end of life, it is merely the end of the body we inhabit in this life, but our spirit will still remain and seek out through the need of attachment, attachment to a new body and new life (ibid: 756).

As I suggested earlier, fear and anxiety surrounding death are centuries old. In each culture and over the centuries, specific rituals have come into being to explain, relieve and handle not only fears around death but also the bodies of the dead. Embedded within many of these rituals around death are prohibitions and taboos. These rituals, prohibitions and taboos materially and symbolically are said to help with the handling and disposal of the dead.

Strub and Frederick (1989) two leading funeral representatives, argue that death has always been a mystery and a burden for the living. They point out that since the dawn of time human beings have tried to alleviate uncertainty surrounding death through various ritualised performances. Early attempts, they argue, where extremely primitive and archaic. As societies began to develop and evolve, the once primitive rituals of burial were dispelled as superstitious and replaced with scientifically based rationalisations. These in turn produced more enlightened attitudes to funeral practices. Whilst these rationales may not, as yet, fully explain the varied uncertainties of death, modern-day rituals are said to help relieve much 
of the fear and anxieties surrounding death by providing at the least an illusion of certainty and finality. It is within this space that the funeral directors/embalmers understand their role, as artists of illusion they argue that they help to relieve some of the fears and anxieties surrounding death and in so doing present death in its true nature. To ensure that this 'illusion' is beyond reproach, those in the industry identify particular preparations that can help to bring about a remembering - a recognition of the past - for those who will look upon the corpse. These preparations include the removal of any visible or olfactory signs of death and decay that may linger in or on the body. For traditional funeral directors and embalmers the corpse is understood to be contagious whether this is through the secretion of post-death fluids and or smells, or hidden bacterial and contagion that might lie within or on the dead body. For the industry, the eradication of pollution, smell, and germs is paramount to a successful viewing.

\section{WHERE THERE IS SMELL THERE IS DIRT}

Mary Douglas (1969) argues against the idea that absolute dirt exists. Dirt, she maintains, exists in the eye of the beholder. Dirt represents disorder and the need to clean dirt or odours away has little to do with cleanliness. Cleanliness represents the need to bring order to society, to our homes, and life itself. In discarding, expelling, creating borders and separating out what is and is not wanted, dirt becomes the 'other' to what is considered a civilised life - meaning that there is no absolute cleanliness. This can be seen in the heightened containment and controlling practices around the acts of birth, death or sex. Cleanliness then is not merely dictated by technological advances but is also tied to shifting attitudes and concepts of ordered-ness. However, one cannot dismiss the role technology plays in changing how landscapes of dirt and cleanliness come to be known (Shove, 2003). Take, for example, daily advertisements aired on television, informing viewers of the importance of cleanliness. These advertisements remind the viewers that unpleasant smells and unsightly dirt lurks in every room in their homes.

Odours are said to assault our sensitive noses whilst 'creepy crawlies' invade the home, shit and piss constantly stain toilets leaving unsightly marks that, according to many advertisements, need more than a bit of a rub. Mould cultivates in showers, and unwelcome odours embed themselves into carpets, lounge suites and 
bedrooms. In addition there is the social isolation that comes about from having smelly feet, bad breath, and unclean clothes. Worse still are the unspeakable issues lurking within one's posterior.

Modern hygiene practices to tackle these 'problems' have developed from the early new sanitation reforms between the 1830s and 1840s in England, the USA, and Australia. Similar sanitary reforms were implemented in ANZ, and like those of our counterparts these reforms focused on water supply, sewage issues and burial practices (Cohen and Johnson, 2005; Bashford, 2000; Prior, 1989; Tomes, 1998). Viewed as a practical approach for dealing with health issues, many of the underlying principles and practices underpinning sanitation became embedded within middle-class ideas of refinement. Sanitation has thus invariably operated from a political discursive space.

The “...pursuit of gentility and politeness, not the fear of disease, fuelled a revolution in cleanliness" (Tomes, 1998: 3). Attitudes surrounding appropriate bodily behaviour, including the purging of body odour, became associated with the civilised and clean middle and upper classes. Daily hygiene was further entrenched into every-day middle-class life. To ensure that sanitation rules were adhered to reformers drew on religious notions that read the body as a temple, thereby encouraging people to treat their bodies with the same extreme cleanliness that one applied to one's home (Bashford, 2000). As the need for cleanliness was extended into the home and eventually scripted onto bodies, being clean became a personal responsibility that ultimately allowed for the distinction between the 'clean' and the many who fell outside this new category. The dead body was not excluded from this onslaught of gentility and cleanliness. The dead body whilst understood to be a decaying corpse became part of an evolving discourse around the need to eradicate germs and therefore make death clean. 


\section{FOUL SMELLING CORPSES}

In the premodern West, odours were thought of as intrinsic 'essences' revelatory of inner truth. Through smell, one interacted with interiors, rather than surfaces, as one did through sight (Classen, Howes and Synott, 1996: 4).

As scientists and doctors began to rely on more visual forms of identifying bacteria and germs, the use of smell as a reliable indicator of illness and disease became less unreliable. Odour became dangerous as it could not be contained. Odour is smell out of control: escaping and crossing borders it becomes an anathema to the growing dependence on rationalism. Such rationalism privileges 'pure thought' over emotion, and while rationalism attempts to control odour through regulation, it is unable to fully contain it. Odour is said to bring about extreme emotional reactions; therefore odour destabilises the borders between emotion and rationalism (Classen et.al., 1996).

Smell came to act as a social indicator denoting certain bodies as different; in turn these bodies were segregated thus enforcing class and ethnic boundaries. For example, men, particularly politicians and businessmen, came to signify cleanliness, which came about thorough their symbolic lack of smell. Until then upper-class bodies had been defined by their excessive smell, particularly through the dousing of their bodies with perfume (Forty, 1986). Racial bodies, women's bodies (especially the bodies of prostitutes), working-class bodies, and ultimately dead bodies took on a more liminal subjectivity. These foreign, undesirable bodies were to be inscribed and contained through greater forms of control and exclusionary practices. However, the most effective form of containment came through the need to (self) discipline the body through the constant reproduction of sanitising practices.

These self-disciplining practices have been extensively explored by Foucault (1977) when investigating how bodies come to act out social principles, standards and moral codes. For Foucault the existence of a truly independent being is non-existent. Human beings are shaped through the various discursive practices, ideas and institutions that come to constitute the social. For Foucault knowledge is of the utmost importance in understanding the, subject being, as it is through knowledge that the subject makes sense of itself. To show how this worked Foucault drew on Jeremy Bentham's notion of the panopticon. The panopticon was a new form of prison surveillance which saw 
prisoners no longer hidden from the prison guard's gaze. Prisoners became exposed to the continuous gaze of authority. However, this surveillance was not embedded solely in a particular authoritative being; instead this form of surveillance was scripted into the very system that managed prisoners. As Foucault pointed out, with the understanding that they could be surveilled at any time the prisoners came to manage and scrutinise themselves, therefore embedding self-discipline and surveillance within the subject. This act of disciplining one's body was not confined to the prison system but became incorporated into other institutions such as schools and hospitals. What is important here is how disciplinary power and surveillance become both visible and invisible. In the case of cleanliness and hygiene issues, filth, which cannot always be seen by the naked eye, had to be managed on a daily basis and the outcome for those who could keep themselves 'clean' was their transformation from uncivilised to civilised beings.

These new understandings and interpretations of smell, however, saw death and the bodies of the dead classified outside this civilising performance. It is for this reason they received the most attention when it came to olfactory vigilance. It was believed that the smell of death circulated in the atmosphere due to the odours emanating from the corpse:

That constant monitoring of the advance of death in the living-being, which spawned a careful analysis of belches, rumblings ...introduced new anxieties. The calculation of degrees of internal decay based on the odor of bodily waste led to the astonishing excremental vigilance (Corbin, 1996: 20).

Through olfactory awareness the living come to understand and internalise the scent of the decaying dead, which comes to represent the loss of the self. The association with smell has of course been constructed around an understanding that whatever smells 'wrong' is out of place and dirty. Death thus comes to be associated with filth, and must be cleansed so as to bring the decaying body back to a place where its simulated subjectivity can be engaged with without fear. For this reason corpses were removed from the spaces of the living to be cleansed of their contagiousness (Bashford, 2000; Classen et.al., 1994; Corbin, 1996; Lupton, 1995; Tomes, 1998) in so doing the spaces that corpses are removed to, became liminal spaces. 
Not all professionals in the industry share these views or relationships to dead bodies however. These professionals, while diverse, fall outside the umbrella of the traditional approach, instead situating themselves in what has come to be understood as the 'green movement'. People such as Lynda Hannah, who is the owner/operator of Living Legacy based in nelson and Mark Blackham to CEO of Natural Burial in Wellington like many of their counterparts, nationally and internationally, are attempting to puncture the taken-for-granted discourse of the traditional funeral industry in ANZ. Their works shifts the dead body from merely a polluting object to a more 'natural' non-polluting body.

\section{COUNTER ARGUMENTS}

Even as recently as last year a literature review by a respected scientist from the London School of Hygiene and Tropical Medicine concluded that "the risk that dead bodies pose for the public is extremely small". (Morgan 2004:307-12)

In Wellington a non-profit organisation known as Natural Burial has taken a decisive stand in challenging the contagion discourse of the funeral industry. Blackham (2003) along with Ian Dickson, Victor Klap, Peter Hehir, Tim McKenzie and David Kerr have argued against the entrenched funeral industry narrative that positions the corpse as a polluting object. Drawing on research undertaken through the Natural Burial Society in the United Kingdom and research undertaken by Natural Burial in ANZ, they argue that the living are more at risk of catching diseases from the living than from the dead. Further to this Natural Burials argues that in times of major disasters such as a tsunami, the spread of diseases via dead bodies is still minimal. When discussing the 2004 Indian Ocean earthquake:

The dead were collected and interred quickly in the mistaken belief that quick interment was necessary to prevent disease. Unfortunately the rapid burials were entirely unnecessary. What happened instead was that relatives could not find their loved ones to grieve over, and the whole world got the impression that the deceased are dangerous to the living. The fact is that in or out of a crisis dead people are not a health risk to the living - they are not an originator of disease. We catch diseases from other living people. This is a critical misunderstanding. Many concluded that decomposition in the heat and dirt was unpleasant to see or smell. It constituted a source of potential disease. This was incorrect. The potential disease sources were actually the survivors... The reality is that they [living] are more dangerous to others when alive than when dead. Upon 
death the body ceases being a warm hospitable host for the bacteria. The 'death' of blood and organs in a body, known as necropsy sterility, results in the death of resident infectious bacteria (for example, Aids and Hepatitis). This can take some hours, so rescue workers are wise to wear protective clothing in the remote chance that someone carried an infectious disease when alive. None-the-less; there is no risk to those who do not touch the infectious person" (Natural Burials, 2006:

http://naturalburials.co.nz/index.php?page=features-tsunami\%20lesson).

Administrators of Natural Burials point out that that:

There is no New Zealand law, bylaw or regulation preventing any of the criteria and practices of natural burials, and there is no requirement that bodies are embalmed (ibid)

They go on to call attention to the fact that dead bodies hold no health risks for the living.

Dead bodies pose no special or particular health risk in the first five days after death provided they are adequately refrigerated and there is no evidence of any significant ante-mortem infection (Delahunt, Dempster and Browett, 2003).

In addition to this information Gill and Penny (1979) argue that “...bacteriologic sterility found in dead bodies for up to 35 days after death..." (ibid).

These controversial statements are challenged by traditional funeral operators from within the ANZ industry. They hold strong to the prevailing discourse which primarily comes from the North American embalming industry. This construction of dead bodies and the spaces within they occur as dangerous and polluting helps the industry hold greater sway over the various rituals and procedures that are seen as necessary when handling the dead (Mitford, 1962). For this reason any counterarguments are rejected by some in the industry as not only potentially dangerous to the health of the living but these counterarguments are understood as having the likely outcome of eroding the sacrosanct funeral rituals particularly those ensuring engagements between the living and the dead. Therefore the industry must walk a tight line between presenting the dead as polluting and dangerous whilst holding firmly to narratives that stress the body's sacredness. To do this the industry has created borders between the back and the front of the funeral home, thereby allowing spaces such as the embalming room to be separate and secluded from the daily activities undertaken in the front of the funeral home. 
To explore the embalming room and the transitional procedures that are undertaken there within this room I will draw on a number of texts produced by the funeral industry, most importantly I will refer to the text produced by Strub and Frederick (1989). This text is understood to be a key text for the traditional embalming and funeral sector in ANZ. The reason for this is that many in the industry defer to the embalming practices developed in North America.

\section{SEPARATION: INITIAL CONTACT}

For the cadaver to be transformed and reintroduced back into the space of the living as a non-polluting object it must be removed - separated from both its place of death and from the living. With its initial removal the body embarks on its journey through a highly controlled and strictly monitored process of separation, transformation and reintroduction. This proscribed and ritualised process is for the most part shrouded within particular readings about death, the dead body and decay. Within these readings the body is juxtaposed as both a potentially polluting and yet sacred object. Vacillating between these two opposing positions the body cannot rest safely in either space until it is transformed and its decaying borders reconstituted. Hence, funeral directors are expected to be exceptionally vigilant when handling the dead. From initial contact funeral directors must act to minimise any unnecessary contact that could in any way offend or interfere with the daily routine of the living. Consequently moving the dead from one space to another must be done with the utmost mindfulness and care.

The ritualised disposal of the dead begins when a medical professional, pronounces a once living person dead. At this point, a funeral director will be contacted by the family and in the case of a death due to a fatal accident the funeral director will be called on by the police to remove the body from the scene. All cadaver transportations must be undertaken as smoothly as possible. How smoothly this can and will be done will depend on where the body is to be picked up. For example, when picking a body up from a family home, family members must be made to feel at ease throughout the whole process. Whilst it is important to make every effort not to further stress the family, the situation in and of itself is extremely stressful. A number of factors must be considered by the funeral director when instigating the removal of the dead. On 
contact the funeral director must assess the state of well-being of the family. Often family members want the removal of their dead to be undertaken as quickly as possible; a sense of wanting to 'get on with' or 'get over' the initial hurdle of death may exist simultaneously with a desire to hold onto the body for as long as possible. Also, entering someone's home to remove their loved one can be interpreted as intrusive:

You're intruding into their environment, you're walking in, you're a stranger, they don't know who you are... you' re taking away someone they love, they've just died. They're [the living] watching everything you do... they're watching everything... and they don't want to let go...its one of those things that hits you 'like far out'...I have to be mindful of what I am doing, I have to be aware of my environment your adrenalin is just going (Embalmer 'A', pers. comm. 2006).

Whilst the funeral director will take every precaution against corpses falling from stretchers, or funeral workers collapsing under the weight of bodies, there is never an absolute guarantee that the pick-up will be the seamless activity on which the industry prides itself: “...in life and death we are human and humans make mistakes” (Wolffram, pers. comm. 2006). In this initial time frame - picking up the body of the deceased - that the backstage - frontstage aspect of funeral directing becomes blurred. Whilst, the funeral director will close doors, thereby creating a barrier between the living and the dead, being in someone's house means that the private work of the director is momentarily made public. However, as Goffman (1959, pp: 288) suggests, backstage work does not always have to be a physical area, a backstage can be constructed "...by the shielding and masking of information in an interpersonal situation...' Consequently moving the body from the home will most often include two funeral workers. Whilst one works with the body the other, often a more experienced director will talk with the family ensuring that they remain in the 'frontstage', the safer area of the house. As part of this separation the funeral director will not overload the family with too many details. Most importantly the funeral director will not discuss any 'unpleasant' details, this includes any discussion around embalming.

Funeral directors are reminded that they must not dilly-dally, whilst they must take their time when securing the body into the body bag so as to prevent any accidents, they must operate between haste and tardiness. Preventing the living from being 
'disturbed' by the dead is crucial. This is not an attempt to deny the death it is merely dealing with the removal so that a space can be created where the death will acknowledged within a designated and socially sanctioned space - a confined, sanitised and controlled environment such as the funeral home.

As I suggested above funeral directors must always be aware of ensuring that a level of care and commitment is adhered to when collecting and handling the dead therefore professional standards must be maintain at all times. This commitment to detail is woven into every aspect of a funeral directors action. Picking bodies up whether it is from a private dwelling or a more public space such as a hospital involves greater scrutiny from non-industry workers. This is especially true when removal is from a home. It is also important to note that each funeral home will have their own specific approach to collecting and transferring bodies. Nevertheless, most funeral directors adhere to the guidelines set out by Strub and Frederick (1989). A removal must never be rushed: removing the body, therefore removing death, must be undertaken efficiently and be accomplished with professionalism, yet with a relaxed manner (Strub and Frederick, 1989). Whilst it may be impractical, the driver is encouraged to drive off in the opposite direction from whence they arrived. Whilst this seems foolish it is more acceptable to drive out of one's way than allow attention to be brought to the fact that death is on the move. Once the body is placed into the hearse the driver then begins the journey back to the funeral home. Momentarily the hearse becomes a holding bay, a space between and betwixt - neither present nor absent - visible yet invisible to the general public. It is vital that the dead body does not linger for longer than is necessary within the domain of the living. This is due in part to the potential psychological stress death has already brought to the family and could in turn bring to those who happen to notice the hearse.

Separation is also understood to allow the family time to begin dealing with the necessary arrangements for the funeral. Whilst, the funeral director is primarily concentrating on the need to embalm the body, he or she will not discuss the procedure with the grievers. For now they are given the space to begin to decide what they wish to see happen at the funeral. With the removal of the body the containment of the dead begins and the living begin to organise a funeral. 
Enclosed in a body bag and momentarily entombed within the hearse the corpse is removed to a more secure space. Aware of the stigma attached to handling dead bodies, funeral directors tend to melt into the background. Even the vehicles that are used must be as inconspicuous as possible: pick-up hearses in ANZ tend to be either grey or white. The rationale behind this is that it helps minimise any public display of the movement of dead bodies, prior to burial in and around communities. Conversely, vehicles that handle 'waste' products such as rubbish trucks or damaged bodies, such as ambulances, prison vehicles are expected to be highly visible to the public, thereby bringing attention to their essential efforts in purging and cleansing. However minimalism is required when handling a pre-embalmed body. Once the body is embalmed the funeral director will do away with being inconspicuous and the hearse which is now a "vehicle of dignity", can be driven directly in and around the streets.

For the funeral director the minimising of publicly proclaiming that a dead body is onboard must wait until the body has been prepared for burial. Prior to this, the body which has momentarily become homeless, is problematic as various readings of its status come into play. Primarily it is the body of a loved one who has recently died; therefore the body of the dead must be treated with respect and dignity. Yet the body is also understood within the funeral industry as a profane object that is potentially hazardous to not only the family but also the general population. Because of this a proliferation of surveillance measures come into play, much of the rules for handling the dead body is entrenched within health regulations.

\section{RITES OF ENGAGEMENT}

Health regulations play a major role in construing the dead body as 'contagious' and prescribing how it must be handled, regulations that are said to be based around notions of 'commonsense'. This was reiterated when in 2006 I spoke with a representative from the Ministry of Health, who sent me a copy of the guidelines set out for handling corpses. When I asked to discuss these guidelines further he suggested that it would be better for me to talk with funeral directors as they not only assist in designing some of the regulations entrenched in the funeral industry, but they implement them in every aspect of their work. The guidelines, he suggested, are commonsense for such work. For example, it is essential that whoever picks up a 
body is fully informed of any hazardous infections or contagions. Identifying potential diseases means that the body must be coffined or bagged for transportation, as opposed to being laid out and covered on a stretcher. In extreme cases the body bag must not be opened but placed directly into the coffin (Occupational Safety and Health Information Series, 2000). Whilst I do not want to deny the possible existence of contagious diseases, one needs to remember that there is an underlying paradigm that brings about a particular reading of death and contagions. Regulations on how the body must be handled as I have suggested begins with the initial pick-up and continue through the post-death / pre-burial process. However, the funeral directors have their own codes of conduct when handling the bodies of the dead.

\section{BACKSTAGE: TRANSFORMATION}

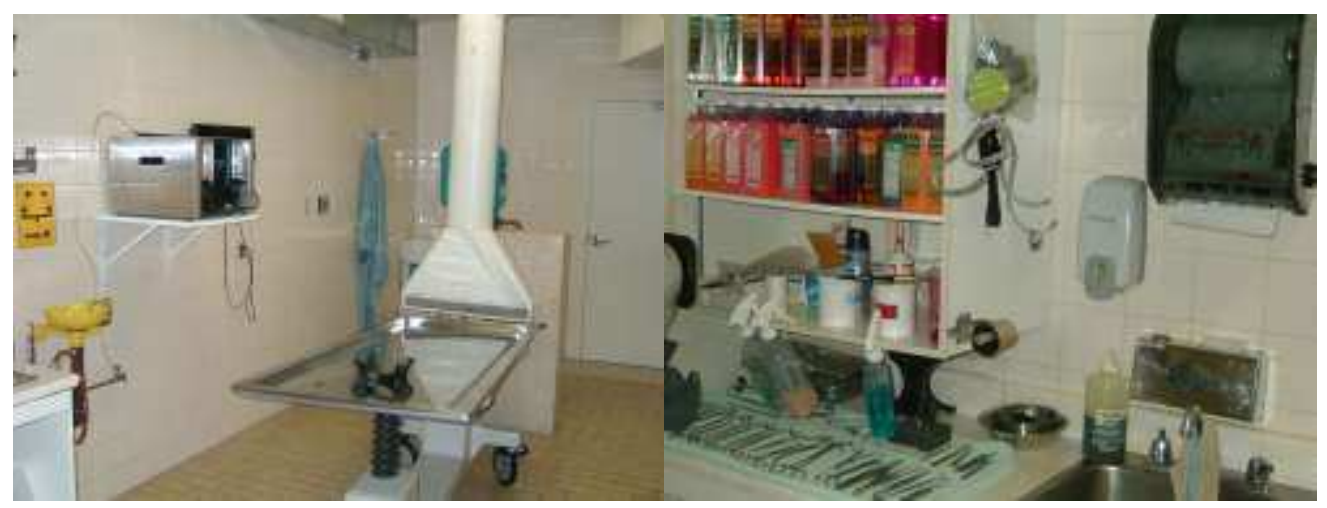

Plate 5.1: A Modern Embalming Room (Neil Bardal Inc, 2008)

I feel apprehensive as I walk into the embalming room - this is it where dead people are preserved, pickled, embalmed - I have to acknowledge a certain morbid fascination overtaking me - I hope that someone has accidentally left a body lying on one of the tables - naked - discarded - waiting. Unfortunately nothing - just a sterile room - a functional sterile room, which smells strangely like - a vet's clinic.

Why a vet's clinic I wonder? Shouldn't it smell more like a hospital? More like say a meat market - more like death.

I am momentarily taken back to the vet's clinic - It's July 1997 and I am putting my dog to 'sleep'. A peculiar smell hangs in the air - an antiseptic smell - yet not just antiseptic - another smell and I think it comes from my dog - does she know she is about to die? Is it a smell of fear - fear of her impending death? 
I turn back to the embalmer and smile - 'strange that it should smell like a vet clinic' I say. The embalmer breathes in. 'I actually can't smell anything - the embalming fluids have destroyed any sense of smell I once had' (Field notes, 16th February, 2006).

Once the body of the dead has arrived at the funeral home it is taken immediately to the rear where it is removed from the hearse and taken to the mortuary. Situating the dead at the back of the funeral home is significant as it highlights the status of the corpse prior to its reintroduction. Restricted to entering the funeral home by the backdoor, the corpse's status becomes comparable to the 19th century etiquette expected from servants and tradesmen who were restricted to entering the homes of the upper and middle classes (see also Barbosa, 2007) by either the backdoor or a servant entrance. This restriction on servants and tradesmen helped create zones that could be kept clean (the front door) or less clean (back entrances). This restriction of movement became inscribed onto the body of the servant - portrayed also as a kind of doorway, a threshold, in that they exist between; ensconced into the daily life of family yet considered an outsider due to their assigned role. They are indispensable yet dangerous (Gallop, 1982). Like the servant, so too the corpse holds an ambiguous and liminal position. It sits between dirt and cleanliness, filth and purity, death and life, and for this reason it is at once needed and prone to exclusion. Once transformed into a less contagious, less contaminating subject, the deceased can be allowed to depart via the front door.

To achieve this transformation the body must be delivered to the mortuary. The mortuary or embalming room is said to be the epicentre of the funeral home, for it is here that the most important work is undertaken - the transformation of the decaying dead body. This transformation is said to bring to the grief-stricken mourners a 'memory picture' (Strub and Frederick, 1989). Memory pictures are able to assist the living in remembering the dead as they 'were' prior to death. In the case of those who died of terminal illness it is said to help wipe away images of the dying persons suffering. Whilst memory pictures are said to comfort the living, approximately 32 per cent of 'consumers' in the USA reported that viewing the dead in fact had a negative effect (Kübler-Ross, 1990). 
Whilst, publicly the industry talks of memory pictures, privately the industry ultimately understands the cadaver as a polluting object. However, because the corpse is someone's loved one they cannot talk in such terms. Therefore, much of the work carried out behind the scenes is filtered through various other discourses.

\section{LIMINAL AND DANGEROUS}

Liminal spaces and the bodies that inhabit these spaces are often marginalised, contained and enmeshed within social and discursive rules and physical containment regulations. These rules and regulations work at both a micro and macro level. At a micro level they help define and monitor the borders of one's own body and one's space, whilst at a macro level they operate to create and monitor the borders and boundaries of nation states. This monitoring and surveying of borders helps construct what and who can inhabit particular spaces, thereby setting up oppositions that over time come to be considered natural - taken for granted. Those considered outside what is considered and performed as natural or normal come to be understood as dangerous. This danger brings with it a strange-ness - therefore some people are considered to be 'strangers' - foreigners who are not allowed to 'fit'. These outsiders are deemed then to have no place. In their homelessness they bring anxiety and fear to those who are legitimately allowed to be present.

The separation of the familiar from the strange is played out through a variety of discourses. Spatial separation through regulatory policies can be brought into play thereby allowing the monitoring of the places and peoples believed to be dangerous. Boundaries may be drawn and borders may be erected in attempts to bring about distance. This distancing defines what is understood as acceptable, in-place and ordered (Bataille, 1988, 1984; Douglas, 1969; Kristeva, 1982). A pertinent example of both micro and macro forms of surveillance can be seen through the policies of the National Socialist Front founded in Germany in the 1930s. The underlying principles and practices of the National Front came to be embedded in narratives of 'otherness' and were perpetrated through and on the bodies of (among others) Jewish men, women and children. Depicted as unclean, blood thirsty baby killers, the Nazi movement unleashed a wealth of propaganda that situated the Jews both spatially and psychologically within the German psyche. The nation state, the father land, was to 
hold within its border only true Germans, Germans who could claim themselves to be 'Aryans'. The Aryan body therefore came to represent the true German.

This true German body was achieved through rigorous forms of discipline and unconditional commitment to the greater cause which was reinforced through heightening anxieties and fears surrounding the body and bodily practices of peoples classified as 'Jewish'. Through the exaggerated use of metaphor, Jews came to be understood as a 'plague', a disease that could not only corrupt but bring about a chaos that would see the ultimate disorder. Jewish bodies came to be depicted as contaminating bodies in need of discipline. The Jewish body came under a disciplinary scrutiny that Sander Gilman (1990) argues saw Jewish people come to frame themselves, thereby desiring invisibility. Racist depictions, which came to be seen as 'commonsense', construed the Jew as vermin, as a plague or disease. It was seen that the Jewish body was eventually capable of invading the purity of the nation state. The body of the Jew was thus like a virus:

Alien viruses seek to pathologize their adversaries. Faced with a threatening outsider the best mode of defence is attack. Again and again the national $\mathrm{We}$ is defined over and against the foreign Them. Borders are policed to keep nationals in and aliens out (Kearney, 2002: $65)$.

Whilst I am not in anyway wanting to compare the suffering experienced by Jewish peoples in Second Word War with the process of exclusion of contemporary dead bodies, I am attempting to show how particular bodies come to be controlled through discourses based on disease. This construction of bodies as unclean and diseased becomes embedded within the human psyche. This othering of bodies classified as unclean, this need to 'other' manifests from a desire to place that which is uncomfortable to the self onto an-other (Kristeva, 1991). What is strange and uncanny, what does not fit, what does not sit comfortably within or around must be excluded.

The result is a denial of the fact that we are strangers to ourselves, a denial which takes the form of negating aliens. To the extent that we exclude the outsider we deceive ourselves into thinking that we have exempted ourselves from estrangement. We fool ourselves into believing that we have purged that singular sense of anxiety which Freud calls the 'uncanny' (das Unheimliche) (Kearney, 2002: 73). 
This 'out-of-placeness', according to Tim Cresswell (1996: 334), is not exclusively part of racist ideological approaches to the 'other'. The notion of being out of place is "...deeply engrained in the way we think". That which is embedded comes to be felt as natural and common. People inscribe this commonsense into and onto their bodies, taking for granted that what they are performing in a belief that this is part of the natural order of things. To ensure that this naturalisation is performed, certain metaphors come into play that allow anything 'outside' to be 'othered' and thus despised. It is here that metaphors of dirt are often applied.

Dirt metaphors, as suggested above, are socially, historically and politically constructed, and whilst the borders may change, defining what is dirt appears to be a constant that can never be fully eradicated. As Kristeva points out, what is being expelled (in this case bodies and spaces defined by dirt metaphors), can never completely be excluded. The dead body is therefore the ultimate example of dirt, for its very presence signifies the loss of identity and the danger that this loss brings "...the ego threatened by the non-ego, society threatened by its outside, life by death" (Kristeva 1982: 71). Thus the dead are removed in an attempt to mask or shore up the borders of the body to prevent death contaminating the living. Death then becomes similar to the body of the Jew, a foreigner unwanted in the ordered, contained spaces of the living. It becomes a plague, a blight on the landscape, and like the Nazi's treatment of the bodies of Jewish people in WWII, had to be segregated and/or eradicated.

The mortuary plays a major role in the segregation and the transformative performance of death. In dealing with the dead, the mortuary itself takes on a paradoxical reading as a sacred space in which the dead are honoured and treated with respect and simultaneously a liminal space that must halt the onslaught of decay. Spaces that are categorised as marginal and pushed to the periphery are places that have been left behind physically and symbolically (Shields, 1991). This is certainly true of mortuaries; as a liminal space they are seldom spoken about outside the funeral home. Deemed mystifying, uncomfortable and disgusting, the procedure undertaken for the reconstruction of the dead is believed to be too sensitive and sacred for the public to fully understand, especially at such an emotionally wrought time as when there is a death in the family. Therefore, embalming procedures are 
rarely, if ever, revealed publicly. Whilst there is a concerted effort to open up the spaces of the mortuary to the public, this is still undertaken, by funeral directors, within the already contained and highly monitored performance associated with funeral work. However, with the growth of the internet, especially the use of YouTube as a site of entertainment, embalming videos are being viewed by the general public. One might argue though, that these videos are more associated with the exhibition of freaks at a macabre carnival. The industry certain finds them distasteful and argues that their inclusion on the internet is a sign of the erosion of respect for and dignity towards the dead.

The most important aspect of this monitoring and containment of both the bodies of the dead and the mortuary itself is the embalming room's location within the funeral home. Here I have chosen to illustrate this through the use of a generic floor plan of a funeral home. This is because funeral homes in ANZ tend to follow the same plan and flow as defined by the American funeral industry. This is due to the need to separate the mortuary and any other space defined as private from the frontstage of the home. Whilst some homes might have the embalming room on a lower floor the embalming room must be separate and difficult for visitors to access and or hear the embalmer at work.

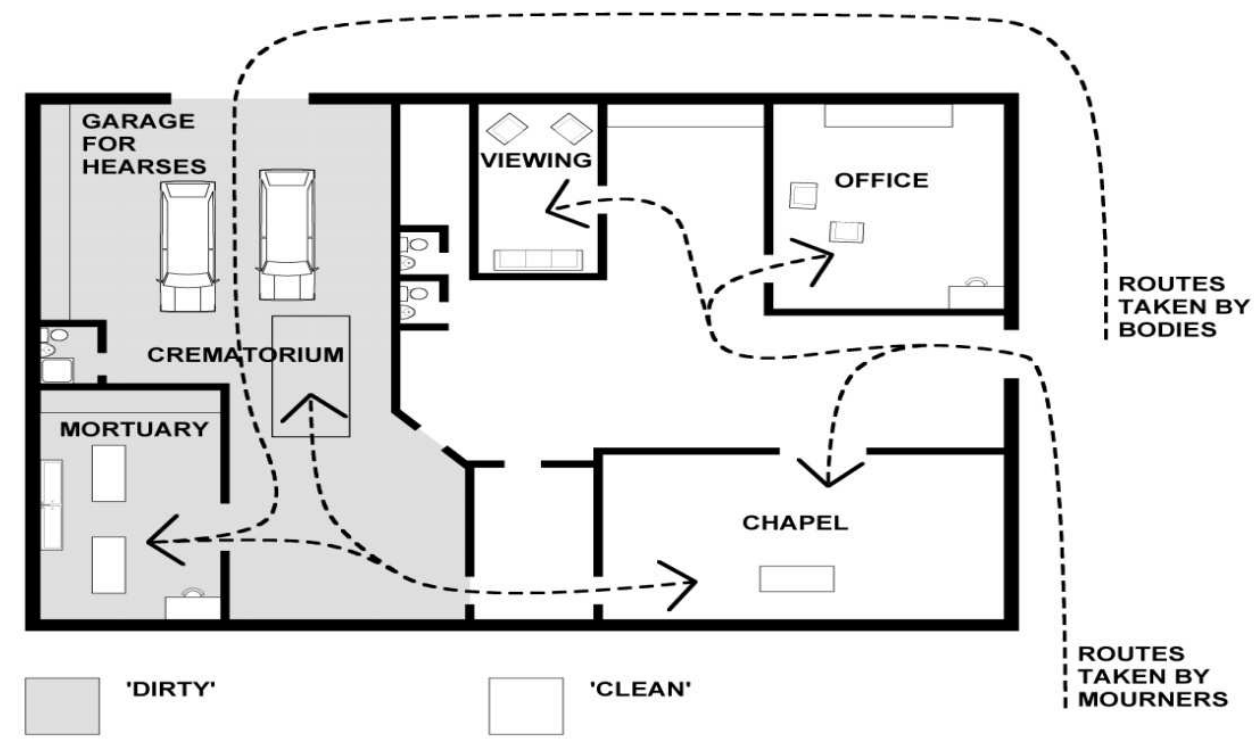

Plate 5.2: The Layout of a Typical New Zealand Funeral Home 
As we can see from the map the routes taken by the mourners are different from that taken by the dead. For sanitary and privacy reasons the mortuary is situated to the rear of the funeral home. In locating the mortuary here it is not only concealed from the general public but its activities are separated from the general running of the home. Important to any reading of the mortuary is the extreme importance placed on it and the activities undertaken within. The mortuary is seen as integral to all other activities in the funeral home.

Nonetheless, the mortuary must not be overtly represented to those outside the industry. For this reason the mortuary holds a paradoxical place, as it is central to the funeral home but must be hidden due to its role within the funeral process. This means that the actual physical space of the mortuary must remain concealed and that the work undertaken within this space be fixed within acceptable narratives of death. Moving the dead body into the funeral home requires that the hearse be driven directly into the internal garage. If this option is not available to the driver, then the hearse must be parked as close to the door as possible. Even once the dead body is securely shut behind closed doors within the home there must be no respite in paying close attention to the careful transportation of the body into the mortuary. Whoever is removing the body from the hearse must continue to treat the dead with the highest reverence whilst conducting themselves with the greatest dignity.

All doors must remain closed while a transferral is being carried out. A number of reasons underpin this: firstly, the public must be prevented from accidentally viewing the body, particularly another family's dead. This preventing an accidental viewing of another family's dead is embedded within narratives surrounding grief and dignity. There is also an understanding that inappropriate contact with ones own dead family member or that of another family can cause emotional anguish (I will discuss this more in chapter Six when I discuss the funeral industries narratives around dignity and grief). Secondly, the family must not view the body until it is deemed viewable. Again, any accidental engagement between the living and the (not prepared) dead body is understood to be unsettling for the living.

To ensure the complete separation of the dead body from the living, a number of narratives are drawn upon. By utilising scientific evidence that reads the dead body as 
a polluting object, and weaving into this discourse notions of stateliness and reverence for the dead, containment becomes manageable through both physical and psychological restraints. For example, doors come to play a necessary function in containing and maintaining separation:

Moving people from one marked place to another, often passing through doors, arches, or gates, appears to be a common way both to signal and to effect a change in social status (Bell, 1997: 36).

Once the dead body is removed from its home, the door by which it has been taken out will be closed and in some cases not opened again during the removal process. This closing finalises the deceased's leaving. Once the deceased has been taken into the garage, the door will be closed to detach their arrival from the outside world - no longer can this body be present in the world without being contained behind doors. Doors therefore represent finality in relation to the dead body. They indicate that this once living being can no longer have free and easy movement in and around the spaces of the living. Whilst death ensures that the body is immoveable, closing the door behind the body as it is taken further away from the family and deeper into the sanctum of the funeral home indicates that is not part of the world - it is on the move away from life.

The living are expected to respect that the closing of doors momentarily restricts their access to their loved one. For a short period of time the body, this once loved being, is 'othered' and must be removed. Once removed, family and friends will have to participate in a ritualised performance that includes waiting for a short period of time before being given permission to attend to their dead. Whilst the separation of the dead is temporary, restricted to a period of time in which the necessary transition of the dead is undertaken, the closed door also indicates an expectation of a return (Throop, 1999).

Closing and locking doors is also an indication that the funeral home has made the dead safe from harm, protected against possible mistreatment and misconduct. However, a closed door can also be a sign that something untoward may be occurring behind the door, demonstrated in this comment from a funeral home worker in Great Britain: 
The sad truth is that the deceased were treated with a lack of respect. This kind of thing happened often - sometimes up to once a fortnight. We were expected to wipe the floors after the bodies had been lying there. Some of us refused to do that so the floor would stay dirty for three or four days at a time. On some occasions there were up to 10 bodies lying on the floor. This would happen during a Bank Holiday or busy weekend when the mortuary was full (BBC News, 2001, no pagination).

Whilst tucked away, (in The United States of America some funeral homes speaking of 'tucking' the dead in - this is a final ritual where family members physically tuck a blanket in and around the dead body before screwing down the coffin lid), in the rear of the funeral home there is a break, a time-out, a breathing space for the living not only from the dead but for a moment from death itself. Whilst, some members of the family will be organising the funeral the dead body will be undergoing its transformation. This containment will ultimately be achieved via embalming (see Chapter Six, pp: 159).

The mortuary is a controlled and confined environment. It elicits fear and interest from those outside the industry. Embalmer A; (2006) Funeral Director 'A', (2002) and Funeral Director 'B', (2006) all spoke about the trepidation one has when publicly stating that they worked in the funeral industry. More often than not people will instantly want to know about the embalming process, particularly interested in any catastrophes that might occur when undertaking an embalming. Yet each pointed out that if a funeral home is to be located in the local community many people will object due to the work carried out behind closed doors.

Both the funeral home workers and the funeral industry restrict access to and information about the mortuary. Whilst, open days allow the general public to view the embalming room, little is spoken about the actual practices and procedures undertaken within this space. When talking with Blackham (pers. comm. 2003) he told me about one situation when he attended an open home. As they stood in the embalming room he began to ask questions about the need for embalming.

The funeral director quickly sidestepped my questions and it was not long before we were rushed out of the embalming room and taken to a 'safer' space within the home. 
Blackham argues that this avoidance is part of the shutting down of any real discussion about embalming and allows the industry to continue to maintain their hold over the dead.

Death is an event similar to other bodily functions, such as shitting and pissing, and is deemed not suitable for public conversation. Death, like shitting and pissing, ruptures the body's borders as it brings what is inside out. In doing so it highlights the vulnerability of the supposedly solid body. Shitting, pissing, ejaculation (both female and male) and vomiting all point to a reality that the impenetrable surface of the body can and does rupture; expelling that which is inside - out (Cresswell, 1997; Longhurst, 2001; Sibley, 1981, 1995, 2001, 2003).

The orifices of the body connect the inside to the outside and the stuff that goes into them or comes out of them is subject to the strictest taboos as such substances transgress the inside/outside ordering of the world. Metaphorical references to such substances invariably imply threats to order (Cresswell, 1997: 341).

The corpse is the ultimate threat to bodily order as it brings about rupture and slippage into what becomes a stinking, decaying mess (Kristeva, 1981). For order to be regained, the dead body, as has been outlined, is removed from its initial deathspace and taken to the funeral home. In situating the corpse within a discourse of filth and as a potential contagion funeral directors and embalmers are able to maintain full control over the dead body. This control is then limited to a particular space - the funeral home or mortuary - where the corpse must be handled. This in turn places the dead body within its rightful place. To do otherwise, to not take it to a funeral home, is to allow it to be out-of-place.

Pollution beliefs can be read as statements about power relations in society. They define, according to the dominant ideology, what is "matter out of place," and this in turn makes it clear who has control of such social definition (Laws, 1990: 3).

Authority over the dead falls to a few: anatomists, doctors, sextons, coroners and funeral directors. Post-death disposal falls solely to funeral directors and embalmers, making the funeral home not only the most appropriate space for handling the dead, but also the only place within which the dead can be handled and because of this the industry keeps a degree of control over its information and its borders. 
Whilst the industry cannot ultimately control who can or cannot open funeral homes in ANZ, they can call on their well established reputation, and membership which is overseen by the New Zealand Embalmers' Association Incorporated and the FDANZ, to affect changes to legislation. In 2002, the NZEA made a submission to the Government for the full registration of all funeral homes and embalmers in ANZ. The submission argued that funeral homes should be limited in what they could offer the general public if there was not a registered embalmer either resident or associated with the funeral home. This move was seen by those advocating alternative funeral and embalming practices as the industries attempt to shore up the funeral industry's hold over the dead. Whilst this attempt to bring about changes to the legislation was unsuccessful the NZEA and the FDANZ continue to be the chief advisers where health and safety issues are concerned.

\section{TRANSITION: THE EMBALMING PROCEDURE}

The development of funeral services emerged through trades such as carpentry and livery work. With the introduction of the mortuary, undertakers acquired new responsibilities, the most important being control over the bodies of the dead. With the development and expansion of preservation techniques (embalming), undertakers started to offer the bereaved specialised funerals (Cleaver, 1996). In the late $19^{\text {th }}$ century whilst embalming was still in its infancy, some Western undertakers recognised its potential and began incorporating it into their growing practice. This saw an expansion of the profession and the growth of various associated industries. The purpose purported by the industry for the inclusion of embalming practices was said to be obvious: it was said to be the only means by which bodies could be preserved for an indefinite time. This was particularly significant as viewing the dead in a type of suspended animation, a state of narcoleptic sleep, allowed mourners an extremely life-like body to mourn over (NZFFD, 1934). For the body to remain lifelike decomposition had to be halted.

Until this time the process of decomposition had signified the final phase of death. Decomposition, which begins approximately four minutes after death, sees the dead body undergo numerous changes. These changes involve the discolouration of the skin (livor mortis), stiffening of the corpse (rigor mortis), and the poisoning of cells 
through the deprivation of air to these cells, which in turn causes them to rupture (Strub and Frederick, 1989; Vass, 2001). It is at this point that the embalmer steps in to preserve the corpse through the scientific art of embalming. Combining both psychological and scientific narratives, stakeholders such as funeral directors, embalmers, and embalming manufacturers construct dead bodies and the spaces they rest in as potentially unclean and contaminating.

In undertaking the removal and reconstruction of the dead body, funeral directors and embalmers see themselves as the guardians of the public's health:

Protection of the public health is at one and the same time the mortician's chief obligation and his most reliable guarantee of privileges ordinarily granted to the most respected professions. In truth the mortician is a man apart from the layman of his community... a person who protects his friends and neighbours against infection and disease (Strub and Frederick, 1989: 3).

Once removed from the hearse into the mortuary, the body is placed on a stainless steel table. This table resembles an operating table, helping situate the practices undertaken in the embalming room within a more medically based discourse. This legitimates the embalmer's professional standing as a scientific 'artist'. Embalming tables must be able to be adjusted and have a non-porous surface, so as to allow for safe and adequate draining of the dead body's fluids (see above, Plate 5.1).

Shifting the body tends to involve two people as the body after death can in some cases be quite weighty and awkward (Embalmer 'A', 2006). Until recently, embalming work was usually restricted to men, due in part to the idea that women were less capable of coping with the physical stress of the job (see Chapter Four for further discussion). However, women are now being employed in larger numbers, due in part to what is considered to be that 'something special' they bring to the industry. The introduction of women into the funeral industry may well have something to do with the technological modernisation of funeral homes. The manual lifting of dead bodies has been eradicated. Pulleys, hoists, moveable tables and trolleys make the transferring of bodies from one place to another far less difficult. Combined with embalming this new equipment has ensured that the corpse has become weightless. Before briefly exploring the importance of weightlessness in deathscapes I want to continue to look at the transitioning process of the dead body. 


\section{TRANSITIONING}

Once the body is placed on the embalming table it undergoes an initial bathing. This initial wash rids the body of any stickiness or sweat. The bathing of bodies has tended to be associated with sacred performances. Christian baptisms or the undertaking of holy or military missions required that the body be ceremonially washed with water. In most cases this ceremonial washing of the body was part of what van Gennep (1960) describes as a tripartite construction of separation, transition and reintroduction. Whilst this ritualised performance had little, if anything, to do with hygiene or cleanliness, the body needed to undergo a cleansing as part of its transitory process. In the case of the contemporary decaying dead, its segregation, stripping naked, and being washed (with a germicide-insecticide-olfactant) is no longer seen as a ceremonial process. Rather, the purpose now is two-fold: firstly, to stop the progress of decomposition, and secondly, to prepare the body for re-entry into the spaces of the living as germ-free as possible.

The body is not 'dirty' in itself; however, it is considered 'dirty' to place it back into the space of the living. In addition, the unattended dead body is matter-out-of-place (Douglas, 1969). Geographically then an un-clean and decaying body would be considered dirt out of place. According to sociologist of health and illness Sophie Laws (1990: 36):

Pollution beliefs can be read as statements about power relations in society. They define, according to the dominant ideology, what is "matter out of place," and this in turn makes it clear who has control of such social definition.

Since the dead no longer have human agency, they no longer have power from within, and become symbolic objects which have grown to be powerful through their absence. Therefore, the performance of the funeral ritual, which positions the deceased as the central protagonist, is underpinned by the management of the funeral director and strengthened through the need for the dead to be gazed upon. Without this performance of engaging and viewing the dead the body, it is said, it would become nothing more than a decomposing carcass. Disposal therefore would be nothing more that an act of tossing corpses away, as opposed to honouring them through a dignified act of departure. 
The cleaning of the corpse includes cleaning both inside and outside of the body. For example, the insides of the nose and mouth are swabbed with the same solution as the surface of the body. This process is done as carefully and as vigilantly as possible, because of the paradox earlier elucidated - the dead body represents the most contagious of objects, yet is simultaneously constituted as a sacred subject. Embalmers therefore are encouraged to remember that the naked body laying in front of them is someone's mother, father, sister, brother, lover, daughter or son someone's loved one (Embalmer 'A', 2006). However, not all embalmers approach the dead body in this manner, instead choosing to engage with the dead whilst embalming them, purely though as an object to be transformed through the rigorous process of scientific embalming (Heath, 2002). Perhaps for some embalmers engaging with the dead within the context of a 'being' brings death and the dead body's murkiness into a more intimate spacing, which may bring with it its own dangers.

This care given to both cleaning and preserving the deceased's characteristics is viewed as a commonsense practice. However, the removal of the dead person's clothing is emblematic of a once daily routine:

To be naked in a social and not erotic context is odd and disjunctive and it has therefore to be presented in terms of a bounded form of intimacy from which the sexual has been consciously excluded (Lawton, 1998: 47).

The embalmer is expected to treat the vulnerable, naked dead body without anything but respect. Even the act of breaking its bones or cutting tendons (when necessary) is an intimate performance that must be achieved with the utmost dignity and decorum. To undress, to bathe, to touch another's naked flesh is transgressive and contravenes the accepted boundaries of social life. The naked, exposed and defenceless corpse is said to be protected not only by ethical codes laid down within the industry, but also by rational notions of dignity, respect and the honouring of the dead. Woven together these rules are said to create a protective barrier around and between the naked dead body and the clothed embalmer.

With this initial procedure complete, the embalmer begins the preservation of the body through arterial embalming, signifying the beginning of the full transformation 
of the body. Whilst injecting embalming fluid into an arterial vein, the deceased's blood is drained from a nearby vein or directly from the heart. The draining of blood is an essential part of the procedure, helping prevent further discolouration of the body. Once all the blood is drained from the body it comes to rest as a monstrous 'other' - it is empty, devoid of life, characterless. However, through the process of embalming the body and cosmetic work (or as is becoming common in some funeral homes the use of lighting to help create the image of the 'sleeping beauty') the dead body can appear for a limited period of time as somewhat human or alive, whereby there appear traces of what once was. Whilst the subjectivity of the body is no longer performed through movement or speech, the skin is awarded a privileged place as the retainer of what once was. Even in its silence the face still maintains the face of someone once known, present but absent.

By extracting blood from the body of the dead, the corpse is placed beyond the borders constructed around the definitions of life - the 'Who am I?' questions that both help and hinder humans in their quest for identity. Bloodless, the body is now an empty vessel devoid of its once life-giving blood. Blood is amongst many of the bodily secretions that bring the body's borders under threat. The extracting and disposal of blood is a significant matter for contemporary funeral practices. For the body to be embalmed and thereby sanitised and no longer contagious, the blood must be pumped from the body. The blood of the deceased now carries the contagions that were supposedly hidden within the body of the dead. The careful disposal of this blood should therefore be paramount as it is now classified as 'dangerous', thereby a by-product, a waste product. Remember the purpose for embalming the dead is said to be carried out to prevent the dead contaminating the living. Therefore, extreme precautions around the contaminating substance, blood, should come into play now that the blood is outside the body. The medical professions, specifically hospitals, see blood as highly contagious and dispose of all blood products through burning. The funeral industry, however, which also reads blood as highly contagious, discards all blood, including blood from ostensibly contagious bodies, down the main sewerage system (Funeral Director 'A', 2002; Funeral Director 'B', 2006; Embalmer 'A', 2006). 
Blood holds a fearful and anxious place within Western societies, one from which the industry clearly draws. The Dodge Company magazine, for example, dedicates much of its works to the need for funeral workers to be aware of the highly contagious state of blood. The industry has utilised fear and anxiety around the extraction of blood in relation to the homosexual body and AIDS. In the 1980s some funeral homes in ANZ enhanced the already growing public fears about blood by refusing to take the bodies of those who had died of AIDS related diseases. Even when this fear was proven to be unsubstantiated some funeral directors continued to refuse to work with 'known' homosexual bodies (Manning, 2002). The manager of Davis Funeral Home in Auckland, Bob Russell, spelt out his business' commitment to working with the bodies of those who had died of HIV related illness, pointing out that they did embalm 'AIDS sufferers', unlike some firms who refused to do so (Matterson, 1993). This fear of the HIV/AIDS body stems from a belief that contagious diseases such as HIV/AIDS are associated with particular behaviours. Therefore the fear had less to do with contagion and more to do with homophobic attitudes surrounding bodies considered unbounded by their sexual behaviour (Tomes, 1998).

This construction of fear may well be at the heart of cultural attitudes and engagements with the handling of blood. For Māori, notions of contagion and disease are bound to spiritual concepts of noa and tapu (equating roughly to notions of profane, in the sense that something is common, and sacred respectively). As discussed previously, the arrival of the Pākehā brought new understandings of hygiene that were imposed on Māori. European colonisation of ANZ not only saw the confiscation of land but also the disregard of indigenous world view(s) (Beatson, 1989; Mead, 1998; Smith, 1999). For the past 180 years Māori and European/ Pākehā have coexisted, each influencing and impacting on the other's culture (Belich, 2001). For Māori, Pākehā customs, traditions, and values have been imposed on them via land wars, land confiscations, religion, and various statutes and laws.

Of particular importance for Māori was the Tohunga Suppression Act of 1907 which saw traditional Māori spirituality dismissed as witchcraft and nonsense and replaced by Pākehā notions of hygiene and sanitation, which came to be understood as 'commonsense'. This has resulted in further acts of degradation of Māori practices, especially when engaging with the dead. Even today with the revival of traditional 
burial practices, Māori are still forced to submit to Pākehā notions of hygiene and sanitation, the result being that for approximately 180 years, many Māori burials have been conducted contrary to proper protocol. Māori blood, which is tapu and must be handled with great respect, has been discarded like waste material into local sewers, thereby disregarding concepts of noa and tapu and denigrating Māori tikanga.

Whilst embalming hazardous bodies is considered by those in the embalming industry as 'commonsensical' (Strub and Frederick, 1989; NZEA, 2006; FDANZ, 2006), certain cultural understandings about contagion and hygiene or particular 'contagious' bodies fall outside their own strict definitions. Whilst the industry would argue this was based around a specific understanding that escapes the layperson, both examples show a political and cultural impetus that prioritises notions of hygiene and cleanliness based upon Western hetero and ethno-normativity. This in turn allows the embalmer to define what contagion is within the spatiality of the funeral home. Blood and death therefore make the corpse a hazardous and infectious object. However, after pumping approximately seven to eight litres of a mixture of formaldehyde, methanol and water into the body, it is then ready to be reintegrated into the spaces of the living until it is buried. If necessary the anus and the vagina will be packed with cotton or gauze so as to prevent seepage. Any incisions or holes are sewn closed, or filled with trocar 'buttons'. The body is again washed and dried. The nails are manicured, any missing facial features are molded from wax and fitted, head hair is styled, and makeup may be used on the face and hands. The body is dressed, which may be undertaken by family or friends in a viewing room off from the embalming room, and then the body is placed into a casket, further contained. The whole procedure can take approximately three hours and like all work that is considered dirty is hidden away from the public space of the funeral home.

This need to consolidate the body's borders and to bring order to the space of the living post-death has various outcomes. According to the funeral industry literature these measures help bring about closure and afford comfort to the living in their time of need, by offering them a life-like memory picture of their loved one. However, I want to argue that this re-ordering of the dead has hidden or at least unmentioned outcomes, one of which is a certain weightlessness from death. By situating the deceased within a discourse of pollution and contamination the body must remain 
separate and divested of its profane state, thereby allowing the living to no longer be dirtied or weighed down by their dead. To help clarify this I want to now turn attention briefly to the notion of weightlessness as explored in Global Women: Nannies, Maids and Sex Workers (Ehrenreich and Hochschild, 2003).

\section{WEIGHTLESSNESS}

Barbara Ehrenreich (2003: 102) posits the notion that those employed to clean up after those who spill allow for these people to negotiate their way through their homes with little or no fear of being dragged down by their own filth:

To be cleaned up after is to achieve a certain magical weightlessness and immateriality. The result is a kind of virtual existence, in which the trail of litter that follows you seems to evaporate all by itself.

There is an absent yet present body constantly in charge of clearing a path so that the family can easily manoeuvre and pass through their landscape dirt-free and unencumbered. By transferring responsibility for filth and dirt to the Philippine maid, American housewives and their families become 'weightless', no longer 'burdened' by their own filth or dirt, no longer 'tied down' to cleaning up after themselves. The materiality of dirt and filth is instead transferred to another visible yet invisible hand that magically cleans. It is the Philippine maid who becomes burdened or weighed down by filth.

Maids, rubbish collectors, and sewage workers are part of the continuous weightlessness of modern societies. The modern toilet was seen as a convenient device intended to make one's ablutions cleaner by distancing these wastes from the body. The need to eliminate, sanitise, transform and exclude dirt not only brings about order, but as suggested allows the living to be weightless, especially in the face of death. Through the ritualised acts of cleaning, containing and minimising the carrying of the dead (through the use of trolleys), a corpse can become a weightless object, with which the living can more easily negotiate. In its weightlessness death appears momentarily easier to engage with - one is not burdened. One's body does not feel weighed down by death. Instead the meaty materiality of the weighted body is placed fully onto the bodies of the funeral director/embalmer, whom, like the Philippine maids, must carry this weightiness. To further highlight this concept of 
weightlessness I draw on Six Feet Under, Season Five - Episode 61: All Alone (HBO, 2005).

It is Nate's funeral and the Fisher family are preparing to bury Nate. Having requested a 'green funeral', which means that his body is neither embalmed nor contained in a traditional casket, Nate is wrapped in a biodegradable body bag. Unlike many dead bodies, which are embalmed and casketed, Nate's dead body appears to be far more weighty and extremely difficult to move around. Plate 5.3 shows Federico, George and Keith carry Nate's body towards a shallow dug grave. They are struggling in their effort to carry him. Sweat pours off George's brow and each of them shows the strain that carrying the body uncontained in a casket places on them.

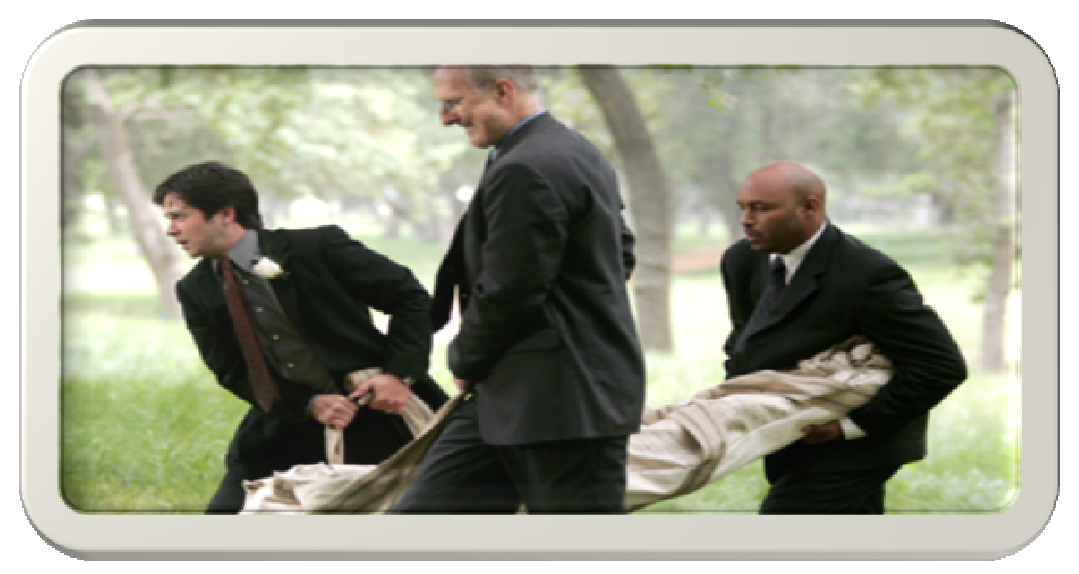

Plate 5.3: Federico, George and Keith are shown carrying Nate's uncasketed body to the grave (HBO, 2005).

At one point Federico, George and Keith drop Nate's body, and Claire, Nate's sister, is forced to step in and help carry the body to the grave. 


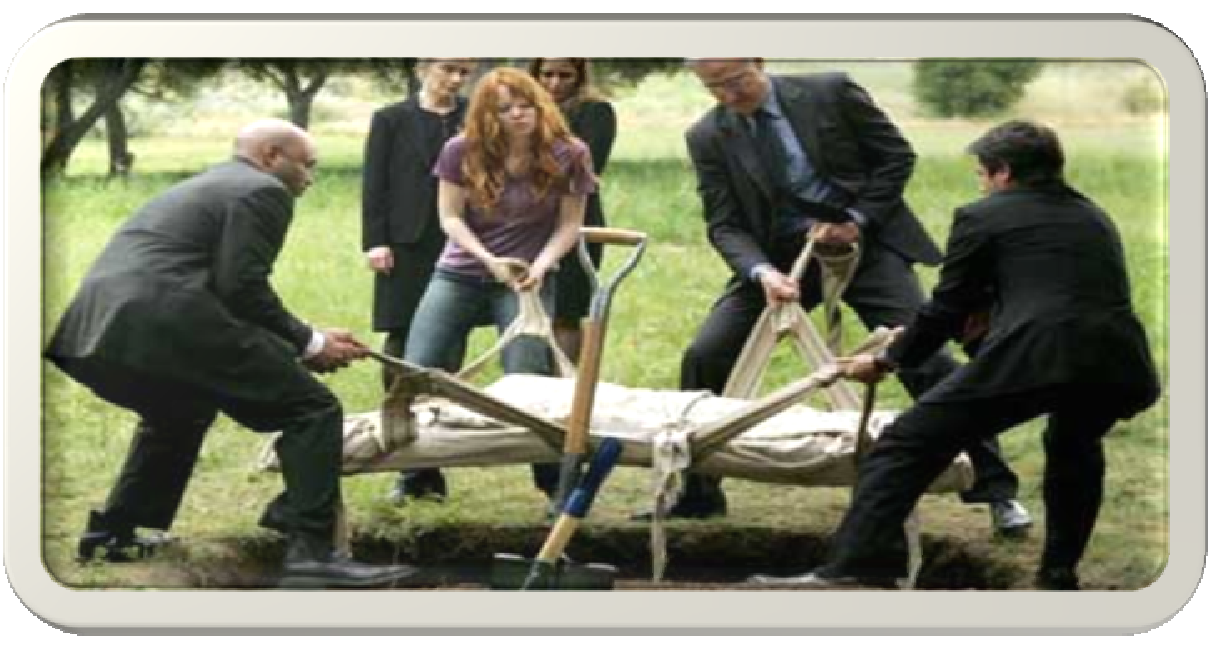

Plate 5.4: Federico, George, Claire and Keith lowering Nate's uncasketed body to the grave - whilst Ruth and Maggie look on (HBO, 2005).

Once there, Ruth and Maggie look on as Federico, George, Claire and Keith proceed to slowly yet awkwardly lower Nate's body into the grave. The suited bodies of the men appear at odds with the stressful carrying and lowing of the body. In fact it is only Claire appears to be dressed 'appropriately' for such a strenuous procedure. The onlookers appear bewildered, perhaps perplexed. From the episode we know that Ruth has reservations about her son's environmental burial.

This scenario can be read in a multiplicity of ways. One reading would be of disgust and horror at the unorthodox 'manhandling' of Nate's body. Without the trappings of traditional funeral props such as trolleys, pre-empted moves by funeral directors and stylised caskets, the funeral appears to come apart at the seams. There is disorder and ineptness in the movement of the bodies of the living, an awkwardness that comes about as the dead body sways. There is messiness and chaos, perhaps even lawlessness, due to the absence of the traditionally fixed and contained body.

In this scenario the visual is spoilt; the 'memory picture' that assists in accepting death vanishes as the body bobs and dips, no longer magically, enchantingly, weightlessly travelling through space. There is no flawless finale to the 'tucking in' of the dead (Wiles-Rosell, 2005). The creators of illusion, “...of pleasant illusions which banish the traces of suffering and death and present the deceased in an attitude of normal, restful sleep" (Strub and Frederick, 1989: 126), are sidelined for the natural, 
for nature in all her ugliness. The dead are seen to be robbed of their dignity, of the respect honoured them; instead they come to be the 'out of control', clumsy, weighty monsters bringing their death back into the spaces of the living, reminding them that they too will one day return possibly unceremoniously to the earth.

\section{CONCLUSION}

In this chapter I began by briefly exploring how human anxiety about death, particularly the visual decomposition of the dead body is understood to be the catalyst for transforming the body from a post-death decomposing corpse into an embalmed body understood to be safe for human engagement. Therefore to understand or attempt to deal with this anxiety it is said that human beings developed rituals for dealing with the dead. Importantly was the need to address the smell that permeated from a corpse. According to Corbin (1996) the smell of decay came to represent the loss of the self. As science came to understand how to temporarily halt the onslaught of decay and mask its smell the once foul smelling corpse could now be re-represented to the living with at least the inescapable stink of death.

As part of the handling of the smell of the dead the dead body also must be removed from the spaces, if only temporary, of the living. This separation and ultimate transformation of the dead body is part of the re-ordering of life and death after a being has died. Separation is total and for the funeral directors to have ultimate authority over the dead they have constructed a ritualised performance based on pollution contamination and dignity for the dead. Whilst counterarguments contest the discourse surrounding the polluting nature of the dead, notions of liminal bodies and space have become so embedded in our understanding of funeral rituals that separating the dead from the living and embalming the corpse has become the norm.

As I have suggested 99.9 per cent of all dead bodies entering funeral homes in ANZ will be embalmed. New Zealanders have embraced embalming with what Lynne Ewart, a funeral director in Karori, Wellington, calls, 'blanket enthusiasm' (Aldridge, 2002: A1). Proclaimed by the funeral industry as the only method by which the body is prevented from spreading contagious diseases, therefore allowing the bereaved 
space to safely engage with their dead, contemporary chemical based embalming has become entrenched within all aspects of the funeral process. Without it many funeral directors argue that there will be a degradation of funerals as they know it (Ninnes, 2005; Strub and Frederick, 1989).

This approach to contemporary funeral practices can only be achieved by containing both the bodies of the dead and the practice of embalming within a liminal space. This controlling of the funeral environment rests on the industry's belief that the disposal process, especially the embalming procedure, is a private matter. The secrecy surrounding the handling of the dead body is enacted through notions of contagion, dignity, respect and honouring the dead. This has to some degree ensured that the funeral industry has a monopoly over the dead body, principally through the construction of sensitive and specialised knowledge about the embalming process. Furthermore, funeral directors have drawn on psychology, which has given them a foothold in monitoring grief reactions (see for example Strub and Frederick, 1989; Weltec, 2006).

Embalming the dead is said to be a sensitive issue, therefore not appropriate for the sensibilities of the living. As a site of pollution the dead body has the potential to engulf the living. This idea is based on the funeral industry's belief that death is a communicable disease. Hence the dead body must undergo an extensively ritualised separation and transformation period. Combined with the supposedly natural fear human beings are said to have about death (Ariès, 1974, 1981; Kubler-Ross, 1974), the cadaver comes to represent all things abject. Therefore, unsupervised encounters with the cadaver are viewed as disturbing and potentially dangerous, not only to the seamless flow of activities being undertaken in the funeral home, but also to the natural separation between life and death. It is for this reason that all funeral work operates within a highly controlled and circumscribed environment. This is particularly true of the embalming room, for it is in this place that the material and non-material worlds are socially and historically constructed, while simultaneously regulated and disciplined. Notions of the profane are negotiated, contained, and eventually transformed. 
Once the dead body has been embalmed attention moves from the dead to maintaining and containing the bodies of the living. In the next chapter I want to explore how containment of death related grief is managed through similar border controls. 


\section{6}

\section{BRINGING HOME THE DEAD}

In the previous chapter I explored the narratives that underpinned the workings of the backstage of the funeral home. The space I largely concentrated on was the embalming room. This space, as I argued in Chapter Five, is the epicentre of the funeral home and tends to be off limits to the general public, unless of course on the now popular open days. As discussed funeral directors give a number of reasons for this space being off limits, however the foremost reason given is because of the sensitive nature of the work undertaken within this room.

Underlying this public explanation is of course the industry's construction of the dead body as a potentially polluting object to the living.

In this chapter I want to move from the backstage of the funeral home into the front of the funeral home. Whilst this movement follows the demarcation between these two spaces as constructed by the funeral home, it is important to remember that this separation does not see the dead and its problems left behind. This separation of the front and back spaces of the funeral home must continue to be monitored. Whilst a major shift has now occurred with the dead body, through its ritualised transformation and securing of its borders, it is now able to rest in the space of the living. Nevertheless precautions to ensure the separation between the living and the dead are safe continue. This means that the surveillance which up until now has rested solely on the body of the dead, shifts onto the actions of the living in and around the funeral home and dead body. This shift is not a letting go of the dead body, nor is it recognition that the dead is now clean and safe, it is merely the acknowledgement of the corpse's continued role at the centre of this new performance. Therefore this securing of the dead body's borders is fragile and contingent and like any constructed performance around cleanliness and filth, it can easily become disrupted if the performance is not adhered to. 
To understand the contemporary approach to the construction of modern funeral homes in ANZ I will begin with a brief discussion of the historical shift from the family parlour to the modern funeral home. This shift has come to be understood as a natural progression as the burgeoning industry began to take greater control of dead bodies. This shift also saw the commercialisation of death. Preparing and handling the dead became a business, however, there is a contradictory element to this business which is reflected in the public and private split embedded in much of the work undertaken at the funeral home. This private public splitting of the business of death must include a clear understanding of what home means to those coming to grieve for their dead. However, this ritualised performance is always close to collapsing in on itself as grief, like death, often threatens to rupture the highly contained and monitored borders constructed by the funeral director. An important means of understanding this is to focus on the living and trace their movement in and around the dead who now rest in the public space of the funeral home.

\section{WELCOME TO THE PARLOUR}

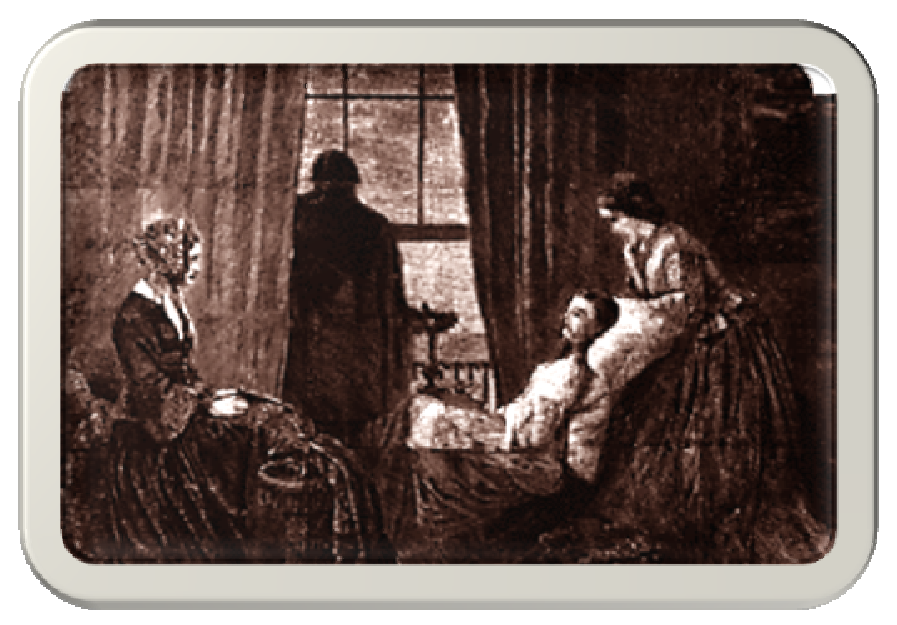

Plate: 6.1: Memento Mori: Death and Photograph in Nineteenth Century America (Meinwald, 2002).

Up until the late 18th century the family home was the pivotal site for the preparation, viewing and disposal of the deceased (see above). It was the role of either a midwife or a female family member to wash and prepare the deceased's body for the wake. Once the body was prepared a wake would then be held in the 
home's front parlour before the deceased was taken away to be buried. Strub and Frederick (1989: 1), funeral service commentators, point out that:

Modern funeral service has its origin in the friendly efforts of relatives and neighbours to aid persons in distress. Through the natural process of evolution these neighbourly efforts eventually developed into a formal vocation.

The above quote by Strub and Frederick (1989) demonstrates the little value placed on the specific role women played in disposing of the dead. At the turn of the 19th century the family home was replaced by the burgeoning funeral service and the funeral parlour. The role of caring for the dead, once women's job, was replaced by the undertaker. This shift of preparing the body of the dead by women, in the deceased's home, to a more business-like undertaking, was due in part to the expansion of capitalism and in turn the entrepreneurship of carpenters. Early death-based traders such as carpenters, livery and sextons were able to expand their work in this entrepreneurial atmosphere. However, nursing and midwifery, which came to be identified as 'women's work' was situated as a voluntary and caring responsibility, which came to be associated with the natural role of women. The rationalisation of funeral work saw much of the post-death preparation of the corpse situated as male work, work that is equated with rationalism and entrepreneurship, thus leaving little room for women to expand into this commercialised environment (Habenstein, 1962).

Carpenters expanded their premises to include a mortuary and a viewing room. This shift from the carpentry craftsman to undertaker is said to have come about because undertakers took on four new responsibilities. Firstly, undertakers became the official caretakers of the deceased. As undertakers, they began to make room for the storage of the physical remains of the deceased. Prior to this only the bodies of those who had been institutionalised were held on the carpenter's premises preceding burial. The second reason for the growth of undertaking can be attributed to the undertakers taking it upon themselves to create a mortuary and a viewing room for viewing the deceased's body. Thirdly, undertakers began to specialise in early forms of preservation (Cleaver 1996). Whilst embalming - or preservation, as it was commonly called - was still in its crude beginnings, many undertakers began practicing some form of preservation. 
This most likely included the use of an alcohol or arsenic based mixture and would have been prepared by the undertaker on their premises (Wolffram, pers. comm. 2006). This saw a shift from either not preserving the dead body or utilising more natural forms of preservation these included freezing; dry cold; dry heat and soil internment (Mayer, 1996: 139). Finally, the undertaker was placed in charge of registering and handling death certificates (Cleaver, 1996; Habenstein, 1962; Habenstein and Lamers, 1962; Laderman, 2003).

The registering of the dead is still not the sole responsibility of funeral directors in many European countries. This job falls to the family of the deceased and cannot be handed over to the funeral director. Funeral homes in ANZ, whilst once having followed the traditional practices of funeral homes in Great Britain, now follow their American counterparts whereby it is the responsibility of the funeral director to obtain a death certificate, even though this can be done by the family if they wish. It appears that most families prefer to let the funeral director deal with this, either for convenience or because few families know that they can obtain a death certificate (Hannah, 2003). With these tasks placed in the hands of the undertaker, guardianship of the dead was permanently removed from the family (Walter, 1992, 1994).

As a result of developing medical understandings about microorganisms and germ theory (see Chapter Five), and the associated burgeoning sanitary practices, the family parlour, once the pivotal site for taking leave of the dead, took on a more negative connotation, losing favour not only amongst architects, but also homeowners. The family home parlour was transformed into what has come to be known as the living room. This was in part due to the negative undertones the parlour held as a mourning space. This shift was further reinforced in the post-war period which saw a move from family homes being places of engagements with the aged and dying to a more child friendly environment (Mowl, Pain and Talbot, 1999). Societies began embracing a more youthful outlook on life, rejecting many of the traditional attitudes around aging, dying and death. The bodies of the old and the dead were removed to spaces that could adequately care for and monitor them, and in regards to the dead prevent the spread of any contagious diseases. 
This rejection of the 'parlour' was carried over into the funeral service.

Undertakers not only transformed their funeral 'parlours' into 'homes' but also replaced the term 'undertaker', which had long been associated with the old parlour, with the new term 'funeral director'. Contemporary funeral directors suggest that the shift in terminology came about because of a change in service delivery. The undertaker's role had been to 'undertake' good service; however, some contemporary funeral directors describe themselves more as 'event' organisers. Their new role is not only to offer service or organise the funeral and provide support for mourners, but they are also at times expected to provide a venue, personalised service sheets, music, sound or video recordings, recommendation of a celebrant or priest, and on some occasions catering (Watkin, 2000: C5).

The early NZFFD argued that severing the old ways meant that modern funeral directors now viewed their role as more than merely a business; funeral work for some became a 'calling' (1939). This new terminology also reflects what the funeral industry identifies as the rise of professionalism. Significant to this professionalism was the practice of embalming. Embalming (see Chapter Five) has played an important role in the rapid expansion of contemporary funeral practices in many Western countries (Habenstein, 1962). Embalming is said to have offered mourners time by expanding the time between death and burial. It has also allowed funeral directors greater opportunity to expand their services and offer far more complex ritualised burial options (FDANZ, 2006). Mitford (1967) argues that this expansion, which has seen a more multifaceted approach to burial, has also seen an increase in costs for mourners.

Whilst the shift from undertaker to funeral director took a little longer to occur in ANZ than in the USA, it eventually came about. By the 1940s 'undertakers' in ANZ came to be known as 'funeral directors' (NZFFD, 1940). However, the swiftness of these changes depended on location. For example, Mr Gerald Dunn, a funeral director from Dargaville, in the Hokianga, argued that it was not possible to make embalming as readily available as it was in the cities (Dunn, 1943). Issues of transportation and availability of the necessary chemicals made this difficult. 
With these changes the funeral industry became what some say is a 'necessary evil' in the disposing of the dead. However, the success of this endeavour rests somewhat on the creation of a place within which the living must feel aesthetically welcome and at ease, yet still allow for a degree of professional expertise and control. For this reason the funeral home must successfully merge its commerce with a certain homeliness that has come to be expected by mourners. In doing so the funeral home becomes quite a paradoxical site, where the private (business) and public (homeliness) aspects of their work must be tempered with the personal needs of mourners utilising the funeral home. However, the business aspect of the funeral home is important as the changes that have occurred since the initial move from the family home to the funeral home has and continues to be business orientated.

\section{BUYING DEATH}

As the appointed caretakers of the dead, funeral directors have been entrusted with the care of the bodies of the deceased between a recent death and the burial. Their role within this period is varied and incorporates transporting and transforming cadavers, selling the necessary funeral items, managing large or small gatherings and creating a comforting environment for the living to engage with their dead. The role then of the funeral director and the funeral home from which he or she is based is both a public and private affair. As a result the general public has taken a backseat in much of the preparation of funerals (Walters, 1994; 1992). By handing over much of the responsibility of funerals to these professionals the living are required to invest for the internment of their dead. The average cost of a funeral in ANZ is approximately $\$ 5000$, however, funeral directors dispute any suggestion that funeral work is a lucrative business.

With a death population of approximately 27,000 per year, the funeral industry in ANZ lays claim to 111 registered funeral homes. Registration of funeral homes is not compulsory, however, the FDANZ encourage registration as protection from possible allegations of malpractice. In addition to these registered homes there are approximately 76 homes which operate independently of the FDANZ (Anon, pers. comm. 2006). Each home varies in size, which is dependent on a variety of factors. 
These factors include the population of the local area - for example some homes in the South Auckland region can organise up to 1000 funerals per year. Other funeral homes choose to remain small, offering a specialised business to their customers. Although each home may vary in size each follow a basic floor plan (see Plate: 6.2.) For smaller homes outsourcing may be utilised so as to cut down on space. Of interest is the attempt by Service Corporation International and Stewart Enterprises Inc. (both funeral companies from the USA) to enter the funeral market in ANZ (Heeringa, 1997). One of the main criticisms of their entrance was the centralisation of its operation. This included having a main embalming and restoration centre at a specific funeral home in ANZ. Cadavers would be brought to this central home, restored, and shipped back to the funeral home to which they had initially been delivered. This practice was viewed as contrary to the process of funeral work and was said to be one of the reasons why funeral directors here would not sell their businesses to these overseas corporations. Funeral directors in this country believed that it was insulting to ship a cadaver out of the original home to be restored in a conveyer 'workshop' environment.

Whilst outsourcing is equated with the grand scale practices proposed by Service Corporation International and Stewart Enterprises Inc., some funeral homes are not equipped to handle embalming for this reason these homes send bodies to larger funeral homes in their immediate region. Size, capacity and operational issues are also influenced by local council laws, which play a role in limiting what a funeral home may offer. Building consent, health and safety regulations and local trade waste bylaws must also be factored into the size and location of a funeral home.

The funeral industry in ANZ oversees a sizeable death market. Consequently, there is a degree of competition within the industry. This competitive nature is tempered by the industries need to be seen as a dignified. Whilst this competitive element is rarely, if ever, publicly spoken about, competition is said to play an extremely important role in what a funeral home offers the general public. One funeral industry commentator suggested that a home's survival is “... really a case of competition and how well a company carries out their functions. Bad work will not attract more people to it" (Wolffram, pers. comm. 2006). 
In ANZ funeral homes are now tending to take an extremely proactive business approach. Wolffram (pers. comm. 2006) describes 'proactive' as being market run as opposed to customer driven. Similar to other Western global funeral homes trends funeral homes in ANZ have tended to offer the general public what they believed were essential service and funeral products (Wolffram, pers. comm. 2006). However, between the late 1970s and early 1980s, changes to how mourners wished to conduct funerals began to have a profound effect on how funerals were being carried out. A movement against an apparent rationalist approach to death has seen mourners begin to challenge traditional approaches to burying their dead. Most importantly mourners began demanding what has become known as 'life-centered' funerals. These funerals not only tell the stories of the deceased's past but emphasise a continuing relationship with the dead whilst allowing mourners to farewell and accept the death of their loved one.

The once staid and disengaged burial rituals of the past have been replaced by quite diverse, sometimes colourful events (Barnes, 1991; Walter, 1992; Wolffram, 2006). These changes have been credited to the appearance of the hospice movement (Jupp and Gittings, 1999) and growing awareness and political activism surrounding homophobia post the AIDS movement (Funeral Director 'A', pers. comm. 2002). Wolffram (pers. comm. 2006) suggests that whilst the AIDS 'epidemic' played a role in much of these changes, it was the still-birth movement that has in fact reshaped the funeral industry and funeral services in ANZ.

This reshaping is has seen the inclusion of celebrants which means funerals are more a celebration of a life lived not merely a mourning of a life lost. One in eight funerals conducted in Melbourne, Australia, are officiated by a celebrant, often in conjunction with family and friends (Walter, 1992). In ANZ the percentage of celebrant officiated funerals is between 40 and 50 percent (Schafer, 2007).The days of obediently listening as a minister preached from the pulpit have gone. As one commentator suggested, the 'post-modern' funeral is the way of the future:

You've seen those modern buildings that mix together arches, and classical columns, and walls of glass. That's post-modernism. It is sometimes done badly - but mixing things is okay - showing contradiction. People have many different sides to them. It is okay to say someone was both wonderful and a pain in the butt. People cannot 
be understood in terms of a single story, or a single set of ideas. It may be quite okay to say she was an atheist and also to sing the twenty-third Psalm (Logan, 1999, no pagination).

Unique to ANZ is the cultural influence that Māori tangihanga has had on Pākehā funerals. As discussed in the previous chapter, tangihanga is the traditional Māori mourning ceremony where:

whanau, hapu and iwi come together under the mantle of whanaungatanga (family relationships) through love, respect and sorrow to grieve unashamedly in the Maori fashion over the loss of loved ones or a loved one. Tangihanga also has a number of stages and procedures that have to be carried out that are important to Maori because it is their personal conviction of tikanga Maori (lore) to this kaupapa passed down from their tupuna (ancestors) (Mata, 1998: 1).

Whilst Pākehā have not fully embraced all that is Māori, some Pākehā have incorporated various aspects of Māori tangihanga into their funeral services. For example, there is far more contact between the body and the living prior to burial, which includes greater touching and kissing of the cadaver. Pākehā have also embraced Māori customs such as allowing mourners to speak 'freely' at the funeral. It is no longer considered derogatory to speak 'honestly' about the dead. However, this could well be a re-embracing of old Celtic ways that were forced out of the funeral scene with the introduction of far stricter Victorian funeral approaches (Stearns, 1994; Walter, 1990).

One could argue that in the 21st century funerals conducted in ANZ are more hybrid, frequently more colourful and far more interactive than funerals held two or three decades ago. As ANZ continues to embrace biculturalism and multiculturalism, funerals will continue to change, particularly as specific cultural groups such as Tagata Pasifika (Pacific Island People) increasingly inject their cultural flavour into modern funerals. Furthermore, one cannot overlook the growing influences on the practice of funerals by those committed to finding more environmentally sustainable ways to conduct funerals (Blackham, 2003; Hannah, 2003). However, Wolffram (pers. comm. 2006) suggests that there are still pockets of resistance in the deathcare business, especially in regards to opening up new market options. Environmentally sustainable funerals are one alternative that certainly challenges the mainstream funeral; one reason being that, as was 
suggested in Chapter Five, alternative funerals bring the materiality of the body back to the funeral process.

This growth in various diverse funeral celebrations also sees an increase in the time and energy needed to arrange and oversee a modern funeral. Along with the opening up of funerals there is now far more funeral accessories offered grievers in turn the role of the funeral director has also expanded. Goffman (1959: 32) suggests any attempt to dramatise what cannot be seen by customers means that overheads are utilised to cover these unseen activities, in the case of the funeral directors role an increase in backstage performance due to the increase demand of more life-centered funerals may well mean that funeral directors can;

Charge a great deal more for their highly visible product - a coffin has been transformed into a casket - because many of the other costs of conducting a funeral are ones that cannot be readily dramatized.

With the modernisation of funeral practices and the commercial adventure associated with owning a home death related accessories has also grown. This has meant new approaches to advertising ones business as has the need to place the funeral home within the public arena. However, this more public inclusion invites a number of dilemmas. Firstly, the balancing acts of being in the public eye so as to promote ones business, whilst maintaining an air of dignity. Secondly, engaging a more open approach about funeral work, while, at the same time, maintaining the necessary containment of certain sensitive activities. This is particularly true when advertising ones business.

\section{MARKETING DEATH}

Funeral homes have predominantly relied on their 'good' family name or community connections to gain customers. Intergenerational loyalty or lack of loyalty has often either guaranteed the survival or demise of particular funeral homes. For this reason there has been little need to publicly advertise one's business with not more that a frontage sign stating the company's name (see Plate $6.2 \mathrm{pp}: 169)$. However, fewer funeral homes are family owned and operated. While there are still small pockets of family owned and operated homes, the industry is 
no longer off-limits to newcomers; anyone with the money and foresight is said to be able to take up their place within the industry (NZEA, 2002; Wolffram, pers. comm. 2006). However, this apparent free-for-all is not entirely supported by such organisations as the FDANZ and NZEA.

Whilst, some in the traditional industry believe there is room to accommodate a range of funeral homes, specialising in, for example, environmentally-friendly funerals, many fear that funeral 'cowboys' may destabilise and tarnish the good name and work the industry have spear-headed. Therefore, to address any potential harm opening up the funeral market could have the governing body attempted to launch an American style governing body through both the FDANZ and NZEA. Any funeral home wishing to come under the industries umbrella must sign up to the 'Rules of the Association' as well as a strict 'Code of Ethics and Code of Conduct'. The FDANZ also maintains the Register of Funeral Directors. The Register contains the name of those considered by the Association to have the criteria necessary for recognition as a funeral director. These criteria include having successfully attained a qualification in funeral directing. These codes, whilst not intended to restrict entry, do however promote and advertise only those homes that adhere to the rules and codes set out by the FDANZ and NZEA. In so doing these homes are understood to be legitimate within a slowly broadening industry.

The industry is divided around some potential operators that are understood to be 'traditional'. In the late 1990s, Service Corporation International and Stewart Enterprises Inc. saw two of the largest North American based 'deathcare' conglomerates make a concerted attempt to buy up as much of the funeral business in ANZ as possible:

The acquisitions have sent a shiver through this country's 200 or so, mostly family-owned, undertaker businesses. "The industry is divided between those who think it can only be good and those who suspect the corporatisation of the industry will lead to a decline in the quality of service," says Masterton funeral director David Dew (Heeringa, 1997: A23).

Service Corporation International and Stewart Enterprises Inc. began to take their particular style of 'death care' world-wide. Their argument for expansion, whilst 
loosely based on a belief of offering professional stability in an ever changing industry, in fact coincides with the need to expand and capture the industry, thereby ensuring some global control of an industry that will take off in 2016. 2016 marks the beginning of a guaranteed death market, namely the demise of the 'baby boomers' (Cottle and Keys, 2004). Combining a heavy sales pitch with a set script, Service Corporation International and Stewart Enterprises Inc. have been accused of putting profits over and above the needs of those they wish to serve (Mitford, 1998). This aggressive approach - coined 'McDonaldization' (Ritzer, 1993) - saw these companies procure small funeral companies, retaining the funeral home's name and some of the funeral directors, and thereby maintaining some connection with the local community. Yet they left "...customers unaware of the change in ownership" (Howarth, 2000: 89).

Stewart Enterprises Inc. and Service Corporation International, however, were eventually forced to withdraw from ANZ. Commentators suggest that their departure came about because New Zealanders and the funeral industry rejected their specific style of business and 'Americanised' funerals. Their approach did not fit well with the type of funerals people in ANZ wanted (Bone, 2003). A funeral director I interviewed in 2002 suggested that New Zealanders want “...'real' funerals, funerals that reflect who we are burying and who we are as a people" (Funeral director 'A', pers. comm. 2002). There was also a fear within the funeral business that the level of service would be lowered:

Dew says some in the industry fear corporatisation may lower standards of service. "In the past, family businesses have tended to measure their success by how well their customers were served," he says (Heeringa, 1997: 23).

Lets be honest, American funerals are perfect, everyone is dressed perfect, the wind doesn't blow and the grass is green and cut just right - everything is perfect (Funeral Director 'A', pers. comm. 2002).

Whilst funeral homes in ANZ do not engage in quite the same level of competitiveness as their North American counterparts, the funeral business here is still a competitive market. Wolffram (pers. comm. 2006) suggests that no-one in the industry can sit idly by and watch as other homes make changes, in the belief that the old ways are secure and safe: 
The industry is a business and it doesn't take long for someone to try something new and for the others to watch, see it work and incorporate it as well. If you don't you go under.

With this increasing competitiveness various challenges face the industry. One particular challenge is advertising. In 2005 whilst having lunch with a friend in downtown Wellington I noticed a small car pull up with an advertisement painted along its side doors. The car was advertising the website for a local funeral home. I pointed this out to my friend who stated that whilst she could understand why some homes would need to advertise she did find it a little insensitive. Advertising funerals should, according to her, be done discretely. Advertising in the telephone directory, she suggested, was the most acceptable form of advertising such a business and whilst she acknowledged that the advertisement was merely for a website, she believed that it opened up the possibility for other types of advertising which might eventually cross a line between decency and vulgarity (Anon, pers. comm. 2005).

In metropolitan cities such as Auckland and Wellington there is a growing tendency to advertise funeral homes. Take, for example, the city of Auckland, which holds nearly a third of the entire population of ANZ; an estimated 1.3 million residents. When the baby boomers begin to die, the total number of funerals required will increase. For this reason alone, advertising may become necessary as funeral homes are forced to compete for an ever changing market. Some argue funeral businesses in ANZ only need to look to the Australian funeral industry to see what may be the future of advertising death. Robert Pattinson is one of the first funeral directors in ANZ to aggressively market his funeral home, in what is seen as a highly sensitive and extremely dignified industry (Matterson, 1993). Bereavement educator Doris Zagdanski from Australia argues that to survive in this very competitive market, funeral homes must be marketed far more aggressively:

Funeral directors, stonemasons, cemetery and crematoria managers have to adopt a new mindset, discarding previously pro-active ways to become far more reactive so as to maintain market shares (cited in Matterson, 1993: 26). 
This thin line between advertising and not advertising is significant as it problematises the neat, contained borders of the industry. Funeral services, one need remember, are founded on notions of respect, dignity and of honouring the dead. Whilst advertising might be able to incorporate these principles, some might argue that the blatant advertising of such a business could be counterproductive to enshrined notions of professionalism and discretion. Take, for example, the Springvale Group of funeral homes in Australia, which has been both applauded and criticised for its advertising. Over the 1992 Christmas period, they ran an advertisement in the local newspaper in an attempt to not only make Australians aware of the risks of drinking and driving - 'Don't turn your break into a wake drive safely this holiday' and 'Don't make it a Christmas mourning' - but also to make Australians aware of its funeral homes (Matterson, 1993: 26). Whilst advertisements warning about the dangers of drinking and driving can be found in newspapers, on the television, or displayed on billboards throughout ANZ, they are generally sponsored by organisations such as the Alcohol Advisory Council of New Zealand (ALAC) and the New Zealand Police. No major anti-drink driving advertisements have yet been posted and/or sponsored by local funeral homes.

The funeral industry in ANZ remains more conservative than its counterparts in Australia and any attempts to utilise similar advertising techniques may still be a fair way off. To date most funeral directors prefer to advertise in what is seen as a more dignified and circumspect manner. Davis funeral home in Auckland, for example, conducts a series of lectures with local school groups about death. In addition to this, Davis funeral home holds open days at their Grange Manor funeral home in Dominion Road, Mt. Eden.

Opening the funeral homes doors to the public is slowly becoming part of the fabric of modern funeral homes in ANZ. Open days are said to allow the public to visit this once secretive and closed industry and allow the living to have some of their questions answered (answering questions from the dead could pose problems). It gives the living a chance to look behind the once closed and closeted spaces of the funeral home:

Visitors will get a look behind the curtains in the chapel, to see the cremator, a furnace operating at temperatures up to $1000 \mathrm{C}$, and the 
button somewhat ironically marked "afterburner". And then, of course, there's the embalming room, one of the biggest mysteries of the funeral process. "There's nothing bad that happens," managing director Simon Manning said yesterday, "but people just don't know about it (the process)."... "The time to have a look is when you don't actually have to face a death," he said. "Funeral homes have never really been opened up ... letting people see what happens demystifies the process and puts them back in control" (Rendle, 2001: A1).

This more 'hands-on' educative approach to understanding the principles and practices behind funeral work is coming under scrutiny by people such as Mark Blackham, who argues that this 'openness' is not what it appears. "Unless one has some prior knowledge about funeral work, and especially embalming, then the open days are merely reiterating what funeral directors already want us to know" (Blackham, pers. comm. 2003). Transparency in the funeral industry is a difficult issue. Whilst the industry draws on the educative nature of such programs as Six Feet Under, others within the industry worry that opening up particular spaces and practices must be carried out with a great deal of thought and consideration about possible negative consequences. This is certainly true of such a sensitive issue as death and the procedures undertaken to prepare the dead.

Even I have experienced the overwhelming consequences of imparting information around the preparation of the dead. Unperturbed by much of the information I was gathering from discussions, texts and interviews, I have at times shared some aspects of the embalming process without considering the affects my stories might be having on those around me. Whilst having knowledge of the funeral process is I believe essential for empowering people about the industry, how much detail is given and how it is communicated is important. Attempting to temper the rational understanding of needing to dispose of our dead with the emotional fact that the corpse that is to be disposed of is a loved member of a community means that any business, personas or organisations operating and or researching funeral practices must be aware of the emotional toll sharing such information might have.

Whatever the outcome, funeral homes are beginning to take on a more business like approach to advertising themselves. Alongside this the general public have 
begun to learn more about the running of the industry through such programmes such as Six Feet Under and information spaces such as YouTube. Along with these spaces and the burgeoning alternative funeral industry, the once firmly closed door of the traditional funeral home is slowly being opened. Whatever the funeral space might look like in the future at present most contemporary homes still place traditional notions of 'home' at the core of theirs services. And even though funerals are recognised as a business home continues to underpin much of their public persona. For this reason I want to discuss how home is understood and publicly displayed by contemporary funeral directors in ANZ.

\section{FUNERAL HOMES}

The nature of domestic space, its meaning at any given time is always open to interpretation (Asquith, 2006: 4).

Notions of 'home' have become embedded within a Western context, wherein a home is seen as more than merely a physical structure (Bowlby, Gregory and McKie, 1997; Giddens, 1984; Mallett, 2004). As Gill Valentine (2001) points out that home is also a space within which social relations are developed and played out. Whilst it is often perceived to be a private and secure refuge, a “...place where inhabitants can escape the disciplinary practices that regulate our bodies in everyday life" (Johnston and Valentine, 1995), this is not necessarily guaranteed, as surveillance of bodies within the home still occurs. Home then may not always be an inviting or safe place, and for some it may well be a place of violence, abuse and disenfranchisement (McDowell, 1999). For many feminist writers home is described as a place of tension, a place where certain bodies must conform. The term home therefore is fraught with complex, contradictory notions of people's relationships (Saunders and Williams, 1988).

When discussing the notion of home Robyn Longhurst (2008: 391) points out that over the past two decades feminist geographers have problematised the dichotomy between public space (exterior and open) and private space (interior and closed).... As a result of this critique the home has increasingly become a legitimate topic of consideration 
The intersections of gender, power, sexuality and home allows geographers to understand home as a space that is both private and public. Deconstructing home has opened up the varying problematic relationships different peoples have about home. For some home is a place of safety, whilst for others home might be a dangerous space, whilst for others home might well be a prison (Meth, 2003; Rose, 1993; Warrington, 2001). Those writing about gay and lesbians understanding of home find many gay and lesbian peoples having felt alienated in and from their family home. Home however, plays an important role in helping to define identity. Blunt and Dowling (2006) argue that:

Home as a place and an imaginary constitutes identities - people's sense of themselves are related to and produced through lived and imaginative experiences of home"

Drawing on Jungian's psychoanalysis, Porteous (1976: 384) argues that the home becomes "....a symbol of the self...[home]...reflects how the individual sees himself, how he wishes to see himself, or how he wishes others to see him". Taking this one step further Porteous suggest that the personalization of one's home helps create a sense of security.

How one understands the boundaries and borders of the home, and how space is located and utilised, “...influences where our domestic routines and rituals may take place...(Asquith, 2006: 6). How rooms are linked to each other, how rooms are set out, made use of, and managed can help understand how power relationships are played out particularly in reference to gender and age. When Rosie Cox and Rekha Narula (2003: 343) explored the experiences of au pairs in the Britain they found that whilst au pairs are given messages that set them as quasi family members rules around where they can or cannot eat or who they can have to visit and where they are allowed these visitors restricts their movements in and around the house as well as their quasi family inclusion into the family.

Relations in au pair employing households are not equal and rules that control space and behaviour within the home are an important way in which power relations are expressed and reinforced. 
Whether home is a theoretical concept or an actual physical space what we know and call home is not only contested but extremely fluid and it is human beings existence that helps create this place we know as home. Within geography much has been written of the private and public place that home is, and much has been written about how home is understood to be a place of the receiving and giving of care. As a space that allows for intimacy and bonding, home is said to be nurturing, familiar, it is a haven, a space where choices, particularly stressful ones do not need to be made (Tuan, 2004). It is this home that the funeral industry attempts to convey to the mourner. Whilst, decisions must be made about the disposal of their loved one, contemporary funeral directors offer grievers the choice to decide about the funeral in their own home or in the director's funeral home. Either space will hopefully offer mourners the intimacy, safety and security needed to undertake the journey associated with burying the dead.

In ANZ the middle-class home came to be constituted as the ideal type of home. Situated on a quarter-acre section, which is now a thing of the past, these standised three bedroom homes were understood to be a lavish - homes set in paradise. These dream homes were established in the early years of European settlement. British immigrants who had been accustomed to living in rows of terrace houses arrived in a country with extensive open space. Hence the quarteracre property became viewed as a suitable size for the New Zealand home and soon became synonymous with the New Zealand dream (Belich, 2001).

Whilst the quarter-acre property and the dream of owning such a space no longer exists for many in ANZ, some in the industry draw on varying aspects of this dream and some 21 st century funeral homes attempt to incorporate aspects of the now middle-class home. The funeral home, which as I suggested early in the chapter, used to once be the funeral parlour, has become the pivotal site for the handling of the bodies of the dead prior to internment. It is here that the funeral director attempts to bring about an engagement that communicates the 'reality of death'. By creating a strong sense of being 'at home' as opposed to being in some stark, sterile and empty space with death, funeral directors have been able to promote their services as an 'unfortunate necessity'. 
In reflecting aspects of middle-class ideas of home, some contemporary funeral homes attempt to either physically or discursively inscribe into their homes particular characteristics associated with middle-class homeliness. These can include giving the internal or external home character through its sturdiness and classical shape/lines. Take, for example, Lychgate Funeral Homes, based in Wellington, (see Plate 6.2) which have been part of the funeral industry since 1876. Located in Karori, Willis and Aro Street, their homes are described as villas or grand colonial residences, thereby giving an air of history as well as elegance and grace, concepts associated with the middle and upper classes.

Our Funeral Homes have been designed and decorated to give a homely atmosphere. Our intention is to create an environment where people feel relaxed, at what can be a stressful time (Lychgate Funeral Homes, 2006: no pagination).

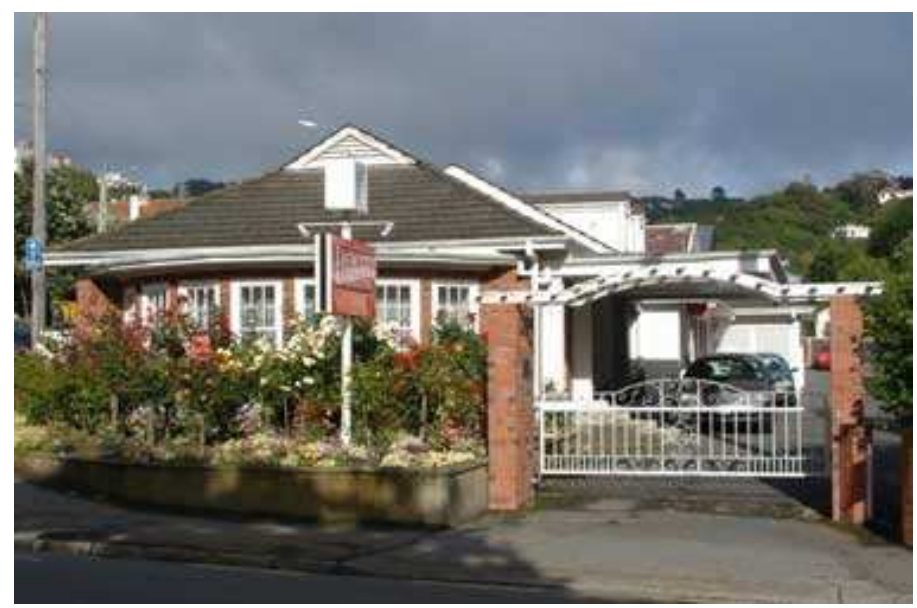

Plate 6.2: Lychgate Funeral Home, Wellington (Lychgate Funeral Home, 2006).

This fixation with character and sturdiness is underpinned in the funeral home by psychological notions of respect and dignity. Funeral homes, like their owners, must present as inviting, tidy and dignified, and both home and funeral workers must embody all the qualities of civility that is necessary to offer a professional service to the customer. By locating funeral homes in middle-class suburban areas, as opposed to more business orientated locations or lower socio-economic areas (the former seen as stark and less private, the latter as less homely and inviting), the funeral home is likened to a particular sense of home, a home where one can be 'at home' with one's grief and most importantly at home with death. 
This reading of home by some funeral home owners draws on the notion that 'home' is a safe, warm and caring environment - a space of solidarity. These homes, with their open fires and comfortable old chairs offer mourners an environment that signals privacy, respectability, discretion, safety and calm. Funeral owners also draw heavily on a quintessential notion of a bygone era, an era of tradition, when home meant stability, refuge and 'family'. This idea of 'family' came to be associated with security and a loving environment. As mentioned previously, Bachelard (1969) described home as the most important place for children to begin to understand the world. David Seamon and Robert Mugerauer (1985) argued that home has come to represent a place of intimacy, a space that people can withdraw to, away from the hustle and bustle of the outside world. These descriptions of home are almost spiritual and perhaps have their origins in biblical stories about prodigal sons who return home to be forgiven for their sins.

While acknowledging the politics of representation associated with the home, it is interesting to note that such sayings as 'Home is where the heart is' personify this wholesome notion of home, represented by funeral directors in ANZ and in some homes plagues or embroidered wall hangings emphasised this notion of the home as heart. With this wholesomeness comes a commitment to the general public that the space that they enter will in fact be free of filth, free of unsightly dirt and most importantly show signs that the presence of decay has been addressed.

Consequently the funeral home, whilst being homely, must to some extent match the cleanliness of a hospital without loosing its homeliness (Strub and Frederick, 1989). By drawing heavily on notions of 'home' the funeral industry attempts to conceal the practical, rational nature of the contemporary funeral practice - the business component - underneath its ostensible primary aim of offering service to the living in their time of need. To do this they take further steps to place their homes away from traditional business environments.

Situating the funeral home in a middle-class suburban setting is for some funeral directors vital as it helps create that illusion that one is visiting an actual home. Similar to the funeral director's concerns with “...'clean shoes' and 'proper' funerals-without-incident (Hockey, 1996: 48), the funeral home is therefore 
appropriately located in the attempt to avoid any outside incidents or overt attention. The home, like the body of the dead, must be present yet absent. This present yet absent positioning of the home is further supported by the public. Take, for example, the outrage when a local funeral home operator set up his business outside what the general public viewed as an appropriate space for a funeral home.

\section{Locals' bodies too close for comfort}

AN ALMIGHTY ROW has erupted in Wainuiomata over an undertaker moving into the central business district, next to shops that include food outlets. Duke's owner Neville Isherwood said many of his customers found the close proximity of the business "offensive".

'I find it incomprehensible that a business involving dead bodies and embalming chemicals can be permitted to operate right next to a food outlet'.

'People do not want to be reminded of their own mortality...every time they use the busiest street in Wainuiomata'

Figure 2: Newspaper article, Trow, 2005: A6.

Having a fully operational funeral home located within close proximity to food outlets horrified many locals, with some people stating that it was 'gross' (Dominion Post, 2005). Dairy owner Neville Isherwood even suggested that the presence of the funeral home made locals far too aware that dead bodies were not only being moved in and out of the area, but that they were actually being worked on. Whilst there was no way of anyone actually being able to see what was being carried out in the funeral home, some locals were worried they would know that dead bodies were being embalmed. Even though the site had been blessed by a local kaumatua, ${ }^{39}$ shoppers and retailers felt that the location of the funeral home was not only inappropriate but that it unnecessarily heightened shoppers' awareness of their own mortality, something dairy owner Isherwood argued was

\footnotetext{
${ }^{39}$ A kaumatua is a respected tribal elder in Māori communities. They are appointed by their people who believe that these chosen elders have the capacity to teach and guide both current and future generations. Kaumatua have knowledge of Tikanga (customs and traditions) and Te Reo (Māori language) and their contribution ensures that the mana (respect, authority, power and prestige) of the whanau (family), hapu (sub-tribe) and iwi (tribe) are maintained (English-Māori Dictionary, 2005).
} 
not acceptable. The embalming was of serious concern for both retailers and their customers, as there was fear that the highly toxic chemicals might in some way contaminate the area. The funeral home eventually closed due to a drop in business. Michael Wolffram (pers. comm. 2006) suggested that the negative reaction from local businesses was certainly influential in the closing of this funeral home. He also suggested that whilst it was a brave move on behalf of the funeral operator, the general public for such close proximity to a funeral home, suggesting that there was still much work to be done by the funeral industry in dispelling misinformation .

To avoid this type of reaction, funeral homes tend to be located as far enough away from major walkways, shopping centres and other sensitive places so as to prevent similar situations to that which occurred in Wainuiomata. Locating homes away from these particular sites also helps to prevent what Wolffram (pers. comm. 2006) calls 'walk-ins'. Walk-ins can be comparable to the shopping behaviour of weekend shopping, where shoppers tend to wander in and out of shops browsing either for recreation 'shopping therapy' or before committing themselves to buying anything specific. By locating funeral homes away from the centre of towns or on the outskirts of cities, funeral directors can minimise unexpected walk-ins by prearranging appointments (ibid).

Nonetheless, walk-ins can and do occur and as Funeral Director 'A' (pers. comm. 2006) pointed out, whilst they do not encourage this, they would never turn anyone away because of the extreme effort it may have taken these people to walk in off the street. However, the idea of people walking in off the street merely to 'look around' threatens the seamless, well organised allocation of time and the orchestrated flow of the funeral home. Funeral shopping is not a dignified approach to funeral arrangement. Arranging a funeral is viewed as a sacred endeavour, one that must be carefully planned and diligently worked at with an eye to detail - it could be comparable to perhaps buying a classically valuable piece of art. As mentioned previously, in 2003 an article specifically looking at the changing face and diversity of the funeral industry in ANZ was published in North and South. To advertise the article, Hannah Sperber, the author, had placed herself in a coffin, eyes wide open and hands across her chest. Some funeral directors 
viewed her actions as abhorrent, arguing that the photograph made a mockery of the sacredness of not only their work, but death itself. One particular commentator that I spoke with argued that it lowered the tone of the article and ridiculed the place of funeral work in this already secular society (Anon, pers. comm. 2003).

Wolffram (pers. comm. 2006) argues for a culture of transparency and contends that walk-ins are one way of achieving this. In 1983 Wolffram owned and operated a funeral home in Tokoroa. The funeral home was located in the centre of town, which allowed the general public to pass by the home on a daily basis. Wolffram purposely did not glaze or tint the front window, allowing passers-by to see into the main foyer of the home. He argued that this was an attempt to create a space that was less foreboding and instead offer passers-by a more inviting and approachable view. In doing so he hoped that by allowing people to at least look into the funeral home they might eventually feel comfortable enough to walk in and talk with staff. In doing so, he hoped that it would break down some of the barriers between the public and the concealed world of the funeral home, resulting, he hoped, in a more open dialogue between funeral directors and the general public. This in turn would create a less closed and more transparent service. Wolffram pointed out that this type of approach to funeral work can be found in parts of Europe. You can walk down some of the streets in Italy, for example, and there are coffins lined up on the streets and everyday people walk past them - it is considered normal (Wolffram, pers. comm. 2006).

As previously pointed out, many funeral homes open their doors at least once a year in a concerted effort to inform the general public about what happens in a funeral home. However, Wolffram (pers. comm. 2006) argues that this should occur to some degree on a more regular and perhaps even daily basis. People rarely consider visiting a funeral home until the necessity to do so occurs. Mitford (1967) argues along a similar line, suggesting that people should be able to visit funeral homes and 'test them out', look around and make enquiries, similar to home buyers visiting property sales. She goes as far as suggesting that when acquiring a coffin one should do so in a similar vein to purchasing a car. Test-drive it, she argues; get into it and see what it feels like, see if it fits. This of course would offend the sensibilities of the funeral workers and perhaps the wider public; 
it would be seen as threatening the dignity and sacredness that has been woven into the fabric of contemporary funeral work. Opening up the funeral home to this type of 'random' activity would destabilise the sense of homeliness within the funeral home and undermine the incident-free space that has been created by drawing on middle-class notions of home.

The funeral director draws heavily on a middle-class understanding of home. This concept of home is located within discourses constructing home as space, especially when visiting another's home, requiring the visitor to act in an appropriate and proper manner. However, funeral homes cannot and never will be merely homes, they are also sacred spaces that are constructed through Rugg's (2000) idea that the repeated visiting of a particular site, in this case the home, makes this space sacred. Therefore as a homely and sacred space, the bodies of the living must embody, if only for a short time, the same standards set down when visiting someone's home. Whilst funeral directors acknowledge that accidents can happen and people's behaviour and conduct will always disrupt the ambiance they attempt to create, other factors will come into play to ensure that the funeral home is respected for the short time people visit it. Consequently tradition alone cannot control or maintain civil and respectful behaviour. To ensure that there are little or no disruptions, the bodies of the living and the dead are continually managed, monitored, separated and securely contained within their appropriate and allocated spaces. This containment begins at the moment mourners arrive at the front door of the funeral home.

To engage with a discussion of the frontstage of the funeral home I will revisit a number of themes discussed in Chapter Five. As well as revisiting these themes I want to reintroduce the layout map utilised in Chapter Five (see plate 6.3 below) so as to assist with the following discussion. 


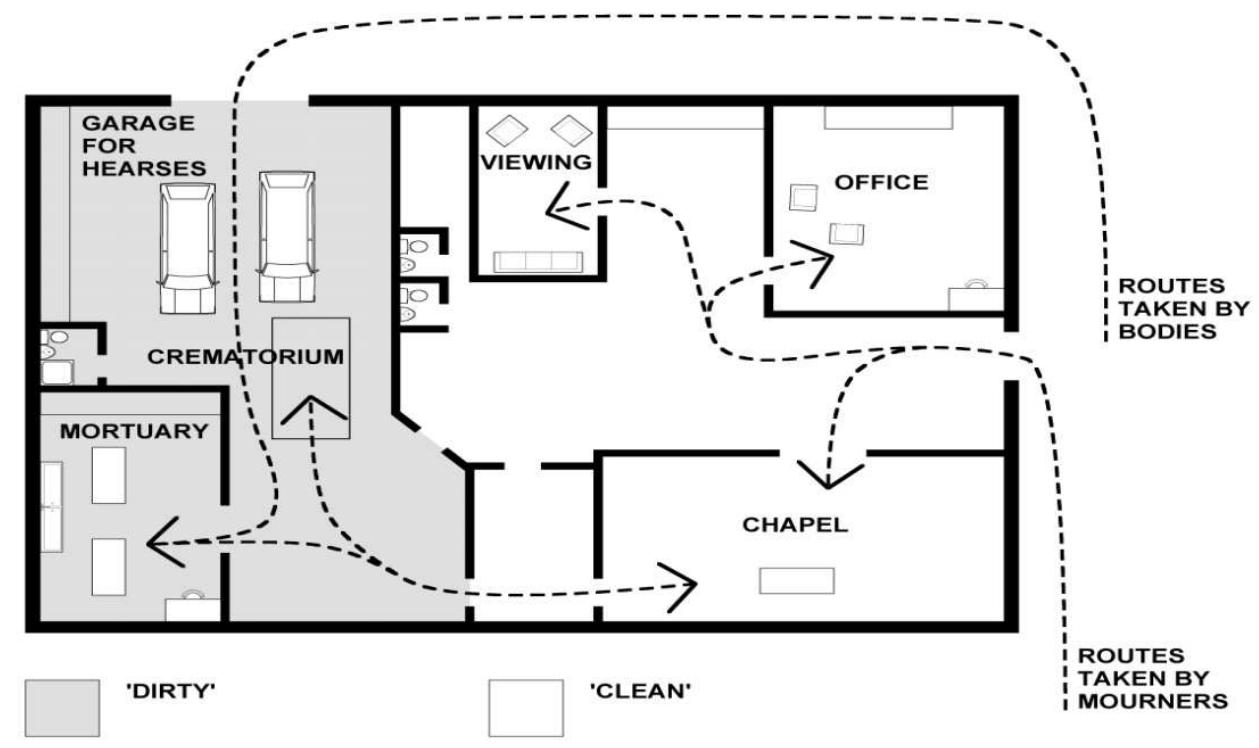

Plate 6.3: The Layout of a Typical New Zealand Funeral Home

As I suggested in Chapter Five, the layout of a funeral home is imperative in containing and maintaining public and private space. Private space is more often than not secured by doors that are locked to the public. Nevertheless, within the public space of the funeral home, public rooms can become private as mourners utilise them for the purpose of discussing funeral plans, viewing dead bodies, grieving or taking time out.

Within the public space of the home the bodies of the living come under a certain degree of surveillance. Their behaviour, whilst situated within grief discourse, must retain a certain degree of self- restraint and respectability. To achieve this self- restraint numerous ritualised performances come into play. As in the rear of the funeral home, doors are also used to help contain and guide mourners about. This is especially true when funeral directors need to ensure the separation of public and private spaces. To trace the movement of the living and the different forms of surveillance experienced by them I begin at the front door of the funeral home. This is where mourners arrive to meet with and discuss with the funeral director the necessary arrangements for the funeral. 
If we look again at Plate 6.2 which shows the Lychgate Funeral Home, one can see that the first main entrance is a gate, which in this case is closed. The single hearse parked outside the front door indicates that a funeral is underway. Like many funeral homes that have the space, they create a border between themselves and the road with bushes and plants and a gate. This landscaping helps to create a certain ambience, both public and private. Funeral homes attempt to have some sort of creative border separating them from the street. The front section of some funeral homes are utilised to enhance the aesthetic nature of the home. As we can see in Plate 6.4 the house which was built in 1926 and located in the country town of Feilding is said to have 'true character' it is a home that offers grievers privacy. Whilst not typical of homes located in ANZ this home has been built, in the style of an English country home, indicating to visitors an elegance and refinement associated with the particular class of people who own these types of home. This style of home can be read in ANZ as a signifier of our colonial past and as a symbol colonisation for Māori.

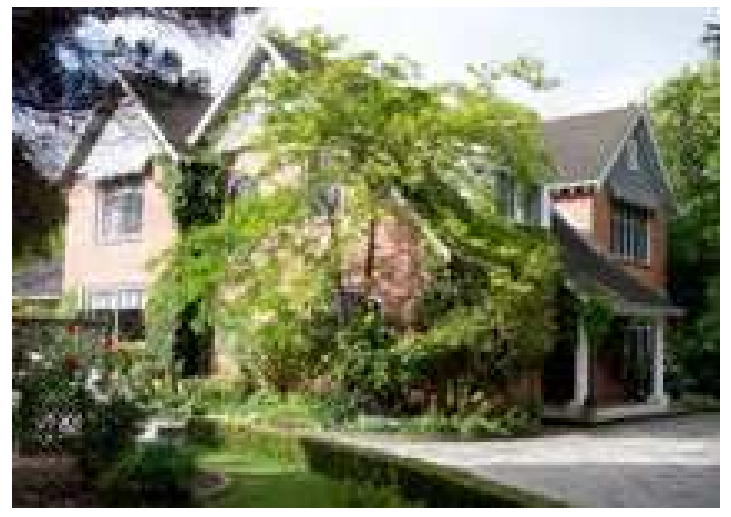

Plate 6.4: Beauchamp Funeral Home, Feilding (http://www.beauchamp.co.nz/feilding.html).

As house and land prices have risen owner/operators in ANZ have turned away from these kinds of homes, instead converting old warehouses, or similar sized buildings into funeral homes. In the larger cities these buildings have less or no frontage, often sitting directly on main footpaths. To give them status similar to traditional funeral homes, some take on a more church like appearance as seen in Plate 6.5. (see below). Whilst this might be understood as a divergence from what is understand as 'home', churches can still be understood as a type of home, God's home in which everyone is welcome. 


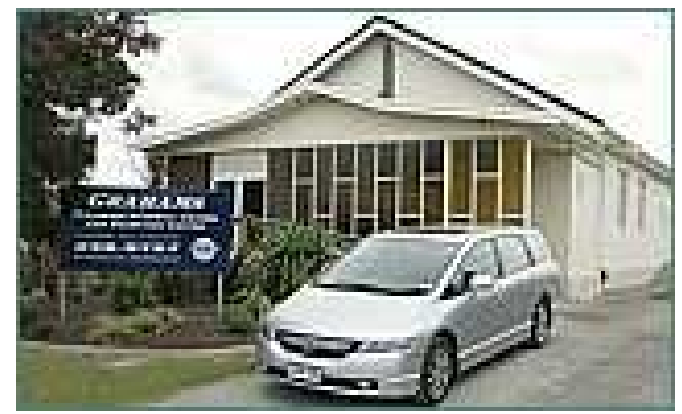

Plate 6.5: Grahams Funeral Services .(http://www.grahamsfunerals.co.nz/).

The initial visit to a funeral home for the majority of the general public will occur after the death of family member. Whilst some funeral homes offer families home visits, more often than not, families will come to the funeral home, so as to meet with the staff and look around the home. For those homes with border entrances, arrival at a funeral home allow visitors an small adjustment period which might run from the front gate to the front door.

Once mourners reach the front door they will be welcomed by a courteous funeral director or by the receptionist if directors are busy. This will be done as promptly as possible. Whoever answers the door will be immaculately dressed - in the case of the funeral directors their shoes will be shined. This seemingly small detail is especially important - the funeral director must have the ability to ensure that all the finer points are correct, as an eye for detail is said to help place mourners at ease. Therefore a funeral director must be of “...good physical appearance, proper carriage, a commanding presence, neatness and taste in dress (Strub and Frederick, 1989: 6). It is also important that the funeral director/embalmer does not have a “...excitable temperament, or a jovial or sour temperament...for persons consumed by grief badly need a quiet calming personality which will help them through the trying period" (Strub and Frederick, 1989: 4). This initial contact forms the foundation of a convivial, supportive, civilised business relationship between director and mourners, which is necessary in managing the bodies of the mourners. To achieve this, every act that sustains the ritualised funeral performance will be organised and monitored by the funeral director. In turn their bodies come to define the normative performance expected at a funeral. 
Of utmost importance to funeral directors is the need not to leave the bereaved standing for long periods of time in any one particular space especially at the front door (Strub and Frederick, 1989). In most cases an appointment will have been pre-arranged, however, if people walk-in unexpectedly, funeral directors will make themselves available or the receptionist will make an appointment for another time. However, funeral directors prefer people to make appointments so as to create the necessary seamless flow understood to create confidence in mourners. Expecting visitors allows for attention to detail. Promptness, like politeness and decorum, are indicators to the bereaved that they are important guests in the funeral home (Selket, 2007).

The frontdoor, like most doors in the funeral home will rarely, if ever, be left standing open, except on the day of the funeral when it will be opened allowing people to come and go without interrupting the procedure. Where possible the entrance is situated next to or between the chapel and the reception area (see Plate $6.3 \mathrm{pp}: 175)$. Of the homes I visited, the main doors lead straight into a foyer or small hallway. Chairs and or a couch were strategically placed, so as to give a sense of intimacy but also space so as not to overwhelm visitors. In one particular funeral home the main door opened into a foyer/hall which took the eye towards a beautiful glass window at the end of the hall area depicting a sunrise. In this case the office was situated down a corridor which ran off the foyer. In another home, one that the general public walked directly in from the street, as opposed to driving or walking down a driveway or long footpath (see Plate 6.4), visitors walked immediately from the street into the foyer where a cheerful receptionist sat behind a beautifully carved mahogany reception desk/pillar.

As previously suggested (see Chapter Five), doors are utilised by the funeral director and embalmers for the smooth running of the funeral home The most important door in a funeral home, especially for mourners, is the front door, this is where the visitor gets their first impression of the home. Decorators and real estate agents advise homeowners that they should not neglect their front door and put time and energy into ensuring that it has “curb' appeal. According to Akiko Busch (1999: 33) the front door invites a '...ceremony of coming home'. If the home has an extensive front yard, such as the funeral home in Plate 6. 4, then the 
entrance begins at the gate and mourners might well begin to assess the home via their drive to the main door, however on arrival at the front door impressions about the home will be galvanized once mourners are welcomed inside.

Doors, especially front doors, give people a sense of arrival - a ceremonial coming home with a certain degree of formality. Doors bridge the space between the public and private, the inside and outside. They are significant in that they can either allow people entry or they can be used to prevent people from entering (Busch, 1999). Doors then are utilised as form of security, a closed border that will only be open if the situation appears safe. Within the funeral home, it is only the living that cross continuously through the funeral home's front door. The corpse is relegated to crossing the funeral home's threshold via the garage. As suggested in Chapter Five, this restriction of entry can be comparative to the restrictions placed on servants and tradesmen entering the homes of the upper and middle classes in the early 19th century. However, unlike the tradesmen and servants of that century, who were also relegated to exiting via the backdoor, the deceased will eventually depart via the front door of the funeral home. The dead body's elevation to exiting through the front door comes about after it is transformed from a polluting object (profane) into a cleansed subject (sacred) (Selket, 2007), it is also a symbol of its final journey to the grave, a leaving home forever.

The front door then is a threshold where one moves from the wider world into a space that brings together the 'family' of mourners. It stands in hushed silence embodying a degree of formality. On opening the door to visitors the director wishes to communicate a friendly, serious, no-nonsense relationship. For the funeral director it is important to be aware of the griever's initial impression of the home and of the director's own decorum. Being welcomed into the funeral home, the funeral director endeavours to create a space of retreat. This is further guaranteed when the funeral director closes doors behind people, ensuring that they are safe from intrusion and free to express grief. Doors then act as a protection from possible threats or intruders (Tuan, 2004).

Once mourners step through the door they will find themselves in a foyer. Foyers or entrance hallways, according to Rosselin Celine (1999: 55) are transitional 
spaces that are utilised to "...prevent or ease transition from the public to the private". The foyer whilst being utilised as a welcoming and transitional space might also be used to help structure power differences. How long guests are held in this transitional space or are move from this will fashion the roles of the actors. It is in the foyer that the decision is made to allow or restrict entry into the inner region of the home whether it is a family or funeral home (Selket, 2007).

Once inside the visitors will be ushered into a waiting room or asked to wait in the foyer. Foyers are decorated with paintings, plants or cut flowers and some homes will play background music, this will often be classical music. A small table may well be located in the foyer, which will hold a variety of information this will include all or some of the following pamphlets:

- $\quad$ My life, my funeral

- $\quad$ Last words (2006)

- $\quad$ Funerals - Knowing what to do when someone dies

- $\quad$ Time together - Spending time with a person who has died

- What you need to know about funeral costs

- Prepaid funerals

- Viewing

- $\quad$ Children grieve too - Supporting grieving children and teenagers

- $\quad$ Loved always - Remembering your baby

- Bereavement \& grieving - Dealing with the death of someone close

- Alternative ceremonies - Can we do it this way?

- Burial or cremation - Making a choice

- Resolving disputes

- The funeral director - Making the right choice

- Tributes on line

- A word to those considering cremation or immediate disposition

- When a pet dies: Practical advice for people dealing with loss

- Griefcare

- Facts about embalming

- $\quad$ Yes - funerals are for the living

- $\quad$ FDANZ family bereavement plan: Prepaid funerals

- Values of the funeral

The majority of these pamphlets are produced by the FDANZ in collaboration with those associated with Funeral-link. ${ }^{40}$

\footnotetext{
${ }^{40}$ Funeral-link produces both a website and pamphlets providing information relating to funerals. The website is a central reference point intended to offer assistance when a death occurs. It also provides a funeral directory of FDANZ registered funeral homes as well as a testimonial page praising the services offered by funeral homes to mourners.
} 
Depending on how many families have appointments around the same time, this of course is managed by the director via their receptionist, visitors may be asked to briefly wait in the foyer. If a drop-in occurs whilst a family is waiting a director will usher the family into a viewing room or office as soon as possible. However, people will be asked to wait until a time or a director is available, this is often due to previous appointments running overtime or a director is handling a call.

Whilst visitors will be aware that there are private spaces located around the funeral home, no one will point out these spaces, nor at any time will mourners be told where they can or cannot go. There is a taken for granted understanding that behind closed doors death related work is being carried out. Also, as I discuss further on, the funeral director utilises his or her control over the bodies of the mourners to navigate them in and around the home, ensuring that overlaps will not occur. However, there is also the reality that mourners themselves do not wish to intrude on other people's space and that they do not wish to disrupt the seamless efficiency created by the director.

Depending on the size of the home the foyer area may be quite large, this is to allow overflow on the day of the funeral. The funeral homes I visited certainly varied in size, for example, some homes may have a large chapel, as does the funeral home shown here (Plate 6.3, p.175); whilst others have smaller, more intimate chapels therefore foyers will be built in relationship to the chapel. On funeral home director I spoke with said that at times they had speaker attachments on the outside wall due to having conducted some very large funerals. These had seen people spill out of the chapel, taking up as much space as comfortable in the foyer and still having people spill out onto the driveway. It was rare but he said on those days he would let local businesses know that a crowd was arriving. To accommodate this sort of spill over some homes have incorporated sliding doors and partitions in order to make viewing rooms, and/or the chapel areas, bigger if and when required.

As I suggested earlier mourners and or visitors to the funeral home have a fair idea that certain spaces within the home will be off limits. They understand that within this particular space, as within a private home, one does not wander into rooms 
that are understood to be off limits, such as bedrooms and cupboards. As a guest one only goes into spaces one is invited into. One understands that where there is death and grief there is a need to be aware of not randomly opening closed doors.

Depending on the size of the funeral home there can be one or two viewing rooms. Viewing can also occur at other places, at a person's home or via open coffins in a church or community hall. Close family and friends are more often than not, encouraged to take the opportunity to view at the funeral home, this is particularly true as more and more people opt for non-religious funerals. The funeral home is understood in this case to be a neutral space.

The viewing rooms, as you can see in Plate: 6.3 (above), are situated between the embalming room and the chapel. This is to allow easy access between these spaces. More often that not there will be either a corridor that in some homes can be is utilised as a holding bay - this allows for homes to store coffined bodies outside the embalming room, thereby freeing the embalming room for new arrivals. Here the bodies of the dead will remain prior to being viewed.

Viewing rooms are categorised as public spaces, yet when in use become private space. Like unexpected walk-ins, some mourners might arbitrarily arrive at the funeral home and ask to view a body without prior arrangement, and whilst funeral directors will attempt to accommodate these unexpected occurrences, they tend to prefer to schedule viewings, so as to prevent any unnecessary incidents. These drop-ins are managed in a number of ways. If there are conflicts of interest, for example the visitor is not family, or there are already far too many people in the viewing room the drop-in might well be asked to come back at an appointed time.

Returning to Plate 6.3(page,175), one can see that the corridor behind the kitchen and the first viewing room would be the most likely place to store the coffined dead as it is accessible to the viewing room whilst remaining outside the funeral home-defined public space. In one particular funeral home I visited, the funeral director said that they could accommodate at least three coffins in a holding space situated behind the main viewing room. Another nine to eleven coffins can be stored in the corridor leading from the embalming area to the viewing room. 
However, it was pointed out that this is a rare occurrence and one that the funeral director preferred not to have to perform.

Today, more families are being offered the opportunity to take their dead home. More often than not the body will be taken home for a day or so then brought back to the funeral home prior to being buried. The family home is understood as a haven where ones feelings can be fully expressed and the funeral director optimises this understanding to encourage healthy grieving. Also in ANZ Māori take their dead as soon as possible to lie on the marae. The percentage of bodies being taken home has not yet been quantified; however, Wolffram (pers. comm. 2008) suggests that it might well be no more than one percent of all bodies:

This process has been increasing rapidly over the past ten years and would likely be greater in rural areas and smaller communities but is also a notable trend in the cities.

With the dead body now being a great deal secure to engage with, the funeral directors time is spent indirectly managing the bodies of the living. Whilst doors play a major role in controlling where the living can or cannot in the funeral home new forms of surveillance is drawn upon. This new form of surveillance includes a number of psychological self-regulatory principles namely dignity and respect and towards the dead and other mourners.

\section{DIGNITY AND RESPECT WITHIN THE FUENRAL HOME}

With the dead body embalmed the funeral directors come into their own, helping shape the grief performance by ensuring that all visitors to the home adhere to appropriate conduct within the funeral home and around the deceased. Within the funeral home the bodies of all those close to the dead come to be understood as being in mourning. Performing grief becomes inscribed through the body particularly through the act of crying. This expression of grief is encouraged within the confines of the funeral home. Similarly, the body of the dead come to be situated not merely as a dead body but as a sacred object, therefore, those who come in contact with it must show it the utmost sign of respect and dignity. 
To be able to fully define the notion of dignity, Douglas Meeks (1984) argues that one would need to fully understand the fundamental meaning of being human. Notions underpinning dignity are "...complex, ambiguous and multivalent" (Moody, 1998: 14), and within the funeral space around the dead body the issue is even more problematical. The Universal Declaration of Human Rights (1948) describes human dignity as a quality, which gives human beings "...equal and inalienable rights...". The charter confers that all human beings are born with the right to be treated with dignity, said to be a birthright. In having the right to dignity, people are assured peace, freedom and justice (Gallagher, 2004). Dignity is manifested through behavioural understandings of respect for not only self but also for others. This in turn sets the guidelines for having pride - being dignified, especially in times of crisis when dignity must be utilised so as to not slip into a state of animalism (Bataille, 1984, 1988; Gallagher, 2004; Jacelon, Connelly, Brown, Proulx, and Vo, 2004). Until the 1970s dignity was associated solely with the rights of the living. However, in the 1970s the campaign demanding the right for those with terminal illness to die with dignity began to gather momentum. In 1976 in the USA, the California Natural Death Act recognised the rights of terminally ill patients by instructing physicians “...to withhold or withdraw lifesustaining procedures in the event of a terminal condition" (Macklin, 2003: 1419). By extending the right to dignity for those wishing to end their life, the framework surrounding the right to dignity was further broadened.

Whilst notions underpinning the respectful handling of the dead are said to have always existed within Western death rituals, 'dignity' towards the dead has been extended due to experimental medical technology and training on the dead. According to Ruth Macklin (2003), a medical ethics professor, using the term dignity within the context of medical experimentation and medical student training is problematic as it encompasses rights and a state of being restricted to an autonomous being:

[Dignity] has nothing to do with respect for autonomy since the object is no longer a person but a cadaver. There may be reasonable concern about how the dead person's relatives would feel if they knew that the body was being used in this way. But that concern has nothing to do with the dignity of the dead body and everything to do with respect for the wishes of the living (2003: 1419). 
With these rights come certain obligations: for example, medical ethicists are demanding that the practice of intubation, (intubation is the insertion of a tube into a body canal or hollow organ - e.g., trachea or stomach) on newly dead bodies be ceased, as it violates the dignity of the dead. This is in part due to the fact that whilst some medical practitioners recognise the corpse as nothing more than an object for scientific study, it (the cadaver) still has significant value to individuals and families, thereby guaranteeing it the right to dignity (Andrews and Nelkin, 1998).

Alison Renteln (2001) investigates the legal understanding of how dignity can and should be applied to the dead. What she finds is that the law contributes little to an understanding of how or why protections are placed around the dead. Instead Western law draws on property rights, arguing that the dead body belongs to noone in post-death. However, this stance is tempered by understandings that the living, depending on their relationship with the dead body, have a "...quasiproperty interest" (Renteln, 2001: 1015). This stance allows a cultural understanding that the corpse retains personhood. This protection of the dead is said to also be based around fears that a malevolent corpse might come back to inflict harm onto the living. This, she argues, lies at the heart of some of the debates around post-death dignity.

This discussion draws from a debate outlined in Chapter Two: subsection 'Absent Present Death'. Here I explored some philosophical discussions about how language is seen to fail to offer a full explanation of death due to its instrumental nature, a coming into being, whilst death was a leaving. In this case death can only ever be understood from the safety of one's livingness. It is therefore from this distancing position that many Western societies (e.g. the USA, New Zealand and Australia) come to ascribe rights to the dead. The living inscribe personhood and protection onto the bodies of the dead in fear of what might happen to their (the living's) own bodies after they have died. This then could be viewed as a narcissistic protection of the 'I' from any post-death misconduct. By inscribing personhood onto the bodies of the dead, in this case through embalming practices and cosmetic reconstitution, the dead body is used to signify the rules of engagement. The dead therefore always symbolise to living bodies their own 
demise, and in this space, this 'between' space of presence and absence, certain protections come into play to relieve the anxiety of possible future abuse. Dignity thus comes to represent some protection against the unspoken possibility of postdeath abuse.

This protection of any post-death abuse is taken seriously by funeral directors for a number of reasons, first and foremost however is the contractual commitment to the family and friends of the dead, the funeral director takes possession of the dead based on a contract of trust between mourners and themselves. This trust is fundamental to the relationship between themselves and their clients. Breaking this trust would not only see whoever broke this contract prosecuted by the law but any suspicion of misconduct would see them lose business. Whilst accusations of necrophilia or any other body interference have not surfaced in ANZ, the funeral industry in the USA has had a number of incidents where funeral directors and or embalmers have been prosecuted for interfering with a funeral. A well known case was that of Karen Greenlee a self proclaimed necrophiliac who worked as an embalmer/funeral director in California in 1979. Instead of delivering the body of a dead man to the cemetery she instead took the body so as to spend time alone with it (Morton, 2006; Ramsland, 2009). Whilst, my thesis does not explore this particular area of death work, it is an issue that sits at the margin of funeral work. Within the funeral setting, showing dignity and respect towards the dead is an essential component for the funeral director in managing a safe and successful funeral. Therefore it means that the funeral director will draw on various forms of guiding principles which will help direct mourners. These guiding principles not only ensure that the funeral operates within a highly monitored atmosphere, but allows the funeral director to oversee the funeral without seeming too controlling or domineering of the process. To achieve this high level of self and external surveillance funeral directors and mourners must accept and comply with the normative performance. To achieve this, normative practices become implicit through the funeral ritual. The body of the funeral director helps to set the tone for what is understood to be appropriate conduct at a funeral.

As I have previously suggested, the industry believes that much of what it offers mourners by way of ritual, aesthetics and support is what the public want. It is 
therefore the funeral director's responsibility to role model, guide and ensure that mourners not only abide by specified legal requirements but also explore the various options made available to them. These options are said to be tailored to each individual death. Research shows, however, that what mourners want is somewhat unclear (Hockey, 1996). In a study undertaken by Hockey (1996: 45) of the experiences of bereaved relatives, she found that the bereaved tended to experience the funeral as something unreal, “. . . as if it's not happening to you...”. Others pointed out that they felt like they had been "....transported to another world" (ibid). Their grief then was not only difficult to acknowledge at the time but often had felt little more than a performance. Another grief commentator suggests that the timing of a funeral can be too early, which can see some family and friends still grappling with the shock of a death, even one anticipated. For this reason the positive psychological effects that should be expected from a collective expression of grief may have little or no effect for some people (Worden, 1991). Whilst not all these feelings of detachment from the process of the funeral can be laid at the feet of the funeral director, it must be remembered that particular deaths, especially sudden death can leave close family members and friends extremely numb. Some of this sense of displacement can also be put down to the extremely controlled approach some funeral directors take. According to bereavement literature it is essential that the bereaved express their grief, but it must be expressed appropriately and within certain defined boundaries (Hallam et al., 1999; Parkes, 1972; Stroebe, 1987; Worden, 1991).

The idea that the dead body is now a sacred object is not merely because of it's' similitude to a person whom once lived, but also because of the ritualised acts performed upon its surface. Inscribing the body with scars and incisions, according to Grosz (1993), helps locate the body within a particular time and space. By the slicing up of skin, draining of blood, and pumping of embalming fluids into the dead, the dead and decaying body becomes inscribed as ready for disposal. This inscribing through the opening and closing of the body, through the shutting of the eyes, the crossing of the hands and the containing of the body within the coffin, signifies that the once living body is not only now ready to be returned to the space of the living and thus moved on but that it is coming back cleansed and 
remembered. Part of the bodies continued position as a sacred object comes about according to Rugg (2000) through the repeated visiting from the living.

Whilst its cleanliness and in turn sacredness must remain consistent when housed in the funeral home, each stage of the bodies transition process etches understandings of dignity onto the dead. Once it enters the frontstage of the funeral home the dead is handed over to those mourning for it, however it is not until the body leaves the funeral home to be buried that the full extent of a hand over is undertaken, until this time the funeral director continues to be in charge of the dead body (Kastenbaum, 1995).

With the dead body embalmed, containing and caring for the dead shifts from the funeral director to a shared responsibility between mourners and the funeral director, however, the funeral director is still ultimately in charge until the corpse has been buried. Death has been enclosed, it has been cleansed away, and therefore the body can now be reintegrated into the spaces of the living. However, traces of death remain, and it falls to the living to ensure that all activities surrounding the dead body are respectful, dignified and controlled.

Entry then to the funeral home is understood as committing to the unspoken rules of being in someone's house, as well as showing respect towards the dead body and other mourners. Whilst funeral directors can curtail access to particular areas within the home, they cannot restrict who can or cannot come into the home, especially when a funeral is in progress. For this reason anyone can attend a funeral, even if the deceased is unknown to them. In ANZ a phenomenon occurred that had some people questioning the public nature of funerals. Local newspapers interviewed people like Kevin O'Connor from Canterbury, who was described as a 'professional mourner' because he regularly attends wakes and funerals of people he does not know (Timaru Herald, 2001). Whilst funeral directors cannot restrict entry to the funeral home, unless under dire circumstances, the funeral director can limit people's entry by insisting that mourners make appointments. The above scenario was understood by the funeral directors I spoke to as disrespectful not only towards the dead but also the mourners. 


\section{DIGNIFIED BODIES}

Like the performance undertaken when removing the dead from its place of death, the funeral director must hone their movements so as to create a space within which particular acceptable and containing behaviours are model whilst allowing for the full expression of grief to be expressed. This balancing act must then allow the full expression of grief without it erupting beyond the borders of what is understood as acceptable. Without appearing to do so, funeral directors will exert their control over the mood of the funeral. One way funeral directors achieve this is through the use of music. Not only does music help set the emotional ambience of a funeral, funeral directors often suggest that music the deceased loved should be played as a way to remember them, but the use of music can also introduce an event or shut the same event down, especially in situations where a funeral is running over time, (Turner and Edgley, 1976).

The funeral gains momentum through the exculpation of grief; however, it is restricted as much as possible to a specific script which is situated within grief and mourning discourse. As Pines (1989) points out, funerals allow the grievers to embody what he terms a 'death-appropriate mask', thereby allowing grief to be expressed more fully. For example, men can shed tears, whilst women can allow themselves to become untidy through their grief. This then allows for the authenticity not only of grief but of the funeral process itself. He goes on to suggest that if the actors do not follow the script and perform the particular role and behaviours set down, then the funeral director will become disconcerted and 'unstuck'.

Whilst this unsettledness or coming 'unstuck' is very rare, due in part to the overall control the funeral director asserts over the proceedings, I have experienced a situation in which the director became extremely flustered. It occurred at the funeral of my friend, Loretta Mullin in 1999, the funeral director, once having seated everyone, took his place at the back of the chapel. Here he was able to monitor the service and make any minor adjustments to the sound level of the music or ensure that late-comers could find seats without disrupting the flow of the service. After a while the director could be seen moving around the room. I remember watching as he became somewhat anxious, due partly to the service 
taking far too long. At one point Loretta's sister, who had been given the role of communicating between the grievers and the funeral director, announced that we would need to begin to wind things down. Fifteen minutes later a number of lesbians went to turn the music up, with the intention of carrying the coffin out of the chapel loudly and proudly. As the group began to manoeuvre the coffin, the funeral director became clearly agitated. The music was deemed too loud and it appeared that the next group of mourners had arrived and were in the process of carrying their coffin into the chapel. One could only watch as 'all hell' appeared to break loose. Coffins were forced back into cars, music was turned down, and the director, whilst attempting to remain calm, showed his disapproval. At this point all appropriate decorum was lost. The incident-free funeral that is viewed as the most appropriate funeral process slid into chaos and the funeral slipped its moorings.

Whilst disorganized funerals are rare Wolffram (pers. comm. 2006) did tell me a few sad but amusing stories that left mourners and funeral directors alike redfaced. In most situations though mourners accept the roles assigned them and behave accordingly. Unfortunately grief is an emotion that erupts across boundaries, and when this occurs the funeral director must be ready to deal with any negative or disruptive consequences. Returning to Six Feet Under, Episode One: The Pilot (Home Box Office, 2001), Ruth Fisher's husband, Nathaniel, has been killed in a car accident and the family has come together to grieve him. Ruth begins to mourn; however, her guilt at having had an affair prior to her husband's death is unlocked and her grief becomes uncontrollable. As she begins to further lose control she is quickly ushered from the chapel, segregated from fellow mourners. Whilst there are numerous reasons for her removal, one being her public confession of infidelity, she is removed for fear that her grief, considered 'out of control', might spill out onto the public (yet private) mourning space of other grievers. Ruth's 'over-emotional' state falls outside of what is considered to be acceptable within this contained funeral environment. Whilst her primary role is to grieve, in fact to lead the grieving process, it must be done therapeutically and as unobtrusively as possible. Ruth's loss of control is seen to contaminate the public space of the funeral home. Grief must be contained, managed and prevented from seeping across defined funeral etiquette borders (Stearns, 1994). Any lose could 
highlight the fragile borders of the dead body, thereby bringing to light the possibility that death is contagious, polluting and uncomfortable.

The role of the funeral director in this situation is to discreetly monitor this border; to create a space where safety is a priority and in this safety grieve can be expressed. If grief erupts beyond the well contained borders then the director will gently usher the griever to a more convenient, less public spaces so that they can regain their composure something that the dead can no longer do. In contrast to this inconspicuous performance expected at the Fischer funerals is a funeral where the outpouring of conspicuous grief appears to Western eyes, in this case Nate Fischer as a loss of control over grief. While travelling on a ship around the coast of Sicily, Nate, Ruth's older son, watches a coffin being taken from the ship to shore where a small group of Sicilian women wait. Once the coffin makes it to shore Nate points out that they (the Sicilian women):

Just went ape-shit: screaming, throwing themselves on it, beating their chests, tearing at their hair, making animal noises. It was just so...so real...it's probably much healthier than this (Home Box Office, 2001).

Whilst tears are viewed as less polluting than the decaying corpse, they are still viewed as being on the margin of what is considered unclean and dangerous. According to Grosz (1994) the orifices of non-polluting leakage hold dual functions, as they may later become 'erotogenic' zones. Tears, however, must be expressed so as to move from a state of mourning into a new state of being, which in turn allows grievers to let go of one attachment so as to develop new attachments (Freud, 1957). It is a public display that one is in mourning yet healing. To not grieve is to fail to embody the purpose of the grief ritual. The funeral of Princess Diana is a pertinent example of the power of grief. Thousands of people all over the UK visibly expressed their emotions, making it a normative and appropriate activity in the light of the tragedy that everyone felt. However, the royal family failed to participate appropriately. Frank Furedi (2004: 37) points out that:

In line with the ethos of emotionalism, sections of the cultural elite were particularly vitriolic against members of the royal family who did not wish to share their inner pain. The media took it upon themselves to instruct Queen Elizabeth and Prince Charles on the form of grieving the public expected of them. The desire to mourn in private and in 
accordance with one's individual feelings was pathologised and denounced as cold and inhuman.

Grief must be for the benefit of all and it is necessary, especially for those close to the corpse, for this grief to be cathartic, if it is not then one may well be considered lesser or inhuman. However this expression of grief must adhere to the same containment processes regulating the bodies of the dead. It can be publicly expressed as long as it does not cross the symbolic borders set down as death and grief etiquette (Stearns, 1994). The hope is always an attempt by the funeral director to offer family and friends an incident free performance. Whilst this might well be part of the containment process that operates around death grief is part of the emotional landscape that constructs the funeral home as a place of respect and honouring of a life recently lost.

With the formal proceedings finished the dead body will be carried to the waiting hearse via the front door. The front door stands as a bridge between private and public - arrival and leave taking. The door which will have been closed to the general public will be opened so that grievers can leave alongside their dead. The work of the funeral director has not finished as they must continue to mange and orderly leave-taking, ensuring that funeral parties or walk-ins do not cross over. This threshold has welcomed mourners into what the funeral director hopes has been a safe space where the mourners have been given the space to discuss death issues. The have also ensured that this space has been safe from intruders who might have disrupted the mourners acts of grief thereby ensuring the individual and collective farewell of the dead. Once the car pulls away and grievers leave the property the funeral home door will be closed until another group or mourners arrive to prepare a funeral.

\section{BRINGING HOME THE DEAD}

In this chapter I explored how the funeral parlour of old has come to be understood as a funeral home. This change has come about with funeral practices shifting from a women's responsibility to that of men. With this shift death was opened up to be a financial enterprise that has seen the industry grow. The move from the 
familiar home to funeral homes occurred with the combination of discourses on contagion as well as physical and psychological discourses around grief. This move also occurred due partly to a societal shift in the use of the home.

Constructing this particular deathspace as a home meant incorporating narratives that read home as a familiar, safe and inviting site of engagement. However, a funeral home is not merely a home, it is a business, as well as being a space that holds, if only momentarily the bodies of the dead. In constructing the business site of the disposal of the dead as a home the funeral director must manage various aspects of their work. They must promote their business without loosing the core values of respect and dignity that underpin their public image and work ethics. They must also balance the private and public spaces of the home ensuring that the work they undertake to ensure the seamless and safe engagements between the dead and the living is never destabilised. Therefore, the public space of the funeral home whilst less abject than the backstage of the funeral home, must continue to be monitored through the use of rooms, doors and performances that allow grief to be expressed safely and with as little trace of the decay of death.

To do this I looked at the construction of 'home' within the funeral context, exploring how its physical and discursive construction carried over from the private spaces of the funeral home, transferring readings of pollution and filth from the bodies of the dead onto the bodies of the living.

However, there is always a threat of contamination through the crossing of the business, service and grief boundaries constructed within and around the home. It is understood that containing the pubic space of the funeral home is more difficult due to it being a space that allows for multitudes of bodies to congregate as well as the mass expression of grief. Yet bodies are maintained and monitored both externally and internally through notions of appropriate behaviour and etiquette. Such standards are set down through understandings of behaviour not only around the dead, but also understandings of how to behave in other people's homes.

To ensure that grief can be freely expressed, both doors and the bodies of the funeral directors are used to direct, manoeuvre and maintain a degree of decorum. 
Whilst many commentators within bereavement literature question the authenticity of this engagement, pointing out that there is a conflict between what the living want and what the funeral director offers, the public space of the funeral home is offered up as a 'necessary evil', one that no-one can do without. In tracing the movements of the living through the public space of the funeral home and exploring various regulatory acts that contain and construct the private spaces of the funeral home, I have highlighted how purity is constructed and maintained within these spaces. For the public space to remain 'safe' there is a need to concentrate on the finer points, such as clean shoes, appropriate location and an eye for detail. This can be reinterpreted as offering mourners a sacred and secure space for engaging with the dead and the notion of death itself. 


\section{7 \\ LETTING GO OF THE DEAD}

In exploring the private and public spaces of the funeral home I set out to understand how the funeral industry came to be an essential facet, in the handling of the dead and in turn become able to take such a prominent place for disposing of the dead in Western societies. Taking as a basis the simultaneously sacred and profane spaces of the funeral home, the central question of my thesis was: what can an exploration of the abject spaces and bodies of the funeral home in ANZ offer to understandings about embodied geographies? To explore this question, I set out the following objectives:

Explore the historical, social and cultural constructs underpinning the conflicting nature of the profane and sacred spaces of the post-death decaying body in the funeral industry, focusing particularly on the abject spaces of embalming rooms;

Deconstruct the major narratives underpinning the use of chemical embalming as a method of containment for decomposing corpses;

Explore the movements of the bodies of the living and the dead in and around the funeral home to ascertain how such narratives construct public (clean) and private (unclean) activities and spaces.

In bringing a close to this research I want to, at the same time, open up my research for further discussion. This concurrent closing and opening is in recognition that nothing can ever be fully known or 'concluded'. It is also an attempt to recognise that whilst death is an ending of a life, it is also for some, an opening up of life, and a movement from one space to another for both the living and the dead. Situating a conclusion as a closed ending is like arguing that there is one truth, a 'grand statement' that sums up all that is to be said - something I cannot lay claim to in this thesis. Research, I believe, is a journey, and in this case, for me, a very personal and at times passionate journey from one place of being to another.

In this thesis I have argued that geography has tended to overlook and at times sideline a number of deathscapes, particularly funeral homes and some aspects of 
the industry, such as the embalming industry. Whilst a few intrepid geographers have begun to explore death, such as Fuchs (1995), Teather (1998, 1999, 2000, 2001, 2002) Yeoh (1999), Lily Kong (1999), Hui and Yeoh (2002), these investigations have predominantly concentrated on post-burial spaces. Few geographers it seems want to enter the deathscapes of post-death and pre-burial. Yet these spaces are of importance as they contain what many people, particularly Western people, fear the most - the body of their inevitable demise. Part of this avoidance, I have argued, is due to a belief that particular subjects are not deemed appropriate within the discipline of geography. Bondi (1999, 2005), Longhurst (1995, 1997, 1999, 2001), Philo and Parr (2003), and Sibley (1981, 1995, 2003) (to name just a few), all argue that there is an inside-outside of geography and in this dualism there are seen to be particular subjects that are inappropriate within the geographical landscape. This need to push the geographical boundary, to tackle new terrains of research underpins much of my work. It was important to understand why many geographers are reticent to explore the subject of death.

For this reason in Chapter One I introduced a brief discussion about knowing death. Here I talked about the material and abstract understandings of death. Drawing on Rosenberg, (1998) I argued that whilst death is a visible material demise of ones life, speaking about death is difficult in that death can never be discussed or understood unless death is present. This absent - presence of death is anxiety-producing, a difficult, personal and abstract subject that brings with it a desire to perhaps investigate it from a reasonably safe distance. Unfortunately, writing on death cannot be separated from the writer, which then lends death the sacred space of being outside research. Who, I ask, wants to face their mortality on a daily basis? Therefore, I hope that this thesis can become part of the growing effort within geography to bring the unclean, in this case the dead, in from geography's cold. If Sibley's (2003) challenge to explore new theoretical approaches is to be taken up, then exploring death and the spaces within which death is hidden could well lead to further understandings of the changing relationships between people and their living and dying environments.

Similar to our fears and anxieties of death, funeral homes and other allied services occupy a paradoxical place in Western societies. Pushed to the margins of society 
the funeral home simultaneously rests close to the heart of Western societies need for someone to handle the bodies of the dead. This paradoxical place of death and the dead body makes the space of the funeral home and the practices undertaken within significant for explorations into the construction of identities - of the living as mourners and the dead as signifiers of death. In this space, notions of fear and anxiety, cleanliness and filth, the private and public, and absent and presence of death are played out through the various rituals and grief performances.

In utilising psycho-geography and feminist geographies, and working with the theoretical narratives of Bataille and Kristeva, who both explore the notion of the abject, I have begun to research the highly contained spaces of the funeral home. I have examined how fear and anxiety underpins various conflicting narrative of death, and how this in turn influences particular practices, such as separating the dead from the spaces of the living, embalming the dead, and reintegrating the dead back into the spaces of the living are constructed and performed. To do this, and to address the first aim of my thesis, I looked at the narratives underpinning the industry. What I found was that whilst these narratives have shifted through an emergence of new discourses on death - most notably the medicalisation of death the industry has attempted to tie these different discourses together to produce an overarching narrative of historical progression and sacred service. In turn these historical discourses are fused with modern understandings of sanitation and containment.

This fusion has sanctioned the industry to produce knowledge that in turn allows them to retain a degree of control over the disposal of the dead body. These narratives, about the dead body, help to construct a belief that contemporary funeral practices are progressive, natural and therefore unchallengeable. Thus the industry has been allowed to grow and expand with little interference from the public. As long as the industry retains a veil over its history, specifically drawing on a notion that the dead are a hazardous and dangerous object to the living, the industry can continue to have a greater control over the rituals surrounding any engagements between the living and the dead. My research does show that this 
purported historical journey is in fact coming under greater scrutiny from the public. In turn green alternatives questioning the industries monopoly over the disposal of the dead, are helping to bring about change and greater transparency.

As part of my first aim, I followed the movement of the dead body as it was separated from the spaces of the living. By drawing on notions of abjection, exclusion and disciplinary practices, specifically utilising feminist and psychogeographical theories, I explored how the funeral industry has taken control of the dead body through discourses that argue that the dead body is polluting and contaminating. This discourse has become 'truth' for the industry and in this 'truth' the living have lost a degree of control over the disposal of their dead. This control has been situated within a discourse of 'good science' which represents an unchallengeable position of insider knowledge. However, good science does not sell funeral rituals. For this reason, owner operators draw on notions of homeliness which have come to be interwoven with understandings of public (clean) and private (contaminated) spaces.

Whilst I did not address every narrative purported by the funeral industry, I did open up those narratives that have become entrenched within their contamination discourse. As part of this opening up of contamination discourses I drew on the cultural thread found operating between Māori tangihanga and Pākehā funeral practices.

This brought me to my second aim, which was to explore and then deconstruct the principles and practices underpinning the use of embalming. Embalming signifies not only that death is present, but that this death is abject and polluting. By drawing on fears and anxieties surrounding death, cleanliness and dirt, the funeral industry have not only taken full guardianship of the dead but have constructed knowledges and practices that have become embedded within Western societies as normal and naturalised. Cadavers, therefore, come to represent all that is abject. By monitoring the living and the dead, material and symbolic seepages are contained and border crossings are minimised. However, to fully separate death from the 
spaces of the living is ultimately impossible, because death, one could argue, is an ever-present foreigner within. In gazing upon the body of the dead one is effectively imagining the self in death.

As part of the separation of the public and private space of the funeral home, I explored the situating of the funeral home as a public space. The location of funeral homes within particular public spaces, and the embedded notions of homeliness within the funeral home, has seen the funeral industry expand with a strong emotional tie to the familial home. This has helped to contain and control specific performances within the home and throughout the ritualised funeral performance. This performance has become accepted by mourners as the appropriate and most acceptable form of saying farewell to the dead. To achieve this status, funeral homes and the bodies that reside within them come under a high degree of external and internal disciplinary activity.

The spatiality of the funeral home therefore is seen as helping the living to make contact with the dead in healthy and safe ways. The practices and processes undertaken, such as embalming and monitoring the movements and grief acts, allow the dead body to be held momentarily within the 'clean' and more public spaces of the home. In so doing the living are, according to those in the grief industry, said to 'understand' death and therefore move on uncontaminated and free to reintegrate into public life.

\section{REVISITING THE THESIS QUESTION}

My research teased out issues surrounding the funeral industries notions of pollution, especially the sacred and profane practices of handling the bodies of the dead in the post-death / pre-burial space. How then does this research inform understandings about embodied geographies? Within the discipline of geography, cultural geographers who explore the spaces and practices of the abject, whilst growing in number are still considered to be a 'polluting threat' on the sanitised spaces of academia.

It is the mundane matter under our fingernails, down our toilets, on and under our streets - hardly the reified substance of conventional academic 
enquiry, one might think; perhaps even a polluting threat to the sanitized environment of the ivory tower (Campkin and Cox, 2007: 7).

Academics such as Sibley, Philo and Parr, Longhurst, to name a few, continue to critique the rigid monitoring of geography's borders, in so doing they bring the unclean and unwanted into the geographical landscapes, however, some subjects remain marginalised or excluded from the geographical lens.

This research enquiry is therefore notable in that it opens up a specific deathscape, which up until now has remained outside or on the margins of the geographer's gaze. Within this space, dead bodies are separated, transformed and reintegrated into the spaces of the living. In this transitory passage from one state of being to another, the bodies of the living also come under intense scrutiny. Therefore the space of the funeral home and the practices and principles of the funeral industry as preformed (performed?) through the bodies of the embalmers and funeral directors bring to geography new readings on how the identities of the living and dead are constructed, negotiated and reproduced, particularly within the sacred and profane spaces of a funeral home.

The research thus draws on the works of Georges Bataille and Julia Kristeva, in particular their works on the abject. Drawing on the theoretical works of Julia Kristeva allowed the researcher to explore the construction of social and spatial order constructed for the handling and post-death and pre-burial engagements with the corpse. By including Georges Bataille in this research the research is attempting to bring a degree of subversion to the exploration of the sacred and profane. In so doing this research also endeavours to enhance theorisations surrounding attitudes to dirt and cleanliness and what this tell us about ourselves and the societies in which we live.

Opening up the deathscape of the contemporary funeral home instigates further questions and possible approaches to researching death within geography. An important outcome of this research is the cognition that subject matters considered inappropriate and outside the academic frame need to be continually introduced so as to challenge the norms of academic enquiry. Such innovative explorations must include the final stage of life - death - and the cleanliness and contamination debates that underpin this particular period. The final journey away from life 
incorporates some of the most rigid approaches and understandings for dealing with containment and cleanliness. Thus, there are some specific avenues for further research that I would like to offer up for thought in this section. This research then directly influences how attitudes constructed by the funeral industry especially post-death / pre-burial practices influences and is influenced by Western concerns with the profane nature of the human identity as it slips into decay. My research also sheds light on the connectedness between social powers and the powers of place.

\section{FURTHER RESEARCH}

First and foremost any further research could attend to an investigation into how the general public understand and interpret the role of the funeral directors and the services they offer in disposing of the dead. This I believe would help lay open the various inconsistencies that are being exposed by the various challenges experienced by the industry.

Further investigations into deathscapes could include autopsy rooms and practices and other mortuary settings. Such spaces help construct understandings of death and identity in the post-death sacred and profane spaces and states of being. Of particular importance though, and specific to ANZ, are the inter-cultural understandings of tangata whenua and Pākehā attitudes around death and the disposal of the dead. Whilst momentarily touching on inter-cultural understandings I did not venture into this area of investigation for a number of reasons. The first reason was due to my own limited understanding of Māori culture and the practice of tangihanga. Any attempt to expand on this area would have seen my investigation operate from a place of limited knowledge - 'outsider' knowledge which, I have argued, contributes to a continued process of colonisation. It was for this reason then that I restricted my writing on understandings of hahunga and tangihanga. This is not to suggest that I might not in the future, with the right support, revisit some of the issues I have discussed in this thesis. However, for present purposes it was more important to bring some of the concerns discussed in Chapter Four into a public domain. 
Another reason for not exploring some of the issues raised about the interweaving practices and contradictions around Māori and Pākehā funeral practices is due in part to the sensitive nature of discussing post-death issues, particularly for Māori. Some of the practices that are undertaken by Pākehā funeral homes are controversial when viewed with a different cultural lens. For a Pākehā researcher to trample around in this space with little knowledge about the cultural implications of undertaking this investigation could again be seen as part of the continued colonisation of Māori cultural practices. I decided to speak with Māori who could advise me on what passage I could take without being part of this misappropriation. It was advised that I outline the issues pertinent to my thesis, but remain at a distance.

Therefore, I would like to suggest that there is a need to further explore differing understandings of how these two cultures come to realise notions of the sacred and profane, as well as cleanliness and hygiene when handling the dead. Of particular interest could be an inquiry into the continued colonisation of Māori cultural deathscapes by the Pākehā funeral industry. This would not only highlight the misappropriation of Māori practices but it would in turn bring to light the contradictory principles and practices of funeral work, in particular the practice of embalming in contemporary ANZ. In doing so, not only would there be a further rupturing of the seamless nature of funeral work, but there would also be a cultural contestation of the dominance of Western practices that continue to underpin contemporary funeral practices in ANZ.

In opening up space, even if only a small crack of space, to allow different narratives to emerge, both personal and theoretical, the industry is facing numerous challenges. This challenge does not mean the disappearance of the funeral industry, for as some funeral directors suggest, challenge is good for the industry and helps it to continue to grow and change. The public needs funeral homes and funeral directors. Their role in working with mourners is important in a time when grief is foremost. However, this I believe needs to be a more honest relationship, one of partnership where knowledge is shared and alternatives and options are opened up. 
In posing my theoretical questions, in thinking about what constitutes death, ritual and deathscapes, my work becomes part of a growing movement of people attempting to challenge the control the funeral industry have over the dead. Initially, I wanted to demonstrate how awful the funeral industry was both to the environment and to those compelled to use their services. In hiding death beneath the sculptured face of the narcoleptic sleeping beauty I believed that the living were unable to engage with a 'real' death. Whilst I am still not a proponent of embalming, I am no longer opposed to the use of embalming as a process to bring about a space for those who need to engage with their dead. I do believe, however, that embalming practices must be further opened up to scrutiny by the general public. One might argue that it is not merely the tool that is to 'blame' but the various narratives that become embedded in the use of certain tools that need to be discussed further.

The funeral industry, whilst having a monopoly over the post-dead body, is neither contemptible nor despicable. Whilst their practices are situated within discourses that help isolate and expel death from life, the general public must take some responsibility for its complicity in wanting death removed from the spaces of the living. For this reason I believe that the ever-faithful catchphrase of the second wave feminist movement rings true when discussing the interrelationship of the living with the funeral industry: 'the personal is political'. In the case of death, the personal needs to be incorporated into any further investigation into funeral industry practices, for what one finds out about one's self in regards to deathrelated issues is most likely present within a wider social understanding of death.

What I - we - fear, can never be fully expelled. Whilst what we fear may never be fully embraced or engaged with, one's fears help open up a space for further understanding. In so doing the stranger without, in this case death, can be acknowledged as being within. 


\section{REFERENCES}

Adams. S. 1993: A gendered history of the social management of death and dying in Foleshill, Conventry, during the inter-war years. In David Clark (eds) The Sociology of Death: theory, culture, practice. Oxford: Blackwell Publishers.

Aldridge, V. 2002: Behind the Scenes at the Crematorium. The Dominion 2 April, A1.

Alley, O. 1998: Woman's Head Moved, Embalmer Tells Court. The Dominion 2 November, A1.

Andreotti, L. 2000: Play-Tactics of the "Internationale Situationniste". JSTOR, 9: 36-58. Retrieved 4 June 2007 from http://www.jstor.org/stable/i231833

Andrews, L. and Nelkin, D. 2001: Body bazaar: the market for human tissue. New York: Crown Publishers.

Anon. 2005: Personal friend, Casual conversation 1 October.

Ariés, P. 1974: Western attitudes toward death: from the Middle Ages to the present. Translated by Patricia M. Ranum. New York: Random House.

Ariés, P. 1981: The hour of our death. Translated by Helen Weaver. New York: Random House.

Asquith, L. 2006: Evaluating and Illustrating Domestic Space Use: Collecting and Analysing Behavioural Data for Space Syntax Analysis. pp: 1 - 13. http://www.space.bartlett.ucl.ac.uk/events/sc06/proceedings/asquith-sssc.pdf

Ausubel, D. 1960: The fern and the tiki: an American view of New Zealand national character, social attitudes, and race relations. London: Angus \& Robertson Ltd.

Bachelard, G. 1969: The poetics of space. Boston: Beacon Press.

Barbosa, L. 2007: Domestic workers and pollution in Brazilian homes. In Campkin, B. and Cox, R., (eds) Dirt: new geographies of cleanliness and contamination. London: I. B Tauris \& Co Ltd, 25-33.

Barclay K. 2006: Pakeha, identity, and indigenous politics: towards a relational practice of justice. Doctoral Dissertation, Victoria University, Wellington.

Bardal, N. 2008: Embalming room. Retrieved 20 January 2008 from http://www.nbardal.mb.ca/Our_Embalming_Room_62176.html 
Barnes, M. 1991: Find down to earth: the changing funeral needs of a changing society. Auckland: Benton-Guy Publishing.

Barthes, R. 1957: Mythologies. Paris: Seuil.

Bartley, B., Hubbard, P., Kitchin, R. and Fuller D. 2002: Thinking geographically: space, theory and contemporary human geography. New York: Continuum Books.

Bashford, A. 2000: Purity and pollution: gender, embodiment and Victorian medicine. London: MacMillan Press Ltd.

Bataille, G. 1984: Death and sensuality: a study of eroticism and the taboo. New Hampshire: Ayer Company Publications Inc.

Bataille, G. 1988: The accursed share: An essay on general economy, Vol. 3. Translated by Robert Hurley. New York: Zone Books.

Baudrillard, J. 1993: Symbolic exchange and death. Translated by Iain Hamilton Grant. London: Sage.

Bauman, Z. 1992: Mortality, immortality and other life strategies. Cambridge: Polity Press.

Bauman, Z. 1995: The Sweet Scent of Decomposition. In Forget Baudrillard? (eds) C. Rojek and B.S. Turner, London: Routledge, 22-46.

BBC News 2001: New row over body 'dumping'. Retrieved 7 June 2007 from http://news.bbc.co.uk/1/hi/health/1123591.stm

Becker, E. 1973: The denial of death. New York: Free Press.

Belich, J. 2001: Paradise reforged: A history of New Zealanders. Auckland: Penguin Press.

Bell, C. 1997: Ritual: perspectives and dimensions. Oxford: Oxford University Press.

Bell, D. 1991: Insignificant others: lesbian and gay geographies. Area, 23, 323329.

Besio, K. and Butz, D. 2004: Commentary: a limited endorsement for autoethnography. The Professional Geographer, 56, 432-438.

Bible.org. 2008: What death means for the believer in Christ. Retrieved 5 January 2008 from http://www.bible.org/page.php?page_id=1969

Biggs, B. 1990(eds): English-Maori, Maori-English dictionary. Auckland: Auckland University Press. 
Biressi, A. and Nunn, H. 2002: An English man's home: reflections on the Tony Martin case. Soundings, 20, 37-45.

Blackham, M. 2003: Manager, Natural Burials, Interview 29 May.

Blunt, A. and Dowling, R. 2006: Home. London: Routledge.

Bondi, L. 1999: Troubling space, making space, doing space. The Group Analytic Society 38(1), 137-149.

Bondi, L. 2005: The place of emotions in research: from partitioning emotion and research to the emotional dynamics of research relations. In Davidson, J., Bondi, L. and Smith, M., (eds) Emotional geographies. Burlington VT and Aldershot: Ashgate Press, 231-246.

Bondi, L., Davidson, J. and Smith, M. 2005: Introduction: geography's emotional turn. In Bondi, L., Davidson, J. and Smith, M., (eds) Emotional geographies. Burlington VT and Aldershot: Ashgate Press, 1-18.

Bordo, S. 1987: The flight to objectivity: essays on Cartesianism and culture. Albany: State University of New York Press.

Boucher, G. 2006: The politics of performativity: a critique of Judith Butler. Parrhesia. Retrieved 5 June 2007 from http://www.parrhesiajournal.org/parrhesia01/parrhesia01_boucher.pdf

Bourdieu, P. 1990: The logic of practice. Translated by Richard Nice. California: Stanford University Press.

BBC News. 2000: Braindead pain fears upset families. Retrieved 16 July 2005 from http://news.bbc.co.uk/1/hi/health/886947.stm

Bremer, J. P., Fletcher C. G. and Osborne, C. 2004: Staphylococcus aureus. New Zealand Institute for Crop \& Food Research Limited.

British Institute of Embalmers. 2001: Retrieved 5 June 2006 from http://www.bioe.co.uk/ British Institute of Embalmers.html

Busch, A. 1999: Geography of home: writings about where we live. New York: Princeton Architectural Press.

Burton, R. 1976: The language of smell. Boston: Routledge \& Kegan Paul.

Butler, J. 1990: Gender trouble. London: Routledge.

Butler, J. 1993: Bodies that matter: on the discursive limits of "sex". New York: Routledge.

Bowlby, S., Gregory, S. and McKie, L. 1997: Doing home: patriarchy, caring, and space. Women's Studies International Forum 20(3), 343-350. 
Brown, B. and Laurier, E. 2005: Maps and journeys: an ethnomethodological investigation. Cartographica 4, 17-33.

Caine, B., Grosz, E. A. and de Lepervanche, M. 1988: Crossing boundaries: feminisms and the critique of knowledges. Sydney: Allen \& Unwin.

Campbell Live. 2004: Interview by John Campbell with Robert Fisk. CanWest TVWorks Limited.

Cassell, J. 1988: The relationship of observer to observed when studying up. In Burgess, R.G., (eds) Studies in qualitative research, Vol.1. Greenwich: Jai Press, 89-103.

Channel Four 2002: Anatomy for Beginners.

Charmaz, K. 1980: The social reality of death: death in contemporary America. London: Addison-Wesley Publishing Company.

Charlesworth, A., Stenning, A., Guzik, R. and Paszkowski, M., 2006: Out of place in Auschwitz? Contested development in post-war and post-socialist Oswiecim. Ethics, Place and Environment 9, 149-72

Cohen, W. J. and Johnson, R., (eds) 2005: Filth: dirt, disgust and modern life. Minneapolis: University of Minnesota Press.

Chodorow, N. 1978: The reproduction of mothering: psychoanalysis and the sociology of gender. Berkeley: University of California Press.

Chodorow, N. 1989: Feminism and psychoanalytic theory. Cambridge: Polity Press in Association with Basil Blackwell.

Chodorow, N. 1994: Femininities, masculinities, sexualities: Freud and beyond. Kentucky: University Press of Kentucky.

Clark, D. 1993(eds): The Sociology of Death: theory, culture, practice. (eds) Oxford: Blackwell Publishers.

Classen, C. 1992: The Odour of the Other: Olfactory Symbolism and Cultural Categories. Ethos 20, 133-166.

Classen, C., Howes, D. and Synnott, S. 1994: The cultural history of smell. London: Routledge.

Cleaver, P. W. 1996: Dealing with death: the Pakeha treatment of death, 1859 1910. Masters Thesis, Victoria University, Wellington.

Cooter, R. and Pickstone, J. 2000: Companion to medicine in the twentieth century. London: Routledge. 
Corbin, A. 1996: The foul and the fragrant: odour and the social imagination. London: Berg Publications Limited.

Cottle, D. and Keys, A. 2004: The monopolisation of the Australian funeral industry. Journal of Australian Political Economy 54, 32-44.

Cox, R. and Narula, R. 2003: Playing happy families: rules and relationships in au pair employing households in London, England. Gender, Place and Culture $10,333-44$.

Creely, S. K. 2001: Infection risks and embalming. Research Report: Institute of Occupational Medicine on Behalf of the British Institute of Embalmers (BIE).

Creswell, T. 2004: Place: a short introduction. Massachusetts: Blackwell Publications.

Creed, B. 1993: The monstrous - feminine: film, feminism, psychoanalysis. London: Routledge.

Crapanzano, V. 1977: On the writing of ethnography. Dialectical Anthropology 2, 69-73.

Danaher, G., Schirato, T. and Webb, J. 2000: Understanding Foucault. St Leonards, NSW: Allen and Unwin.

Delahunt, Brett Dempster Alex and Browett, Peter 2003: In H. Sperber: The new undertakers. North and South August, 49-59.

Dekker, D. 2002: The young undertakers. The Evening Post 22 June, A25.

Denzien, N. K. and Lincoln, Y. S. 2000: Methods of collecting and analyzing empirical materials ( $2^{\text {nd }}$ ed.). In Denzien, N. K. and Lincoln, Y.S., (eds) Handbook of qualitative research. London: Sage, 35-45.

Department of Health New Zealand 1971: Chronological list of some noteworthy events in the history of New Zealand health services. Wellington: Government Printer.

Department of Labour 1985: Immigrants and ethnic minorities: what words should I use? Wellington: Department of Labour.

Derrida, J. 1981: Writing and difference. London: Routledge and Kegan Paul.

Derrida, J. 2001: Work of mourning. Chicago: University of Chicago Press.

Documentary New Zealand 2005: Deadly Business. New Zealand on Air.

Douglas, M. 1969: Purity and danger: An analysis of concepts of pollution and taboo. London: Routledge \& Kegan Paul. 
Dowling, R. 2000: Power, subjectivity and ethics in qualitative research. In Hay. I., (eds) Qualitative research methods in human geography. Victoria: Oxford University Press, 23-36.

Drobnick, J. 2006: Introduction: Olfactocentrism In Drobnick, J (eds) The smell culture reader. Oxford: Berg.

Duncan, J. 2003: Interview 18 July 200

Duncan, N. 1997: Bodyspace. New York: Routledge.

Dunn, L. 1943: A Funeral Director's Experience with the Maoris. New Zealand Federation Funeral Directors June, p. 11.

Dyck, I. 2002: Further notes on feminist geography. In Moss, P., (eds) Feminist geography in practice: research and methods. Massachusetts: Blackwell Publishers Ltd, 234-244.

Eagleton, T. 1991: Ideology: an introduction. New York: Verso.

Ehrenreich, B. 2003: Maid to order. In Ehrenreich, B. and Hochschild, A., (eds) Global woman: nannies, maids and sex workers in the global economy. New York: Henry Holt, 85-103.

Eliade, M. 1961: Images and symbols: studies in religious symbolism. Translated by Philip Mairet. New York: Sheed \& Ward.

Ellis, C. 1997: Evocative autoethnography: writing emotionally about our lives. In Tierney, W. G. and Lincoln, Y. S., (eds) Representation and the text: reframing the narrative voice. Albany: State University of New York Press, 115-139.

El Mahdy, C. 1991: Mummies, myth and magic in Ancient Egypt. New York: Thames \& Hudson.

Embalmer 'A' 2006: Interview 18 July.

Encyclopaedia of World Religions 1999: Hertfordshire: Wordsworth Edition Limited, 756.

England, K. 1994: Getting personal: reflexivity, positionality, and feminist research. The Professional Geographer 46(1), 80-89.

Epstein, R., Kalus, C. and Berger, M. 2006: The continuing bond of the bereaved towards the deceased and adjustment to loss. Mortality 11(3), 253-269.

Fairclough, N. 1989: Language and power. London: Longman.

Fairclough, N. 1992a: Discourse and social change. Cambridge: Polity. 
Fairclough, N. 1992b: Introduction. In Fairclough, N., (eds) Critical language awareness. London: Longman.

Feuerbach, L. 1851: Lectures on the essence of religion. Translated by Ralph Manheim - 1967. New York: Harper \& Row.

Feuerbach, L. 1821: The Essence of Christianity. Edited and abridged by E. Graham Waring and F. W. Strothmann. New York: F. Ungar Pub. Co.

Flax, J. 1990: Thinking fragments: psychoanalysis, feminism, and postmodernism in the contemporary West. Berkeley: University of California Press.

Flax, J. 1993: Disputed subjects: essays on psychoanalysis, politics and philosophy. London: Routledge.

Forbes, D. 2000: Reading texts and writing geography. In Hay, I., (eds) Qualitative research methods in human geography. Melbourne: Oxford University Press, 122-143.

Forty, A. 1986: Objects of desire: design and society since 1750. London: Thames and Hudson.

Fost, N. 1999: The unimportance of death. In Younger, S. J., Arnold, M. R. and Schapiro, R., (eds) The definition of death: contemporary controversies. Baltimore: The Hopkins University Press, 161-178.

Foucault, M. 1977: Discipline and punish: the birth of the prison. Translated by Alan Sheridan. 1st American eds. New York: Pantheon Books.

Foucault, M. 1978: The history of sexuality. Translated by Robert Hurley. New York: Pantheon Books.

Foucault, M. 1989: The birth of the clinic: an archaeology of medical perception. Translated by A. M. Sheridan Smith. 1st American Ed. New York: Pantheon Books.

Foucault, M. 1989a: The archaeology of knowledge. Translated by A.M. Sheridan Smith. New York: Routledge.

Foucault, M. 2001: The order of things: an archaeology of the human sciences. London: Routledge.

Francaviglia, R, 1971: The cemetery as an evolving landscape. Annals of the Association of American Geographers. 84, 501-509.

Friedan, B. 1963: The feminine mystique. New York: Norton.

Freud, S. 1957: Mourning and melancholia. In Strachey, J., (eds) Standard edition of the complete works of Sigmund Freud. London: Hogarth Press. 
Fuchs, C. 1995: Death is irrelevant: cyborgs, reproduction, and the future of male hysteria. In Gray, C. H., (eds) The cyborg handbook. New York: Routledge.

Funeral Director 'A' 2002: Interview 9 July.

Funeral Director 'B' 2006: Interview 14 October.

Funeral Directors Association of New Zealand (Inc.). Retrieved 24 March 2006 from http://www.fdanz.org.nz/

Funeral Directors Association of New Zealand (Inc.) 1987: 1937 - 1987: A golden anniversary history supplement. New Zealand: Funeral Directors Association of New Zealand, 13-17.

Funeral Directors Association of New Zealand (Inc.) 1935: Morris, Flyger and Co. 20, New Zealand: Funeral Directors Association of New Zealand, 4.

Funeral-Link New Zealand (Inc.) 2004: Offering assistance when a bereavement occurs. Retrieved 23 February 2005 from http://www.funeral-link.co.nz/aboutus.htm

Furedi, F. 2004: Therapy culture: cultivating vulnerability in an uncertain age. London: Routledge.

Gallop, J. 1982: Feminism and psychoanalysis: the daughter's seduction. London: MacMillan.

Giddens, A. 1984: The constitution of society: outline of the theory of structuration. Cambridge: Polity Press.

Gilbert, M. R. 1994: The politics of location: doing feminist research 'at home'. Professional Geographer 46, 90-96.

Gill, O., and Penny, N. 1979: Survival of bacteria in carcasses. Applied and Environmental Microbiology 37(4), 667-669.

Gilman, S. L. 1990: Jewish self-hatred: anti-Semitism and the hidden language of the Jews. Baltimore: The Johns Hopkins University Press.

Goffman, E. 1959: The presentation of self in everyday life. New York: Anchor Books.

Griefcare. Retrieved 12 June 2006 from http://www.griefcare.org.nz/options/tangi.html

Grosz, E. 1993: Bodies and knowledge: feminism and the crisis of reason. In Alcoff, L. and Potter, E., (eds) Feminist epistemologies. New York: Routledge, 187-215. 
Grosz, E. 1994: Volatile bodies: toward a corporeal feminism. N.S.W: Allen \& Unwin.

Grosz, E. 1995: Sexy bodies: the strange carnalities of feminism. London: Routledge.

Guardian Funeral Home 2004-2006: Embalming. Retrieved 23 November 2005 from http://funeraldirector.co.nz/embalming.html

Habenstein, R. W. 1962: Sociology of occupations: the case of the American funeral director. In Rose, A., (eds) Human behaviour and social processes. London: Routledge \& Kegan Paul, 225-246.

Habenstein, R. W. and Lamers, W.M. 1962: The history of American funeral directing. Milwaukee: Bulfin.

Haggerty, K. 2004: Ethics creep: governing social science research in the name of ethics. Qualitative Sociology 27(4), 391-414.

Hallam, E., Hockey, J. and Howarth, G. 1999: Beyond the body: death and social identity. London: Routledge.

Hannah, L. 2003: Living Legacy. Retrieved 7 September 2006 from http://www.livinglegacies.co.nz/

Haraway, D. 1991: Situated knowledges. The science question in feminism and the privilege of partial perspective. In Haraway, D., (eds) Simians, cyborgs and women: The reinvention of nature. London: Routledge, 575-599.

Harbour City Funeral Home nd. Retrieved 17 June 2005 from http://www.harbourcityfunerals.co.nz/

Harrington, A. 1977: The immortalist. California: Celestial Arts.

Haste, H. 1993: The sexual metaphor. New York, London: Harvester Wheatsheaf.

Hastrup, K. 1992: Writing ethnography: state of the art. In Okely, J. and Callaway, H., (eds) Anthropology and autobiography. London, New York: Routledge, 116-33.

Haussamen, B. 1998: Death and syntax. Death Studies 22(4), 307.

Heath, D. 2002: Recently dead. Masters Thesis, University of Auckland.

Heeringa, V. 1997: It's odds-on the Yanks will bury us. The Independent 21 March, A20. 
Hegel, GWF. 1827: Lectures on the philosophy of religion: the lectures of 1827 edited by Peter C. Hodgson; translated by R.F. Brown, P.C. Hodgson, and J.M. Stewart, with the assistance of H.S. Harris. Oxford: Clarendon Press

Heidegger, M. 1927: Being and time (Reprint). New York: Harper and Row.

Hockey, J. 1993: The acceptable face of human grieving? The clergy's role in managing emotional expression during funerals. In (eds) David Clark's The Sociology of Death: theory, culture, practice. Oxford: Blackwell Publishers.

Hockey, J. 1996: Encountering the 'reality of death' through professional discourses: the matter of materiality. Mortality 1(1), 45-60.

Hockey, J., and Draper, J. 2005: Beyond the womb and the tomb: identity, (dis)embodiment and the life course. Body \& Society 11(2), 41-57.

Holmes 2003: Funeral options. TV1, Television New Zealand.

Home Box Office (HBO) 2000-2005: Six Feet Under. Season One - Episode One: Six Feet Under (Pilot).

Home Box Office (HBO) 2000-2005: Six Feet Under. Season Two - Episode 19: In Place of Anger.

Home Box Office (HBO) 2000-2005: Six Feet Under. Season Two - Episode 20: Back to the Garden.

Home Box Office (HBO) 2000-2005: Six Feet Under. Season Five - Episode 61: All Alone.

Hubbard, P. Kitchin, R. and Valentine, G. 2004: Key thinkers on space and place. London: Sage Publications Ltd.

Hui, T. B. and Yeoh, B. 2002: The remains of the dead: spatial politics of nationbuilding in post-war Singapore. Human Ecology Review 9(1), 1-13.

Immortality Institute 2005: The scientific conquest of death: essays on infinite lifespans. Retrieved 26 May 2005 from http://imminst.org

Irigaray, L. 1974: Speculum of the other woman. Translated by Gillian C. Gillnew. York: Cornell University Press.

Jacelon, C. S., Connelly, T. W., Brown, R., Proulx, K. and Vo, T. 2004: A concept analysis of dignity for older adults. Journal of Advanced Nursing 48(1), 76-83.

Jacyna, L. 2004: The localization of disease. In Brunton, D., (eds) Medical transformed: health, disease and society in Europe, 1800 - 1930. Manchester: The Open University, 1-27. 
Johnston, L. and Valentine, G. 1995: Wherever I lay my girlfriend, that's home: the performance and surveillance of lesbian identities in domestic environments. In Bell, D. and Valentine, G., (eds) Mapping desire: geographies of sexualities, 99-112.

Jupp, P. C. and Clare, G. 1999: Death in England: an illustrated history. Manchester: Manchester University Press.

Kastenbaum, R. and Costa, P. T. 1977: Psychological perspectives on death. Annual Review of Psychology 28, 225-249.

Kearney, R. 2002: Strangers, gods and monsters: ideas of otherness. London: Routledge.

Kellehear, A. 2007: A social history of dying. Cambridge: Cambridge University Press.

Kelley-Lainé, K. 1997: Peter Pan: the story of lost childhood. English Translation. Paris: Calmann Lévy.

Kilpatrick-Ayre, P. 1998: Photography and the crisis of looking. In Townsend, C., (eds) Vile bodies: photography and the crisis of looking. New York: Prestel.

Klein M. 1975: Love quilt and reparation: and other works. London: Hogarth Press.

Kitchin, R. and Dodge, M. 2007: Rethinking maps. Progress in Human Geography 31(3), 331-344.

Kobayashi, A. 2001: Negotiating the personal and the political in critical qualitative research. In Limb, M. and Dwyer. C., (eds) Qualitative methodologies for geographers. London: Hodder Headline Group, 55-70.

Kong, L. 1999: Cemeteries and columbaria, memorials and mausoleums: narratives and interpretation in the study of deathscapes in geography. Australian Geographical Studies, 37, 1-10.

Kristeva, J. 1982: Powers of horror: an essay on abjection. Translated by Leon S. Roudiez. New York: Columbia University Press.

Kristeva, J. 1991: Strangers to ourselves. Translated by Leon S. Roudiez. New York: University of Columbia Press.

Kübler-Ross, E. 1970: On death and dying. London: Routledge.

Kübler-Ross, E. and Kessler, D. 2005: On grief and grieving: finding the meaning of grief through the five stages of loss. New York: Scribner.

Lacan, J. 1968: The language of the self: the function of language in psychoanalysis. Baltimore: Johns Hopkins University Press. 
Laclau, E., and Mouffe, C. 1985: Hegemony and socialist strategy. London: Verso.

Laclau, E., and Mouffe, C. 1987: Post-Marxism without apologies. New Left Review 166, 79-106.

Laderman, G. 2003: Rest in peace: a cultural history of death and the funeral home in twentieth-century America. Oxford: Oxford University Press.

Laws, S. 1990: Issues of blood: the politics of menstruation. London: Macmillan.

Lawson M. 2005: Forward. In Akass, K. and McCabe, J., (eds) Reading Six Feet Under. London: I. B. Tauris, xvii -xxii.

Lawton, J. 1998: Contemporary hospice care: the sequestration of the unbounded body and dirty dying. Sociology of Health and Illness 20(2), 121-43.

Leder, D. 1990: The absent body. Chicago: University of Chicago Press.

Lees, L. and Longhurst, R. 1995: Feminist geography in Aotearoa / New Zealand: a workshop. Gender, Place and Culture (2)2, 217-222.

Lefebvre, H. 1991: The production of space. Translation by Donald Nicholson Smith. Malden, MA: Blackwell.

Lewis, C. S. 1961: A grief observed. London: Faber and Faber.

Lewis, I. M. 1985: Social anthropology in perspective. Cambridge: Cambridge University Press.

Lloyd, G. 1993: The man of reason: 'male' and 'female' in Western philosophy (2nd ed.). Minneapolis: University of Minnesota Press.

Longhurst, R. 1995: The body and geography. Gender, Place and Culture 2(1), 97-105.

Longhurst, R. 1997: (dis)Embodied geographies. Progress in Human Geography (21) $4,486-501$

Longhurst, R. 1999: Gendering place. In Le Heron, R., Murphy, L., Forer, P. and Goldstone, M., (eds) Explorations in human geography: encountering place. Oxford: Oxford Press, 151-172.

Longhurst, R. 2001: Bodies: exploring fluid boundaries. Routledge: London.

Longhurst, R. and Johnston, L. 1998: Embodying places and emplacing bodies: pregnant women and women body builders. In du Plessis, R. and Alice, L., (eds) Feminist thought in Aotearoa/New Zealand: differences and connections. Auckland, Oxford University Press, 156-163. 
Leiboff, M. 2005: A beautiful corpse. Continuum: Journal of Media and Cultural Studies 19(2), 221-237.

Lowenthal, D. 1961: Geography experience and imagination: towards a geographical epistemology. Annals of the Association of the American Geographer 51, 241-260.

Lucey, H. and Reay, D. 2000: Social class and the psyche. Soundings 15, 139-154.

Logan, B. 1999: Changing World, Changing Funerals. Retrieved 7 March 2001 from http://www.bl.co.nz/Funerals/Changing_world_Changing_Funerals.htm

Lupton, D. 1995: The imperative of health: public health and the regulated body. London: Sage.

Lychgate Funeral Homes. Retrieved 6 April 2006 from http://www.lychgate.co.nz/funeral_homes.aspx

McGreevy, P. 1992: Reading the texts of Niagara Falls: the metaphor of death. In Barnes and Duncan (eds) Writing Worlds: Discourse, Text and Metaphor in the Representation of Landscape. London: Routledge. Pp: 50-72.

Macklin, R. 2003: Dignity is a useless concept. British Medical Journal 237, 419420.

Mako, C. 1998: Some statistical issues for Maori: definitions and application. Te Oru Rangahau: Maori Research and Development Conference. Massey University, Palmerston North, School of Maori Studies.

Mallett, S. 2004: Understanding home: a critical review of the literature. The Sociological Review 52(1), 62-89.

Matterson, H. 1993: Grief trade finds a zest for life. Marketing Magazine 26.

Matthews, J and Herbert D. 2004: Unity in geography: prospects for the Discipline. In Matthews, and Herbert (eds) Unifying Geography: Common Heritage, Shared Future. London: Routledge.

McAfee, N. 2004: Julia Kristeva. New York: Routledge.

McDonnell, D. 1986: Theories of discourse: an introduction. New York: Basil Blackwell.

McDowell, L. 1999: Gender, identity and place: understanding feminist geographies. Cambridge: Polity Press.

McLafferty, S. 1995: Counting for women. Professional Geographer 47, 436-442.

Manning, D. 2003: The special care series. Oklahoma: In-Sight Books. 
Manning, S. 2002: Contested space of lesbian funerals: the lesbian/straight negotiation and the implications for funeral industry practice. In Kyro Selket Masters Thesis. Victoria University of Wellington.

Marae 2007: Tangi. TV One, Television New Zealand.

Marion-Young, I. 1990: Justice and the politics of difference. New Jersey: Princeton University Press.

Massey, D. 1994: Space, place and gender. Cambridge: Polity Press.

Massey, D. and Allen, J. 1987: Geography matters! A Reader. Cambridge: Cambridge University Press.

Mayer, R. 1996: Embalming: history, theory and practice. London: Routledge.

Meinwald, D. 2002: Site of death. In memento mori: death and photograph in nineteenth century America. Retrieved 23 September 2006 from http://vv.arts.ucla.edu/terminals/meinwald/meinwald2.html

Miah, A. 2003: Dead bodies for the masses: the British public autopsy $\&$ the aftermath. CTheory: International Journal of Theory, Technology \& Culture, Event-Scene, E119.

Miah, A. 2006: The public autopsy: somewhere between art, education, and entertainment. Med Ethics 30, 576-579.

Maxey, I. 1999: Beyond boundaries? Activism, academia, reflexivity and research. Area 3(3), 199-208.

McKessar, P. 2002: Death pros see light side of grave concerns. New Zealand Herald 3 May, A14.

Mead, S. M. 1997: Landmarks, bridges and visions: aspects of Maori culture. Wellington: GP Print.

Meeks, M. D. 1984: Introduction. In Moltmann, J., (eds) On human dignity: political theology and ethics. Philadelphia: Fortress Press.

Merleau-Ponty, M. 1962: Phenomenology of perception. Translated from the French by Colin Smith. London: Routledge \& Kegan Paul.

Metcalf, P. and Huntington, R. 1991: Celebrations of death: the anthropology of mortuary ritual ( $2^{\text {nd }}$ ed.). Cambridge: Press Syndicate.

Meth, P. 2003: Rethinking the domus in domestic violence: homelessness, space and domestic violence in South Africa. Geofomm 34, 317-28.

Millett, K. 1970: Sexual politics. Garden City, New York: Doubleday. 
Mitchell, J. 1974: Psychoanalysis and feminism. London: Allen Lane.

Mitchell, J. 2000: Psychoanalysis and feminism: with a new introduction. London: Allen Lane.

Mitford, J. 1962: The American way of death. New York: Random House.

Moody, H. R. 1998: Why dignity in old age matters. Journal of Gerontological Social Work 29(2-3), 13-38.

Moore, W. 2002: Corpse exhibition faces threat of ban. The Observer. Retrieved 26 April 2006 from. http://www.guardian.co.uk/uk/2002/mar/10/arts.highereducation.

Morrall, A. 2007: Stillborn babies recalled. The Press. Retrieved 29 May 2007 from http://www.stuff.co.nz/4200916a6427.html

Morsink J. 1999: The universal declaration of human rights: origins, drafting and intent. Pennsylvania: University of Pennsylvania Press.

Morton, J. 2006: The unrepentant necrophile: an interview with Karen Greenlee. Retrieved 23 July 2006 from http://www.nokilli.com/sacto/karen-greenlee.htm

Mowl, G. Pain, R and Talbot. C. 2000: The ageing body and the homespace. Area 32, 2. 189-197.

Murnane, W. 1983: The Penguin guide to Ancient Egypt. Middlesex: Penguin Books.

Ministry of Health and Safety. 2000: Occupational Safety and Health Information Series. Wellington: Ministry of Health.

Ngata M, H. 1993: English-Māori dictionary. Wellington: Learning Media.

Natural Burials 2006: Retrieved 23 March 2003 from http://www.naturalburials.com/

New Zealand Embalmers Association 2006: Retrieved 23 March 2006 from http://www.nzembalmers.org.nz/index.php

New Zealand Federation of Funeral Directors (Inc.) 1940: What's in a name? New Zealand Federation of Funeral Directors.

New Zealand Federation of Funeral Directors (Inc.) 1939: Australia interested in New Zealand federation funeral directors. New Zealand Federation of Funeral Directors.

Nietzsche, F. 1967: Beyond good and evil: prelude to a philosophy of the future. Translated by Helen Zimmern. London: Allen \& Unwin. 
Nietzsche, F. 1967a: The will to power. A new translation by Walter Kaufmann and R. J. Hollingdale. New York: Random House.

Neil Bardal Inc. 2008: Our Embalming Room. Retrieved 4 June 2008 from http://www.nbardal.mb.ca/Our_Embalming_Room_62176.html.

Noys, B. 2005: The culture of death. New York: Berg.

Patterson, D. 1994: Postmodernism/feminism/law. In Patterson, D., (eds) Postmodernism and Law. New York: New York University, 305-368.

Paulston, R. G. 1996: Social cartography: mapping ways of seeing social and educational change. New York: Garland.

Pehi, M. 2003: Mahia i roto i te wairua Māori: in the Māori Spirit. Retrieved 7 May 2004 from http://www.massey.ac.nz/ wwpubafs/magazine/2002_Nov/stories/funeral.html

Perkins, C. 2003: Cartography: mapping theory. Progress in Human Geography 27, 341-51.

Phillips, L. and Jorgensen, M. 2002: Discourse analysis as theory and method. London: Sage Publications.

Philo, C. 2000: The birth of the clinic: an unknown work of medical geography. Area (32)1, 11-19.

Philo, C. 2000: Foucault's Geography. In M, Crang and N. J. Thrift (eds) Thinking Space. New York: Routledge. 205-238.

Philo, C. and Parr, H. 2003: Introducing psychoanalytic geographies. Social \& Cultural Geography 4(3), 283-293.

Pile, S. 1993: Human agency and human geography revisited: a critique of 'new models' of the self. Transactions of the Institute of British Geographers 16, 458-469.

Pile, S. 1996: The body and the city: psychoanalysis, space and subjectivity. New York: Routledge.

Pile, S. and Rose, G. 1992: All or nothing? Politics and critique in the modernism postmodernism debate. Environment and Planning D: Society and Space 10(2), 123-136.

Pines, V. R. 1989: Death, loss, and disenfranchised grief. In Dorka, K. J., (eds), Disenfranchised grief: recognizing hidden sorrow. Massachusetts: Lexington Books, 13-23.

Pitte, J. 2004: A short cultural geography of death and the dead. GeoJornal, 60, 345-351. 
Plumwood, V. 1993: Feminism and the Mastery of Nature. London: Routledge.

Pope, H. 1884: Health for the Maori: a manual for the use in Native Schools. In Williams, D. 2001, (eds), Crown policy affecting Māori knowledge systems and cultural practices. Wellington: Waitangi Tribunal Publication.

Porteous, D. 1985: Smellscape. Progress in Physical Geography, 9, (3), 356-378

Pratt, G. 1992: Spatial metaphors and speaking positions. Environment and Planning D: Society and Space 10(24), 144.

Prior, L. 1989: The social organization of death: medical discourse and social practices in Belfast. Basingstoke: MacMillan.

Prosser, J. 2005: Dr. Richard Burr, Embalming Surgeon, Army of the James: embalming a dead soldier. In Prosser, J., (eds) A haunting environmental legacy? Arsenic and other toxic material in historic cemeteries. Repository: New York Historical Society - Digital ID: nhnycw/ad04001. Retrieved 5 June 2004 from http://www.ncdot.org/doh/preconstruct/highway/geotech/trb/download/presentations/6a/03 \%20A\%20Haunting\%20Legacy.pdf

Quigley, C. 1996: The corpse: a history. Jefferson: McFarland \& Company Inc.

Raether, H. C. and Slater, R. C. 1974: The funeral and the funeral director. In E. A. Grollman, E. A., (eds) Concerning death: a practical guide for the living. Boston: Beacon Press, 187-209.

Rainbow, P. 1977: Reflections on fieldwork in Morocco. Berkeley: University of California Press.

Ramsland, K. 2009: Necrophiles http://www.trutv.com/library/crime/serial_killers/notorious/necrophiles/4c.html

Rendle, S. 2001: Death's mystery removed. The Evening Post 16 June, A1.

Renteln, A. 2001: The rights of the dead: autopsies and corpse mismanagement in multicultural societies. The South Atlantic Quarterly 100(4), 1005-1027.

Richardson, L. 1990: Writing strategies: reaching diverse audiences. London: Sage Publications.

Richardson, L. 1997: Fields of play: constructing an academic life. New Jersey: Rutgers University Press.

Richardson, L. 1998: Writing: a method of inquiry. In Denzin, N. and Lincoln, Y., (eds) Collecting and interpreting qualitative materials. London: Sage, 345371. 
Richardson, L. 2002: Skirting a pleated text: de-disciplining an academic life. In Denzin, N. K. and Lincoln, Y. S., (eds) The qualitative inquiry reader. London: Sage Press.

Richardson, L. 2003: Writing strategies: reaching diverse audiences. London: Sage Publications.

Rinpoche, S. 1993: How to live free of fear of death. Retrieved 11 May 2006 from http://www.katinkahesselink.net/tibet/fear-death.html

Ritzer, G. 2004: The McDonaldization of society. California: Pine Forge Press.

Rodaway, P. 1994: Sensuous Geographies. London: Routledge.

Rose, G. 1993: Feminism and geography: the limits of geographical knowledge. Cambridge: Polity Press.

Rose, G. 1997: Situating knowledges: positionalities, reflexivities and other tactics. Progress in Human Geography 21(3), 305-320.

Rosenberg, F. J. 1998: Thinking clearly about death. Cambridge: Hackett Publications.

Rugg, J. 2000: Defining the place of burial: what makes a cemetery a cemetery? Mortality 5(3), 259-275.

Santos, B. 1995: Towards a new common sense: law, science and politics in the paradigmatic transition. London: Routledge.

Sarantakos, S. 1993: Social research. MacMillan Press Ltd: London.

Saunders, P. and Williams, P. 1988: The constitution of the home: towards a research agenda. Housing Studies 3(2), 81-93.

Sawyer, D. 1993: When comfort is not derived from viewing. The Dodge Magazine 3, 8.

Sawyer, D. 1994: Don Sawyer on embalming: the contagious case. The Dodge Magazine Part I, 1, 9.

Schäfer, C. 2005: Post-mortem personalisation: an ethnographic study of funeral directors in New Zealand. Doctoral dissertation, University of Otago.

Schab, F. and Robert, C. 1995: Memory for odors. New Jersey: L. Erlbaum Associates.

Schäfer, C. 2007: Post-mortem personalization: pastoral power and the New Zealand funeral director. Mortality 12(1), 4-21. 
Schäfer, C. 2007: Dead Serious? Funeral Directing in New Zealand Sites: New Series. 4(1), 95-121.

Schoenberger, E. 1992: Self-criticism and self-awareness in research: a reply to Linda McDowell. Professional Geographer 44(2), 215-218.

Schumaker, J. F., Warren, W. G. and Groth-Marnat, G. 1991: Death anxiety in Japan and Australia. Social Psychology Journal 131(4), 511-518.

Shumer-Smith, P. and Hannam K. 1994: Worlds of Desire, Realms of Power: A Cultural Geography. London: E. Arnold.

Schwass, M. 2006: Last words: approaches to death in New Zealand's cultures and faiths. Auckland: Bridget Williams Books and the Funeral Directors Association of New Zealand.

Seamon, D. and Mugerauer, R. 1985: Dwelling, place, and environment: towards a phenomenology of person and world. Boston: Kluwer Academic Publishers.

Segal, C. 1990: Lucretius on death and anxiety. Princeton: Princeton University Press.

Selket, K. 2007: Bringing home the dead: purity and filth in contemporary funeral homes. In Campkin, B. and Cox, R., (eds) Dirt: new geographies of cleanliness and contamination. London: I. B Tauris \& Co Ltd, 49-59.

Serrano, A. 1992: The morgue. Retrieved 11 May 2006 from http://www.contemporary-magazine.com/feature36.htm

Shields, R. 1991: Places on the margin. London: Routledge.

Shildrick, M. 2002: Embodying the monster: encounters with the vulnerable self. California: Sage Publications.

Shilling, C.1993: The Body and Social Theory. London: Sage.

Shiva, V. 1997: Women in nature. In Visvanathan, N., Duggan, L., Nisonoff, L. and Wiegersma, N., (eds) The women, gender and development reader. London: Zed Books, 62-67.

Shove, E. 2003: Comfort, cleanliness and convenience: the social organization of normality. Oxford: Berg Publications.

Sibley, D. 1981: Outsiders in urban societies. Oxford: Basil Blackwell.

Sibley, D. 1995: Geographies of exclusion. London: Routledge.

Sibley, D. 2003: Geography and psychoanalysis: tensions and possibilities. Social \& Cultural Geography 4(3), 1-11. 
Smith, L. T. 1999: Decolonizing methodologies: research and indigenous peoples. Dunedin: University of Otago Press.

Smith, N. and Katz, C. 1993: Grounding metaphor: towards a spatialized politics. In Keith, M. and Pile, S., (eds) Place and the politics of identity. London: Routledge, 67-83.

Soja, E. 1996: Thirdspace: journeys to Los Angeles and other real-and-imagined places. Oxford: Blackwell Publishers.

Sperber, H. 2003: The new undertakers. North and South August, 49-59.

Stacy, M. 1990: Issues of blood: the politics of menstruation. London: MacMillan.

Standing, K. 1998: Writing the voices of the powerful. In Ribbens, J. and Edwards, R., (eds) Feminist dilemmas in qualitative research. London: Sage Publications.

Stearns, P. 1994: American cool: constructing a twentieth-century emotional style. New York: New York University Press.

Steele, D. 1993: To view or not to view. The Dodge Magazine Part I, 1, 14-27.

Strub, C. and Frederick, L. G. 1967: The principles and practices of embalming (4th ed.). U.S.A: Frederick.

Strub, C. and Frederick, L. G. 1989: The principles and practices of embalming (5th ed.). U.S.A: Frederick.

Surya, M. 2002: Georges Bataille: an intellectual biography. London: Verso.

Teather, E. K. 1998: Themes from complex landscapes: Chinese cemeteries and Columbaria in Hong Kong. Australian Geographical Studies 36(1), 21-36.

Teather, E. K. 1999: The heritage significance of Hong Kong's Chinese cemeteries. Proceedings of International Forum UNESCO, University and Heritage, Deakin University, Melbourne, Australia, 4-8.

Teather, E. K. 2000: High rise homes for the ancestors: cremation in Hong Kong. Geographical Review 89(3), 409-430.

Teather, E. K. 2001a: Time out and worlds apart: tradition and modernity meet in the time-space of the gravesweeping festivals of Hong Kong, Singapore. Journal of Tropical Geography 22(2), 156-172.

Teather, E. K. 2001b: Seoul's deathscapes: incorporating tradition into modern time-space. Environment and Planning A 33, 1489-1506.

Teather, E. K. 2002: The road home: repatriating Chinese emigrants after death. The New Zealand Geographer 58(1), 10-19. 
Terzich, A. 2006: Palpate urbanism: conflux. Design institute: the knowledge circuit. Retrieved 4 June 2007 from http://design.umn.edu/go/knowledgeCircuit/current.kc06.conflux

The Natural Death Centre 2000: Retrieved 27 May 2006 from http://www.naturaldeath.org.uk/

The Press 2002: Toe Tags. 7 September, A1.

The Wordsworth Encyclopedia of World Religions 1999: Buddhist view on death and rebirth. Retrieved 4 June 2007 from http://www.urbandharma.org/udharma5/viewdeath.html

Thrift, N. 2002: The future of geography. Geoforum, 33: 291-298.

Thrift, N. 2004: Thinking across the divide: perspectives on the conversations between physical and human geography. Area 36(4), 435-442

Throop, E. 1999: Net curtains and closed doors: intimacy, family and public life in Dublin. Westport: Bergin \& Garvey.

Timaru Herald 2001: Mourner Honours the Dead. 15 June, A1.

Tomes, N. 1998: The gospel of germs: men and women and the microbe in American life. Cambridge: Harvard University Press.

Treknature 2008: Kawakawa - Pepper Tree. Retrieved 26 May 2008 from http://www.treknature.com/gallery/Oceania/New_Zealand/photo12952.htm

Trow, R. 2005: Locals bodies too close for comfort. Dominion Post 9 May, A6.

Tuan, Y. F 2004: Home. In Harrison, S., Pile, S. and Thrift, N. (eds), Patterned ground the entanglements of nature and culture. London: Reaktion Books, 164-65.

Turner, R. and Edgley, C. 1976: Death as theatre: a dramaturgical analysis of the American funeral. Sociology and Social Research 60(4), 377-92.

Turner, S. B. 1984: The body and society: exploration in social theory. New York: Basil Blackwell.

Turner, S. B. 1992: Regulating bodies: essays in medical sociology. London: Routledge.

Turner, V. 1967: The forest of symbols: aspects of Ndembu ritual. New York: Cornell University Press. 
Turnock, R. 2005: Death, liminality and transformation in Six Feet Under. In Akass, K. and McCabe, J., (eds) Reading Six Feet Under: TV to die for. London: I. B Tauris \& Co Ltd, 39-49.

Universal Declaration of Human Rights 1948-1998. Retrieved 23 July 2006 from http://www.un.org/Overview/rights.html

Valentine, G. 2001: Social geographies: space and society. New York: Prentice Hall.

Valentine, G. 2002: People like us: negotiating sameness and difference in the research process. In Moss, P., (eds) Feminist geography in practice: research and methods. Massachusetts: Blackwell Publishers Ltd, 116-126.

Van Gennep, 1960: The rites of passage. Translated by B. Monika. London: Routledge Keagen \& Paul Ltd.

Vass, A. A. 2001: Beyond the grave: understanding human decomposition. Microbiology Today 28, 190-192.

von Hagens, G. Body World: the original exhibition of real human bodies. Retrieved 2 March 2006 from http://www.bodyworlds.com/en.html

Walter, T. 1992: Funerals and how to improve them. London: Hodder and Stoughton.

Walter, T. 1994: The revival of death. London: Routledge.

Walter, T. 2004: Plastination for display: a new way to dispose of the dead. The Journal of the Royal Anthropological Institute 10(3), 603-627.

Warrington, M. 2001: I must get out: the geographies of domestic violence. Transactions of the Institute of British Geographers (26), 365-82.

Watkin, T. 2000: The funeral director. New Zealand Herald 17 June, C5.

Webb, J. and Webb, L. 2004: Dead or alive. In Klaver, E., (eds) Images of a corpse: from the Renaissance to cyberspace. Wisconsin: University of Wisconsin Press, 220-228.

Webster Online Dictionary 2005: Conclusion. Retrieved 3 March 2008 from http://www.websters-online-dictionary.org/definition/conclusion

Weltec 2008: The National Certificate in Funeral Directing (L5). Retrieved 14th May 2007 from http://www.cit.ac.nz/funeral/1funeraldir.php

Wiles-Rosell, R. 2005: Tucking in time: a funeral director's perspective on the goodnights of disposal. Unpublished Conference Proceedings, Seventh International Conference on the Social Context of Death, Dying \& Disposal, University of Bath, 15-18 September. 
Williams, D. 2001: Offering an alternative way to go. The Nelson Mail 3.

Williams, H. W. 1992: Dictionary of Maori language. Wellington: GP Print Limited.

Withers, C. W. J. and Mills, C. 1992: Teaching qualitative geography as interpretative discourse. Journal of Geography in Higher Education 16(2), 159165.

Wolffram, M. 2006: Programme Leader, Wellington Institute of Technology. Personal Communication 22 February.

Wolffram, M. 2008: Programme Leader, Wellington Institute of Technology. Personal Communication 30 May.

Worden, J. W. 1991: Grief counselling and grief therapy: a handbook for the mental health practitioner (2nd ed.). New York: Routledge.

Wright, J. K. 1947: Terrae incognitae: the place of the imagination in geography. Annals of the Association of American Geographers 37(1), 1-15.

Wyoming Funeral Association 2000: History of embalming. Retrieved 6 July 2006 from http://www.wyfda.org/basics_3.html

Yeoh, B. 1999: The body after death: place, tradition and the nation-state in Singapore. In Teather, E.K., (eds) Embodied geographies: spaces, bodies and rites of passage. London: Routledge, 240-255.

YouTube 2008: Must be watched: the embalmer. Retrieved 9 March 2007 from http://video.google.com/videoplay?docid=-3069100159888160852

YouTube 2008: Embalming pictures. Retrieved 9 March 2008 from http://www.embalmingpictures.com/category/embalmingpictures

Yve-Alain, B. and Krauss, R. 1997: Formless: a user's guide. Cambridge: The MIT Press.

Zucker, A.1998: Death and Language: Some Comments on Haussamen. Death Studies, London: Routledge, 22 (4), 321 - 328. 